\title{
NETZWERKEN
}

FÜR DIE
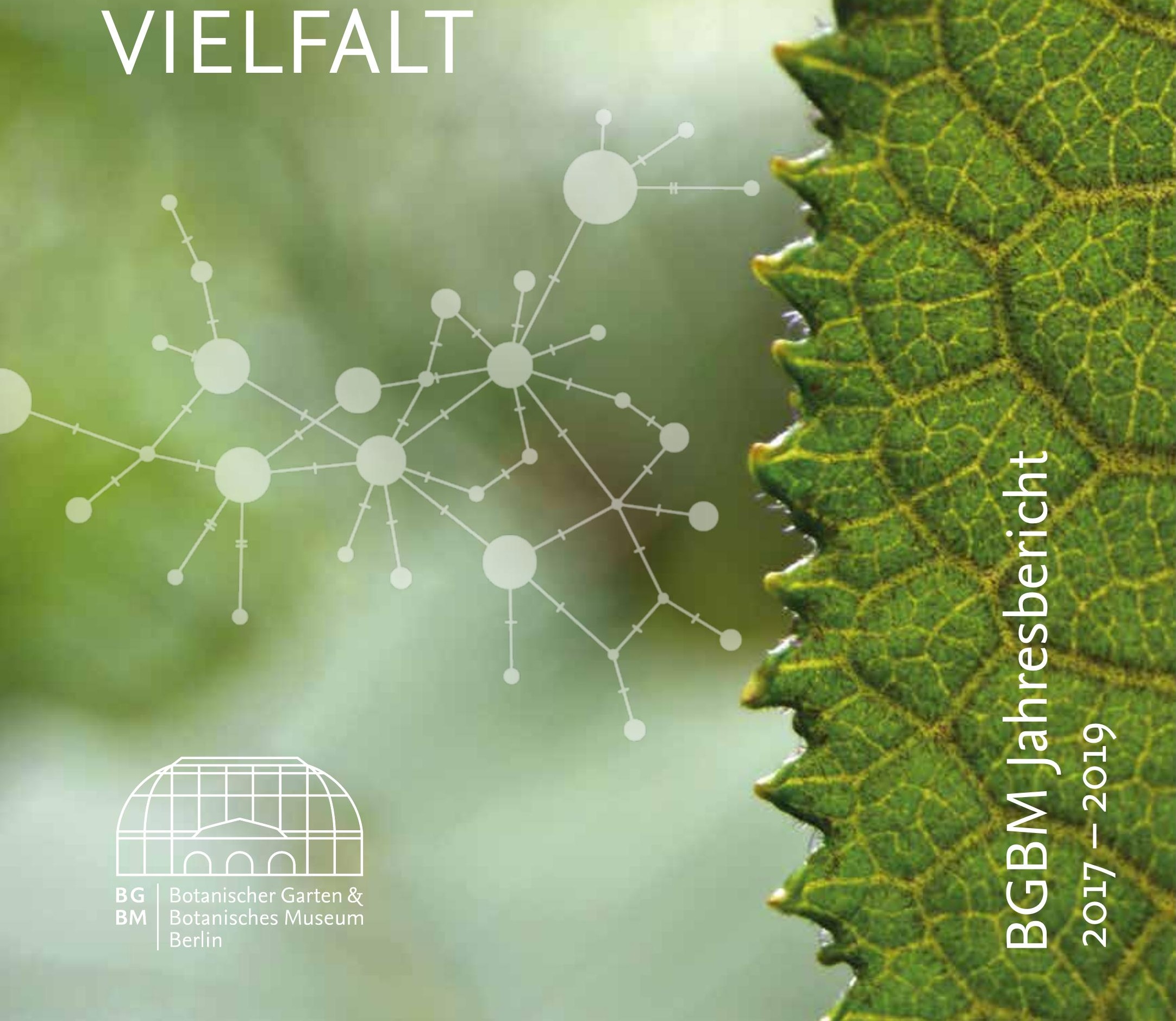


\section{BGBM Jahresbericht}

\section{$2017-2019$}

Bild Titelseite: Die Erforschung der globalen Biodiversität und ihrer Bedeutung für die Menschheit ist ohne Netzwerken nicht möglich. Das Thema Netzwerken drückt sich hierbei auf unterschiedlichen Ebenen aus: In der Natur bei den Lebensvorgängen innerhalb eines Organismus - sichtbar am Netzwerk der Adern eines Blattes -, der genetischen Vielfalt in Populationen von Pflanzen - das Netzwerken findet mittels Pollen über Bestäuber oder auch den Wind statt. In der Forschung sind die einzelnen Objekte, wie etwa ein Individuum einer Pflanze mit den davon gewonnenen Daten vernetzt. Damit diese Daten als Wissensgrundlage zur Lösung globaler Zukunftsfragen ihre Wirkung entfalten können, ist ebenso das Netzwerken ganz entscheidend: die inter- und transdisziplinäre Zusammenarbeit von wissenschaftichen Expertinnen und Experten untereinander und mit Stakeholdern auf regionaler, nationaler und internationaler Ebene.

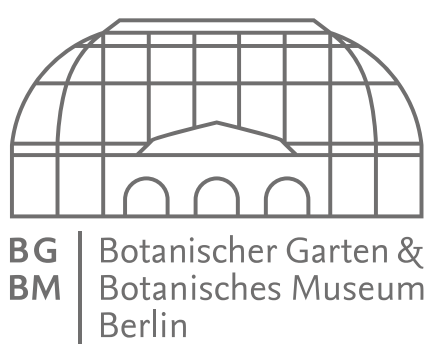




\section{Inhalt}

Vorwort

Ein Netzwerk für Pflanzen

Highlight-Events der Jahre 2017 bis 2019

Wenn die Vielfalt ins Netz geht

Fahnden nach der Vielfalt

Die unsichtbare Vielfalt

Humboldt 2.0

Zwischen Orient und Okzident

Im Dienst der Wissenschaft

Das forschende Museum

Wissenschaft zum Mitmachen

Im Zeichen der Kornrade
Organisation

56

6

Zahlen \& Fakten

Personal, Gastwissenschaftlerinnen und Gastwissenschaftler,
Doktorandinnen und Doktoranden

Assoziierte und ehrenamtliche Wissenschaftlerinnen und

Wissenschaftler, Ehrenamtliche $\quad 58$

BGBM-Publikationen

Neu beschriebene Arten von BGBM-Autoren

Neu beschriebene Familien und Gattungen von BGBM-Autoren 82 Online-Ressourcen und Datenbanken $\quad 83$

Forschung: Drittmittelprojekte $\quad 87$

Ausgerichtete wissenschaftliche Veranstaltungen 92

Sammlungen 93

Bibliothek 96

BGBM Press: Publikationen $\quad 97$

Botanisches Museum 99

$\begin{array}{ll}\text { Presse- und Öffentlichkeitsarbeit } & 101\end{array}$

Besucherzahlen Botanischer Garten und Botanisches Museum 102

Budgetentwicklung 103

$\begin{array}{ll}\text { Impressum } & 104\end{array}$

\section{7}

57

.

.

.

83

83
87

2

6

9




\section{Vorwort}

\section{BGBM-Jahresbericht 2017-2019}

Wir stehen vor großen Herausforderungen. Der Klimawandel ist in aller Munde, und spätestens seit der medialen Debatte zum Bericht des Weltbiodiversitätsrates (IPBES), der im Frühjahr 2019 veröffentlicht wurde, finden auch die Biodiversitätskrise und das weltweite Artensterben die Aufmerksamkeit der breiten Gesellschaft. Jüngst führt uns eine globale Pandemie vor Augen, welche dramatischen gesundheitlichen, sozialen und wirtschaftlichen Auswirkungen durch neu aufkommende Krankheiten in kurzer Zeit entstehen können. Das immer tiefere Eindringen der Menschen in bisher unberührte Naturräume wird diese Risiken noch verstärken.

Die Bewältigung dieser gesellschaftlichen Herausforderungen ist nur gemeinsam zu schaffen: Entscheidend sind Zusammenarbeit und Vernetzung, nicht nur auf internationaler Ebene, sondern auch zwischen Politik, Zivilgesellschaft und Wissenschaft sowie den wissenschaftlichen Disziplinen. Um Lösungswege zu erarbeiten ist Wissen erforderlich die Wissenschaft hat damit einen hohen Stellenwert. Eine lebenswerte Zukunft für uns alle wird von den Entscheidungen abhängen, die wir heute treffen. Fakten- und wissenschaftsbasierte Entscheidungen erfordern nicht nur die breite Verfügbarkeit von Wissen, sondern auch einen positiven Dialog zwischen Wissenschaft und Gesellschaft und die breite Akzeptanz von Wissenschaft.

Der Titel des vorliegenden Jahresberichtes „Netzwerken für die Vielfalt“ unterstreicht, wie wichtig Wissenschaftsnetzwerke und internationaler Wissensaustausch für die Lösung globaler Probleme sind. Zu den zentralen Anliegen des Botanischen Gartens und Botanischen Museums Berlin gehört es, Wissen zu generieren und erhaltene Forschungsdaten mit relevanten Sammlungsobjekten und anderen Daten weltweit zu vernetzen, um neue Wissenspotenziale zu entschlüsseln und nutzbar zu machen. Wir entwickeln Standards und Software-Tools und machen Biodiversitätsdaten digital verfügbar - beispielsweise für die Modellierung von Zukunftsszenarien. Biodiversitätsdaten als Wissensressource müssen weltweit zugängig und FAIR nutzbar sein. Denn nur als weltweit vernetzte Wissensgemeinschaft werden wir den Herausforderungen der Zukunft begegnen können.

Menschen für Natur zu sensibilisieren und für Pflanzen zu begeistern, gehört zu unseren zentralen Aufgaben. Als positive und erholsame Orte können gerade Botanische Gärten dazu beitragen, ein neues $\mathrm{Na}$ turverständnis zu entwickeln und damit auch den Wunsch stärken, ihre

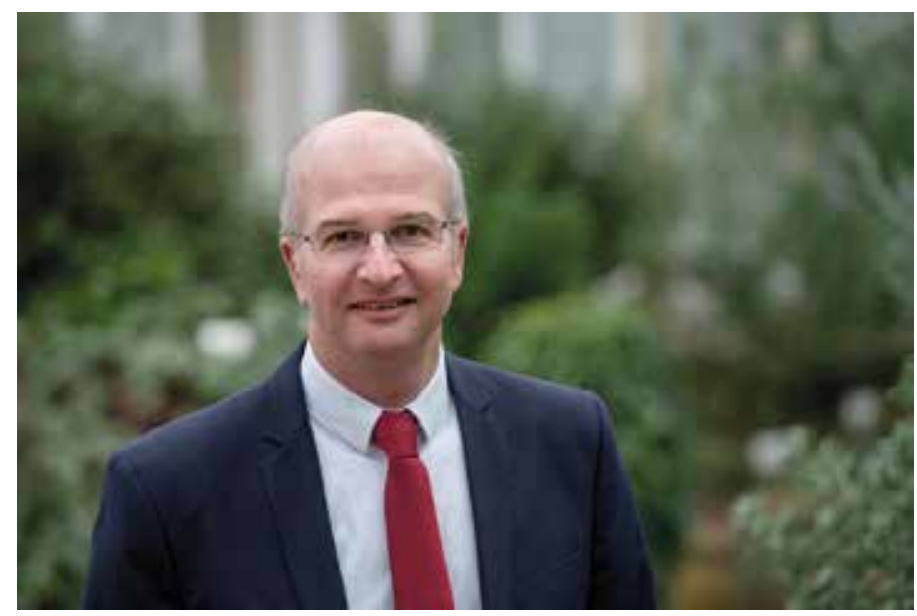

Vielfalt zu bewahren. Wir sehen das am steigenden Zuspruch unserer Besucherinnen und Besucher. Mit neuen Ausstellungen, Gartenbereichen und digitalen Tools werden wir in den kommenden Jahren den Botanischen Garten neu erschließen und das Botanische Museum zeitgemäß erneuern. Und mit dem neuen Besucherzentrum entsteht ein lebendiges Forum urbaner Offenheit am Eingang Königin-Luise-Platz für unsere Gäste.

Mein herzlicher Dank gilt unseren Mitarbeiterinnen und Mitarbeitern sowie allen Zuwendungsgebenden und Fördernden des Botanischen Gartens und Botanischen Museums Berlin. Ohne ihr Engagement wäre nicht möglich, was wir Ihnen in diesem Bericht zeigen können.

Ich wünsche viel Freude beim Lesen und Betrachten!

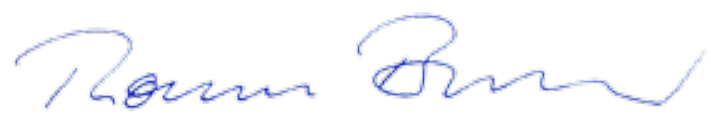

Prof. Dr. Thomas Borsch

Direktor des Botanischen Gartens und Botanischen Museums Berlin im November 2020 


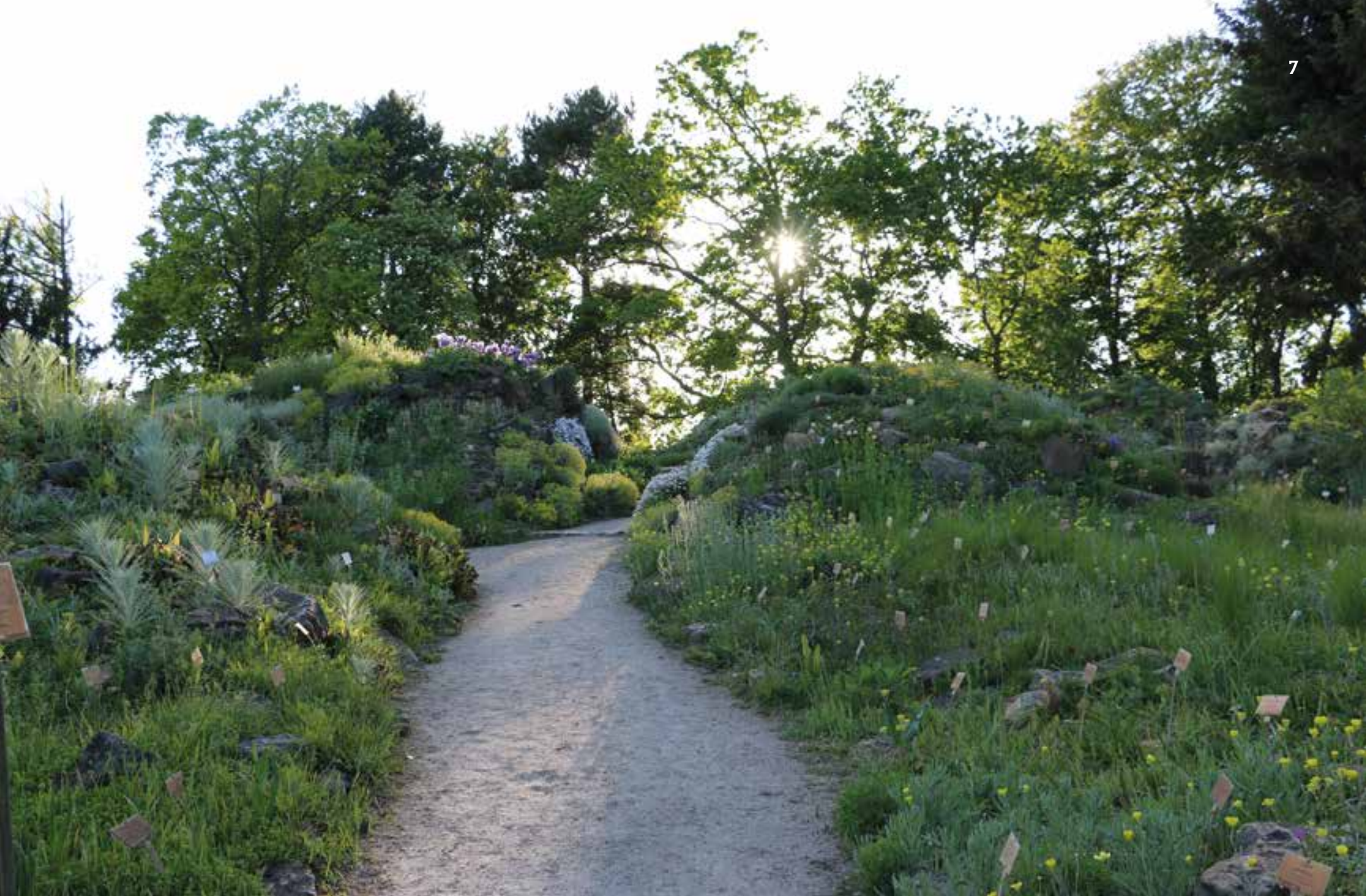

Pflanzengeografische Abteilung (Griechenland) in der Nachmittagssonne.

ist im Laufe der traditionsreichen Geschichte des BGBM ein stabiles Netzwerk entstanden, das Sammlungen und Institutionen, Daten und Menschen miteinander verbindet. Der Jahresbericht 2017-2019 stellt dieses Geflecht des Wissens, Wachsens und Forschens vor.

Wer einen Spaziergang durch den Garten unternimmt oder die grünen Schätze in den Gewächshäusern bewundert, bekommt bereits einen Teil des grünen Netzwerkes zu sehen: Rund 20.000 verschiedene Arten, Unterarten und Varietäten von lebenden Pflanzen hat der BGBM gemeinsam mit Partnern im In- und Ausland zusammengetragen. Dazu kommen noch weitere botanische Schätze hinter den Kulissen wie die fast vier Millionen getrockneten Pflanzen des Herbariums, die etwa 50.000 Gewebe- und Erbgut-Proben der DNA-Bank oder das eingefrorene Saatgut tausender Wildpflanzen. Der BGBM ist damit Teil eines globalen Gedächtnisses der Artenvielfalt, das in Herbarien und anderen naturkundlichen Sammlungen bewahrt wird.
Allerdings ist es nicht damit getan, die Proben und Daten einmal einzulagern und dann in den Schubladen schlummern zu lassen. Die Informationen aus diesem Gedächtnis sollen schließlich jederzeit wieder abrufbar sein, um neue Forschungsfragen zu beantworten. Deshalb beschäftigen sich Informatik-Fachleute am BGBM mit der Frage, wie man all die wertvollen Daten am besten zugänglich macht.

Sie haben beispielsweise eigene Software entwickelt, um die verschiedenen Sammlungen im Haus sowie die Forschungsdaten, die an den Objekten generiert werden, miteinander zu verknüpfen. Damit kann man nicht nur nachvollziehen, wer eine lebende Pflanze im Gewächshaus von wo mitgebracht hat, wo das zugehörige Material im Herbarium und in der DNA-Bank liegt und ob auch Samen eingelagert wurden. Sondern auch, welche DNA-Sequenzen oder elekronenmikroskopischen Bilder zu einem Individuum gehören, und wo dieses Individuum bereits in einem der publizierten Stammbäume zur Rekonstruktion der Evolutionsgeschichte zu finden ist. 

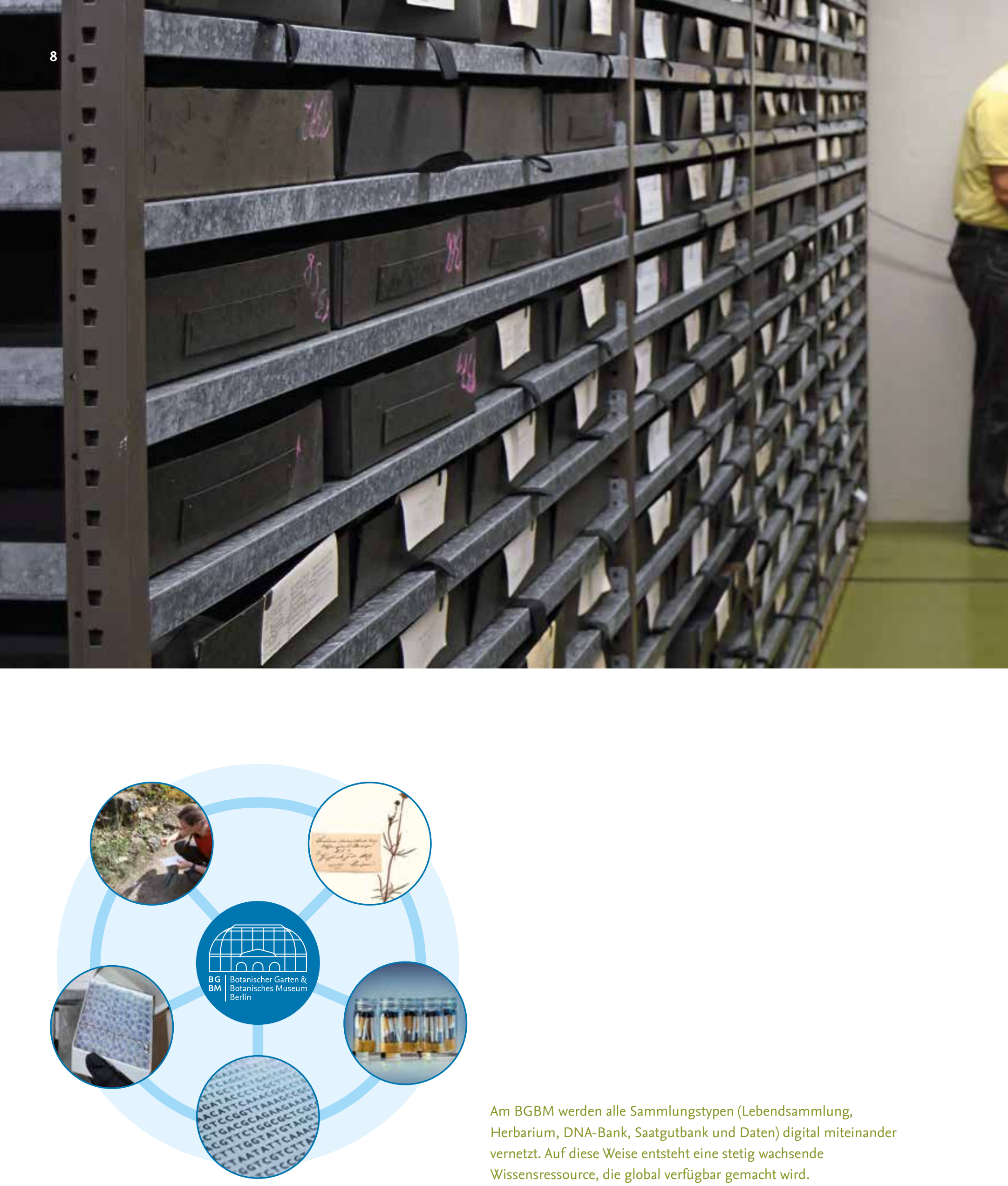

Am BGBM werden alle Sammlungstypen (Lebendsammlung, Herbarium, DNA-Bank, Saatgutbank und Daten) digital miteinander vernetzt. Auf diese Weise entsteht eine stetig wachsende Wissensressource, die global verfügbar gemacht wird. 


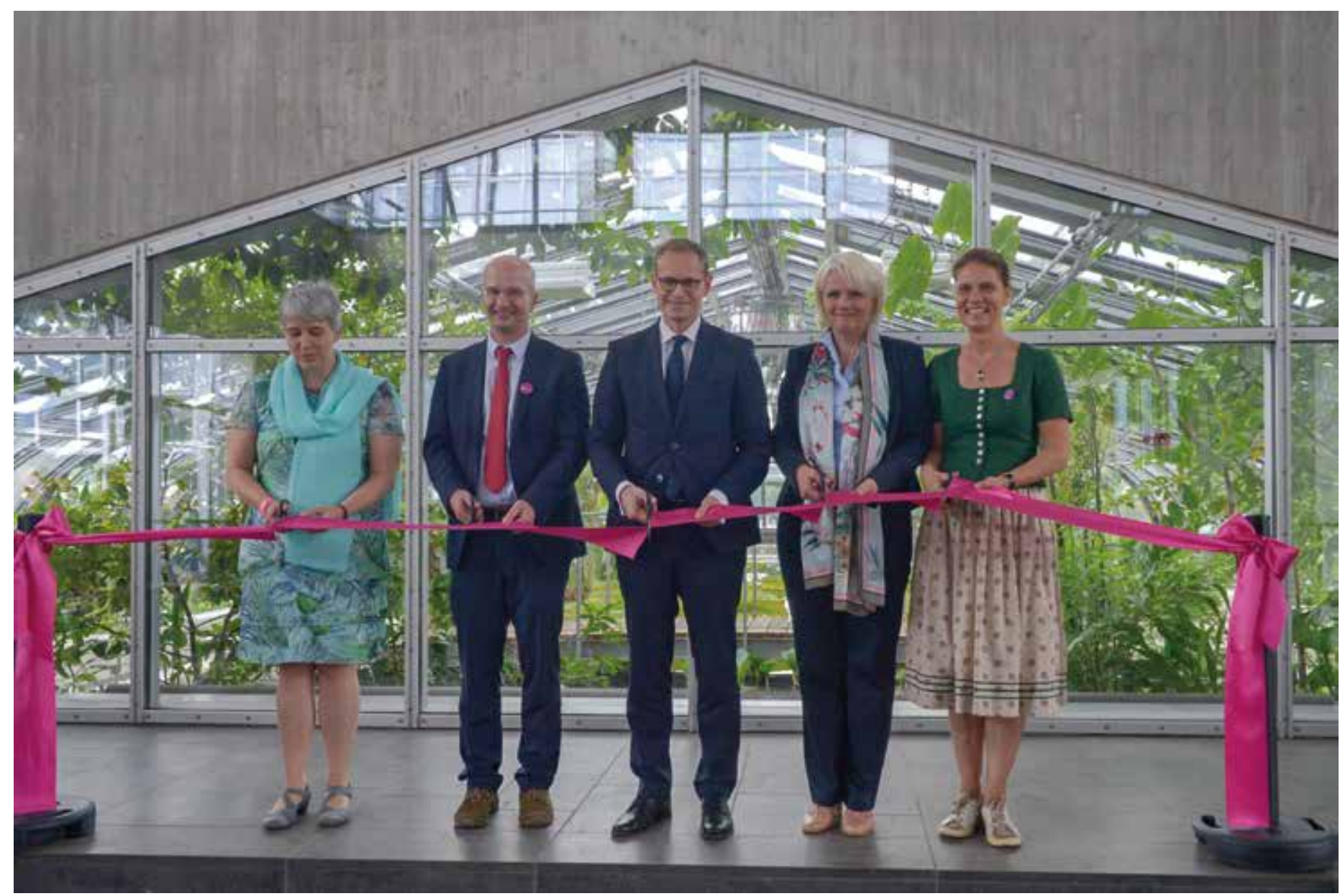

Berlins Regierender Bürgermeister Michael Müller (Mitte), Regine Günther, Senatorin für Umwelt, Verkehr und Klimaschutz (2. v. r.), Sarah Wiener (r.), Dr.-Ing. Andrea Bör, Kanzlerin der Freien Universität Berlin (I.) und Prof. Dr. Thomas Borsch (2. v. I.) beim Festakt zur Wiedereröffnung des Victoriahauses.

Highlight-Events der Jahre 2017 bis 2019
Audienz bei der Königin Die Wiedereröffnung des Victoriahauses 


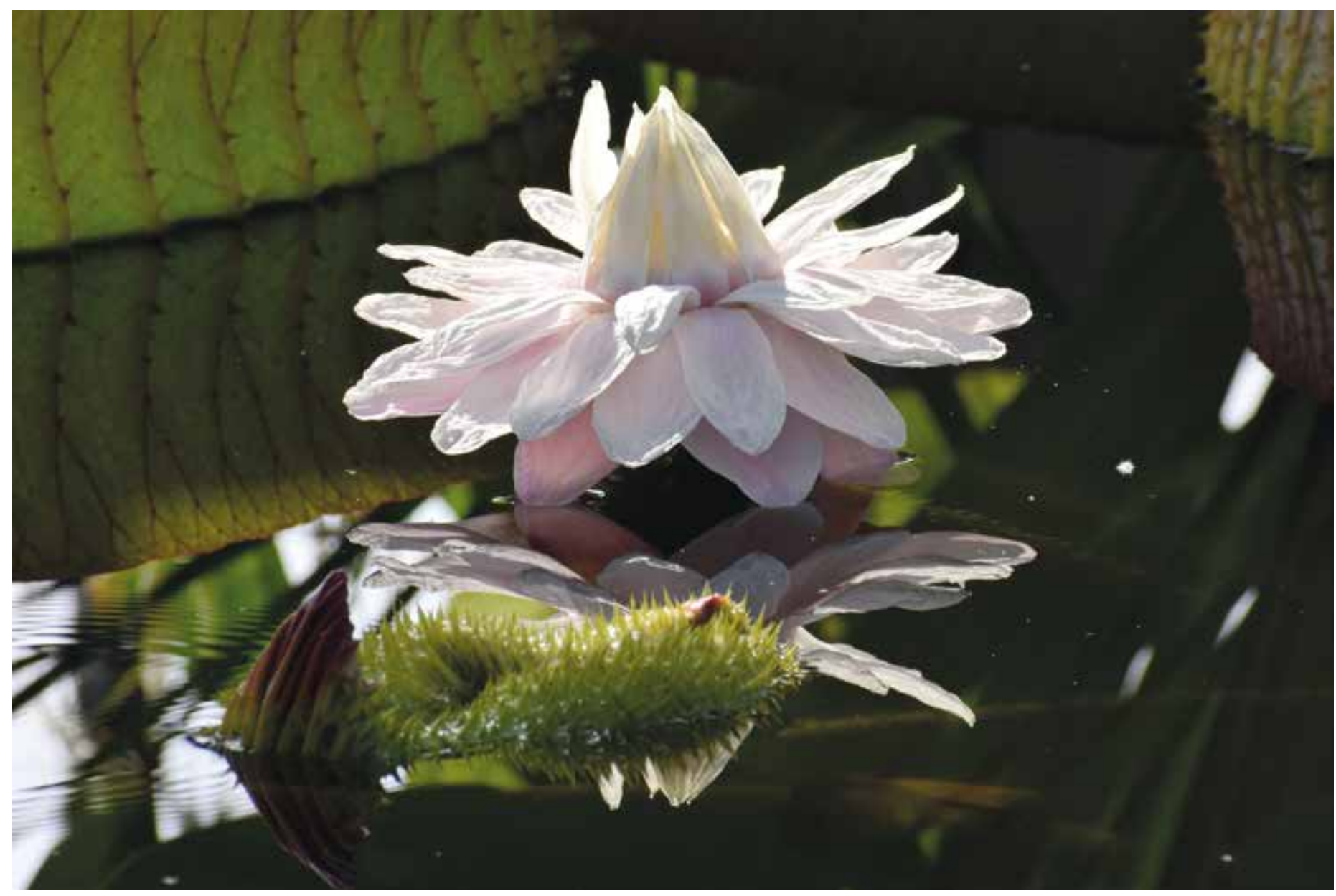

Blüte und junges Blatt der Art Victoria cruziana (heimisch im Rio Paraná in Brasilien) zeigten sich im Juni 2018 im frisch sanierten Victoriahaus im Botanischen Garten Berlin.

Die südamerikanischen Riesen-Seerosen der Gattung Victoria gelten als die Königinnen aller Wasserpflanzen. Welches andere Gewächs kann schließlich mit zwei Meter großen Schwimmblättern aufwarten, die Lasten bis zu 100 Kilogramm tragen können? Oder mit prächtigen Blüten, die mit einem Durchmesser von bis zu 35 Zentimetern zu den größten der Welt gehören?

Seit dem 15. Juni 2018 kann man diese botanische Attraktion auch in Berlin wieder bewundern. Bei einem Festakt mit mehr als 600 Gästen aus Politik, Wirtschaft, Wissenschaft und Kultur wurde an diesem Tag das Victoriahaus des BGBM wiedereröffnet. Das mehr als 100 Jahre alte Gewächshaus war zwölf Jahre lang geschlossen und wurde seit 2013 dank denkmalschutzgerechter Grundsanierung auf einen energiesparenden Betrieb getrimmt. Ermöglicht wurde dies mit Mitteln des Landes Berlin, des Europäischen Fonds für regionale Entwicklung (EFRE) im Rahmen des Umweltentlastungsprogramms II sowie Eigenmitteln der Freien Universität Berlin.

Seither ist eine der wichtigsten Wasserpflanzensammlungen der Welt wieder für die Öffentlichkeit zugänglich. 


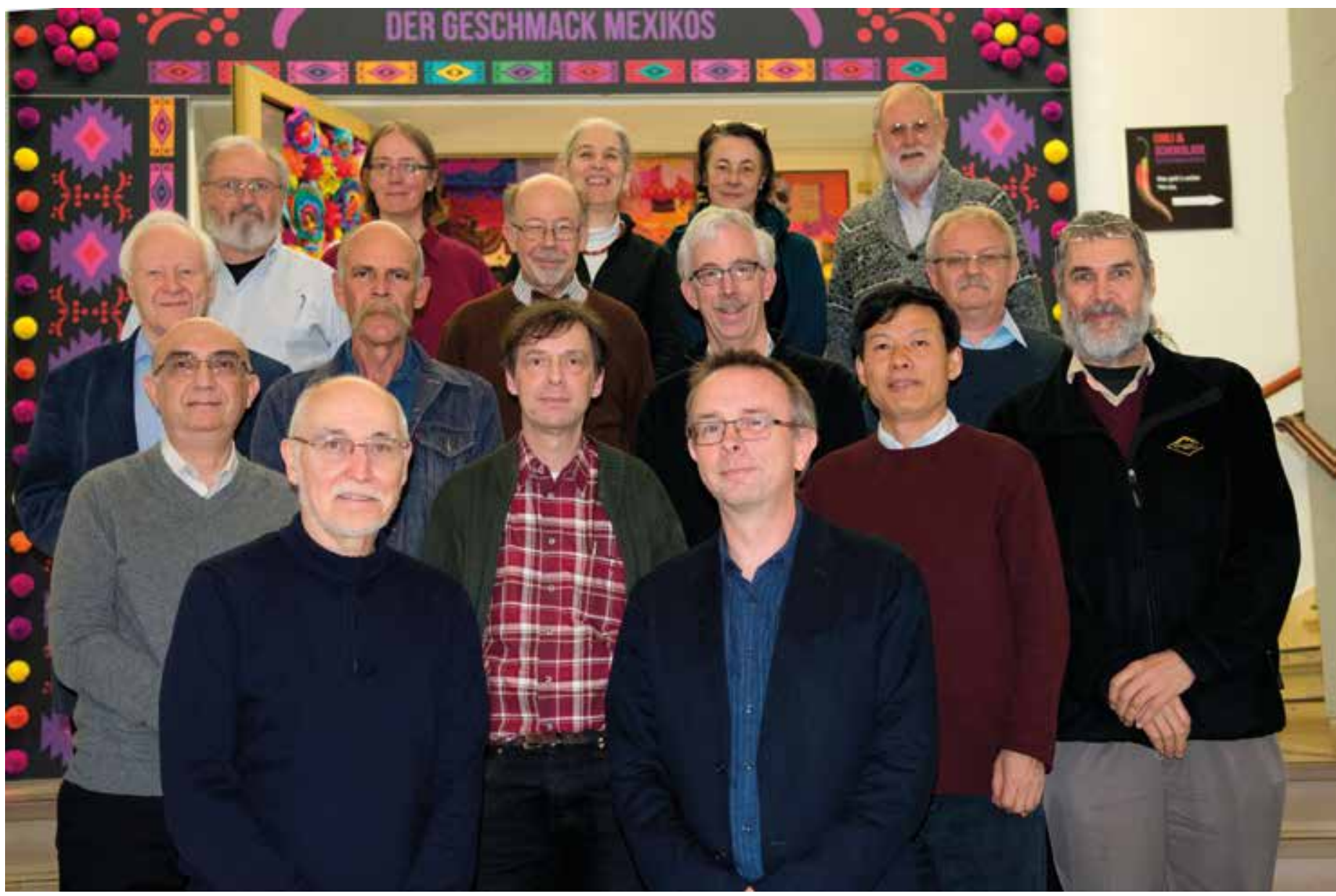

Redaktionsausschuss, von links nach rechts und von hinten nach vorne: Fred R. Barrie, Anna M. Monro, Sandra Knapp, Michelle J. Price, Werner Greuter, John McNeill, Gideon F. Smith, David L. Hawksworth, Patrick S. Herendeen, Karol Marhold, Tom W. May, Jefferson Prado, WolfHenning Kusber, De-Zhu Li, John H. Wiersema (Sekretär) und Nicholas J. Turland (Vorsitzender).

\section{Das Buch für die Namen Die Erstellung des Shenzhen Code}

Damit bei der Erforschung der Artenvielfalt nicht heillose Verwirrung ausbricht, müssen sich alle Wissenschaftlerinnen und Wissenschaftler weltweit für jede Art auf einen gültigen Namen einigen. Das klingt allerdings einfacher, als es ist. Problematisch wird es zum Beispiel, wenn sich hinter mehreren historischen Namen die gleiche Art verbirgt. Oder wenn Forschungsergebnisse zeigen, dass eine Art zu einer anderen Gattung gehört. Nicht nur bei Neuentdeckungen kommt es also immer wieder vor, dass Pflanzen neu benannt werden müssen.

Welche Regeln dabei zu beachten sind, ist im „Internationalen Code der Nomenklatur für Algen, Pilze und Pflanzen“ festgelegt, der alle sechs Jahre aktualisiert wird. Die neueste Version wurde am 29. Juli 2017 auf dem 19. Internationalen Botanischen Kongress in der chinesischen Stadt Shenzhen verabschiedet. Nicholas Turland vom BGBM hatte dabei die Leitung des 16-köpfigen Redaktionsausschusses inne. 


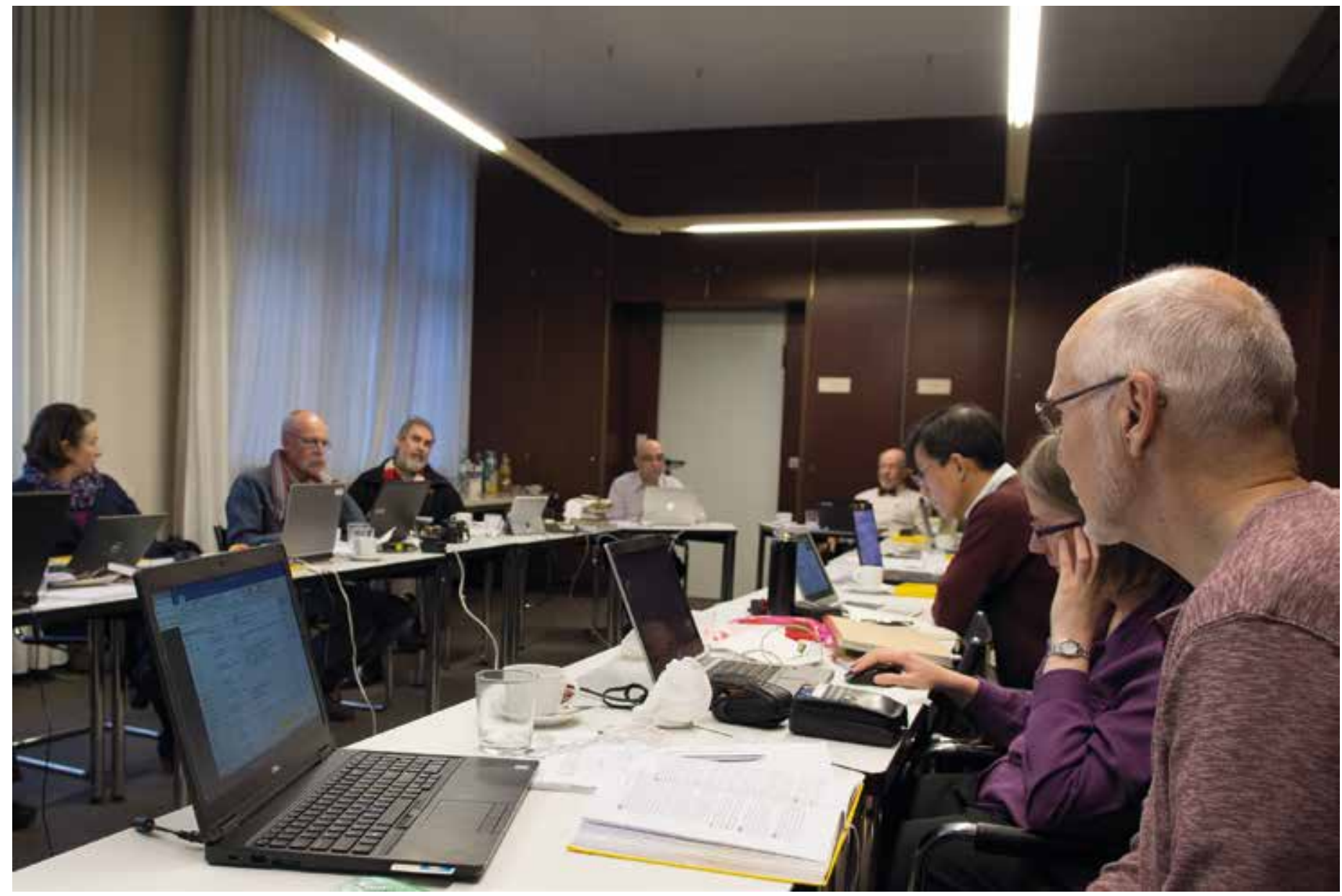

Der Redaktionsausschuss bei der Arbeit.

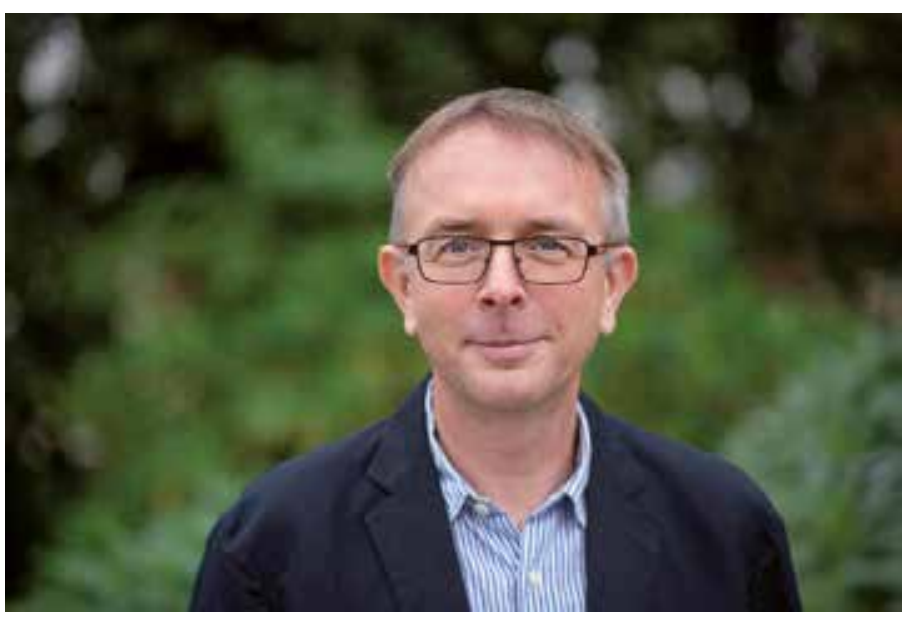

Wenn es um die Namen von Pflanzen geht, ist Nicholas J. Turland Experte. Sein Interesse daran erwachte 1994, als er sich am Natural History Museum in London mit den Arten beschäftigte, die Carl von Linné schon im 18. Jahrhundert beschrieben hatte. Doch auch aus eigener Erfahrung kennt er die Herausforderungen bei der Erstellung von Florenbearbeitungen. So arbeitete er am Missouri Botanical Garden von 1997-2012 an der Flora von China, dies ab 2006 als Projektleiter. Mit über 31.000 darin beschriebenen Gefäßpflanzenarten wurde das Florenprojekt 2013 abgeschlossen. Am BGBM leitet er seit 2012 den Bereich Verlag und Grafik, der die beiden wissenschaftlichen Journale Willdenowia und Englera herausgibt. Außerdem ist er Rapporteur-général für die Nomenklatur-Sektion des Internationalen Botanischen Kongresses (2017 und 2023) und Vorsitzender des Redaktionsausschusses des International Code of Nomenclature for algae, fungi, and plants, der die international geltenden Regeln für die wissenschaftliche Benennung dieser Organismen festlegt. 


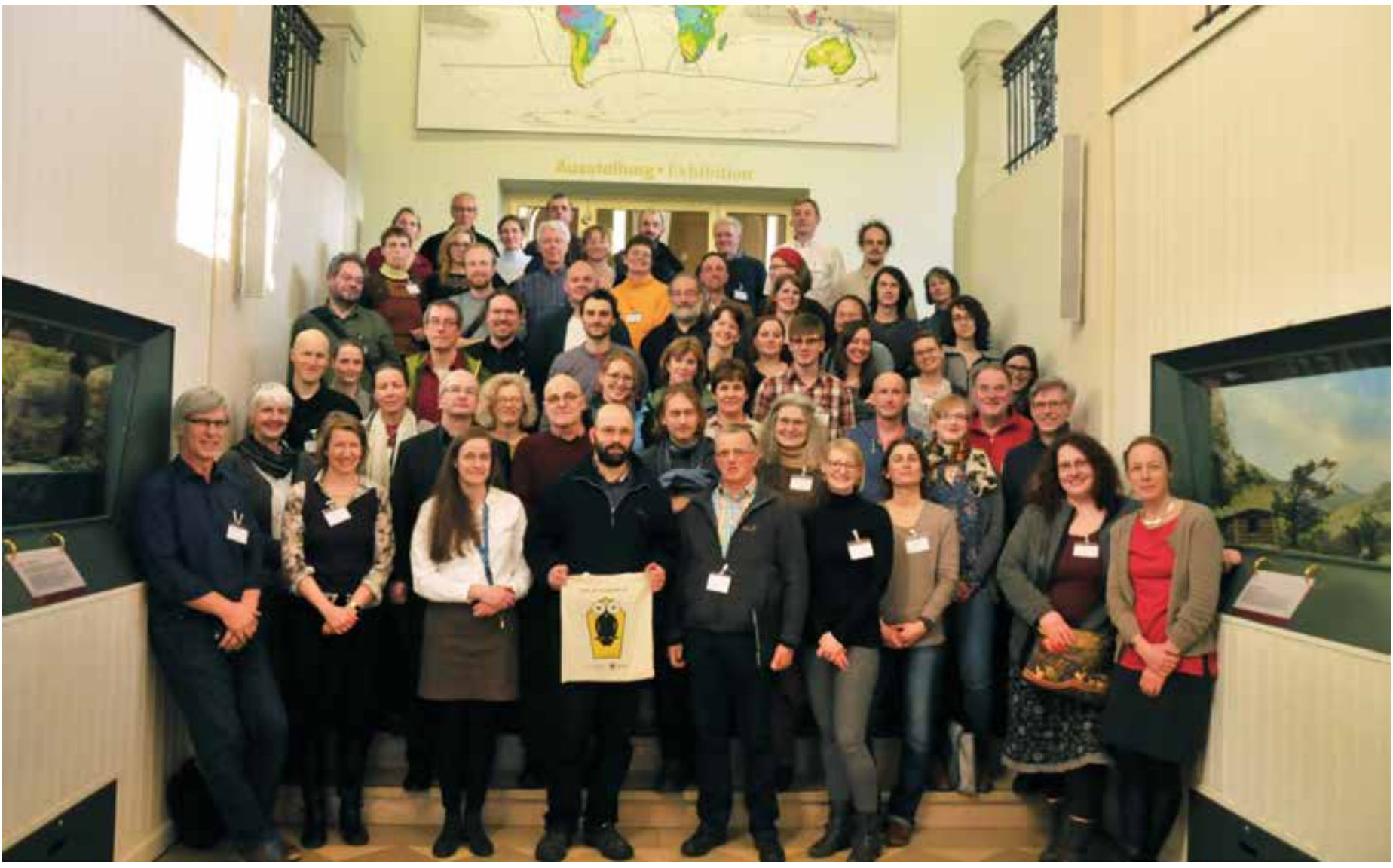

Die Teilnehmerinnen und Teilnehmer des Fachsymposiums „Schutz bedrohter Pflanzenarten in Mitteleuropa“ vor dem Eingang des Botanischen Museums.

\section{Ein botanischer Rettungsschirm Fachsymposium zum Schutz mitteleuropäischer Pflanzenarten}

Das gemeinsame Ziel ist klar: Es geht darum, die schwindende Pflanzenvielfalt in Mitteleuropa so weit wie möglich zu erhalten. Nur wie lässt sich das am besten bewerkstelligen? Welchen Beitrag kann die Wissenschaft dazu leisten, welchen der praktische Naturschutz? Und wie lässt sich beides verbinden, so dass die richtigen Forschungsfragen gestellt werden und die Forschungsergebnisse auch tatsächlich genutzt werden können? Über solche Fragen diskutierten rund 80 Teilnehmerinnen und Teilnehmer aus ganz Deutschland, Österreich und der Schweiz bei der Tagung "Schutz bedrohter Pflanzenarten in Mitteleuropa“, die vom 23. bis 25. Februar 2017 am BGBM stattfand. Die genetische Vielfalt von Pflanzenbeständen war dabei ebenso Thema wie Maßnahmen und Konzepte zum Artenschutz. Vor allem aber wurde die Veranstaltung zu einem naturschutzfachlichen Forum, bei dem Expertinnen und Experten aus Wissenschaft und Praxis sich austauschen und ihre Bedürfnisse formulieren konnten. Das Fachsymposium war Teil eines Projektes, das vom Bundesamt für Naturschutz gefördert wurde, um die Umsetzung von Deutschlands Naturschutzzielen zu befördern. 


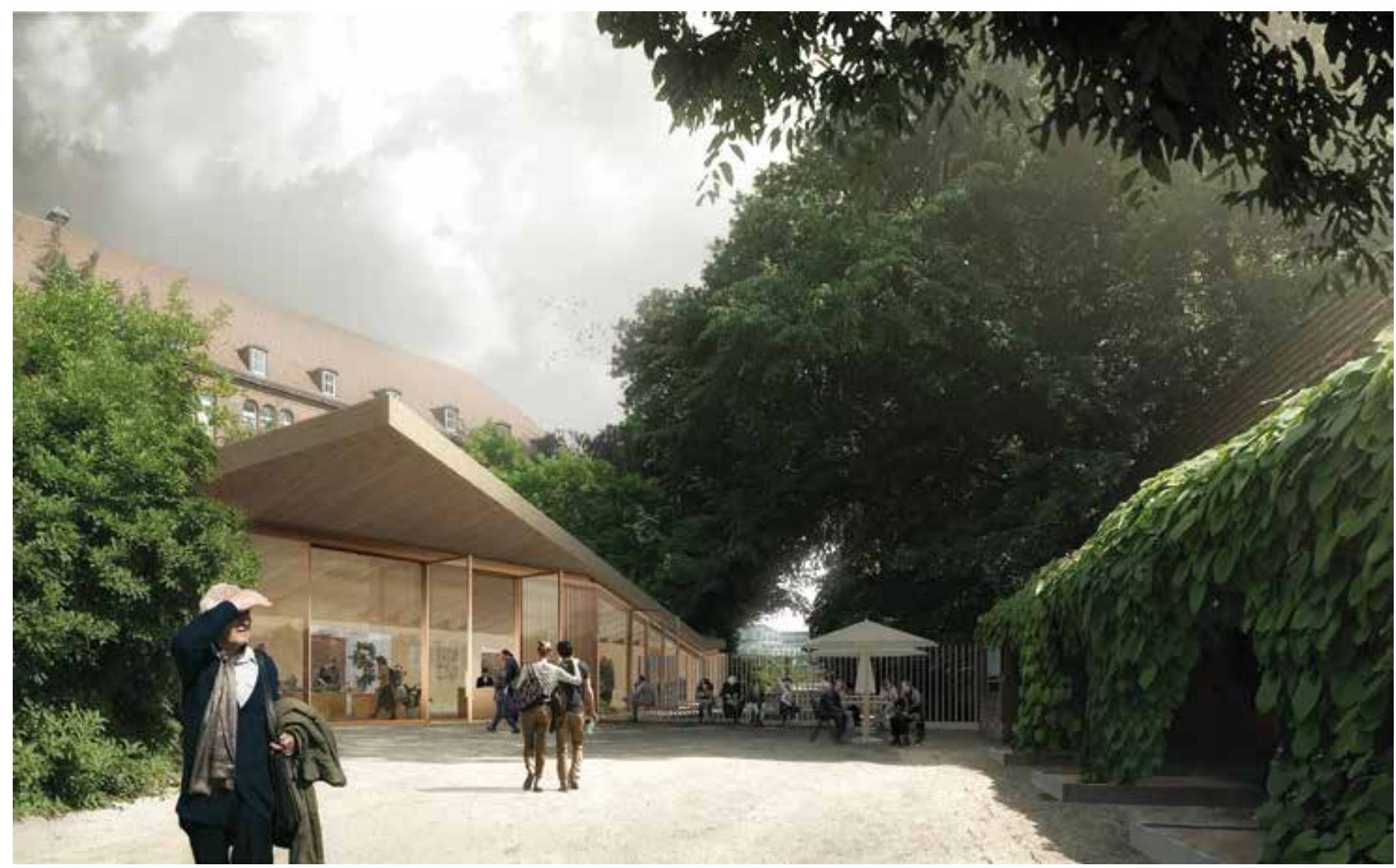

Entwurf des Besucherzentrums von heneghan peng architects.

\section{Moderne Infrastruktur für einen Botanischen Garten mit Geschichte Der Bau des neuen Besucherzentrums beginnt}

Der Botanische Garten Berlin blickt stolz auf seine über 300-jährige Geschichte zurück. Doch auch ein Garten mit Geschichte braucht eine moderne Infrastruktur, um seine architektonische Visitenkarte möglichst attraktiv zu gestalten. Und in Sachen Infrastruktur soll sich hier mit Hilfe von Mitteln aus der Gemeinschaftsaufgabe „Verbesserung der regionalen Wirtschaftsstruktur" (GRW) einiges verändern. Der Bau eines neuen Besucherzentrums ist die für Besucherinnen und Besucher sichtbarste Veränderung in einer ganzen Reihe von geplanten Baumaßnahmen, die ein neues Besucherleit- und -informationssystem, die Instandsetzung eines großen Teils der Gartenwege und die Neugestaltung des Museums umfassen.

„Wir freuen uns, dass das neue Besucherzentrum auf dem nun vorbereiteten Boden Wurzeln schlagen kann“, so Prof. Dr. Thomas Borsch, Direktor des Botanischen Gartens und Botanischen Museums, im Dezember 2019. Nach dem Entwurf der Architekten heneghan peng architects wird ein lichtes Gebäude entstehen, das unter einem Holzdach Platz für Shop, Infozentrum, Schließfächer und Kassenbereich bietet und über einen Hofgarten mit dem Botanischen Museum verbunden sein wird. Zusammen mit einem Café und einem großzügigeren Eingangsbereich entsteht so am Eingang Königin-Luise-Platz bis Ende 2021 ein neues, informatives Forum für Naturfreunde, Erholungssuchende und Botanikbegeisterte. 


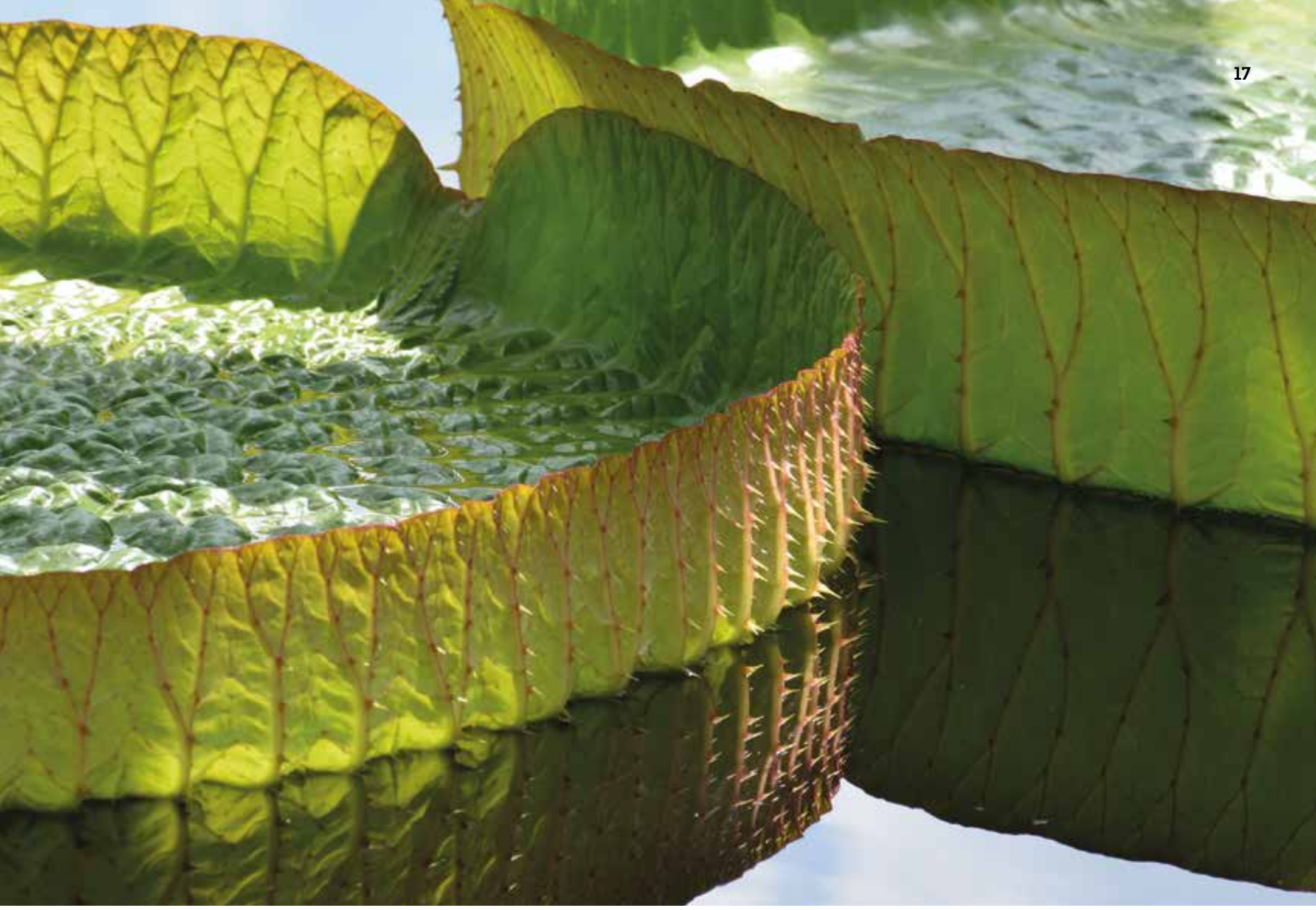

Auch das Blatt der Riesenseerose Victoria verlässt sich auf ein Netzwerk. Dank des leistenförmigen Stützgewebes auf der Blattunterseite kann es bis zu 100 Kilogramm Gewicht tragen.

„Inzwischen haben unsere Kolleginnen und Kollegen vom Field-Museum Macbrides Foto-Sammlung digitalisiert, und so sind diese wertvollen Belege nun zumindest virtuell zu uns zurückgekehrt", freut sich Prof. Dr. Walter Berendsohn, der am BGBM die Abteilung Forschung und Biodiversitätsinformatik leitet. Für ihn ist das ein schönes Beispiel dafür, wie lange botanische Forschungseinrichtungen schon miteinander vernetzt sind - und wie wertvoll dies ist. Macbrides Foto-Initiative hat damit Pioniercharakter für die bildliche Verfügbarmachung von Sammlungsmaterial.

„Im Zeitalter der Digitalisierung bieten sich dazu natürlich noch viel bessere Möglichkeiten als zu Macbrides Zeiten“, sagt der Botaniker. So arbeiten er und sein Team an einer komplexen digitalen Infrastruktur, die Menschen und Daten institutionenübergreifend miteinander verbindet. Informationen über die lebenden und gepressten Pflanzen, das Saatgut und die DNA-Proben in den Sammlungen des BGBM werden dazu in Datenbanken eingespeist, die das Berliner Team zum größten Teil selbst oder zusammen mit Kooperationspartnern entwickelt hat. Wichtig ist es dabei auszutüfteln, wie man all diese Daten am besten erfasst und strukturiert. Denn nur, wenn das nach einheitlichen Standards vor sich geht, lassen sich die Informationen international vernetzen und zugänglich machen. Und genau das ist das Ziel: Wer sich für bestimmte Arten (oder eine bestimmte Gegend) interessiert, soll über einen zentralen Zugangspunkt im Internet auf Sammlungen in aller Welt zugreifen können.

Schon weit gediehen sind diese Bemühungen bei einem internationalen Netzwerk namens Global Biodiversity Information Facility (GBIF), das 2001 gegründet wurde und in dem mittlerweile mehr als 50 Staaten Mitglied sind. Jeder davon muss mindestens einen nationalen Knoten einrichten, über den Museen, Botanische Gärten und andere Institutionen ihre Daten zur biologischen Vielfalt mit dem Rest der Welt teilen können.

In Deutschland gibt es acht dieser Knoten, jeder davon ist für eine andere Gruppe von Organismen zuständig. Der BGBM hat dabei neben der Gesamtkoordination auch den Bereich Botanik übernommen. Über die jeweiligen Knoten können die beteiligten Forschungseinrichtungen direkt mit der GBIF-Plattform kommunizieren. Mithilfe einer 


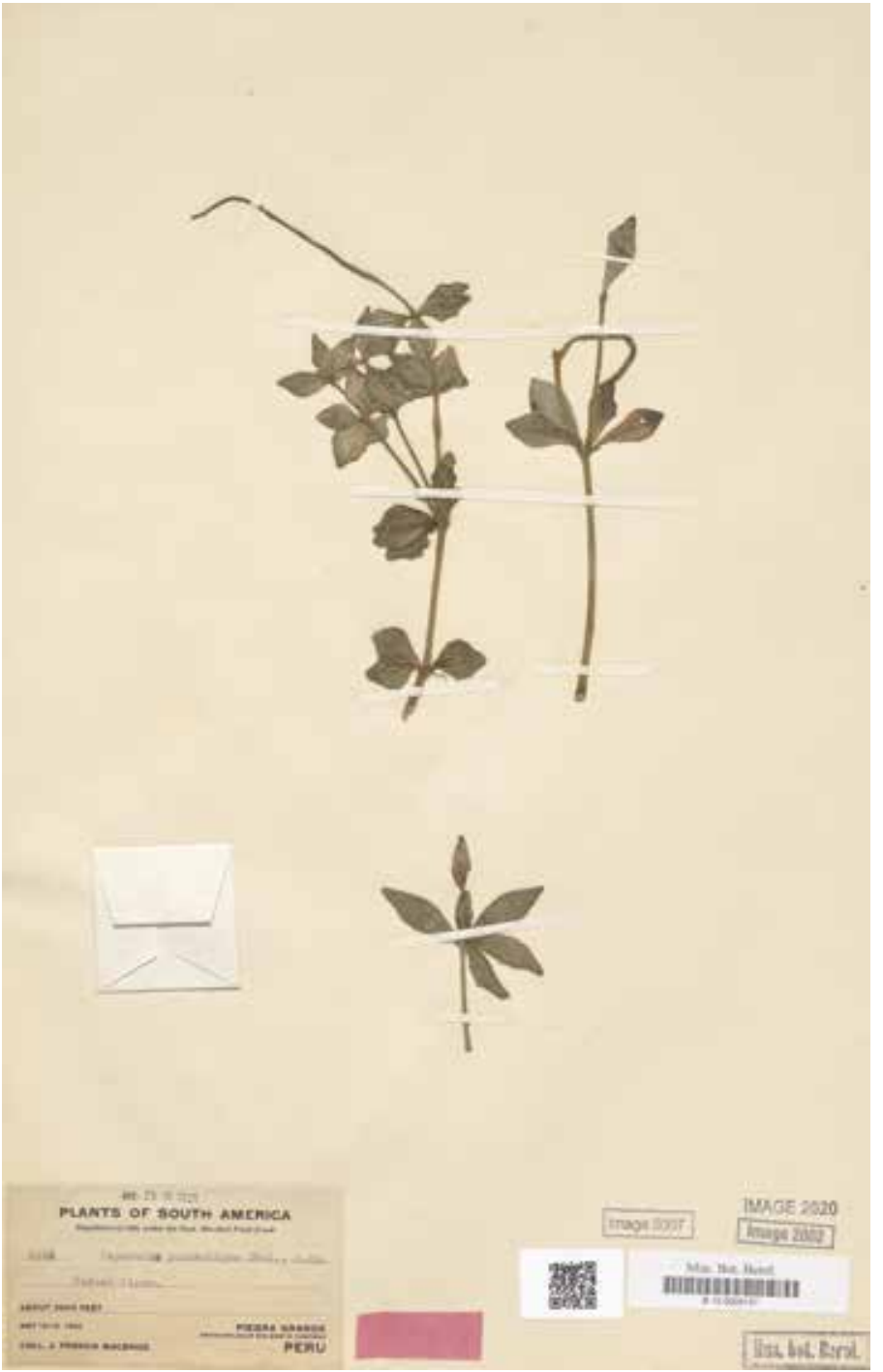

Von James Francis Macbride im Jahre 1923 in Peru gesammelter Herbarbeleg. Auf Grundlage dieses Materials (Typus) wurde von William Trelease die Art Peperomia puberulipes Trel. beschrieben.

speziellen Software wird ihre lokale Datenbank dazu in den GBIF-Standard integriert und ist dann zentral abrufbar.

So ist eine riesige virtuelle Bibliothek entstanden, die mehr als eine Milliarde Einträge über die biologische Vielfalt der Erde enthält. Sie verraten zum Beispiel, wann eine bestimmte invasive Pflanzenart erstmals in Deutschland gesammelt wurde oder wann eine bestimmte Vogelart wo beobachtet wurde. Die Informationen aus GBIF sind allein im Jahr 2019 in fast 800 wissenschaftliche Studien eingeflossen.

Denn es gibt zahlreiche Möglichkeiten, den Datenschatz von GBIF zu nutzen. Man kann damit zum Beispiel Verbreitungskarten für einzelne Arten erstellen und schauen, ob sich die Vorkommen mit den Jahren

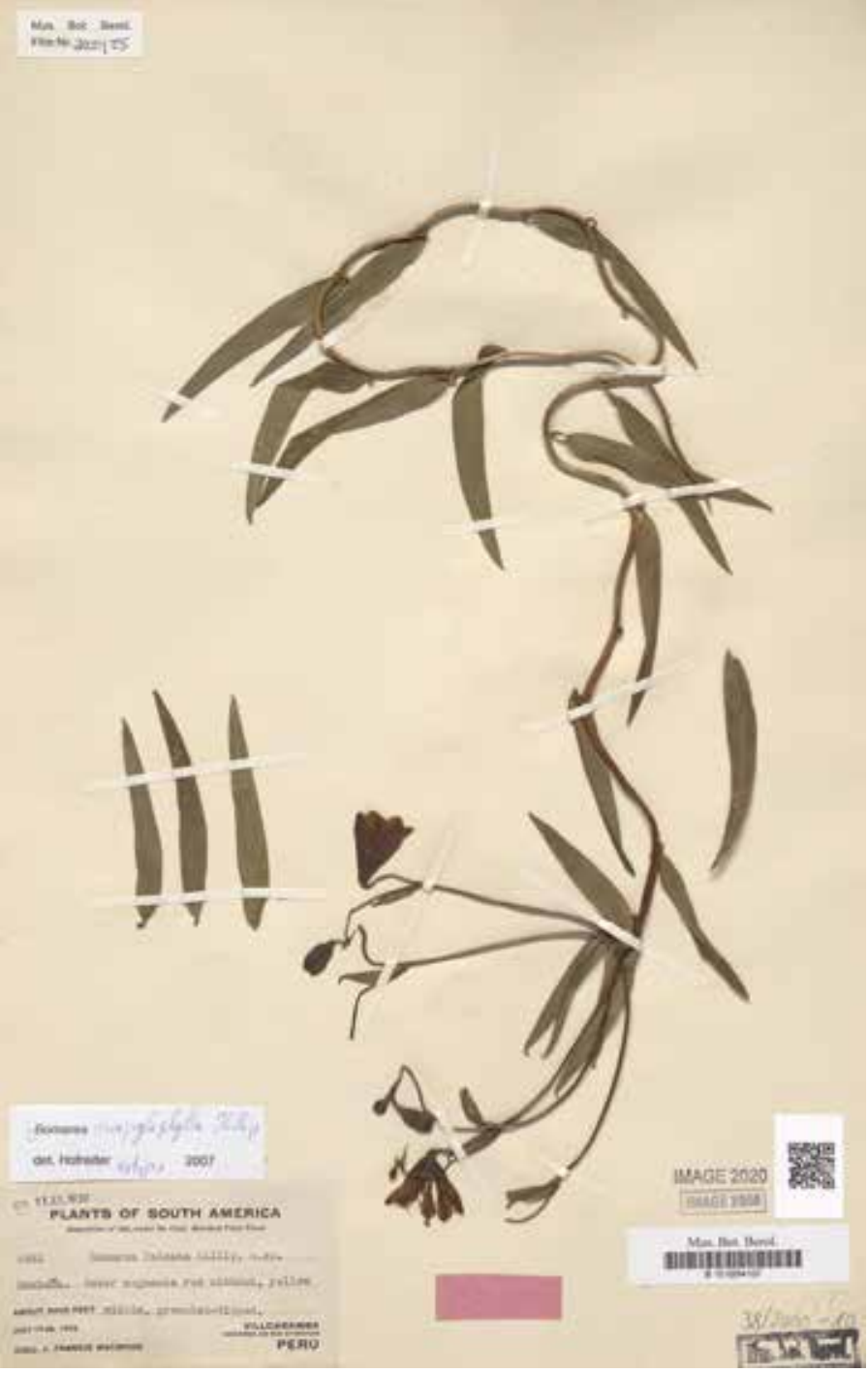

Von James Francis Macbride im Jahre 1923 in Peru gesammelter Herbarbeleg. Auf Grundlage dieses Materials (Typus) wurde von Ellsworth Paine Killip die Art Bomarea campylophylla Killip beschrieben.

verändert haben. Und manchmal werden auch die Trends der Zukunft greifbar. „Wenn man zum Beispiel feststellt, dass eine Miniermotte die Agaven in Argentinien zerstört, kann man die Vorkommen des Insekts mit Klimadaten verknüpfen“, erklärt Walter Berendsohn. So lässt sich abschätzen, wo der Schädling eingeschleppt werden könnte. Und das kann auch wirtschaftlich interessant sein - etwa, wenn die Motte nach Mexiko vorzurücken und mit den dortigen Agaven auch die Tequila-Produktion zunichtezumachen droht.

Die Daten spielen auch bei der Einschätzung der Gefährdung der Biodiversität eine große Rolle. So sind je nach Artengruppe heute zwischen 20 und über 50 Prozent der Pflanzenarten vom Aussterben bedroht - 
aber für viele liegen keine verlässlichen Daten vor. Die Digitalisierung und Verknüpfung der mit den Herbarbelegen gesammelten Daten stellt daher eine wichtige Grundlage für die vom Weltbiodiversitätsrat IPBES (Intergovernmental Science-Policy Platform on Biodiversity and Ecosystem Services) veröffentlichten Ergebnisse dar.

„Die Software-Komponenten, die wir entwickelt haben, sind aber nicht nur in GBIF eingeflossen“, sagt Anton Güntsch, der Leiter Biodiversitätsinformatik am BGBM. Es gibt noch eine ganze Reihe weiterer Plattformen, die ganz ähnlich organisiert sind. Dazu gehört zum Beispiel das 2011 gegründete Global Genome Biodiversity Network (GGBN), in dem mittlerweile 96 Forschungsinstitutionen Mitglied sind. Hier kann man sich einen Überblick darüber verschaffen, welche DNA- und Gewebe-Proben wo aufbewahrt werden.

Fast drei Millionen solcher Proben sind in der Datenbank bereits erfasst. Doch das ist nur ein Bruchteil der schätzungsweise zehn bis zwölf Millionen Exemplare, die insgesamt bei den beteiligten Einrichtungen lagern. Bis auch die alle online durchsucht und angefordert werden können, wird es noch einige Jahre dauern. „Wir nehmen dabei Material von allen möglichen Organismen außer dem modernen Menschen auf", erklärt BGBM-Mitarbeiterin Gabriele Dröge, in deren Händen das technische Sekretariat von GGBN liegt. „Die Palette reicht dabei vom Bakterium bis zum Menschenaffen."

Auf einem weiteren Portal, bei dem die in Berlin entwickelte Software zum Einsatz kommt, sind dagegen ausschließlich Pflanzen vertreten. Evo-BoGa ist als eine Art Online-Katalog für die Lebendsammlungen von etwa 90 botanischen Gärten in Deutschland geplant. Wer für seine Forschungsarbeit bestimmte Arten in lebendem Zustand braucht, soll in Zukunft dort nachschauen können, wo sie kultiviert werden. Für die großen Pflanzenfamilien der Orchideen und Bromelien befinden sich bereits zahlreiche Datensätze im Portal.

Doch auch auf europäischer Ebene gibt es Bemühungen, die Schätze der naturkundlichen Sammlungen für die Wissenschaft besser nutzbar zu machen. So haben sich Botanische Gärten, Naturkundemuseen und andere Sammlungseinrichtungen zu einem Verbund namens Consortium of European Taxonomic Facilities (CETAF) zusammengeschlossen. Eines der Projekte dieses Konsortiums heißt Distributed System of Scientific Collections (DiSSCo), an dem derzeit 120 Einrichtungen in 21 europäischen Ländern beteiligt sind. Der BGBM ist eine von inzwischen sieben deutschen Forschungseinrichtungen, die sich daran beteiligen. DiSSCo wird den Zugang zu Sammlungen europaweit mit modernsten Methoden koordinieren, so dass die Fahndungssysteme für Sammlungsstücke noch effizienter werden. Man kann dann zum Beispiel nach Herbar-Belegen von bestimmten Pflanzen suchen und diese bei Bedarf ausleihen oder an einem hochauflösenden Bild studieren.

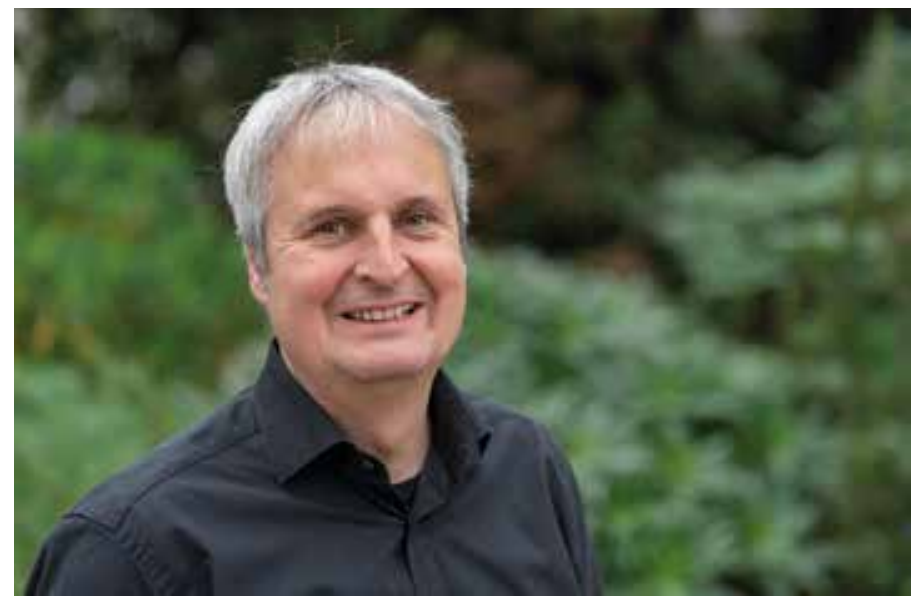

Anton Güntsch ist Diplom-Informatiker und leitet seit 2005 die Forschungsgruppe Biodiversitätsinformatik am BGBM. Er hat sich auf Datenbanken und Expertensysteme spezialisiert und interessiert sich vor allem dafür, wie man biologische Daten für die verschiedensten Forschungsfragen bereitstellt und miteinander verknüpft. In zahlreichen Projekten und Kooperationen tüftelt er an fortschrittlichen Methoden der biologischen Informationsverarbeitung mit. An einer so forschungsstarken botanischen Einrichtung wie dem BGBM zu arbeiten, kann dabei nur nützlich sein - vor allem, wenn es darum geht, die von seinem Team entwickelten Software-Produkte zu erproben und einzuführen.

„Bilddaten sind bei der Digitalisierung von Sammlungsobjekten in letzter Zeit immer wichtiger geworden“, sagt Biodiversitätsinformatiker Anton Güntsch. Denn James Francis Macbrides hundert Jahre alte Idee ist heute aktueller denn je: Wenn Fotos im Internet zur Verfügung stehen, können sie die eine oder andere teure Reise zu den Sammlungen der Welt überflüssig machen. Und heute wie damals werden die Bilder mitunter zur letzten Erinnerung an verlorene Schätze. So hat erst im September 2018 ein verheerender Brand zahllose Kostbarkeiten im Naturkundemuseum in Rio de Janeiro vernichtet. „Die Digitalisierung ist zwar kein Ersatz für so eine physische Sammlung“, betont Walter Berendsohn. „Aber zumindest bietet sie eine Art Absicherung für den Notfall.“ 


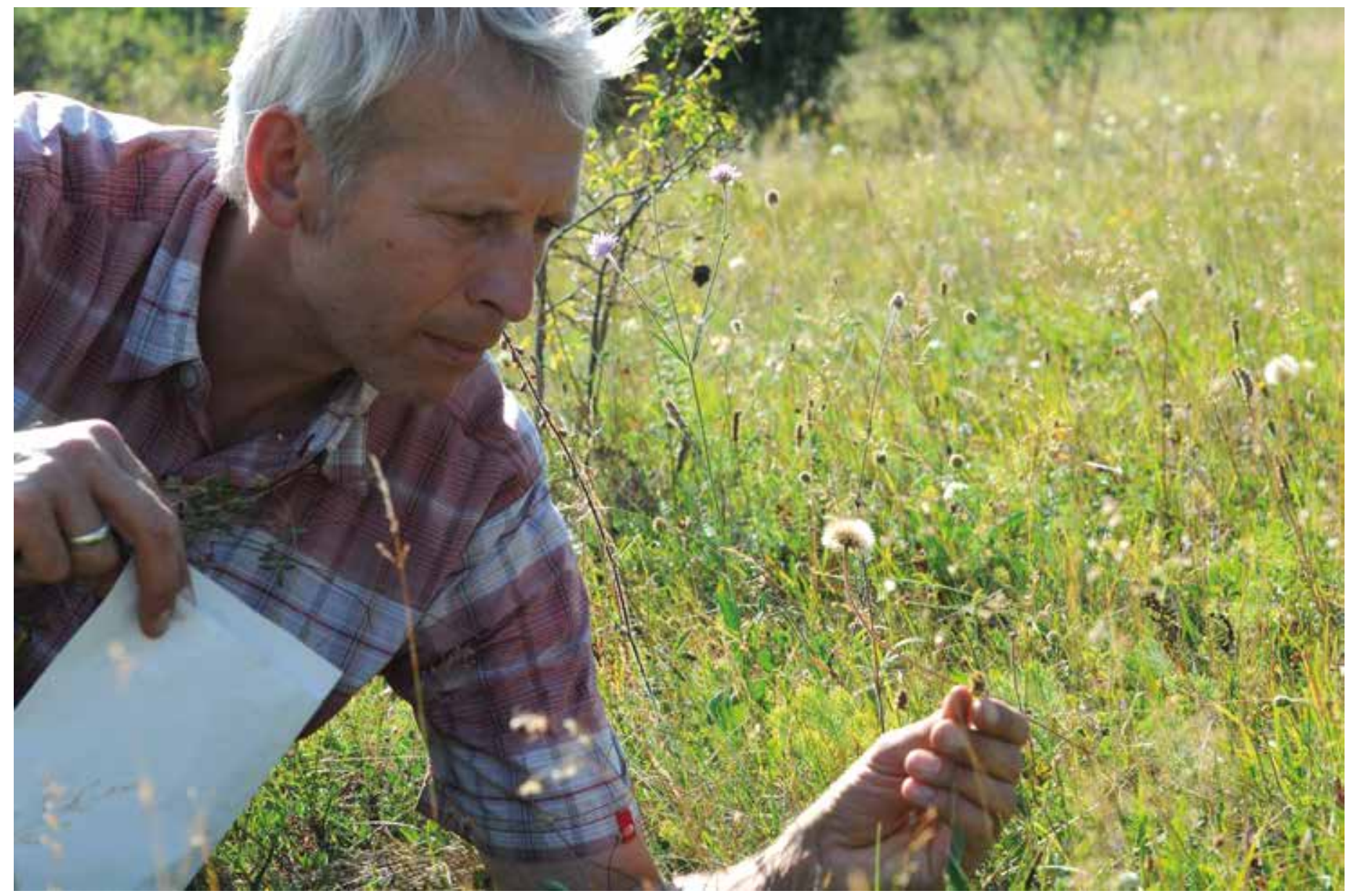

Die Sammlung von Saatgut von Wildpflanzen am natürlichen Wuchsort erfordert sehr gute Kenntnisse der Pflanzenarten sowie der Morphologie von Früchten und Samen.

Fahnden nach der Vielfalt Um Arten zu schützen und den Zustand von Lebensräumen zu beurteilen, braucht man gute Beobachtungsprogramme.
Es ist eine echte Detektivarbeit. Wer mehr über die schwindende Artenvielfalt unseres Planeten wissen will, kommt um akribische Bestandsaufnahmen nicht herum. Wo kommen welche Arten vor? Wie groß sind ihre Bestände, wachsen oder schrumpfen sie? Wie hoch ist ihre genetische Vielfalt? Und welche Schlüsse kann man daraus ziehen? Solche Fragen zu beantworten, ist für Wissenschaftlerinnen und Wissenschaftler am BGBM aus verschiedenen Gründen von Bedeutung. Zum einen kann ein solches Monitoring der biologischen Vielfalt verraten, welche Arten wie stark gefährdet sind und wie man den besonders bedrohten Kandidaten vielleicht helfen kann. Zum anderen sind bestimmte Organismen lebende Indikatoren, die mehr über den Zustand ihres Lebensraumes verraten.

„So haben die Kieselalgen, die wir untersuchen, ganz unterschiedliche Ansprüche“, sagt Dr. Jonas Zimmermann, der die Forschungsgruppe Diatomeen des BGBM seit 2019 leitet. Manche sind auf höhere Temperaturen, $\mathrm{pH}$-Werte oder Salzgehalte angewiesen, andere brauchen niedrigere. Anhand fossiler Kieselalgen-Schalen können Fachleute für Paläontologie zusätzlich auf das Klima längst vergangener Zeiten 


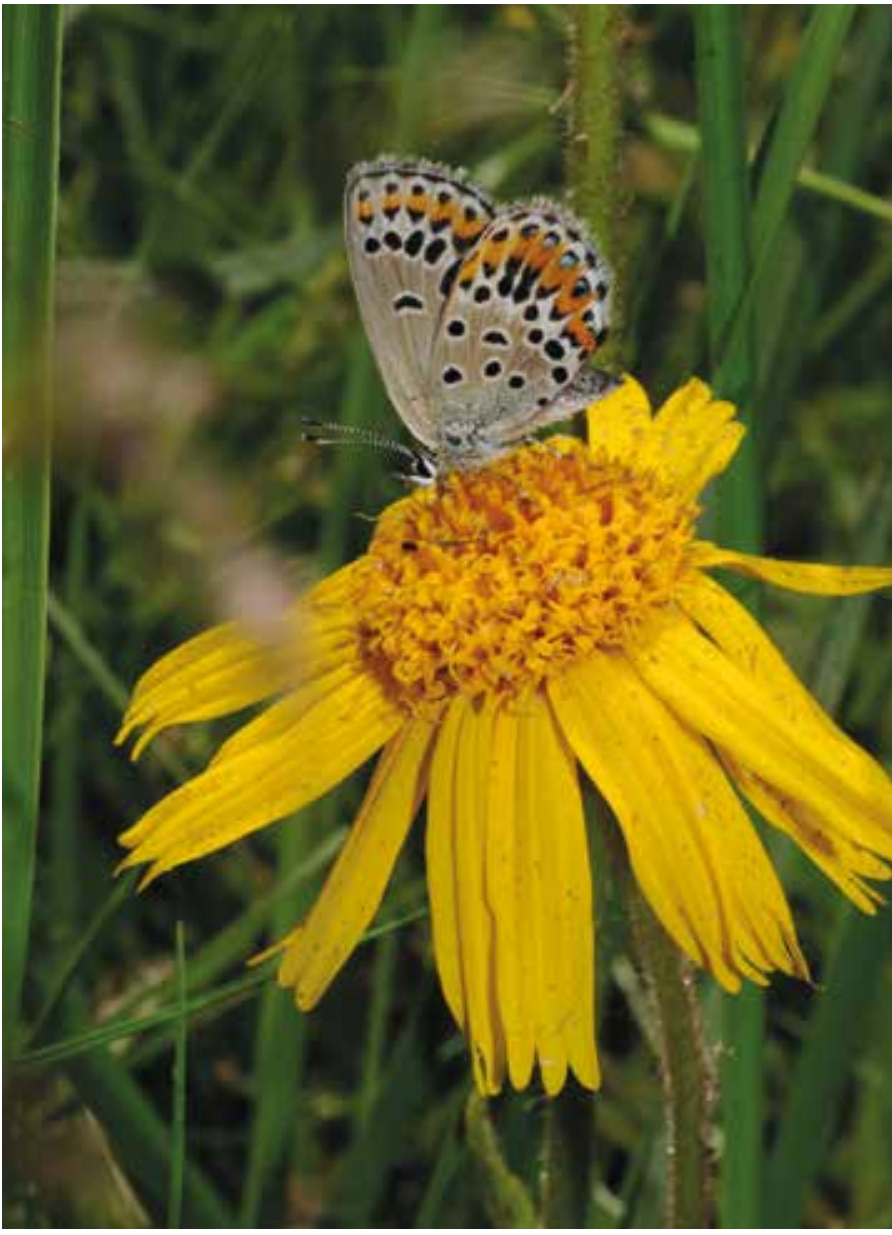

Die Arnika (Arnica montana) ist im Tiefland fast überall ausgestorben. Das letzte Vorkommen in Vorpommern wurde von Mitarbeiterinnen und Mitarbeitern des BGBM und den Behörden vor Ort mit nachgezogenen Jungpflanzen gestützt. Inzwischen lockt die wieder reich blühende Population viele Blütenbesucher an.

schließen. Und manchmal sind die winzigen Zeugen auch in Kriminalfällen interessant. „Eine Wasserleiche mit Süßwasserarten in der Lunge kann zum Beispiel nicht im Meer ertrunken sein“, erklärt der Forscher. Die Fachleute der Forschungsgruppe Diatomeen haben sich allerdings aus anderen Gründen auf die Spur der verräterischen Winzlinge gesetzt. Laut Wasserrahmenrichtlinie der EU gehören Kieselalgen nämlich zu den Organismen, die als Indikatoren für den Zustand von Gewässern herangezogen werden sollen. Denn am Auftreten oder Fehlen bestimmter Arten bzw. an deren Häufigkeit kann man ablesen, wie stark das Wasser mit Nährstoffen belastet ist.

Dazu muss man die Palette der vorkommenden Diatomeen natürlich möglichst genau analysieren. Klassischerweise betrachtet man dazu die Schalen der Einzeller unter dem Mikroskop. Doch da das sehr aufwändig ist und nicht immer ganz eindeutige Bestimmungsergebnisse

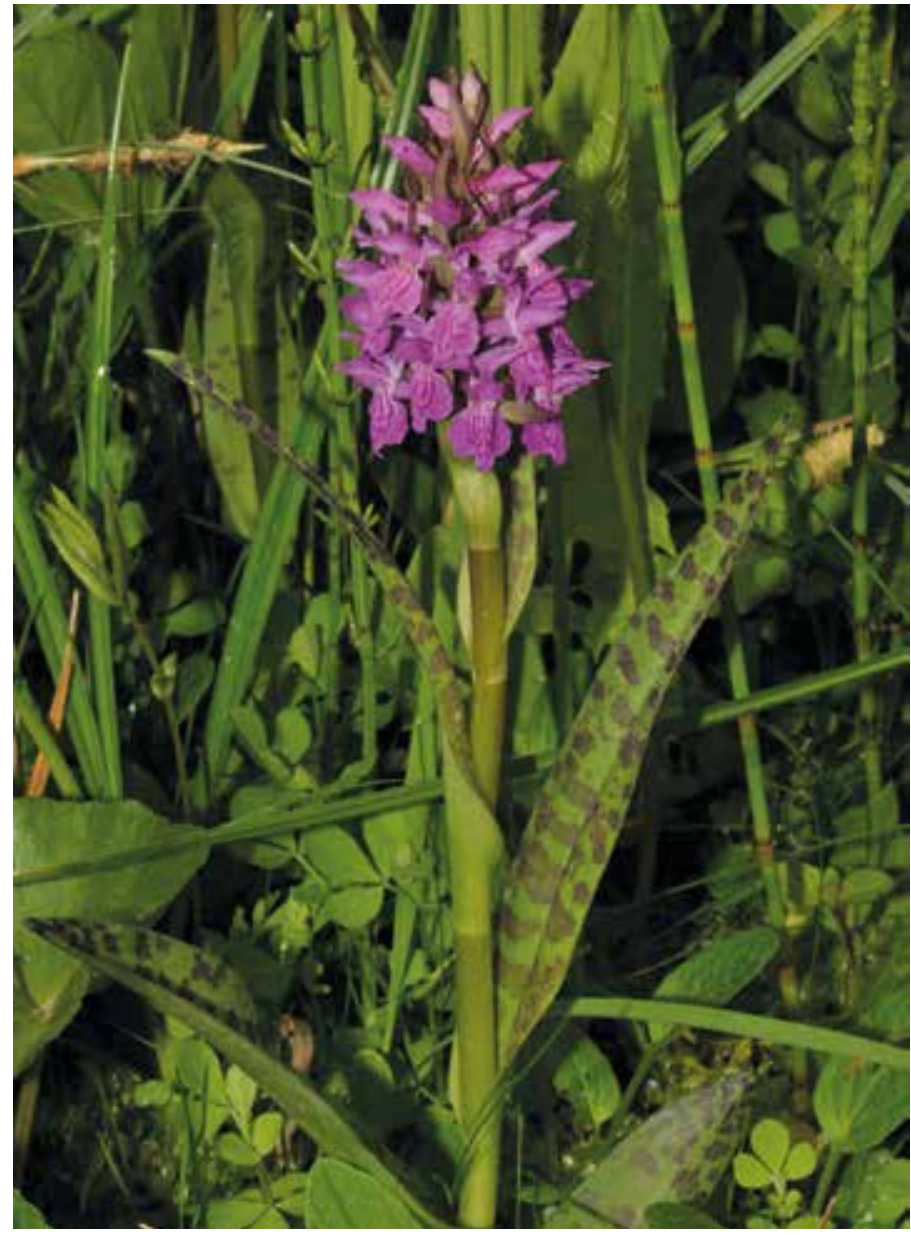

Das Breitblättrige Knabenkraut (Dactylorhiza majalis) war einst in Deutschland eine weit verbreite Art der Feuchtwiesen. Mit Hilfe angepasster Pflege kann die selten gewordene heimische Orchidee auch noch heute in individuenreichen Populationen wachsen. In der Dahlemer Saatgutbank lagern Samen von zahlreichen Vorkommen aus Ost- und Mitteldeutschland, die dem Aufbau neuer Bestände dienen können.

liefert, setzt die Forschungsgruppe Diatomeen auch auf eine spezielle Methode der Erbgut-Analyse, das sogenannte DNA-Barcoding, bzw. im Fall von Umweltproben mit vielen darin befindlichen Organismen das Umwelt-DNA-Metabarcoding.

Vorbild sind dabei die Strichcodes, die an Supermarktkassen eingescannt werden und so im Handumdrehen den Artikel samt Preis ausspucken. Nach einem ähnlich einfachen Identifizierungscode suchen Biologinnen und Biologen seit einigen Jahren auch bei Lebewesen: Ein winziges Stück aus dem Erbgut einer Pflanze oder eines Tieres soll rasch verraten, um welche Art es sich handelt. Unterstützt durch das Projekt German Barcode of Life (GBOL) arbeiten Forschungseinrichtungen bundesweit daran, solche DNA-Barcodes für die in Deutschland lebenden Arten zu entwickeln. Ein am BGBM angesiedeltes Teilprojekt konzentriert sich dabei auf die Diatomeen. 


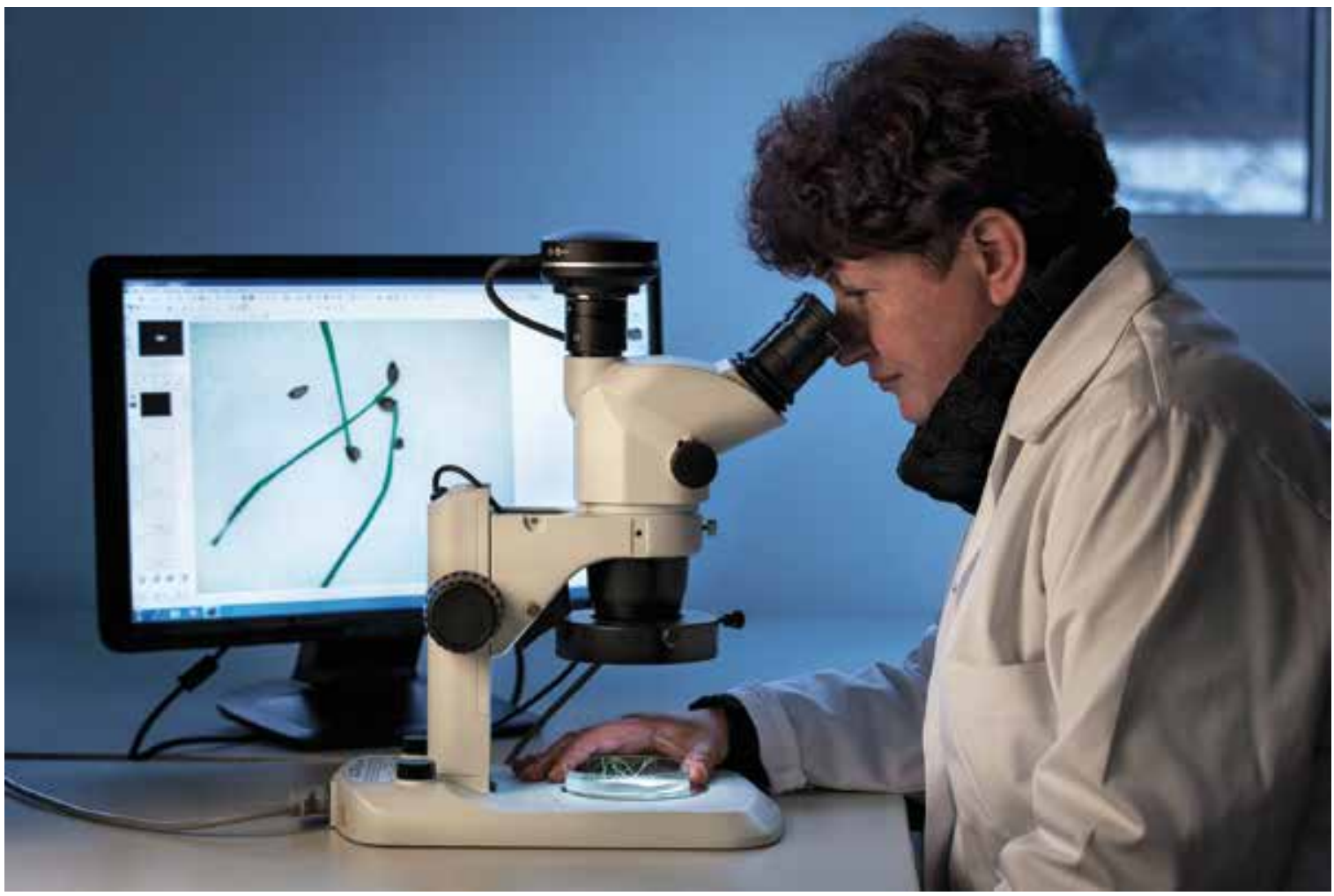

Keimungsversuche dienen dazu, die Bedingungen, die ein Samen für die Keimung benötigt, zu erforschen. Wenn die Keimungsbedingungen bekannt sind, geben Keimungstest Aufschluss über die Vitalität der gesammelten Samen.

Tatsächlich hat sich der neue Ansatz bereits bewährt. Wenn die Forscherinnen und Forscher eine Wasserprobe aus einem Fluss oder See geholt haben, können sie diese mit modernen DNA-Sequenzier-Geräten automatisch nach Kieselalgen-Barcodes durchforsten. Dabei gewinnen sie oft ein deutlich genaueres oder zumindest ein ergänzendes Bild von der Diatomeen-Gemeinschaft im Vergleich zum Blick durchs Mikroskop. Das klappt allerdings nur, wenn sie die entdeckten DNA-Sequenzen mit möglichst vielen anderen vergleichen können.

„Uns geht es da ähnlich wie der Polizei, wenn sie DNA-Spuren von einem Tatort einem Verdächtigen zuordnen will“, erklärt Jonas Zimmermann. Je größer die Vergleichsdatenbank ist, umso besser sind in beiden Fällen die Chancen auf einen Ermittlungserfolg. Also hat das BGBM-Team eine umfangreiche Referenzbibliothek für Diatomeen-Barcodes zusammengetragen, die ständig erweitert wird.

Allerdings gibt es auch noch andere winzige Algen, die etwas über den ökologischen Zustand von Gewässern verraten können. Allein die Europäische Wasserrahmenrichtlinie führt mehr als 350 solcher Indikatoren auf. Ein Team um Wolf-Henning Kusber, der Mitglied der Forschungsgruppe Diatomeen ist, hat für die 50 wichtigsten davon Steckbriefe erstellt, die Algen-Fahndern die Arbeit leichter machen. Darin ist zum Beispiel aufgeführt, wie die jeweilige Art aussieht, wo sie vorkommt und welche ökologischen Ansprüche sie hat.

Letzteres verrät oft auch etwas über ihre Zukunftschancen. „Für Ar- ten, die auf nährstoffarmes Wasser angewiesen sind, sieht es heute ziemlich düster aus“, sagt der Wissenschaftler. Sehr deutlich zeigt sich dieser Trend in der neuen „Roten Liste der Farn- und Blütenpflanzen, Moose und Algen“, die das Bundesamt für Naturschutz im Dezember 2018 herausgegeben hat. Wolf-Henning Kusber war darin z.B. für das Kapitel über die Zieralgen verantwortlich. Diese hübschen einzelligen Algen wachsen in nährstoffarmen Seen und Mooren und sterben ab, wenn diese durch Nährstoffeinträge überdüngt werden. Entsprechend stuft die Gesamtartenliste jede zweite der 968 analysierten Arten als „Rote-Liste“-Art mit einem Gefährdungsstatus ein.

Ähnliche Hiobsbotschaften gibt es auch von den höheren Pflanzen; hier steckt etwa ein Drittel der wildwachsenden Arten in Schwierigkeiten. „Direkt vor unserer Haustür haben wir eine echte Biodiversitätskrise“, warnt Dr. Elke Zippel, die am BGBM das Projekt „Wildpflanzenschutz Deutschland“ (WIPs-De) koordiniert. Fünf Botanische Gärten haben sich darin zusammengeschlossen, um das Saatgut bedrohter Wildpflanzen zu sammeln. Den Großteil davon lagern sie als eine Art Konserve für später ein. Aus dem Rest ziehen sie neue Pflanzen heran, um damit die Bestände an ihren natürlichen Standorten zu stärken oder neu aufzubauen.

Ursprünglich hatten sie sich dabei auf 15 Arten konzentriert, die in Deutschland einen Schwerpunkt ihrer Verbreitung haben. Im Jahr 2018 


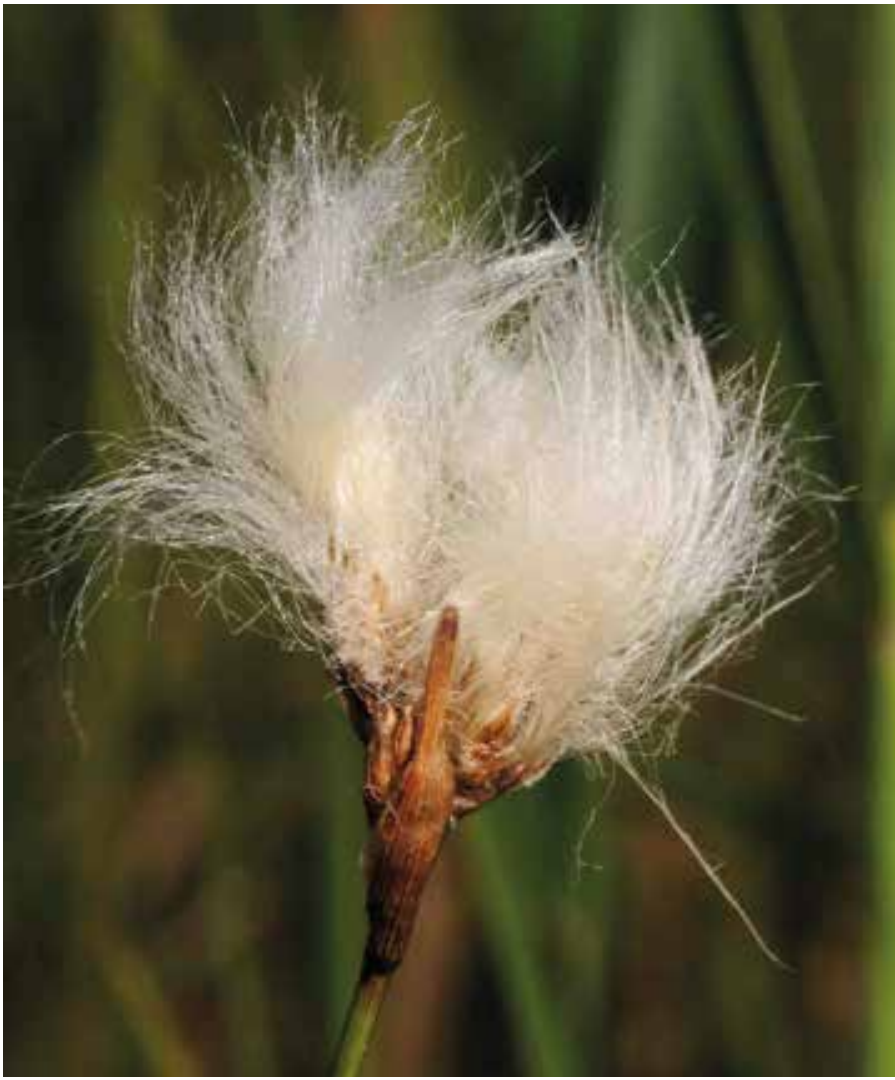

Vom Zierlichen Wollgras (Eriophorum gracile) gibt es in Nordostdeutschland nur noch wenige Pflanzen in einem einzigen uckermärkischen Moor. Mit Hilfe von Nachzuchten und dem Aufbau einer Vermehrungskultur im BGBM soll der Bestand am Naturstandort in Zukunft vergrößert werden.

aber wurde die zweite Phase des Projekts bewilligt, die diese Liste auf 92 Arten erweitert. Damit auch dieser größere Kandidaten-Kreis von Saatgutsammlungen und Wiederansiedlungen profitieren kann, hat das Bundesamt für Naturschutz dem BGBM für fünf Jahre insgesamt fast eine Million Euro bereitgestellt.

„Wer eine Art tatsächlich retten will, muss sie allerdings sehr gut kennen", betont Prof. Dr. Albert-Dieter Stevens, der Abteilungsleiter Biologische Sammlungen am BGBM. Man muss nicht nur wissen, wann ihre Samen reif zum Ernten sind, sondern vor allem, wo sie überhaupt noch vorkommt. Auch für diese Art botanischer Arbeit ist deshalb ein gutes Monitoring entscheidend.

In vielen Fällen können Elke Zippel und ihr Team dabei zwar auf Bestandserhebungen von Behörden und Naturschutzverbänden zurückgreifen. Doch wenn diese schon ein paar Jahre alt sind, stellt die Wissenschaftlerin manchmal dramatische Veränderungen fest: Von einst üppigen Beständen sind mitunter nur kümmerliche Reste geblieben. Oder gar nichts mehr. „Diese Entwicklung trifft auch Arten wie das Breitblättrige Knabenkraut oder die Sandstrohblume, die früher weit verbreitet und sehr häufig waren“, berichtet Elke Zippel. Und nicht nur

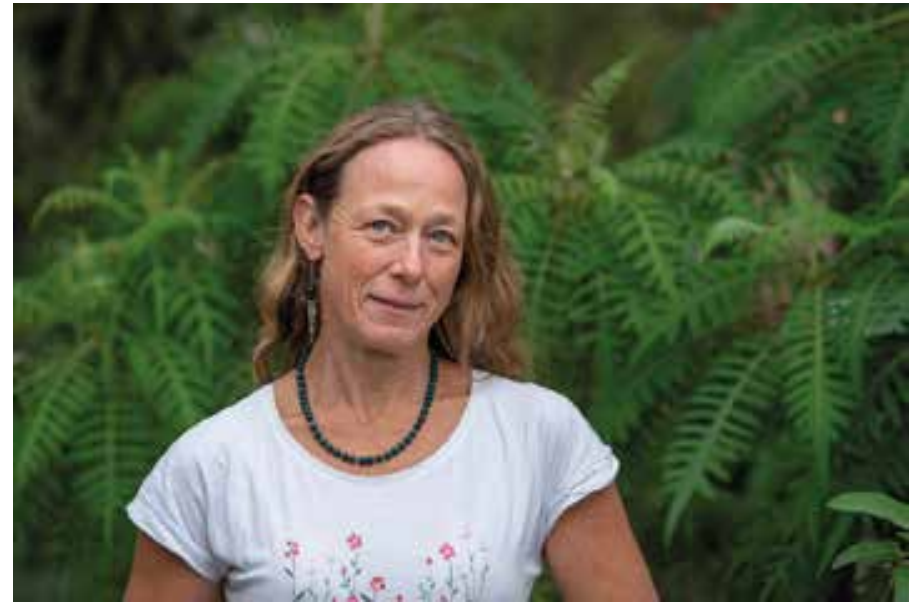

Der Schutz von bedrohten Pflanzenarten ist Dr. Elke Zippel ein besonderes Anliegen. Die Biologin kam 2003 zum BGBM und arbeitet seit 2009 an der Dahlemer Saatgutbank. Dort ist sie als Kustodin für den Tausch, das Sammeln und die langfristige Lagerung von Samen aus aller Welt verantwortlich. Einer der Sammlungsschwerpunkte liegt aber auch auf heimischen Pflanzenarten. Neben den gefährdeten Arten aus Mitteleuropa ist ein Ziel, langfristig Saatgut von allen Pflanzenarten Nordost- und Ostdeutschlands einzulagern und dabei die genetische Diversität verschiedener Herkunfts-Populationen zu repräsentieren. Frau Dr. Zippel hat viel Erfahrung darin, Bestände bedrohter heimischer Pflanzen vor Ort zu stabilisieren oder wieder anzusiedeln.

die Arten an sich geraten in Gefahr: Auch die genetische Vielfalt innerhalb einer Art nimmt ab - und diese ist oft eine Voraussetzung für das Überleben einer Art.

Allerdings weiß sie auch, dass sich der Schwund zumindest in einigen wenigen Einzelfällen aufhalten lässt. Wenn sie Jahr für Jahr den Erfolg ihrer Ansiedlungen kontrollieren, sehen die Forscherinnen und Forscher durchaus positive Entwicklungen. „So wird die Arnika in Mecklenburg-Vorpommern wohl nicht vollständig aussterben", sagt Elke Zippel. Damit sich solche Erfolge einstellen, muss man beim Sammeln, der Anzucht und der sehr aufwändigen Wiederansiedlung allerdings zahlreiche Details beachten. Welche das sind, hat das WIPsDe-Team in einem Leitfaden zusammengefasst.

Denn seine Mitglieder sind davon überzeugt, dass sich der Aufwand für solche Schutzprojekte lohnt - und zwar nicht nur für die betroffenen Pflanzen, sondern auch für den Menschen. „Wir stecken ja mitten drin im Netz der Natur", sagt Albert-Dieter Stevens. „Im Moment zerreißen wir es überall und hoffen, dass wir trotzdem nicht runterfallen. Aber es ist abzusehen, dass wir irgendwann entscheidende Fäden kappen werden." 


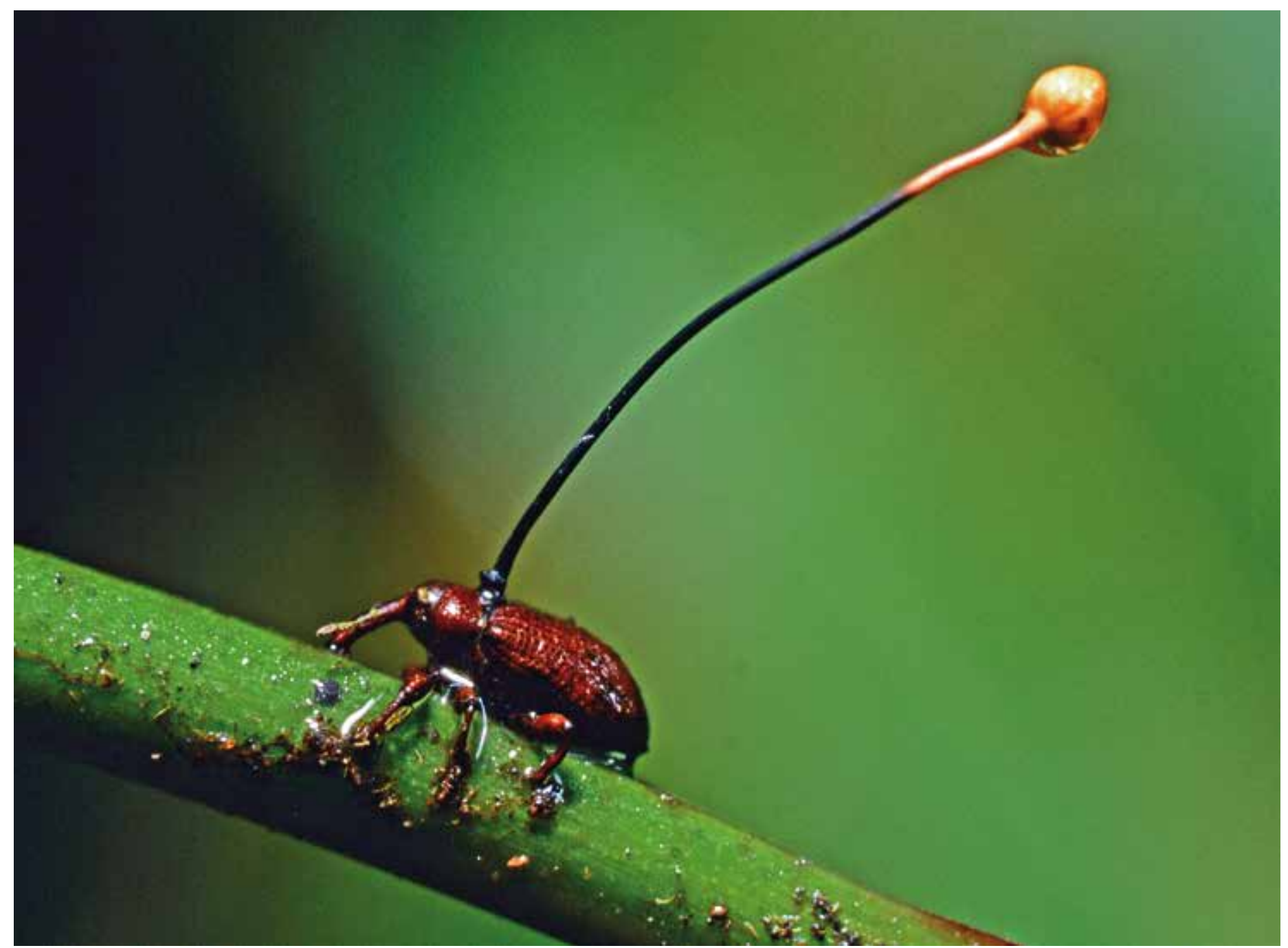

Spannend ist die Biologie der Zombie-Kernkeule (Ophiocordyceps curculionum): sie befällt Rüsselkäfer und beeinflusst deren Verhalten vor dem Abtöten, um die Ausbreitung der Sporen zu sichern. Die dahinterstehenden biochemischen Prozesse sind von großem Interesse für die pharmazeutische Industrie und in dieser Gruppe von Pilzen gibt es noch eine Vielzahl unerkannter Arten.

Die unsichtbare Vielfalt In der Welt der Algen, Pilze und Flechten gibt es noch viel Spannendes zu entdecken 


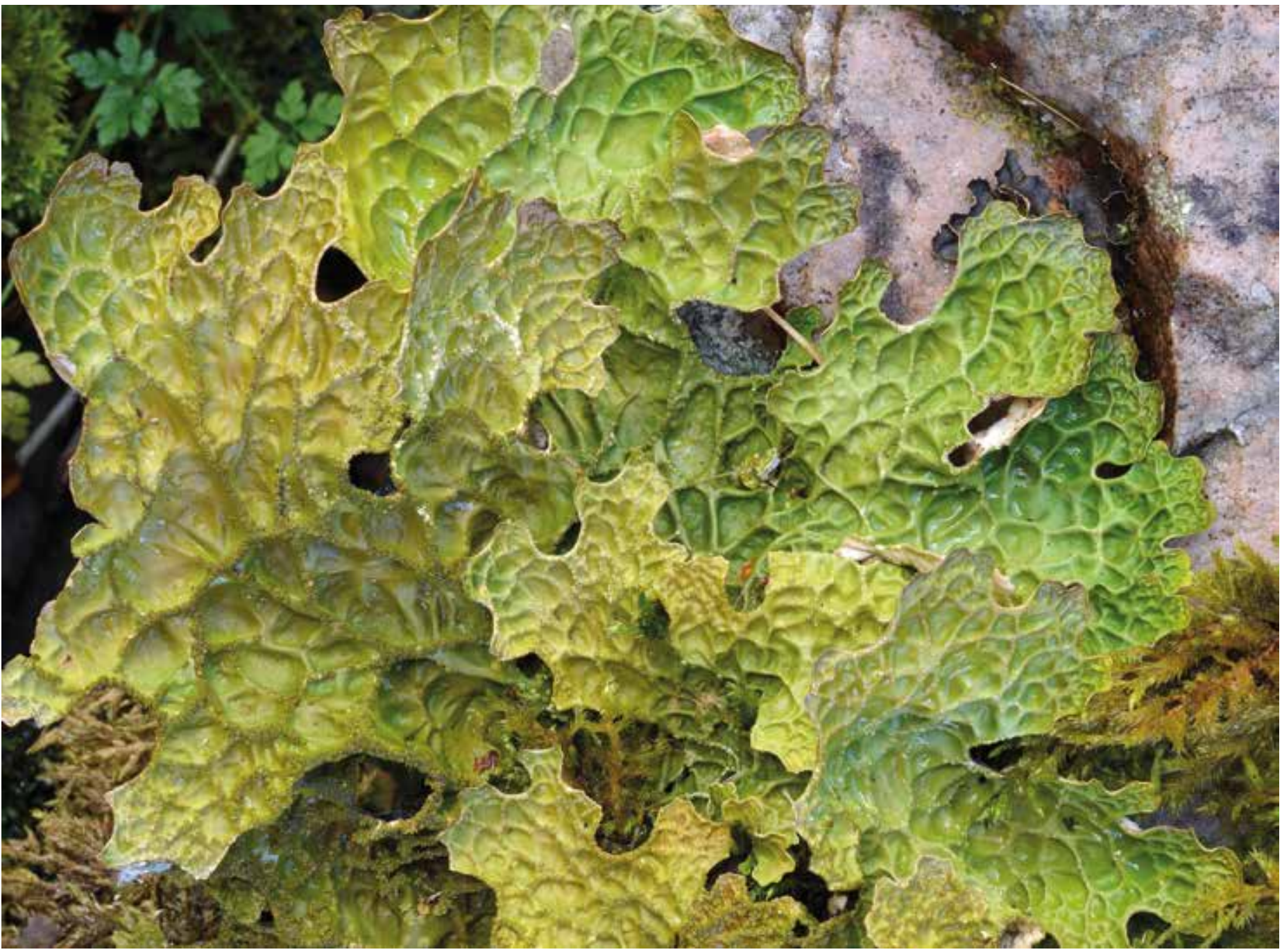

Die Lungenflechte (Lobaria pulmonaria) ist eine Zeigerart naturnaher Lebensräume mit hoher Luftqualitat.

Auf den ersten Blick gehören sie nicht unbedingt zu den spektakulärsten Bewohnern der Meere, Flüsse, Seen und Böden. Dafür aber zu den häufigsten und wichtigsten. Die auch als Diatomeen bekannten Kieselalgen sind nicht nur ein unersetzlicher Baustein des globalen Nahrungsnetzes, zu dem auch der Mensch gehört; sie sind auch stark an der Bindung von Kohlendioxid beteiligt und puffern damit den Treibhauseffekt ab. Als Nebeneffekt sorgen sie auch gleich noch für mindestens ein Viertel der globalen Sauerstoffproduktion. Doch was sind das für Organismen, die der Menschheit jeden vierten Atemzug ermöglichen? Eine Forschungsgruppe am BGBM hat es sich zur Aufgabe gemacht, die einflussreichen Einzeller besser kennenzulernen.
Dabei dringt das Team in eine Welt vor, die selbst für Fachleute noch voller Überraschungen steckt. Denn die winzigen einzelligen Algen leben in kunstvoll aussehenden glasartigen Schalen aus Kieselsäure und enthüllen ihre Geheimnisse oft erst auf den zweiten Blick. Mit bloßem Auge sind sie nicht einmal zu sehen. Doch unter dem Licht- oder Elektronenmikroskop präsentieren sie eine verblüffende Vielfalt. „In Berliner Gewässern sind die Diatomeen so gut untersucht wie in kaum einer anderen Region auf der Welt“, sagt Dr. Regine Jahn, langjährige Leiterin der Forschungsgruppe Diatomeen am BGBM. „Trotzdem finden wir sogar hier immer wieder neue Arten." 


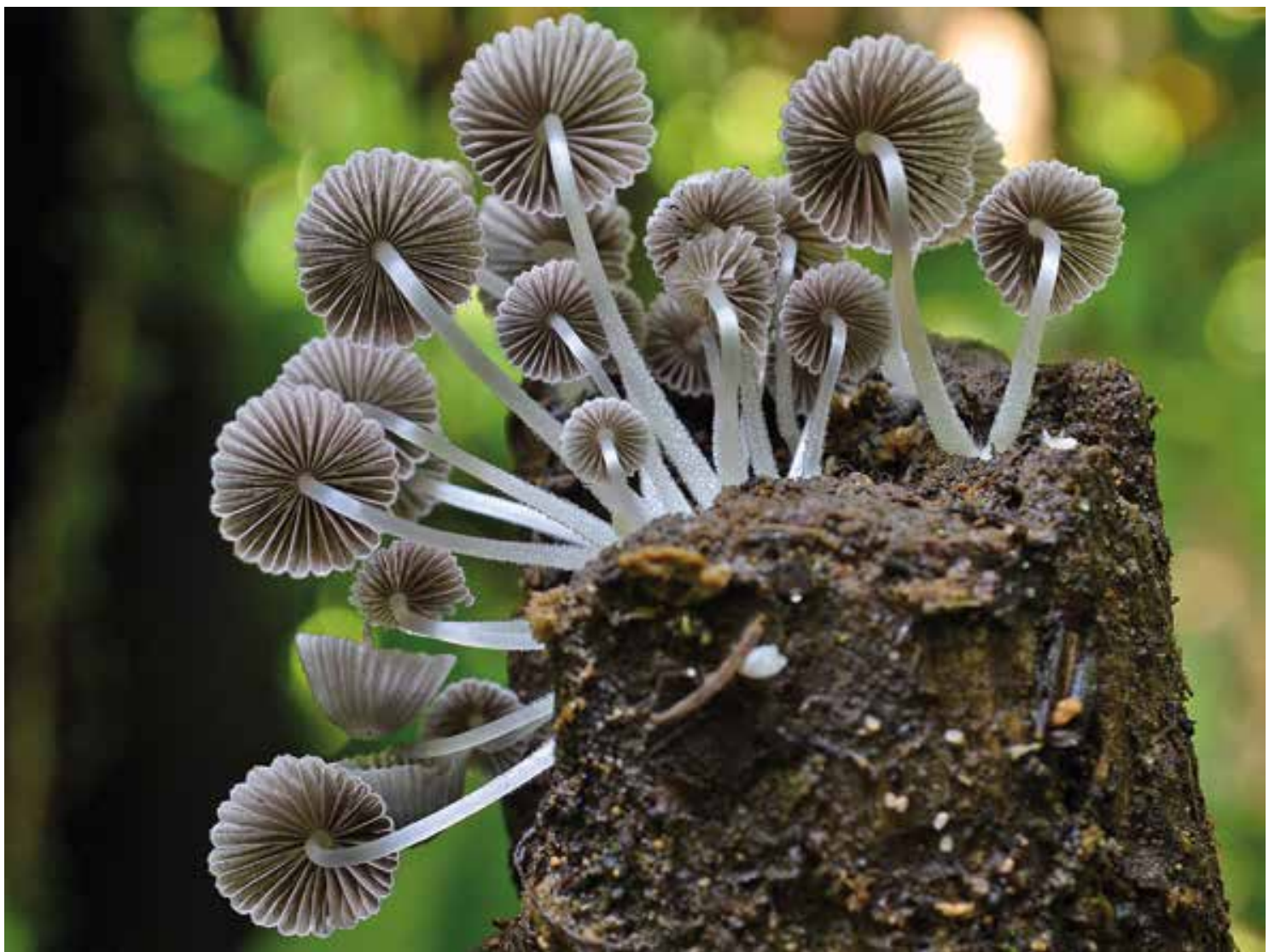

Einer der wichtigsten und effektivsten Holzzersetzer ist der Gesäte Tintling (Coprinellus disseminatus), welcher eine weltweite Verbreitung hat.

Deren Bestimmung kann allerdings zu einer echten Herausforderung werden. So werden die bei der Zellteilung neu gebildeten Kieselschalen immer etwas kleiner als die der Mutterzelle. Nach einigen Generationen sehen die Zellen daher nicht mehr so aus wie ihre Vorfahren. Dieses Schrumpfen kann natürlich nicht endlos weitergehen. Irgendwann wären die Algen nicht mehr lebensfähig. Deshalb haben sie Möglichkeiten gefunden, schlagartig wieder auf Maximalgröße heranzuwachsen, beispielsweise wenn zwei Zellen miteinander verschmelzen und große Fortpflanzungszellen bilden. Auch sonst können sich Artgenossen äußerlich sehr deutlich voneinander unterscheiden.

„Wer einen Überblick über die Artenvielfalt der Kieselalgen gewinnen will, muss deshalb sowohl auf winzige Äußerlichkeiten achten, als auch einen Blick ins Erbgut werfen“, erklärt Dr. Jonas Zimmermann, der die Forschungsgruppe Diatomeen seit 2019 leitet. Er wird dabei von Dr.
Nélida Abarca unterstützt, die seit 2019 als Kustodin die Betreuung des Diatomeen-Herbars am BGBM übernommen hat. In Deutschland haben Wissenschaftlerinnen und Wissenschaftler bisher rund 2.000 Arten identifiziert. Weltweit sind derzeit ca. 20.000 Arten von Kieselalgen beschrieben, und jedes Jahr werden neue Arten entdeckt. „Wir vermuten, dass wir bisher höchstens zehn Prozent aller Diatomeen-Arten auf der Erde kennen“, sagt Regine Jahn. Schätzungen zufolge existieren weltweit also mindestens 200.000 und eventuell bis zu zwei Millionen Arten dieser bemerkenswerten Einzeller.

Ähnlich dürften die Verhältnisse auch bei den Pilzen liegen. „Es gibt unzählige Pilzarten und bei weitem nicht genug Experten, die diese Vielfalt dokumentieren könnten“, erklärt Pilz- und Flechten-Experte Dr. Robert Lücking vom BGBM. In vielen Regionen der Tropen sind die 


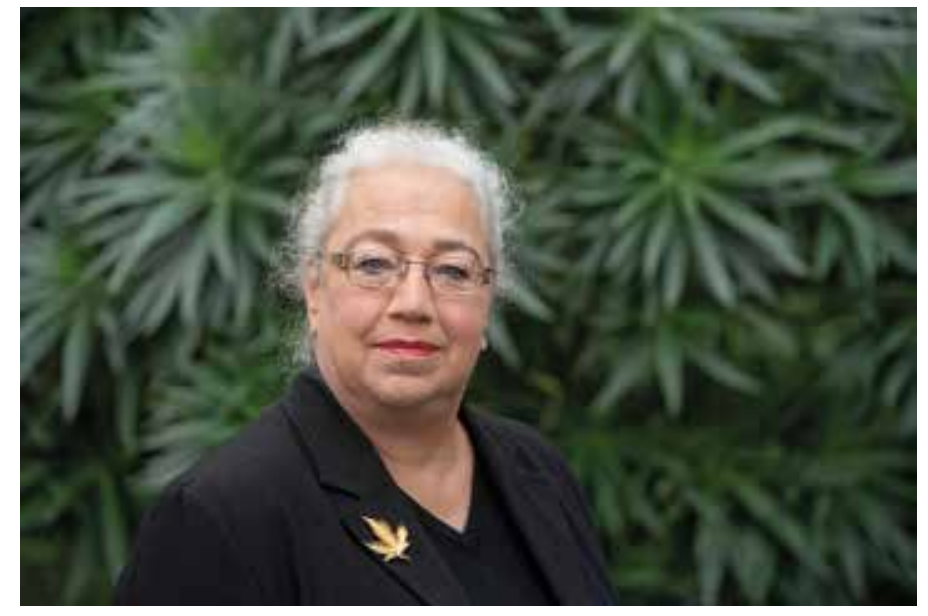

Dr. Regine Jahn begeistert sich seit Jahrzehnten für die mikroskopisch kleine Welt der Kieselalgen. Schon während ihrer Promotion an der Freien Universität Berlin hat sie sich mit der ökologischen Bedeutung und den vielfältigen Formen dieser Einzeller beschäftigt - und seither hat sie dieses Thema nicht mehr losgelassen. 1991 kam sie als Algenkustodin zum BGBM, wo sie 1999 auch die Leitung der Labore übernahm. Durch Drittmittelprojekte baute sie dort die Forschungsgruppe Diatomeen auf, die sie bis März 2019 leitete. Dieses Team erforscht, wie man die Winzlinge identifizieren, ihre Verwandtschaftsverhältnisse klären und sie zur Umweltbeobachtung einsetzen kann.

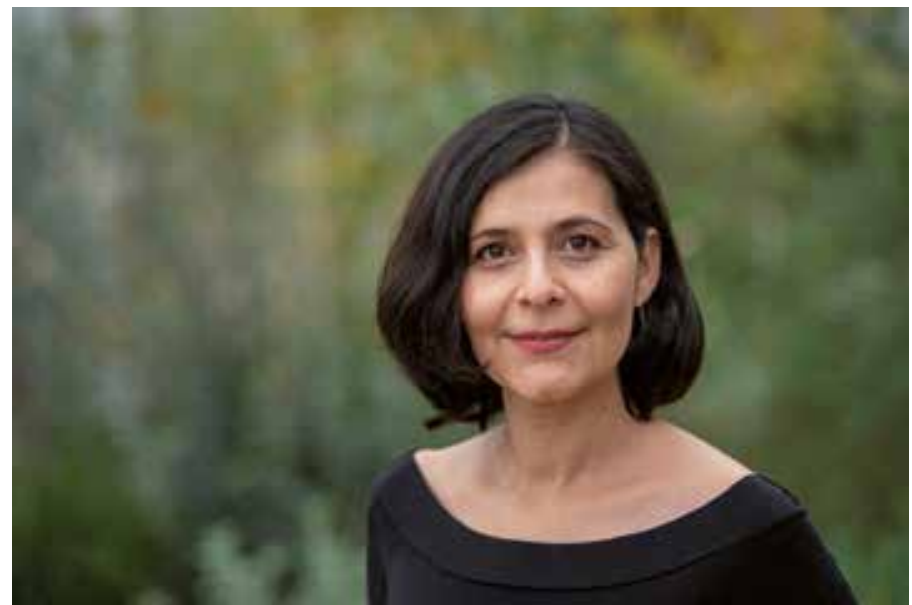

Dr. Nélida Abarca ist seit 2019 Algenkuratorin in der BGBM-Forschungsgruppe Diatomeen. Sie studierte Biologie und Naturwissenschaften an der Universität Michoacana de San Nicolas de Hidalgo, Morelia, Mexico. Sie wurde 2010 an der Freien Universität Berlin über die Biodiversität der Diatomeen im Lerma-Einzugsgebiet in Mexiko promoviert und arbeitete anschließend als Postdoc in verschiedenen Diatomeen-Projekten am BGBM. Ihre Forschungsschwerpunkte sind die Phylogenie und Taxonomie von Diatomeen, wobei sie sich insbesondere auf die lichtund elektronenmikroskopische Analyse mikromorphologischer Merkmale konzentriert.

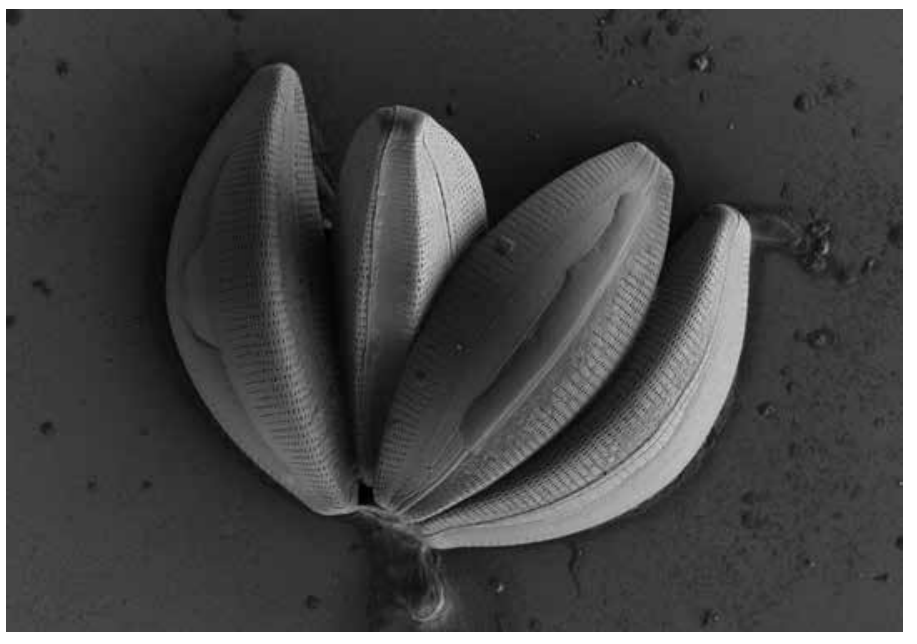

Vier Zellen der Süßwasser-Diatomee Cymbella sp. im Rasterelektronenmikroskop. Diese großen Kieselalgen bleiben nach der mitotischen Teilung häufig zusammen auf einem gemeinsamen Gallertstiel, der jeweils an einem Schalenende ausgeschieden wird, am Substrat festgeheftet. Die Zellwand aus Kieselsäure bildet Schachteln aus Ober- und Unterschale, die mit sogenannten Gürtelbändern zusammengehalten werden. Bei dieser Art sind die Schachteln keilförmig und die breiten Gürtelbänder sind hier bei den Zellen links sowie mitte-rechts und rechts gut sichtbar. 


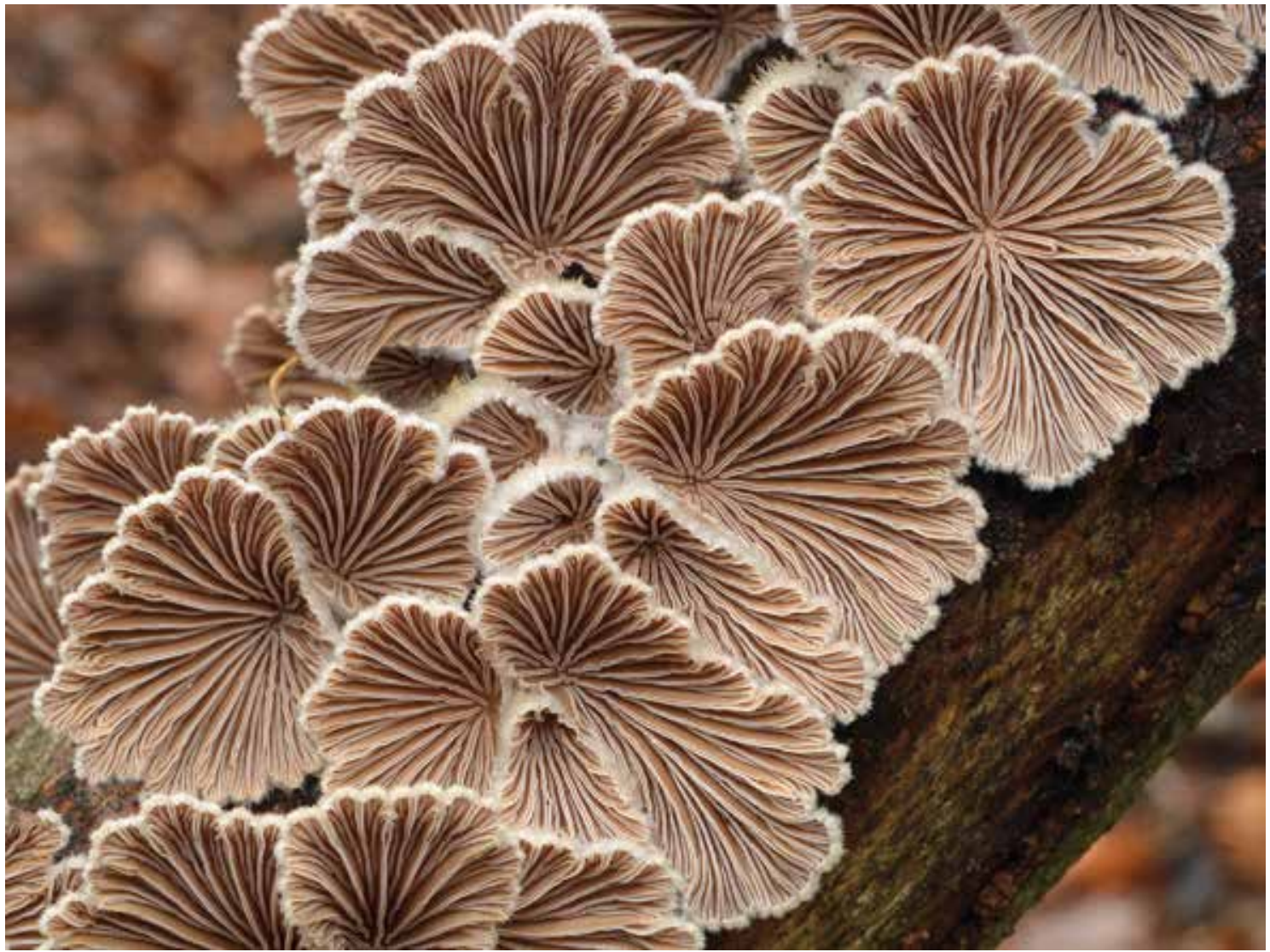

Als biologisch einzigartig gilt der weltweit verbreitete Gemeine Spaltblättling (Schizophyllum commune), ein

Holzzersetzer, welcher experimentell zur Verbesserung der Erdölförderung untersucht wird.

Vorkommen noch weitgehend unerforscht. Und wie bei den Algen verbergen sich auch bei diesen Organismen oft mehrere Arten hinter einem einzigen Namen. So haben genetische Untersuchungen gezeigt, dass es keineswegs nur einen Fliegenpilz gibt, sondern zehn bis zwölf verschiedene. Pilze haben oft wichtige Funktionen. Im Naturhaushalt tragen sie zum Beispiel in Lebensgemeinschaft mit Bäumen zu deren Ernährung bei. Auch Menschen nutzen Pilze auf vielfältige Weise, sei es bei der Brotherstellung oder bei der Gewinnung von lebensrettenden Medikamenten. Und Flechtenpilze sind wichtige Zeigerorganismen für die Qualität unserer Umwelt. Entsprechend wichtig ist es, die Arten genau zu kennen, und groß ist daher das Rätselraten über die Gesamtzahl der Pilzarten auf der Erde. Die Schätzungen schwanken meist zwischen einer halben und zehn Millionen. Robert Lücking und sein
Kollege Prof. David Hawksworth vom Londoner Naturkundemuseum haben 2017 eine neue Hochrechnung dazu veröffentlicht, die sich auf verschiedene Quellen stützt. „Man hat zum Beispiel festgestellt, dass sich hinter einer bekannten Pilzart im Schnitt zehn neue verbergen“, erklärt der BGBM-Forscher. Andere Erfahrungswerte besagen, dass mit jeder höheren Pflanzenart im Mittel etwa neun verschiedene Pilzarten zusammenleben. Und schließlich findet man in Wasser- und Bodenproben verdächtig viel DNA von Pilzen, die niemandem aufgefallen waren, weil sie keine Fruchtkörper bilden. Wenn sie das alles mit einrechnen, kommen die beiden Forscher auf 2,2 bis 3,8 Millionen Pilzarten weltweit. „Mehr als 90 Prozent davon kennen wir nicht“, sagt Robert Lücking. „Und viele dieser Unbekannten verschwinden, bevor wir etwas über sie herausfinden können." 


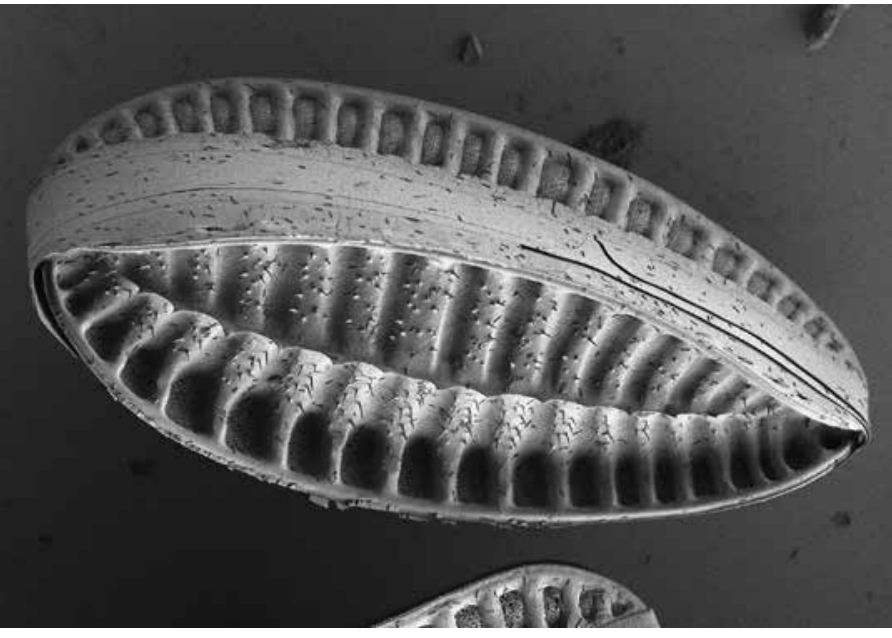

Die Diatomee Iconella sp. im Rasterelektronenmikroskop. Diese große Kieselalge ist ein typischer Vertreter des Süßwasser-Litorals. Ansicht einer ganzen Zelle. Die Zellwand aus Kieselsäure ist mit verschiedenen Auswüchsen und Stacheln grob skulpturiert. Die Raphe, die Fortbewegungsstruktur der Kieselalgen, sitzt bei dieser Gruppe auf einem Kiel an der Schalenkante und läuft einmal um die gesamte Schale herum. Details dieser Struktur sind auf Seite 41 zu sehen.

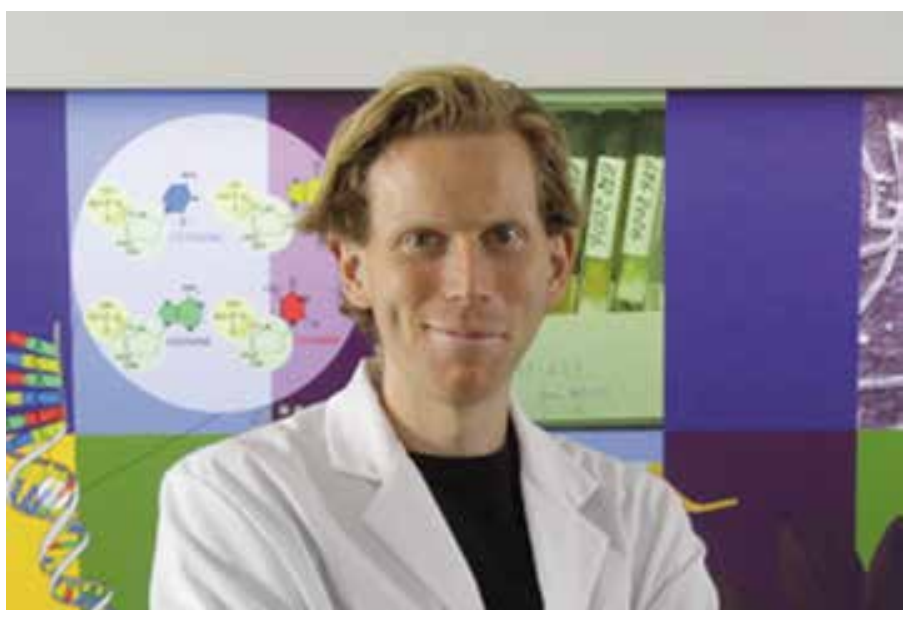

Dr. Jonas Zimmermann hat die Leitung der Forschungsgruppe Diatomeen von Regine Jahn übernommen. Er studierte Biologie an der Freien Universität Berlin, schrieb seine Diplomarbeit am BGBM in der FG Diatomeen und wurde 2015 über die Etablierung von DNA-Barcoding und Metabarcoding für Diatomeen an der Justus-Liebig-Universität Gießen promoviert. Seine Forschungsschwerpunkte sind die integrative Taxonomie der Kieselalgen sowie die Entwicklung und der Einsatz von eDNA-Metabarcoding zur Bewertung der Wasserqualität anhand von Kieselalgen im Kontext der EU-Wasserrahmenrichtlinie. 


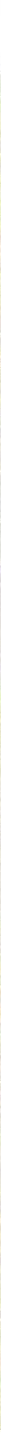

Lebensraum Páramo in den Anden im Hinterland von Bogotá: Die gelb blühenden Schopfrosettenbäumchen (Espeletia-Arten aus der Familie der Korbblütler) sind hier ein typischer Anblick und werden frailejones genannt.

\section{Humboldt 2.0}

Das kolumbianisch-deutsche Projekt ColBioDiv untersucht die biologische Vielfalt des südamerikanischen Landes aus den verschiedensten Perspektiven
Alexander von Humboldt hätte das alles vielleicht noch allein geschafft. Immerhin gilt er als einer der letzten Universalgelehrten der Wissenschaftsgeschichte: Ein Mann, der Pflanzen sammelte und Vulkangestein untersuchte, meteorologische Messungen durchführte und die gesellschaftlichen Zustände in anderen Ländern beschrieb. „Für ihn war es ganz normal, Botanik, Geografie und Politik zu verbinden“, sagt Prof. Dr. Marianne Braig vom Lateinamerika-Institut der Freien Universität Berlin. „Wenn wir dieses Spektrum heute abdecken wollen, brauchen wir mindestens sechs oder sieben Disziplinen dazu."

Das macht die Forschungsarbeit nicht einfacher, aber auch besonders spannend. Denn jede Fachrichtung hat ihren eigenen Blick auf die Welt. Und je mehr dieser Perspektiven man mit einbezieht, umso facettenreicher wird das Bild, das man von einer Region gewinnen kann. 


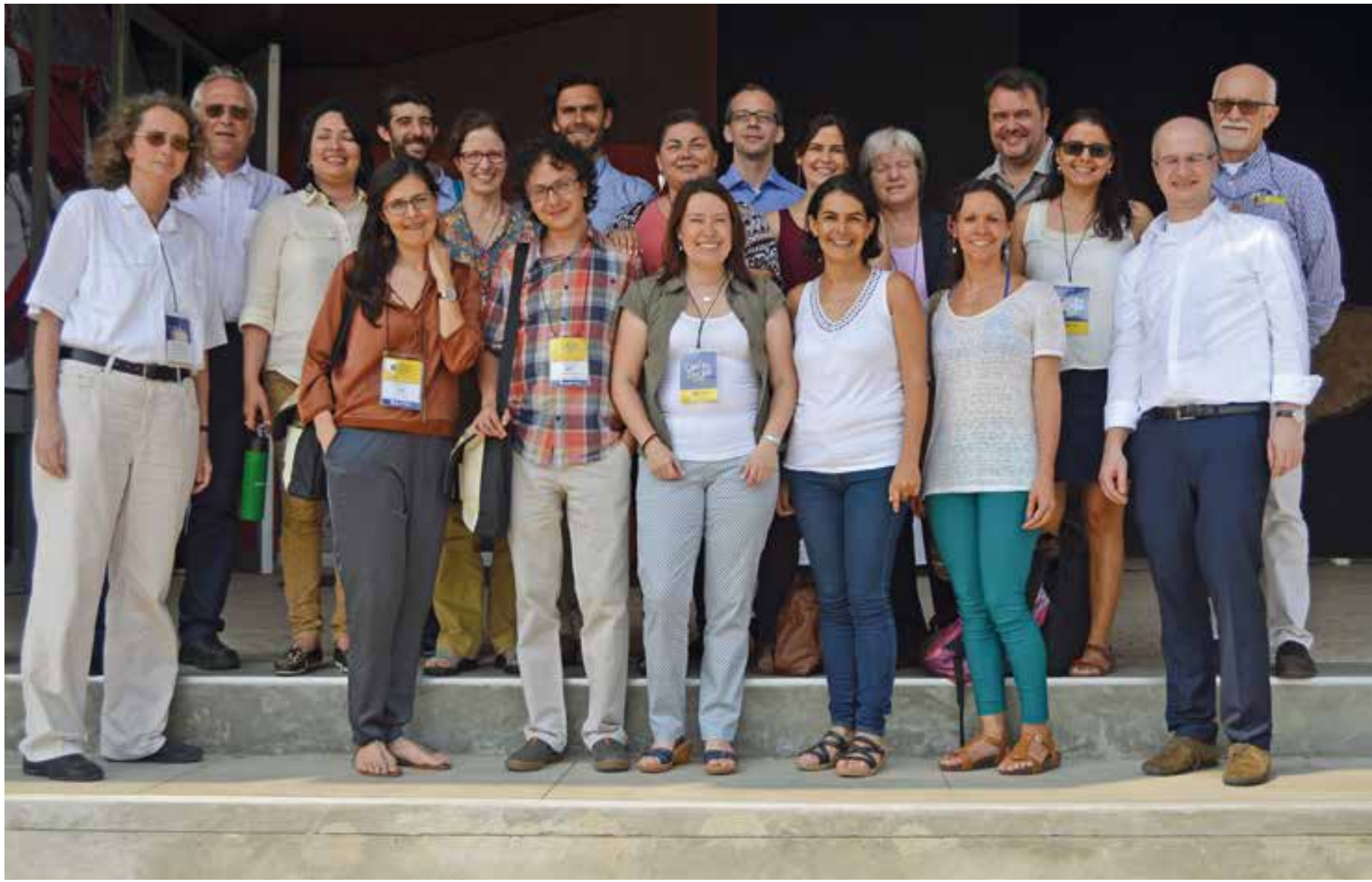

Gruppenfoto des kolumbianisch-deutschen ColBioDiv-Forschungsnetzwerks auf der Cátedra Europa in Barranquilla, Kolumbien.

en Universität Berlin dabei, aus Kolumbien der Botanische Garten von Bogotá, Universitäten wie die Universidad del Norte und die Universidad del Rosario und das kolumbianische Biodiversitätsinstitut Instituto Alexander von Humboldt. Gemeinsam wollen die Beteiligten herausfinden, wie Natur und Mensch die biologische Vielfalt des südamerikanischen Landes prägen.

„Das ist besonders interessant, weil die Biodiversität Kolumbiens noch längst nicht komplett erfasst ist", sagt Projektkoordinator Dr. Grischa Brokamp vom BGBM. Wer in Deutschland auf eine ihm unbekannte Pflanze stößt, kann sie mithilfe eines gängigen Bestimmungsbuches normalerweise gut identifizieren. Für Kolumbien aber gibt es solche Literatur bisher nur in Ansätzen; niemand hat einen kompletten Überblick darüber, welche Arten es gibt und wo sie wachsen. „Fünfzig Jahre Bürgerkrieg haben diese Situation natürlich nicht verbessert“, sagt Prof. Marcela Celis von der Universidad del Norte, die das Forschungs- programm auf kolumbianischer Seite leitet. „Aber der Friedensprozess bietet nun die Möglichkeit, die Flora des Landes besser kennenzulernen."

Das ist gerade jetzt besonders wichtig, weil mit dem Ende der Kämpfe auch der Druck auf viele Landschaften gestiegen ist. Landwirtschaft und andere Nutzungen weiten sich in neue Gebiete aus und dadurch steigt das Risiko, dass Arten verschwinden, bevor die Wissenschaft überhaupt Notiz von ihnen genommen hat. Deshalb arbeitet das ColBioDiv-Team daran, die Biodiversität Kolumbiens besser zu verstehen und die Gründe und Faktoren zu identifizieren, welche einerseits zu Biodiversitätsverlust führen und welche andererseits ein nachhaltiges Management von Ökosystemen ermöglichen.

Vorher aber gilt es erst einmal, das dafür nötige Grundwissen zu sammeln. Dabei konzentrieren sich die Forscherinnen und Forscher auf zwei Beispielregionen. Die eine umfasst die Umgebung von Bogotá 


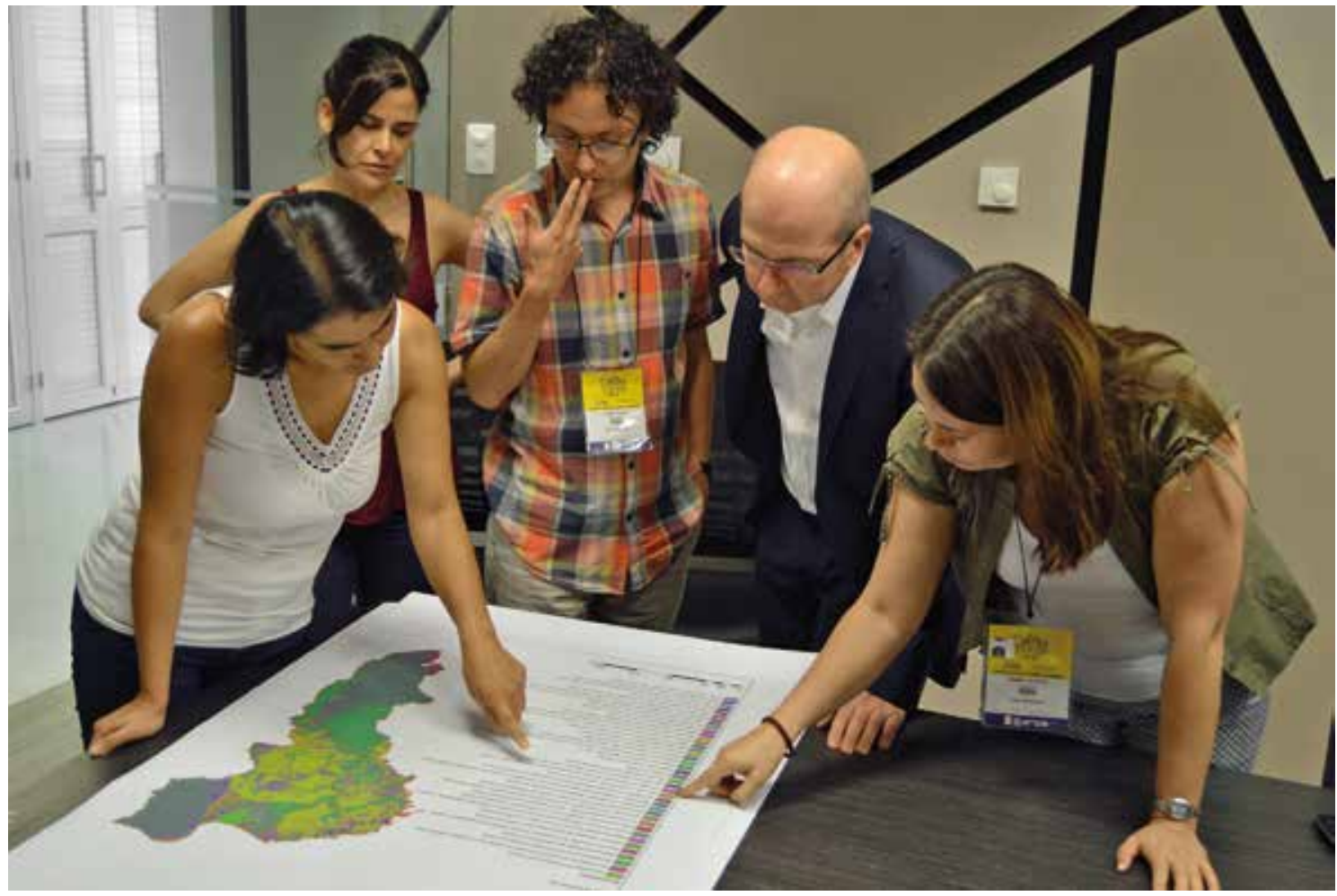

Biodiversitätsforschung bedarf enger internationaler Zusammenarbeit. Kolumbianische und deutsche Forscherinnen und Forscher während eines Workshops zu Landnutzung und Landnutzungsänderung im Departement Atlántico (Kolumbianische Karibik) während der Cátedra Europa an der Universidad del Norte in Barranquilla (v.l.n.r. M.C. Martínez-Habibe, B. Salgado-Negret, O. Rojas, T. Borsch, B. Moncada).

und die noch vorhandenen Andinen Wälder. Die andere liegt im Norden des Landes an der Karibikküste und stellt den tropischen Trockenwald um die Stadt Barranquilla in den Fokus.

„Die Botanikerinnen und Botaniker in unserem Projekt müssen dort erst einmal feststellen, welche Pflanzen und Pilze wo vorkommen", sagen Dr. Robert Lücking vom BGBM und Dr. Bibiana Moncada von der Universidad Distrital in Kolumbien, die in den Probeflächen des Projektes schon mehrere neue Flechtenarten entdeckt haben. Um Artgrenzen besser zu verstehen, werden ausgewählte Pflanzengruppen auch mit molekularen Methoden untersucht, so die Weidengewächse aus der Gattung Casearia oder die tropischen Verwandten der Kapern in der Gattung Capparidopsis. Im Hinterland von Bogotá haben sie zudem auf mehr als 30 Probeflächen von 20 mal 20 Metern Größe sämtliche Bäume von mehr als fünf Zentimeter Stammdurchmesser erfasst, aber auch Lianen und Kräuter bestimmt. Die Doktorandin Mariasole
Calbi vom BGBM und der Nachwuchswissenschaftler Franciso Fajardo vom Jardín Botánico de Bogotá haben hier in monatelanger Feldarbeit große Datensätze erarbeitet und konnten damit zeigen, dass es sechs unterschiedliche Typen des Andinen Bergwaldes in der Region um Bogotá gibt, die sich in ihrem Artenspektrum und ihrer Ökologie unterscheiden. „Langfristig wollen wir herausfinden, wie sich die menschliche Nutzung auf die Struktur solcher Ökosysteme auswirkt", erklärt Thomas Borsch.

Auch die Geografinnen und Geografen im Projekt interessieren sich dafür, wie der Mensch der Landschaft seinen Stempel aufdrückt und welche Folgen das hat. Um das herauszufinden, setzt das Team um Prof. Dr. Brigitta Schütt vom Institut für Geographie der FU Berlin unter anderem auf den Blick aus dem All. Denn aus Satellitenbildern kann man viel darüber erfahren, wie sich die Landschaft durch Nutzung verändert hat und wie empfindlich sie ist. 


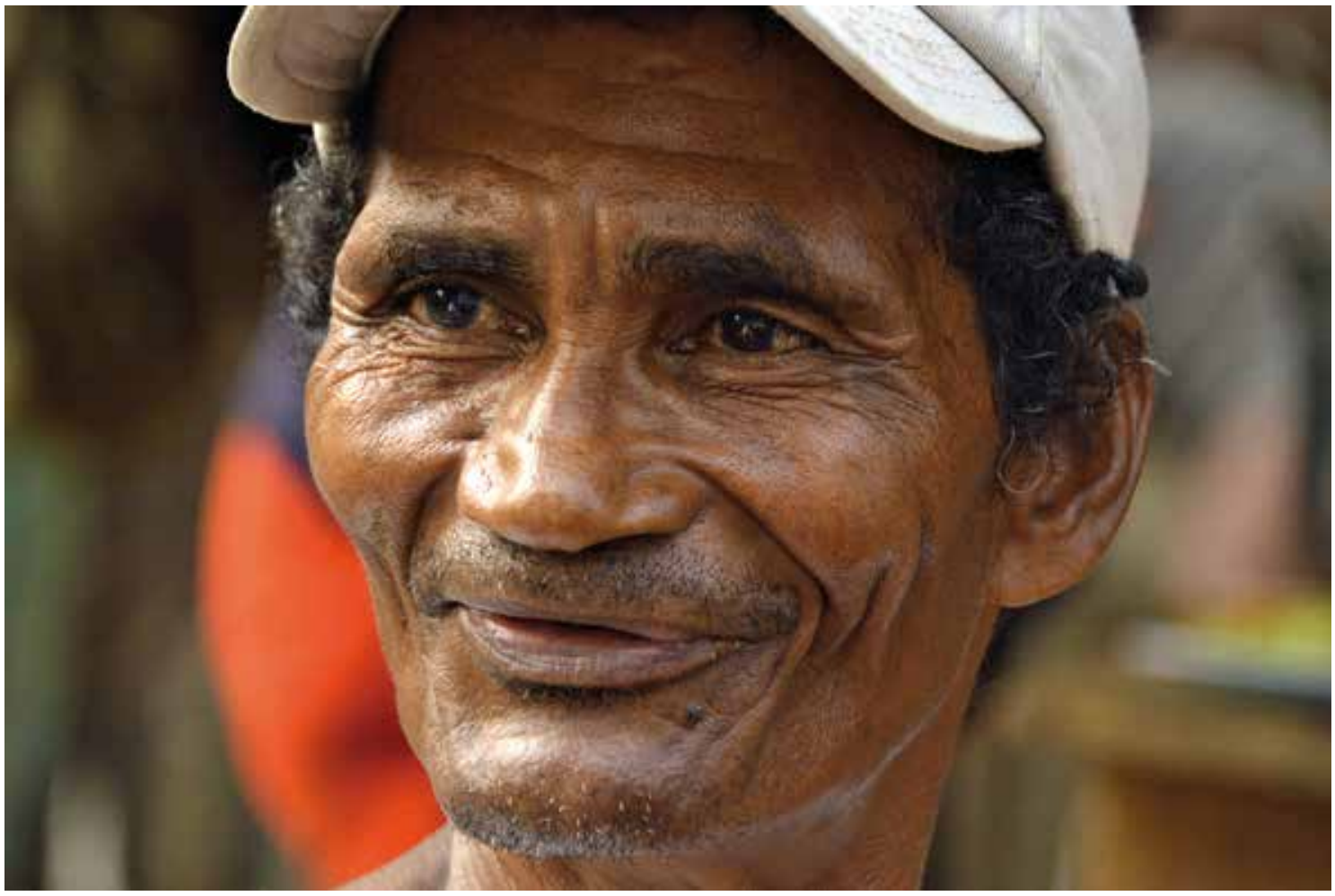

Lino Olivares ist einer der sachkundigsten und leidenschaftlichsten Experten für die Flora der Trockenwälder der kolumbianischen Karibik und wirkt seit etwa 20 Jahren bei der EcoSecos-Initiative und anderen Naturschutzbemühungen in der Region mit.

Fernerkundungsdaten aus den Jahren 1987 bis 2017 verraten zum Beispiel, dass sich die Vegetationsdecke im Hinterland von Barranquilla in dieser Zeit immer wieder verändert hat. Wälder sind verschwunden, wieder hochgewachsen und erneut etwa durch Rinderbeweidung beeinflusst worden. „Seit 2001 nehmen die Waldflächen in der Region zwar wieder zu“, sagt Marcela Celis. „Die Frage ist aber, welche Qualität dieser Wald hat." Wird eine einmal abgeholzte Fläche später wieder so artenreich wie zuvor? Und bringt sie die gleichen ökologischen Leistungen? Oscar Rojas, Doktorand an der Universidad del Norte, geht etwa der Frage nach, wie das Regenerationspotential aus Samen ist, die noch im Boden vorhanden sind. Die Antworten auf solche Fragen sind nicht nur für den Naturschutz interessant, sondern vor allem auch für die Menschen vor Ort. „Wenn die Vegetation geschädigt ist, steigt zum Beispiel das Risiko für Erdrutsche“, erklärt Thomas Borsch. „Da möchte man schon gern wissen, wie sich die Landnutzung verbessern lässt“.

Speziell für die politischen und sozialen Aspekte der biologischen Vielfalt interessieren sich Marianne Braig und ihr Team vom Lateinamerika-Institut. „Wir schauen auf die Menschen in der jeweiligen Region und untersuchen zum Beispiel, wie sich das Stadt- und Landleben verändert", erklärt die Politikwissenschaftlerin. So haben viele wohlhabende Familien aus Barranquilla ihre Häuser 50 bis 80 Kilometer außerhalb der Stadt gebaut - genau in der Region, in der auch Bauern ihr Vieh weiden lassen. „Es begegnen sich unterschiedlichste Lebensstile, die einerseits mit der Gentrifizierung von stadtnahen, ländlichen Gebieten und andererseits mit neuen Produktionsformen zu tun haben, die in Spannung zueinander stehen und stets in Konflikt mit dem Naturschutz geraten“, sagt Marianne Braig. „Wir wollen wissen, was sich durch diese vielgestaltigen Urbanisierungsprozesse verändert und welche Folgen das für die Landnutzung hat."

So steuert jede der beteiligten Disziplinen ihre eigenen Mosaiksteine zum bunten Bild von Kolumbiens biologischer Vielfalt bei. Für Grischa Brokamp, der die Aktivitäten von drei Fachrichtungen und zwei Nationalitäten koordiniert, ist das mit viel Organisationsarbeit verbunden. „Die Idee, dass man etwas zusammen machen könnte, verwirklicht sich nicht von selbst", weiß er aus Erfahrung. Aber die Mühe lohnt sich. Und aus seiner Sicht gibt es ohnehin keine Alternative dazu: „Wir stehen heute vor globalen Problemen, die man auch nur in Zusammenarbeit lösen kann." 

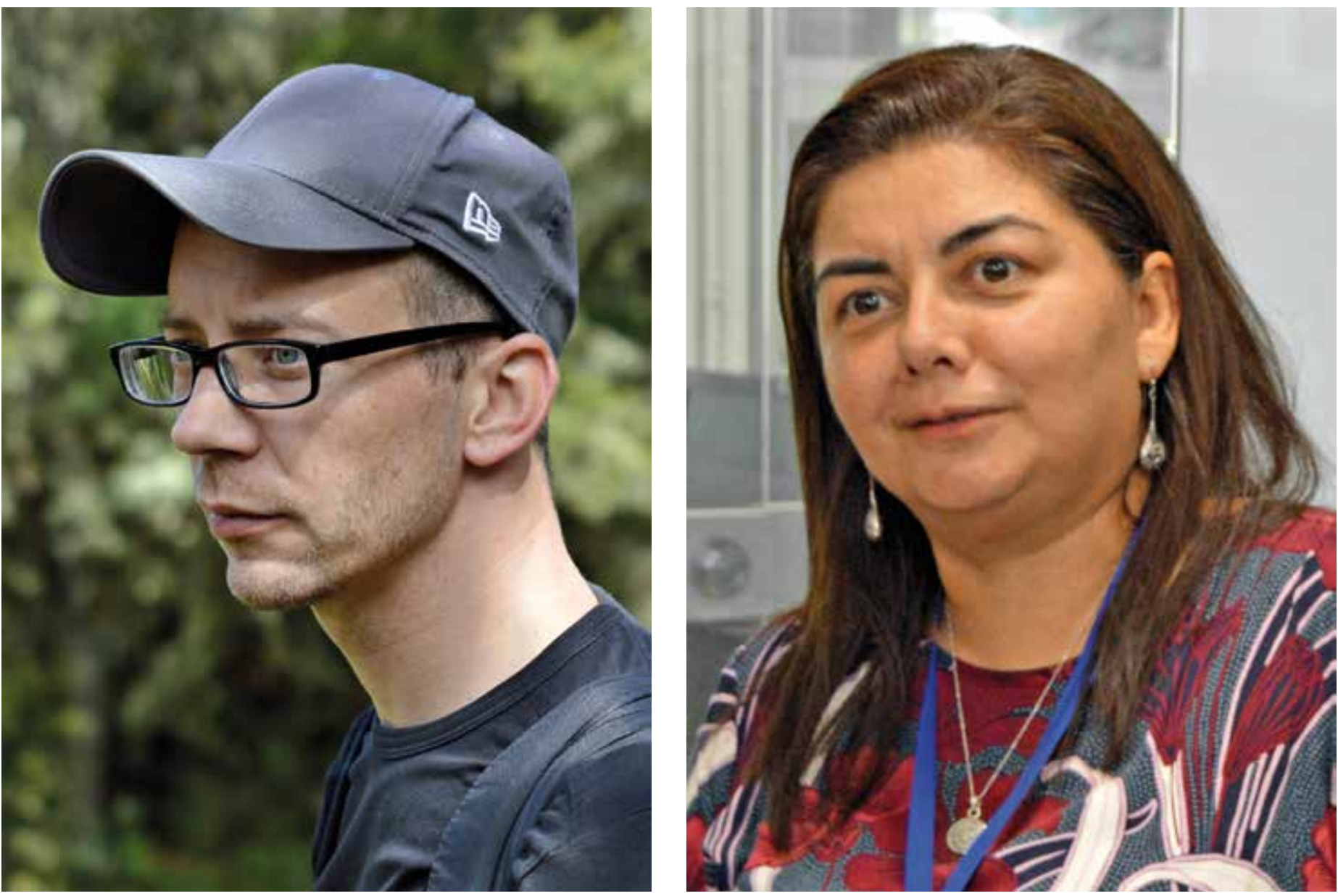

Seine umfangreiche Südamerika-Erfahrung ist für Dr. Grischa Brokamp unverzichtbar. Denn der Biologe koordiniert seit 2015 die gemeinsamen Biodiversitäts-Forschungsprojekte mit Kolumbien. Dabei gilt es insbesondere, die verschiedenen Institute und Fachdisziplinen unter einen Hut zu bringen und einen engen Kontakt der Partner in Deutschland und Kolumbien zu unterstützen. Das zentrale Projekt ist dabei derzeit „Integriertes Biodiversitätsmanagement in Modellregionen Kolumbiens (ColBioDiv)", das vom Bundesministerium für Bildung und Forschung gefördert wird. Grischa Brokamp ist damit auch Ansprechpartner für Gastwissenschaftlerinnen und -wissenschaftler aus Kolumbien am BGBM. Zu seinen eigenen Forschungsinteressen gehören die Effekte menschlicher Nutzung auf tropische Wälder und die Frage, wie man pflanzliche Ressourcen erhalten und nachhaltig nutzen kann.

Prof. Dr. Marcela Celis ist Biologieprofessorin an der Universidad del Norte in Barranquilla, der größten Stadt in der kolumbianischen Karibik. Zu ihren Forschungsschwerpunkten zählen Systematik und Taxonomie der Blütenpflanzen und die Biodiversität Kolumbiens. Sie hat an der Gefäßpflanzen-Checkliste Kolumbiens mitgearbeitet und sich mit dem Aufbau und der Erschließung von Herbarien beschäftigt, so am Instituto Humboldt, im Jardín Botánico Bogotá und der Universidad del Norte. Derzeit ist sie Kuratorin des Herbariums UNO, das an der Universidad del Norte neu aufgebaut wird und koordiniert die Forschungsaktivitäten der kolumbianischen Partner im bi-nationalen Forschungsprojekt ColBioDiv. 


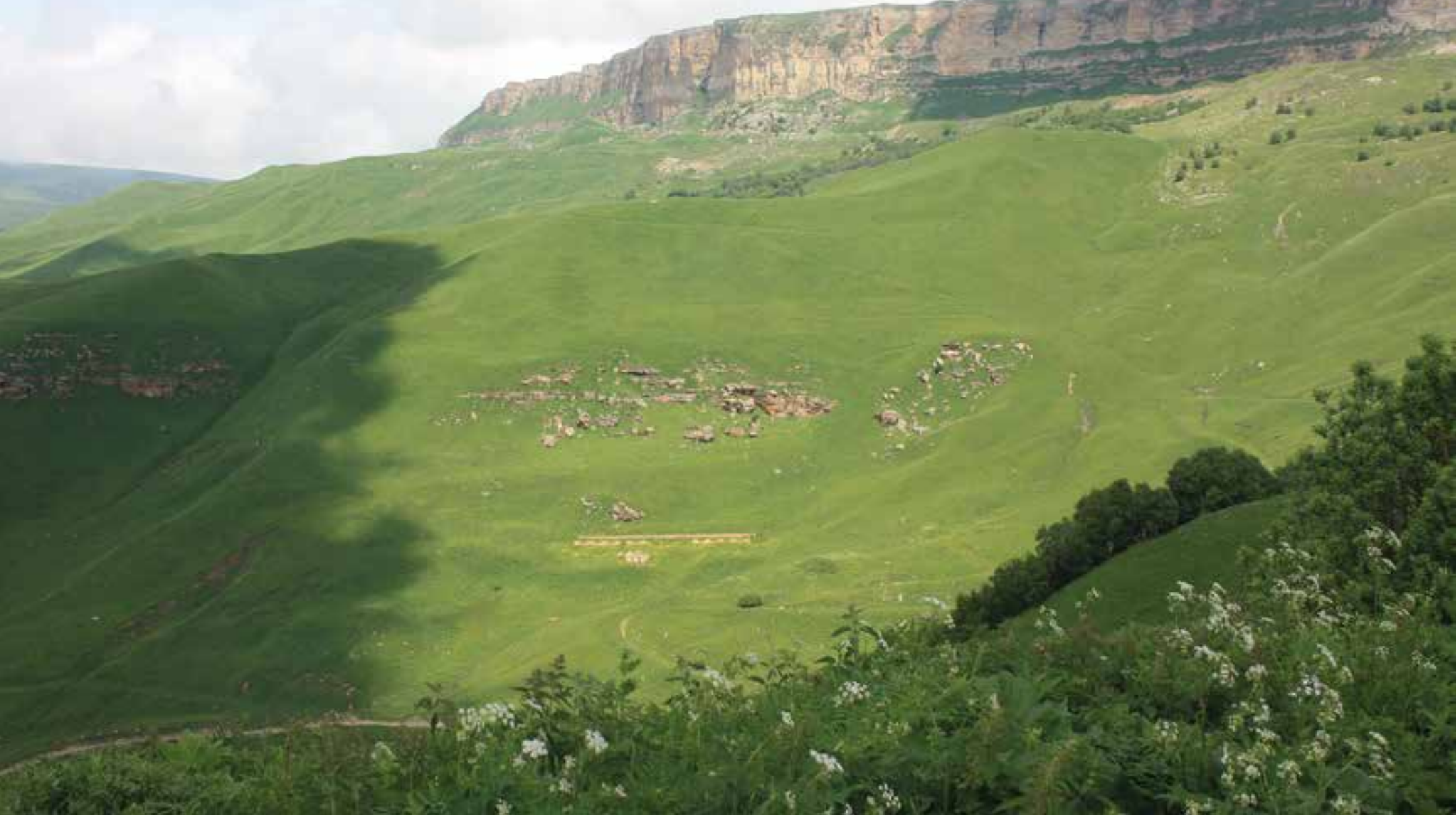

Ansicht des Gumbaschi-Passes im Nordkaukasus.

\section{Zwischen Orient und Okzident: Die Pflanzenvielfalt des Kaukasus erfassen und verstehen}

Der Kaukasus kann mit spektakulären Landschaften und einer ungewöhnlich reichen Pflanzen- und Tierwelt aufwarten. Das liegt unter anderem daran, dass die gebirgige Region zwischen Schwarzem und Kaspischen Meer eine riesige Palette an Lebensräumen für die unterschiedlichsten Ansprüche bietet. Da ragen im Norden die mehr als 5.000 Meter hohen Gipfel des Großen Kaukasus mit ihren Gletschern, Gebirgswiesen und -wäldern empor. Typisch für den Kleinen Kaukasus im Süden sind dagegen Wälder und Wiesen auf sanften Hügeln. Am Schwarzen Meer liegt das regenreiche Gebiet der Kolchis, in deren günstigem Klima zahlreiche Pflanzen die letzte Eiszeit überdauert haben und dichte Wälder gedeihen. Entsprechend dazu findet sich am südlichen Ufer des Kaspischen Meeres das Hyrkanische Waldgebiet - beide Waldregionen beherbergen eine große Zahl verschiedener Bäume und Sträucher, einige davon mit Vorfahren aus subtropischen Klimaten. In den trockeneren, kontinentalen Landschaften im Osten prägen offene Steppen die Landschaft, die sich dann auf der Ostseite des Kaspischen Meeres auf riesigen Flächen in Südwest- und Zentralasien fortsetzen. Kein Wunder also, dass die Kaukasus-Ökoregion als eine der Schatzkammern der weltweiten Artenvielfalt gilt. In dem Gebiet, das mit 580.000 Quadratkilometern Fläche ungefähr ein-einhalb 


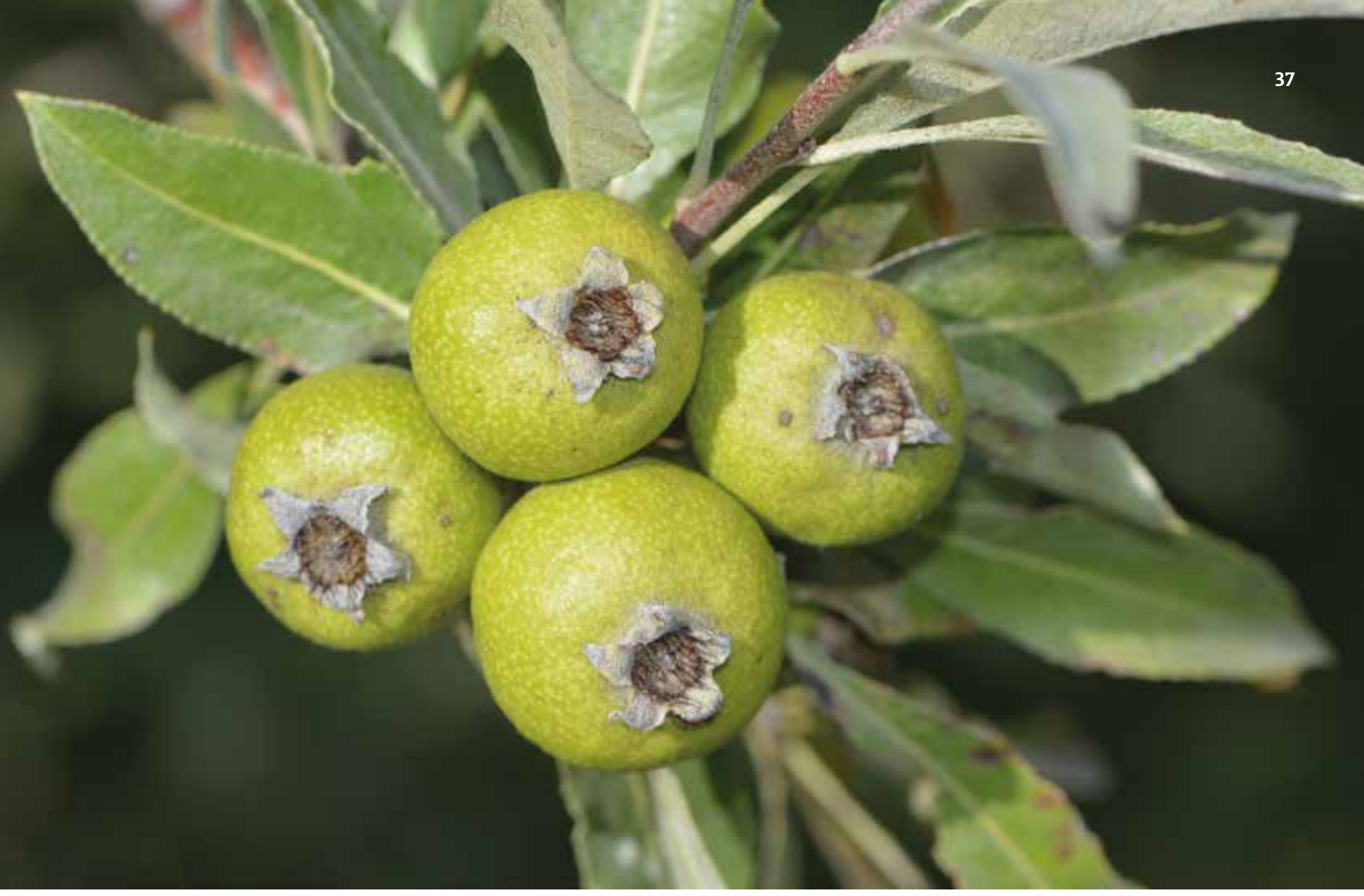

Die Wildbirnenart Pyrus demetrii in Georgien.

Mal so groß wie Deutschland ist, gibt es schätzungsweise $6.300 \mathrm{Ge}$ fäßpflanzenarten. Und die Flora des Kaukasus besteht keineswegs nur aus Allerweltsgewächsen: Etwa ein Viertel der dortigen Gefäßpflanzen wie der Kaukasus-Rhododendron (Rhododendron caucasicum) oder die Kaukasus-Skabiose (Lomelosia caucasica) sind sogenannte Endemiten, die nirgendwo sonst auf der Erde vorkommen.

Für Botanikerinnen und Botaniker ist diese faszinierende Region daher schon lange ein spannendes Arbeitsgebiet. Zu Zeiten von Adolf Engler, der als Direktor des Berliner Botanischen Gartens zum Ende des 19. Jahrhunderts die Erforschung der weltweiten Pflanzenvielfalt maßgeblich voranbrachte, gab es bereits gute Beziehungen dorthin. Und diese sind nach dem Fall des Eisernen Vorhangs wieder aufgelebt.

„Wenn wir die Flora des Kaukasus verstehen wollen, müssen wir möglichst in der gesamten Region arbeiten“, betont BGBM-Direktor Prof. Dr. Thomas Borsch. Mit Forschungsinstitutionen aus der Russischen Föderation arbeitet das Berliner Team daher ebenso zusammen wie mit solchen aus Armenien, Aserbaidschan und Georgien. „Im Jahr 2009 haben wir zusammen mit Partnern in der Region die Kaukasus-Biodiversitäts-Initiative ins Leben gerufen“, sagt der BGBM-Direktor. Sie bildet den Rahmen für Projekte mit dem Ziel, die Pflanzenvielfalt des
Kaukasus zu erforschen, den wissenschaftlichen Austausch und die Kapazitäten in den Kaukasus-Ländern zu fördern und das Wissen für den Schutz und die nachhaltige Nutzung der kaukasischen Biodiversität verfügbar zu machen.

Durch die Förderung der VolkswagenStiftung konnte ab 2012 in zwei Phasen das Projekt „Developing Tools for Conserving the Plant Diversity of the South Caucasus" umgesetzt werden. Beteiligt waren das Takhtajan Institut für Botanik und das Orbeli Institut für Physiologie der Nationalen Akademie der Wissenschaften der Republik Armenien, das Institut für Botanik der Nationalen Akademie der Wissenschaften der Republik Aserbaidschan mit dem Botanischen Garten in Baku sowie das Institut für Botanik der Ilia-State Universität und der Nationale Botanische Garten in Tbilisi, der Botanische Garten Batumi und das Georgische Nationalmuseum in Georgien. Im November 2019 fand in Berlin der Abschluss-Workshop statt.

In diesem Projekt ging es zunächst darum, ausgewählte Pflanzengruppen modellhaft zu untersuchen, die im Kaukasus mit vielen Arten vorkommen. Die Wahl ist dabei unter anderem auf die Flechten und die Glockenblumen, die Korbblütler, die Lippenblütler, die Nelkengewächse und die Wildbirnen (Rosengewächse) gefallen. Wildbirnen spielen 
auch als Verwandte von Kulturpflanzen eine wichtige Rolle - zumal viele der Wildarten an trocken-warme Umweltbedingungen angepasst sind. Ihr Erhalt könnte daher für die künftige Züchtung von Kultur-Birnen in Zeiten des Klimawandels von ganz praktischer Bedeutung sein. „Für die Wildbirnen der Gattung Pyrus gilt der Kaukasus als absoluter Hotspot weltweit", sagt Dr. Nadja Korotkova, die im Kaukasus-Projekt am BGBM an dieser Modellgruppe geforscht hat. Je nach Quelle sind für die Region 30 bis 50 verschiedene Birnen-Arten beschrieben worden. Unklar ist allerdings, wo genau die Artgrenzen verlaufen. Denn in den letzten 150 Jahren haben Botaniker die Birnen-Verwandtschaft nach unterschiedlichen Kriterien unterteilt: Mal ging es dabei vor allem um das Aussehen der Blätter, in anderen Fällen lag das Augenmerk eher auf Merkmalen von Früchten. „Heute können wir dagegen einen detaillierten Blick ins Erbgut von Arten aus dem Kaukasus werfen und dieses dann mit den Verwandten in anderen Regionen Europas und Asiens vergleichen“, erklärt Thomas Borsch. So lässt sich herausfinden, welche Arten es überhaupt gibt, wie diese untereinander verwandt sind und wann sich ihre Entwicklungslinien getrennt haben.

Das Problem ist allerdings, dass die Geschichte der Wildbirnen-Vielfalt erst seit dem Pliozän (also vor etwa 5 Millionen Jahren) Fahrt aufnahm. In den Maßstäben der Evolution ist das ein Wimpernschlag. Das aber bedeutet, dass sich die einzelnen Arten genetisch noch sehr ähnlich sind. „Mit den normalen Markern kann man ihre Entwicklungsgeschichte deshalb kaum rekonstruieren“, sagt Nadja Korotkova. Also sind die Projektmitarbeiterinnen und -mitarbeiter dazu übergegangen, neben verschiedenen Genen aus dem Zellkern die kompletten DNA-Sequenzen der Chloroplasten zu analysieren.

Diese winzigen, grünen Zellorgane sind in den Blättern für die Photosynthese zuständig und besitzen ein eigenes Erbgut. Mit dessen Hilfe kann man den genetischen Gemeinsamkeiten und Unterschieden verschiedener Birnbäume sehr detailliert auf die Spur kommen und so gut aufgelöste Stammbäume erstellen, bei denen sich die zeitliche Aufspaltung der Arten anhand einer molekularen Uhr genau berechnen lässt. Hier werden dann die neuesten Methoden zur Sequenzierung und bioinformatischen Analyse kompletter Plastidengenome eingesetzt, mit denen sich Dr. Michael Grünstäudl, Nachwuchswissenschaftler und Habilitand am Fachbereich Biologie, Chemie, Pharmazie der Freien Universität und ebenfalls Projektmitarbeiter, beschäftigt. Kandidatinnen und Kandidaten aus den Biologie-Studiengängen sowohl aus den Kaukasus-Ländern wie aus Deutschland profitieren davon in ihrer akademischen Ausbildung. Allerdings geht es natürlich nicht nur darum, einen Blick in die Geschichte der Birnen zu werfen. Die untersuchten Pflanzen sind so vielfältig wie die Natur des Kaukasus selbst. Im Projekt ist derweil Dr. Rashad Salimov vom Institute of Botany der Azerbaijan National Academy of Sciences den Geheimnissen der Lippenblütler aus der Gattung der Helmkräuter (Scutellaria) auf der Spur, die im Kaukasus viele Endemiten hat. Und Nana Silakadze aus Georgien forscht im Rahmen ihrer Doktorarbeit an einer Artengruppe von Glockenblumen, die über der Waldgrenze in den Hochlagen des Kaukasus vorkommen. Genauso wie für Dr. Anush Nersesyan von der Armenischen Nationalen Akademie der Wissenschaften, die sich mit Nelken der Gattung Dianthus beschäftigt, hat hier der Vergleich von Gensequenzen mit den anderen Glockenblumen- und Nelkenarten aus Europa und Asien entscheidende neue Erkenntnisse über den Ursprung und die Evolution der kaukasischen Endemiten erbracht. Die stammesgeschichtliche Analyse der Gattung Jurinea (Silberscharte aus der Familie der Korbblütler), die neben dem Kaukasus vor allem in Zentralasien ein Diversitätszentrum hat, zeigte, dass die Arten des Kaukasus in vier verschiedenen Evolutionslinien stehen, eine davon mit vielen Endemiten im Nord-Kaukasus. Die Analyse erfolgte durch Dr. Eckhard von Raab-Straube vom BGBM gemeinsam mit Dr. Alexander Sennikov vom Komarov Institut in St. Petersburg, Prof. Svetlana Livinskaya von der Kuban State University in Krasnodar, Prof. Georgy Lazkov von der Kirgisischen Akademie der Wissenschaften. Dabei wird ein Grundmuster offenbar: Pflanzenwanderungen zwischen Orient und Okzident seit mehreren Millionen Jahren und anschließende Artbildung in den speziellen Lebensräumen der Gebirge hatten großen Einfluss auf die Entstehung der Artenvielfalt im Kaukasus. Aus Aserbaidschan hat Elmira Maharramova ihre Doktorarbeit zur Biogeografie und genetischen Vielfalt von typisch kaukasischen Baumarten wie der Kaukasischen Flügelnuss (Pterocarya fraxinifolia) aus der Familie der Walnussgewächse und der Kaukasischen Zelkove (Zelkova carpinifolia), einem Ulmengewächs geschrieben. Die Ergebnisse sind auch von großer praktischer Bedeutung für das Management und den Erhalt dieser forstlichen genetischen Ressourcen.

Je kleiner die Organismen sind, desto mehr Neues gibt es oft zu entdecken. So hat Arsen Gasparyan im Rahmen seiner Doktorarbeit alleine für Armenien 196 Arten von Flechten erstmalig für das Land nachgewiesen, darunter vier Arten, die zusammen mit den Flechten-Spezialisten am BGBM, Dr. Robert Lücking und Dr. Harrie Sipman als neu für die Wissenschaft beschrieben wurden.

Zu den ausdrücklichen Zielen der Kaukasus-Kooperation gehört nicht nur die Vermittlung und Etablierung moderner Forschungsmethoden, sondern auch der Aufbau von molekularen Laborkapazitäten und die Entwicklung von Sammlungen wie Herbarien oder dokumentierten Lebendpflanzen in Botanischen Gärten. Auf unzähligen gemeinschaftlichen Exkursionen in der gesamten Kaukasus-Region wurden in den letzten zehn Jahren tausende von Proben gesammelt und in den Sammlungen der Kaukasus-Länder sowie am BGBM hinterlegt. Mit der Förderung der VolkswagenStiftung konnten in Armenien, Aserbaidschan und Georgien außerdem technische Kapazitäten verbessert und mit der Digitalisierung der Herbarbelege, insbesondere in den untersuchten Modellgruppen, begonnen werden. Dazu konnte eine Datenbank-Infrastruktur etabliert werden, die den Datenaustausch zwischen den Herbarien vereinfacht und den Rückfluss von Informationen in die Sammlungen, wie etwa neue Bestimmungsergebnisse, erleichtert. Erreicht wurde außerdem, dass diese Biodiversitätsdaten direkt aus den Herbarien in die Global Biodiversity Information Facility 


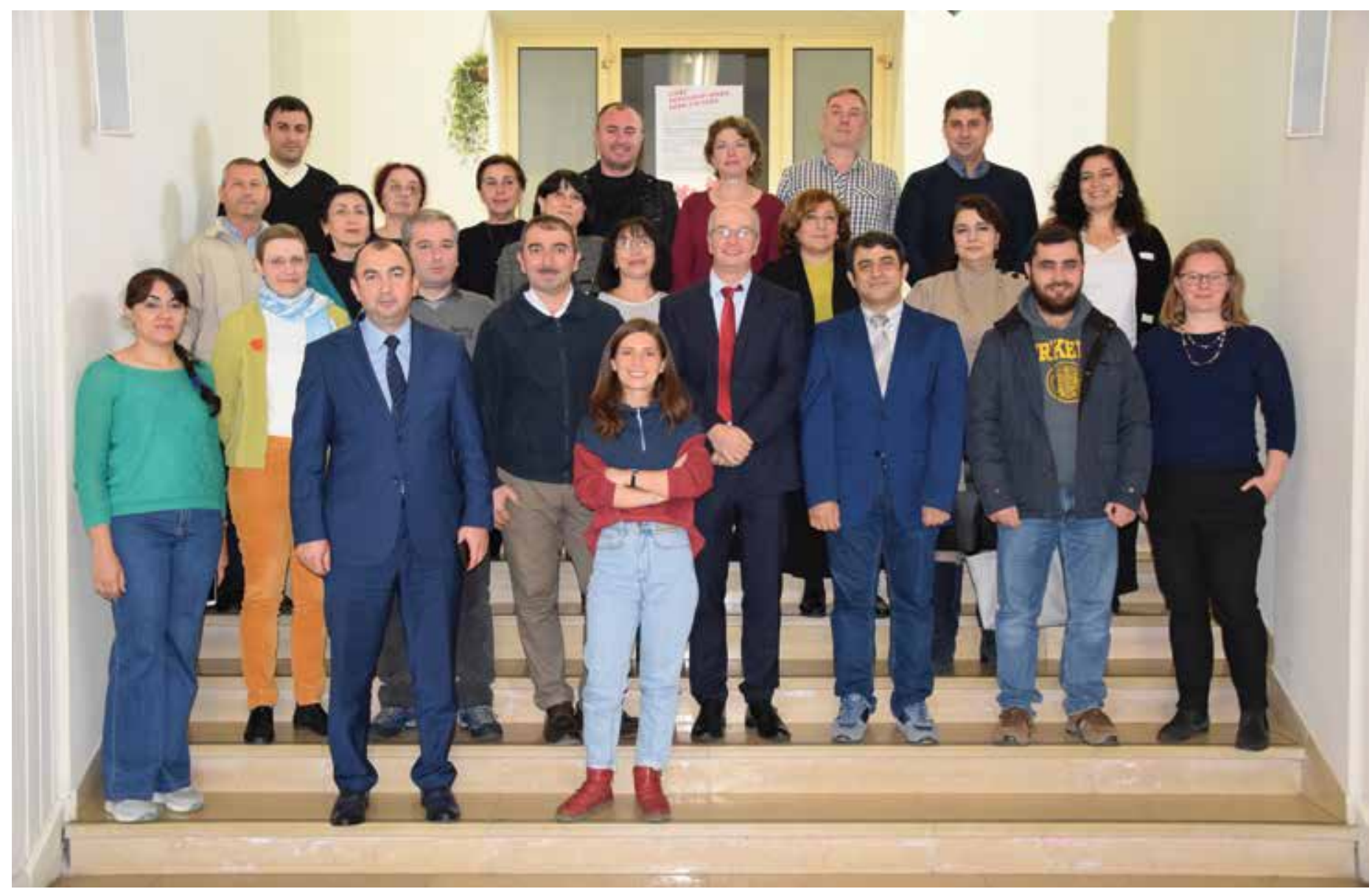

Wissenschaftlerinnen und Wissenschaftler aus Armenien, Aserbaidschan und Georgien sowie des BGBM beim Abschluss Status-Seminar des Projektes „Developing tools for conserving the plant diversity of the South Caucasus“, das vom 11.-15. November 2019 am BGBM stattfand.

(GBIF) eingespeist werden und damit die beteiligten Institutionen in Armenien, Aserbaidschan und Georgien direkt an weltweiten Biodiversitätsprogrammen teilnehmen. Herbarien sind als Informationsquellen für das Auftreten einer Pflanze an einem bestimmten Ort und zu einer bestimmten Zeit von großer Bedeutung - und sie sind Quellen für Biodiversitätsinformation von großer Qualität, denn die Art-Identifikation der Objekte kann jederzeit überprüft werden. Das Team will daher künftig die Digitalisierung der Herbarien an den Institutionen im Kaukasus weiter vorantreiben und mit den Datenbeständen weiterer wichtiger Sammlungen wie etwa in der Russischen Föderation vernetzen. In gleicher Weise werden auch die Sammlungen aus dem Kaukasus im Botanischen Garten und Botanischen Museum Berlin, die umfassendsten aus der Region in Deutschland, digitalisiert und verfügbar gemacht. Auf dieser Basis sollen dann u.a. detaillierte Verbreitungskarten für die Arten entstehen.
Solche Erkenntnisse sind vor allem für den Naturschutz sehr wichtig. Denn wer die einzigartige Pflanzenvielfalt des Kaukasus erhalten und auch nutzen will, muss sich zunächst erst einmal einen Überblick verschaffen: Welche Arten gibt es überhaupt? Und wo kommen sie vor? Welche davon sind wodurch bedroht? Und was kann man dagegen tun? Um dazu fundierte Aussagen treffen zu können, fehlt es noch immer an Daten. Auch in den nächsten Jahren geht das Engagement des BGBM und seiner Partnerorganisationen im Rahmen der gemeinsamen Kaukasus-Initiative daher weiter. Konkret soll ein ständig aktualisierter, allgemein verfügbarer Online-Katalog der gesamten Pflanzenvielfalt des Kaukasus entstehen, der auch mit internationalen Infrastrukturen der Biodiversitäts-Information wie etwa der Euro+Med PlantBase und der Online-Flora der Welt abgestimmt ist. Die Schatzkammer der Artenvielfalt in einer digitalen Version. 


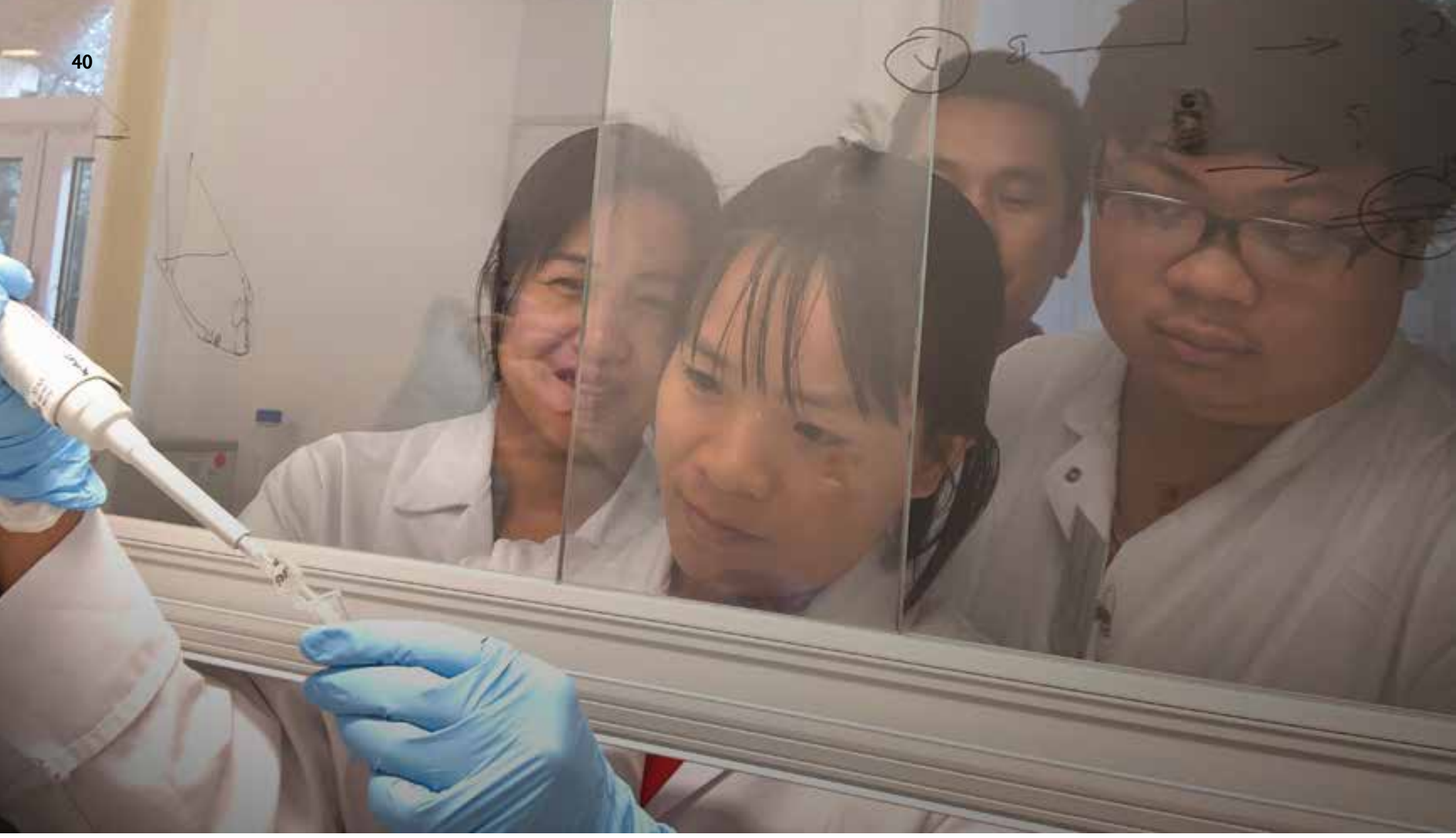

Vietnamesische Gastwissenschaftlerinnen und Gastwissenschaftler untersuchen im Labor des BGBM während des VIETBIO-

Trainingsaufenthaltes Pilzproben im September 2019 (Lücking R. et al.: Caveats of fungal barcoding: a case study in Trametes s.lat.

(Basidiomycota: Polyporales) in Vietnam reveals multiple issues with mislabelled reference sequences and calls for third-party annotations. Willdenowia 50: 383-403. doi: https://doi.org/10.3372/wi.50.50302).

\section{Im Dienst der Wissenschaft Die Abteilung „Administration und wissenschaftliche Services" schafft die Voraussetzungen für eine erfolgreiche Forschungsarbeit}

Mal scheinen es winzige Keksdosen zu sein, mal mikroskopisch kleine Schiffchen, Sternchen oder Schmuckstücke. Für Juliane Bettig ist ihre Arbeit sehr oft auch ein ästhetisches Vergnügen. Wenn sie die gläsernen Schalen von Kieselalgen unter dem Elektronenmikroskop betrachtet, bekommt sie überraschend vielfältige Kunstwerke im Miniaturformat zu sehen. „Diese Schalen sind an sich schon winzig, haben aber noch viel kleinere Details“, sagt die Technische Assistentin vom Laborbetrieb des BGBM. „Und selbst die können wir hier sichtbar machen. Das ist total faszinierend, fast ein bisschen wie Zauberei.“

Dessen ungeachtet versteht sich die Abteilung Administration und wissenschaftliche Services ,als Team von Dienstleistern mit hoher Serviceorientierung" sagt Abteilungsleiterin Sylke Gottwald. Neben dem Laborbetrieb gehören auch die Bereiche Allgemeine Verwaltung, IT und Projektunterstützung dazu. Und überall arbeiten Menschen daran, den Forschungsbetrieb Tag für Tag am Laufen zu halten. Sie kümmern sich um die Infrastruktur und schaffen das nötige Umfeld, um wissenschaftliches Arbeiten überhaupt erst möglich zu machen. 


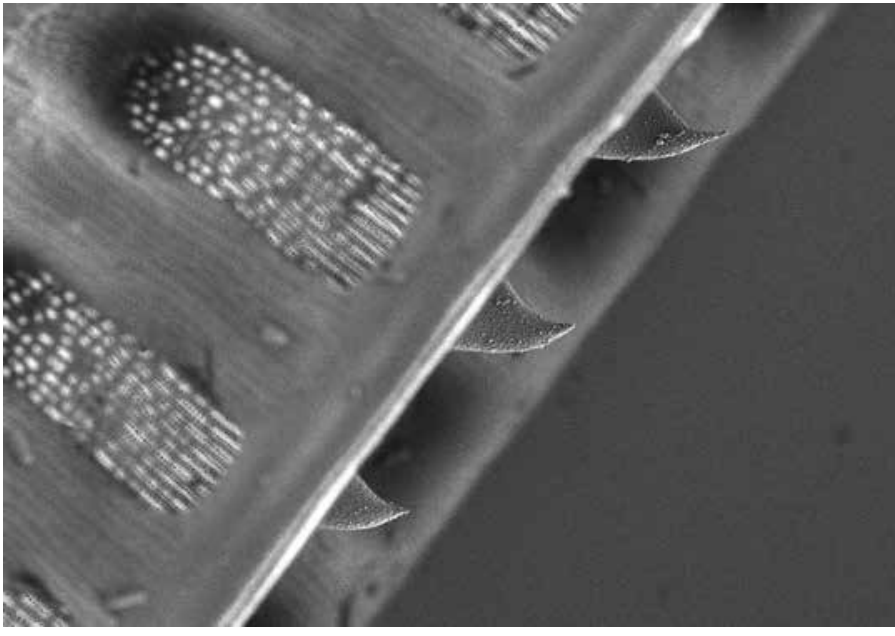

Die Diatomee Iconella sp. in 5.000-facher Vergrößerung im Rasterelektronenmikroskop. Ausschnitt aus einem Teil der Kieselschale mit Stachelrücken sowie Raphe (Naht) auf einem Kiel mit fensterartigen Durchbrüchen. Die gesamte Zelle ist auf Seite 29 zu sehen.

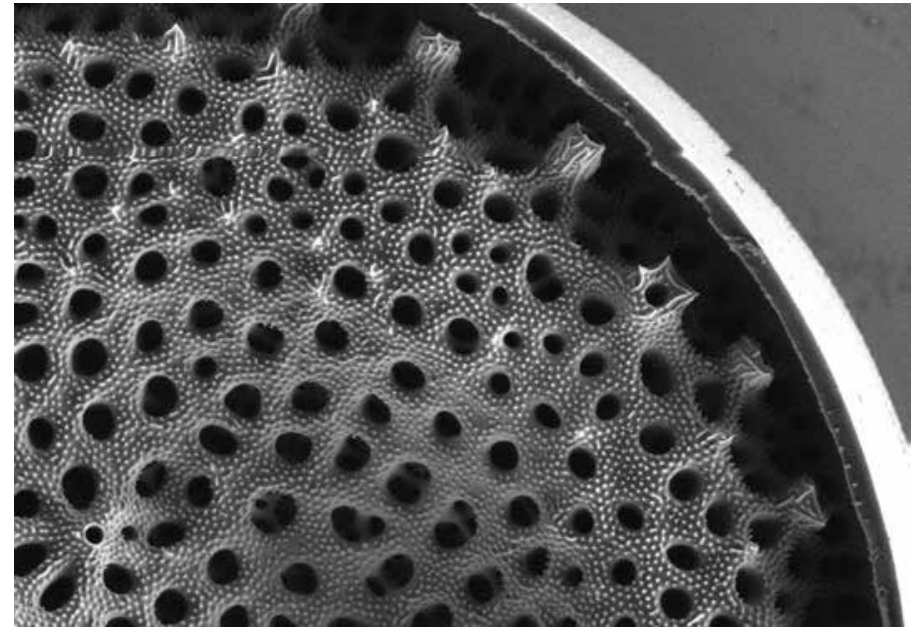

Die Diatomee Thalassiosira sp. in 11.000-facher Vergrößerung im Rasterelektronenmikroskop. Details der Zellwand, die durch warzenförmige Oberflächenstrukturen, Stützenfortsätzen und Areolen (Durchbrüche) skulpturiert ist. Die Leichtbauweise wirkt einem Absinken in der Wassersäule entgegen und ermöglicht den Stoffaustausch mit dem umgebenden Wasser. Die gesamte Zelle ist auf Seite 29 zu sehen.

einer Stunde Arbeit sieht Juliane Bettig auf ihrem Monitor schließlich alle feinen Erhöhungen und Löcher, jede Krümmung und jeden Schatten der Kiesel-Schalen. Bei 150.000- bis 180.000-facher Vergrößerung erscheinen Kunstwerke mit Details, die kleiner als einen Tausendstel Millimeter sind.

„Um solche eindrucksvollen Ergebnisse zu erzielen, braucht unser Gerät nur eine Spannung von 1000 Volt“, sagt Labormanager Kim Govers. Bei früheren Modellen musste man dagegen 30.000 Volt anlegen, so dass die Elektronen stark beschleunigt wurden. Die überschüssige Energie musste dann abgeleitet werden, damit die Bildqualität nicht litt. „Man musste die Objekte deshalb mit Gold oder Platin bedampfen, damit sie leitfähig wurden“, erklärt Kim Govers. Diese bei anderen Elektronenmikroskopen noch immer übliche Praxis ist im Labor des BGBM inzwischen überflüssig geworden. Ein wunderbarer Nebeneffekt ist, dass die winzigen Strukturen der Schalen nun sichtbar sind und nicht mehr zugedeckt werden.

Auch die modernen Geräte sind allerdings noch anfällig gegen Störungen von außen. So steht das Rasterelektronenmikroskop im Erdgeschoss des Botanischen Museums in einem Raum, der wie ein Faraday'scher Käfig konstruiert ist: Er schirmt Magnetfelder ab, die ansonsten die Messungen beeinflussen würden.

Im gesamten Laborbereich arbeitet der BGBM eng mit der Arbeitsgruppe Systematische Botanik und Pflanzengeografie am Fachbereich Biologie, Chemie, Pharmazie zusammen, die ihre Räumlichkeiten in plastisch wirkenden Schwarz-Weiß-Bild verrechnet werden. Nach etwa 


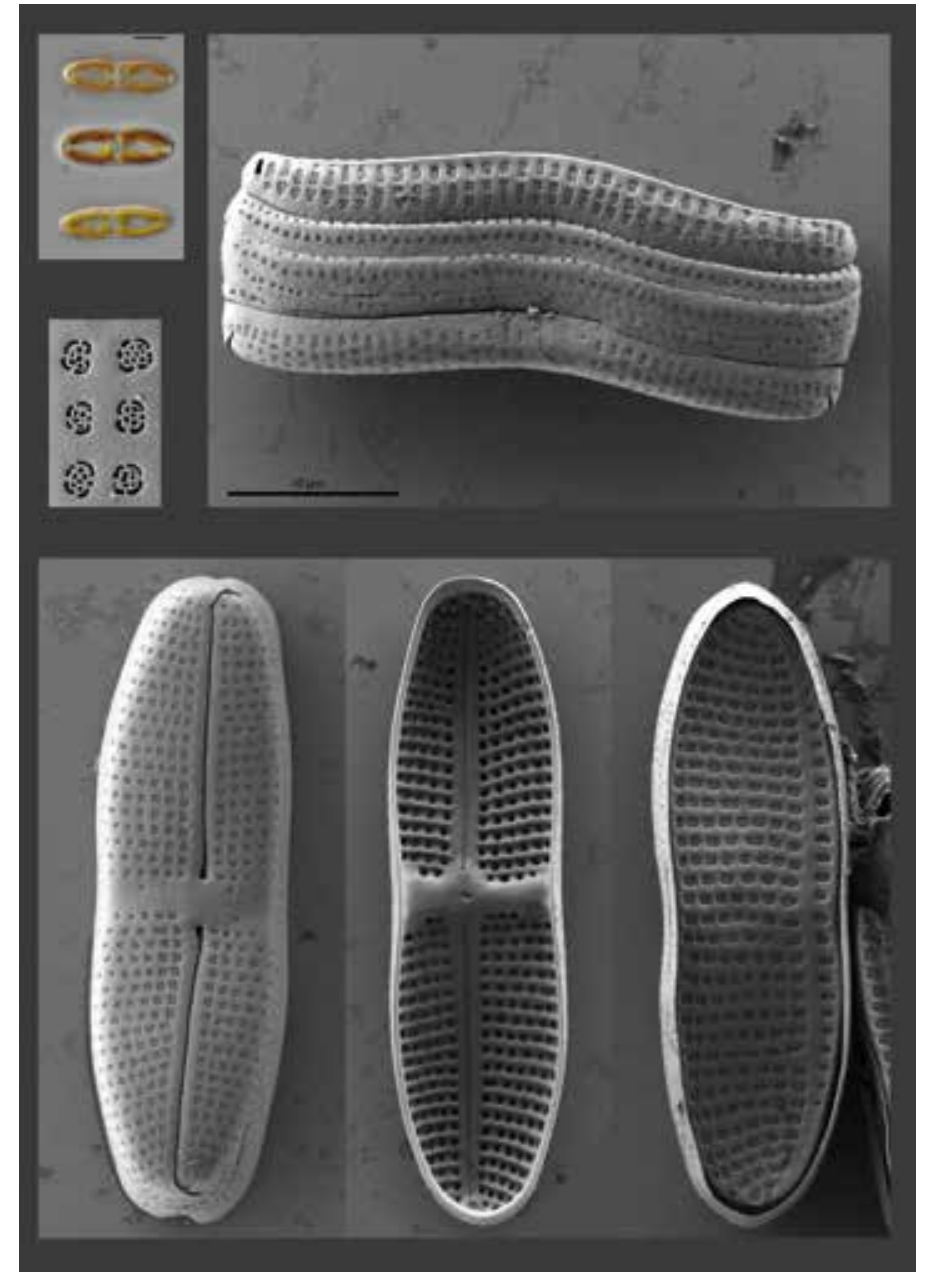

der Altensteinstraße in unmittelbarer Nachbarschaft zum Botanischen Museum hat. Entsprechend sind auch die Labore organisiert: Statt eigener Räume und Geräte für jedes Team gibt es gemeinsame Einrichtungen, die von beiden Bereichen der Universität genutzt werden können. Acht Mitarbeiterinnen und Mitarbeiter aus dem Servicebereich Laborbetrieb halten das Ganze am Laufen und sorgen dafür, dass alle Untersuchungen nach festen Standards ablaufen. Sie kümmern sich um die Arbeitssicherheit, bestellen Laborbedarf, weisen wissenschaftliche Gäste aus dem In- und Ausland in den Umgang mit den Geräten ein und übernehmen die gesamte Labororganisation. Auf insgesamt 450 Quadratmetern Fläche betreiben sie nicht nur das Elektronenmikroskop, sondern beispielsweise auch moderne Geräte zur DNA-Analyse.

Seit 2009 ist die Freie Universität Berlin mit dem BGBM und ihren Fachbereichen Biologie, Chemie, Pharmazie sowie Mathematik, Informatik in einem Konsortium namens Berlin Center for Genomics in Biodiversity Research (BeGenDiv) zusammengeschlossen, zu dem auch drei Leibniz-Institute (das Institut für Zoo- und Wildtierforschung, das Institut für Gewässerbiologie sowie das Museum für Naturkunde Berlin) und Arbeitsbereiche der Universität Potsdam gehören. Räumlich
Verschiedene Ansichten der Diatomee Achnanthes sp. Diese mittelgroße Kieselalge ist ein typischer Vertreter des Brackwassers. Oben links: Drei lebende Zellen mit Chloroplasten im Lichtmikroskop. Im Rasterelektronenmikroskop: Oben rechts: Seitenansicht der Kieselalge mit Gürtelbändern zum Zusammenhalt der Valven (Schalen). Unten links: Außenansicht der Raphenschale, darüber Ausschnittvergrößerung; Mitte: Innenansicht der Raphenschale; rechts: Innenansicht der raphenlosen Schale. Maßstäbe $10 \mu \mathrm{m}$.

ist es am BGBM angesiedelt und bündelt die Expertise auf dem Gebiet der Genomik, also der Erforschung der Erbinformation (DNA) eines Organismus, im Rahmen der Biodiversitäts- und Evolutionsforschung. In den Laboren wird dafür das High-Throughput-Sequencing eingesetzt. Ziel dieses Verfahrens ist es, aus meist kurzen, überlappenden DNA-Schnipseln, die in hoher Zahl sequenziert werden, das Erbgut einer Art zu rekonstruieren. „Im Prinzip ist das so, als ob man zehn Kopien des gleichen Buches hätte, die aber in lauter Fragmente von nur ein paar Seiten zerfallen wären“, erklärt Kim Govers. „Und aus diesen Bruchstücken wird dann der ganze Text rekonstruiert.“ Auch für diese molekularbiologische Puzzlearbeit bietet der Laborbetrieb am BGBM hervorragende Arbeitsmöglichkeiten und Geräte.

Doch nicht nur die richtige Ausstattung des Arbeitsplatzes ist entscheidend für einen gelungenen Forschungsalltag. Deshalb leisten auch im Bereich Allgemeine Verwaltung neun Menschen die verschiedensten Servicearbeiten im Hintergrund. Sie kümmern sich um Personalwesen und interne Organisation, um Haushalt und Einkauf, Dienstreisen und Verträge. „Wir sind Dienstleister für insgesamt 29 verschiedene Personengruppen“, sagt Carola Andersen, die stellvertretende Verwaltungsleiterin am BGBM. Da gilt es, eine Fülle an Details und Besonderheiten 


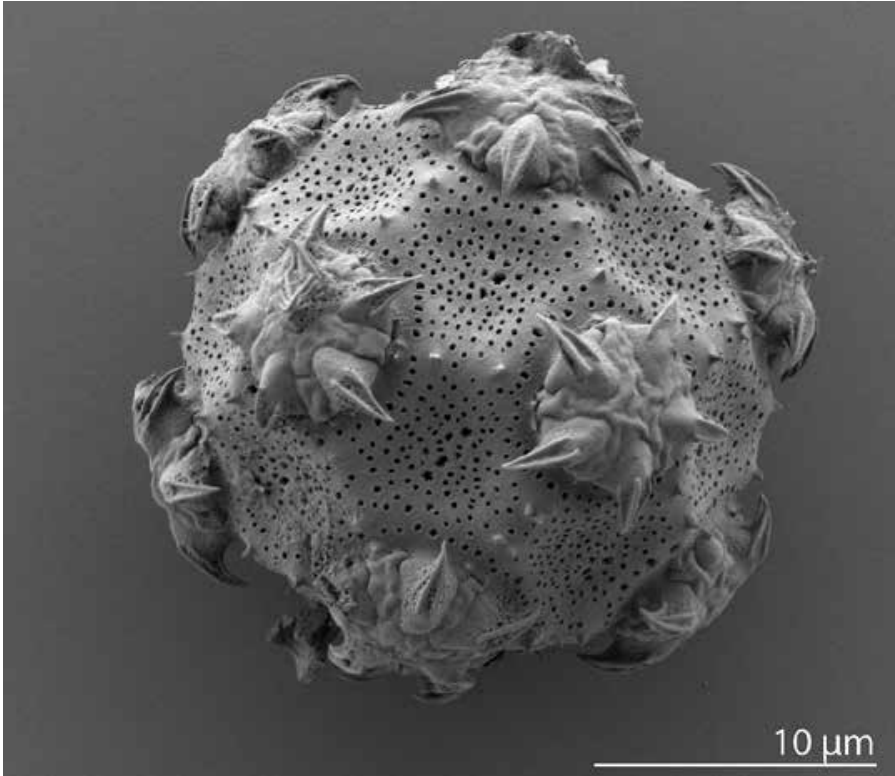

Pollenkorn eines Fuchsschwanzgewächses der Gattung Centemopsis. Die 3000-fache Vergößerung im Rasterelektonenmikroskop erlaubt die genaue Analyse von Pollenmerkmalen.

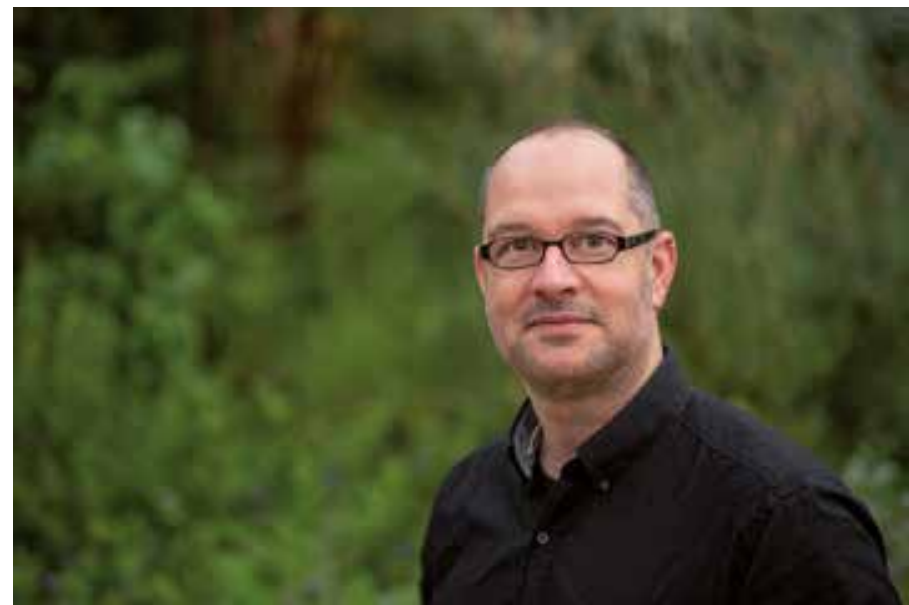

Kim Govers ist Ingenieur für Labortechnik. Der gebürtige Niederländer hat in verschiedenen Laboren in den Bereichen „Forschung und Entwicklung“ und „Qualitätskontrolle“ gearbeitet, bevor er 2008 zum BGBM kam. Dort leitet er den Servicebereich Labore. Unterstützt von einem Team von Technischen Assistentinnen und Assistenten, die auf die unterschiedlichsten Verfahren und Methoden, von Elektronenmikroskopie bis Next-Generation-Sequencing spezialisiert sind, steht damit eine umfassende Landschaft für die Erstellung wissenschaftlicher Daten bereit. Zur Zeit arbeiten etwa 65 Personen in den Laboren an ihren Forschungsprojekten. im Blick zu behalten. Die wissenschaftlich Beschäftigten brauchen beispielsweise einen anderen Vertrag als die Doktorandinnen und Doktoranden und diese wiederum einen anderen als die Ehrenamtlichen. Eine besonders komplizierte Aufgabe hatte das Verwaltungsteam in den Jahren 2017 und 2018 zu bewältigen. Im April 2007 übernahm eine eigene Betriebsgesellschaft im Zuge von Sparmaßnahmen Tätigkeiten am BGBM. Sie unterstützte bei infrastrukturellen, technischen und gärtnerischen Aufgaben. Nun aber ist der BGBM zu einem der wenigen Fälle geworden, in denen dieses umstrittene Outsourcing rückgängig gemacht wurde. Die Betriebsgesellschaft hat Ende 2017 ihre Arbeit eingestellt, so dass danach alle Mitarbeiterinnen und Mitarbeiter in ein Beschäftigungsverhältnis an der Freien Universität Berlin eingegliedert wurden. Für die 96 Beschäftigten wurde zum 1. Januar 2018 eine eigene Abteilung namens Gartenbetrieb im BGBM gegründet. Dies hat sowohl innerhalb der Allgemeinen Verwaltung des BGBM als auch bei der Zentralverwaltung der Freien Universität Berlin einen hohen Einsatz erfordert. „Diese Reintegration war ziemlich kompliziert und wird uns auch noch weiter beschäftigen“, sagt Carola Andersen. „Aber es haben sich alle gefreut, dass es nun wieder einen einheitlichen BGBM gibt."

\section{Laborausstattung am BGBM}

Der Servicebereich Labore am BGBM bietet eine hochmoderne workflow-basierte Arbeitsumgebung für Forschungsprojekte über die Evolution, Diversität und Systematik der Pflanzen, Flechten und Kieselalgen. Der Servicebereich verfügt über 14 Laborräume, in denen das hochauflösende Feldemissions-Rasterelektronenmikroskop die technische Speerspitze bildet. Daneben verfügt der Servicebereich Labore über mehrere Stereo-Mikroskope mit hochauflösenden Kameras. Weitere nennenswerte Laborgeräte sind ein automatisierter Critical Point Drier (CPD) für die Probenvorbereitung im Bereich Rasterelektronenmikroskopie, ein Fragment Analyzer für die Qualitätskontrolle der DNA-Proben und mehrere Thermocycler für PCR(polymerase chain reaction)-basierte Analysen. Zur Erforschung der Erbinformationen werden zudem mehrere Methoden des High-Throughput Sequencing eingesetzt. 



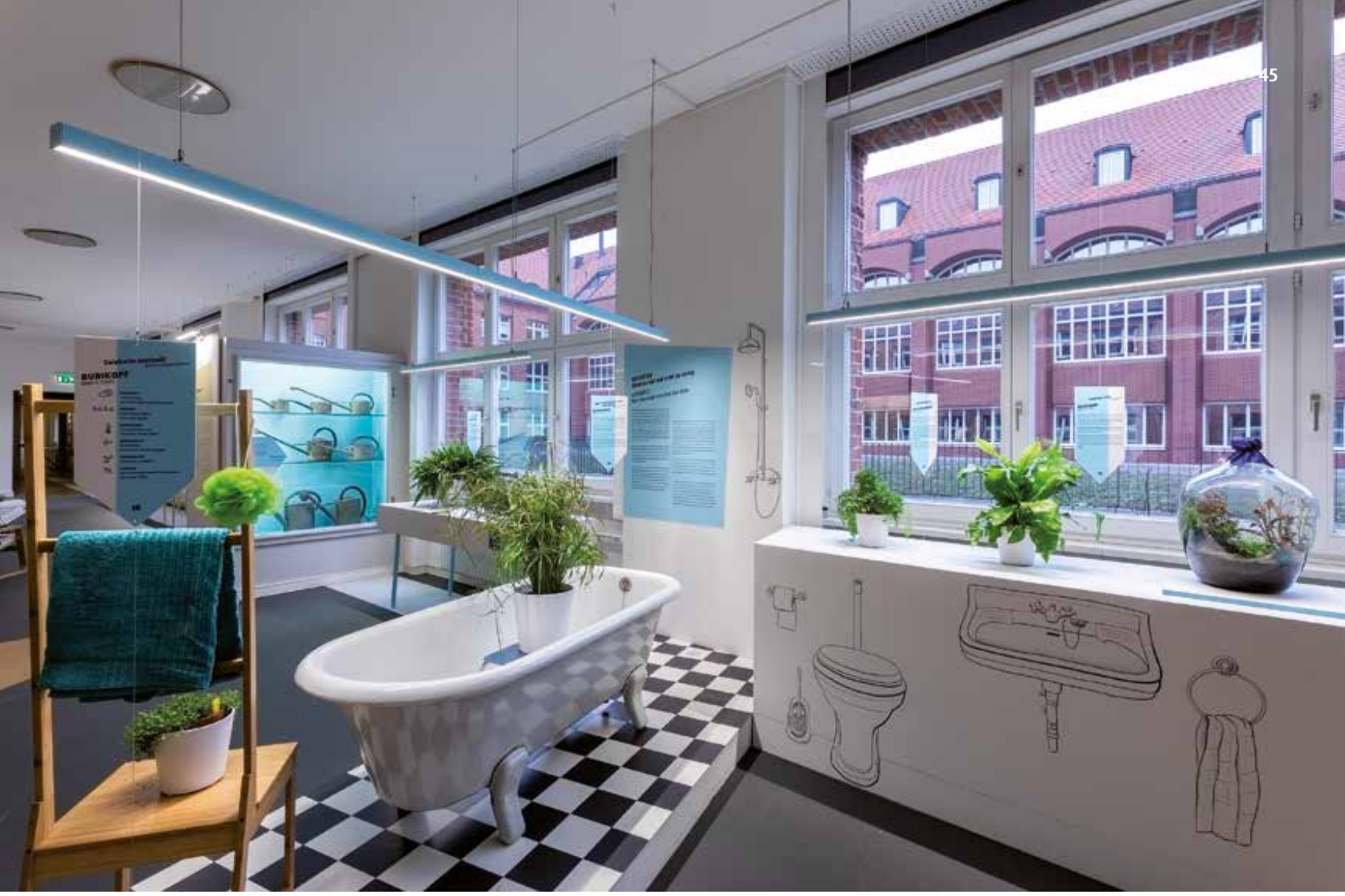

Ausstellungsansichten „Geliebt - Gegossen - Vergessen. Phänomen Zimmerpflanze“.

ßigten Breiten Nordamerikas auf die tropische Flora des Südens. Es bietet auch Lebensräume für die unterschiedlichsten Ansprüche - von knochentrockenen Wüsten bis zu tropischen Regenwäldern. Und auch die hohen Bergketten, die verschiedene Regionen voneinander isolieren, haben Mexiko zu einem besonders produktiven Labor der Pflanzen-Evolution gemacht.

So gibt es dort allein 120 Kiefern-Arten, so viele wie in keinem anderen Land der Erde. In den Wäldern zwischen 1.300 und 2.400 Metern Höhe wächst ein Drittel aller 900 weltweit bekannten Salbei-Arten. Dazu kommen knapp 700 verschiedene Kakteen-Arten, von denen die meisten nirgendwo sonst auf der Erde vorkommen. Landesweit haben Botanikerinnen und Botaniker bisher rund 30.000 Pflanzenarten gezählt - etwa dreimal so viele wie in Mitteleuropa. „Damit gehört Mexiko zu den fünf artenreichsten Ländern der Welt und ist auch für die For- schung am Botanischen Garten von besonderem Interesse“, erklärt Dr. Patricia Rahemipour, bis 2019 Leiterin des Botanischen Museums und der Abteilung Wissenskommunikation am BGBM.

Aus diesem großen Reservoir haben Menschen im Laufe der Jahrtausende die verschiedensten Nutzpflanzen gezüchtet. Für Kathrin Grotz war das eine naheliegende Entwicklung: „Aus einem der Hotspots der Artenvielfalt ist letztendlich auch einer des guten Geschmacks geworden." So stammen kulinarische Errungenschaften wie Tomaten und Bohnen, Chili und Avocados, Vanille und Agaven-Schnaps ursprünglich aus Mexiko. Dazu kommen viele international beliebte Zierpflanzen wie Dahlien, Weihnachtssterne und Studentenblumen.

Allerdings gibt es auch noch viele andere Regionen auf der Welt, die populäre grüne Mitbewohner für Wohnungen und Häuser geliefert 


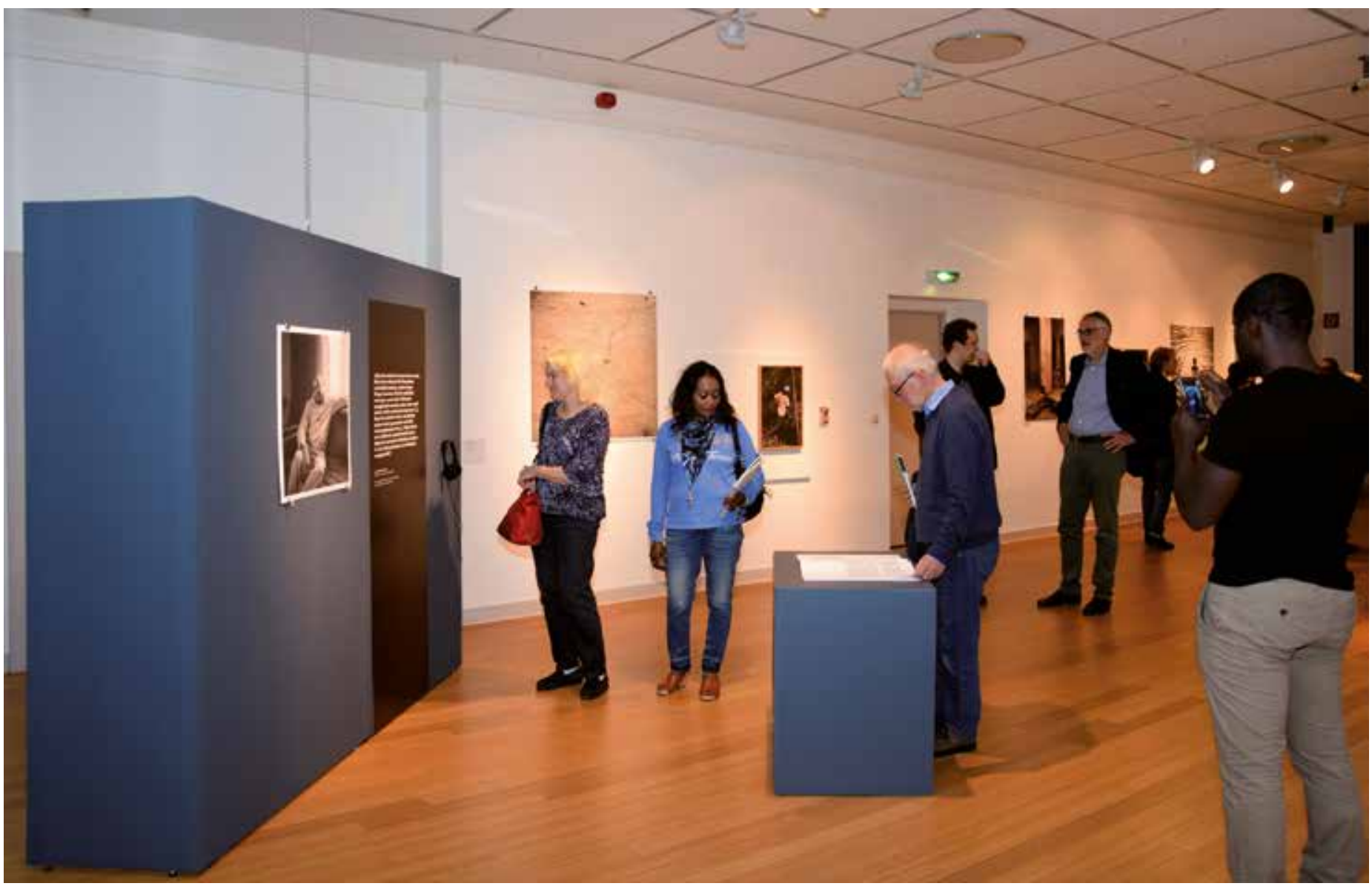

Besucherinnen und Besucher in der Ausstellung „Zenkeri. Fotografien von Yana Wernicke \& Jonas Feige“, 11.10.2018 - 6.1.2019 im Botanischen Museum Berlin.

haben. Mit diesen Nachbarn auf der Fensterbank beschäftigte sich eine weitere Ausstellung des Botanischen Museums, die im Dezember 2018 eröffnet wurde. Unter dem Titel „Geliebt, Gegossen, Vergessen“ entführte sie ihr Publikum in die Welt der Zimmerpflanzen, einem bis dahin aus kulturgeschichtlicher Sicht wenig beachteten Thema. Die beiden Kuratorinnen Kathrin Grotz und Patricia Rahemipour mussten daher erst einmal zentrale Aspekte einer Geschichte der Zimmerpflanzen identifizieren, um die Ergebnisse dann in die Ausstellung einfließen lassen zu können. Auf dem mit etwa hundert Metern längsten Fensterbrett Berlins waren 50 typische Arten zu bewundern. Man konnte nicht nur erfahren, woher diese jeweils stammen und welche Ansprüche sie stellen. Die Ausstellung erzählte auch, wie sich die wechselvolle Geschichte der Wohngemeinschaft von Mensch und Pflanze entwickelt hat.

Welche Arten wann vor den Fenstern standen, hing dabei nicht nur von wechselnden Moden ab. „Man musste auch erst einmal die technischen Voraussetzungen haben, um sich eine Art erfolgreich ins Haus zu holen“, erklärt Kathrin Grotz. Der Knackpunkt war dabei häufig die Temperatur. In einer per Kachelofen geheizten Wohnung des 19. Jahrhunderts war es zum Beispiel meist so kühl, dass dort nur Pflanzen aus den gemäßigten Klimazonen oder den Subtropen gediehen. Für Zimmerlinden oder Alpenveilchen zum Beispiel sind zehn bis $15 \mathrm{Grad}$ ideal und auch Farne erfreuten sich damals großer Beliebtheit. Tropische Orchideen und andere wärmeliebende Arten eroberten die Wohnungen dagegen erst, als sich im 20. Jahrhundert die Zentralheizung durchsetzte.

Derzeit scheint Grün in den eigenen vier Wänden gerade wieder voll im Trend zu liegen. Unter dem Schlagwort Urban Jungle werben zahlreiche Zeitschriften und Internetseiten dafür, sich wieder mehr Grün in die Wohnung oder ins Büro zu holen - und zwar nicht nur aus ästhetischen Gründen. „Tatsächlich können Pflanzen eine sehr starke psychologische Wirkung haben“, sagt Patricia Rahemipour. Am Arbeitsplatz sollen sie zum Beispiel nicht nur beruhigend wirken, sondern auch die Kreativität und sogar die Zufriedenheit mit dem Chef oder der Che- 


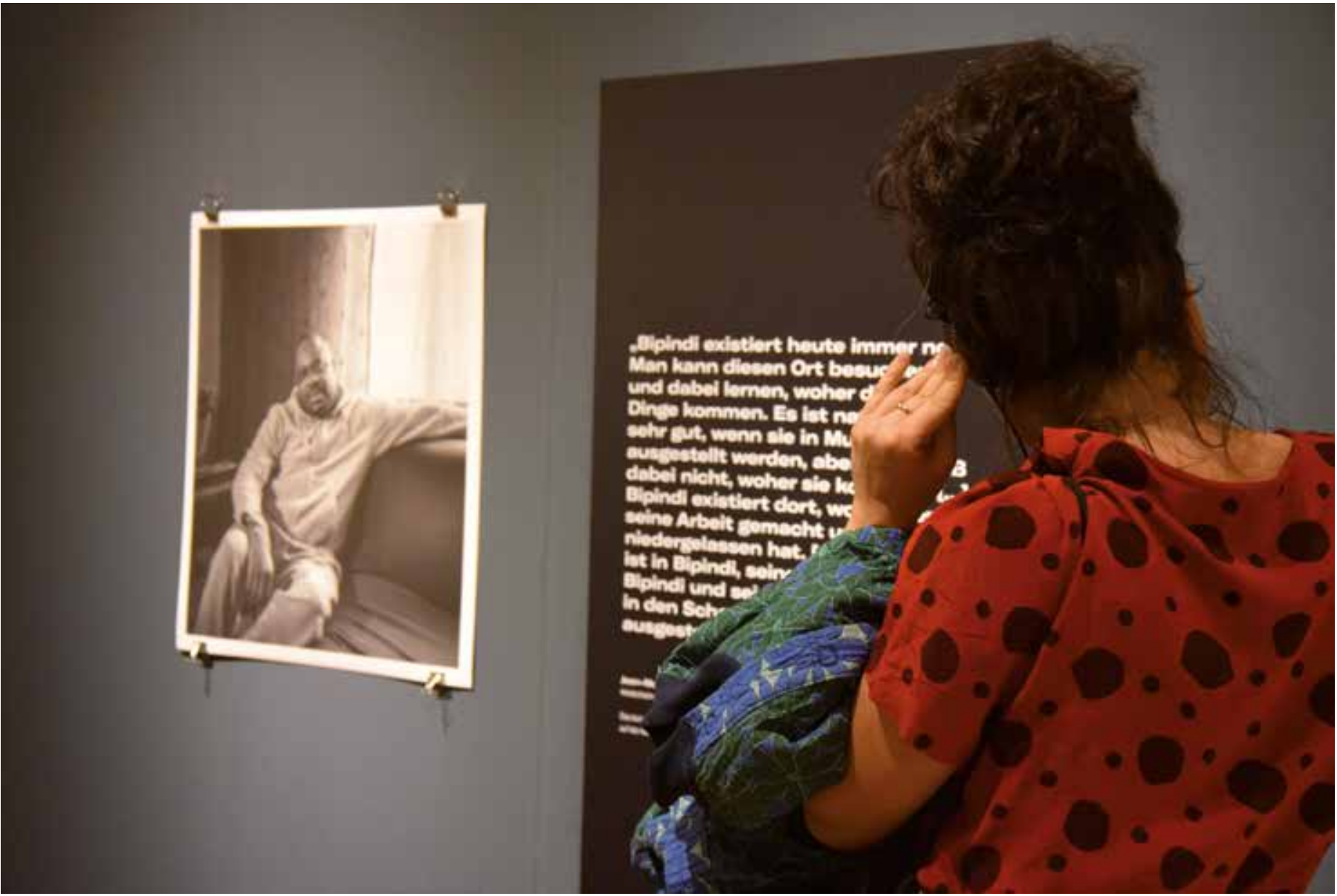

fin steigern. Erstaunlicherweise finden sich solche Effekte sogar bei Menschen, die sich selbst als Pflanzenhasser bezeichnen. „Das könnte eine Folge der gemeinsamen Evolutionsgeschichte von Menschen und Pflanzen sein“, sagt Kathrin Grotz. „Möglicherweise haben unsere Urahnen so lange in einer von Pflanzen dominierten Umgebung gelebt, dass diese Vorliebe noch immer tief in unserem Gehirn verwurzelt ist." Wer die Zimmerpflanzen-Schau besuchte, konnte also nicht nur etwas über die Geschichte seiner grünen Mitbewohner erfahren. Sondern auch über seine eigene.

Die Forschung im Rahmen von Ausstellungsvorbereitungen ist nicht die einzige wissenschaftliche Leistung, die vom Botanischen Museum ausgeht. Das Botanische Museum ist auch zentraler Akteur kulturhistorischer Forschung - zusammen mit etlichen anderen Museen und Sammlungen in Berlin. Elf solcher Einrichtungen haben sich 2015 auf Initiative des BGBM zu einem Verbund namens KOSMOS Berlin: Forschungsperspektive Sammlungen zusammengeschlossen. Was sie zusammengetragen haben, ist so vielfältig wie die Stadt selbst. Die Pa- lette reicht von ethnographischen Objekten und Herbarbelegen über Reisetagebücher und Tonaufnahmen bis hin zu historischen Medizingeräten und präparierten Tieren. Doch die Mitglieder des Netzwerks verfolgen alle ein gemeinsames Ziel: Die Geschichte Berlins anhand seiner Sammlungen zu schreiben. Dazu ist die interdisziplinäre Sicht auf die Sammlungen unerlässlich. „Im Rahmen dieses Netzwerkes veranstalten wir regelmäßige Treffen mit Saloncharakter, bei denen wir über mögliche gemeinsame Forschungsvorhaben diskutieren. So sind schon gute Antragsideen entstanden, an denen wir dann in kleineren Gruppen weiter arbeiten.", sagt Patricia Rahemipour.

Zu den jüngsten Projekten von KOSMOS Berlin gehört eine neue Publikationsreihe über die Geschichte von Berliner Sammlungen, die im eigenen Verlag BGBM Press erscheint. Im ersten Band Bipindi - Berlin portraitierte die Historikerin Katja Kaiser im Herbst 2018 den Sammler Georg August Zenker - einen Kolonialbeamten und späteren Plantagenbesitzer, der um die Wende vom 19. zum 20. Jahrhundert unzählige Pflanzen und Tiere, aber auch Amulette, Tanzrasseln und andere eth- 


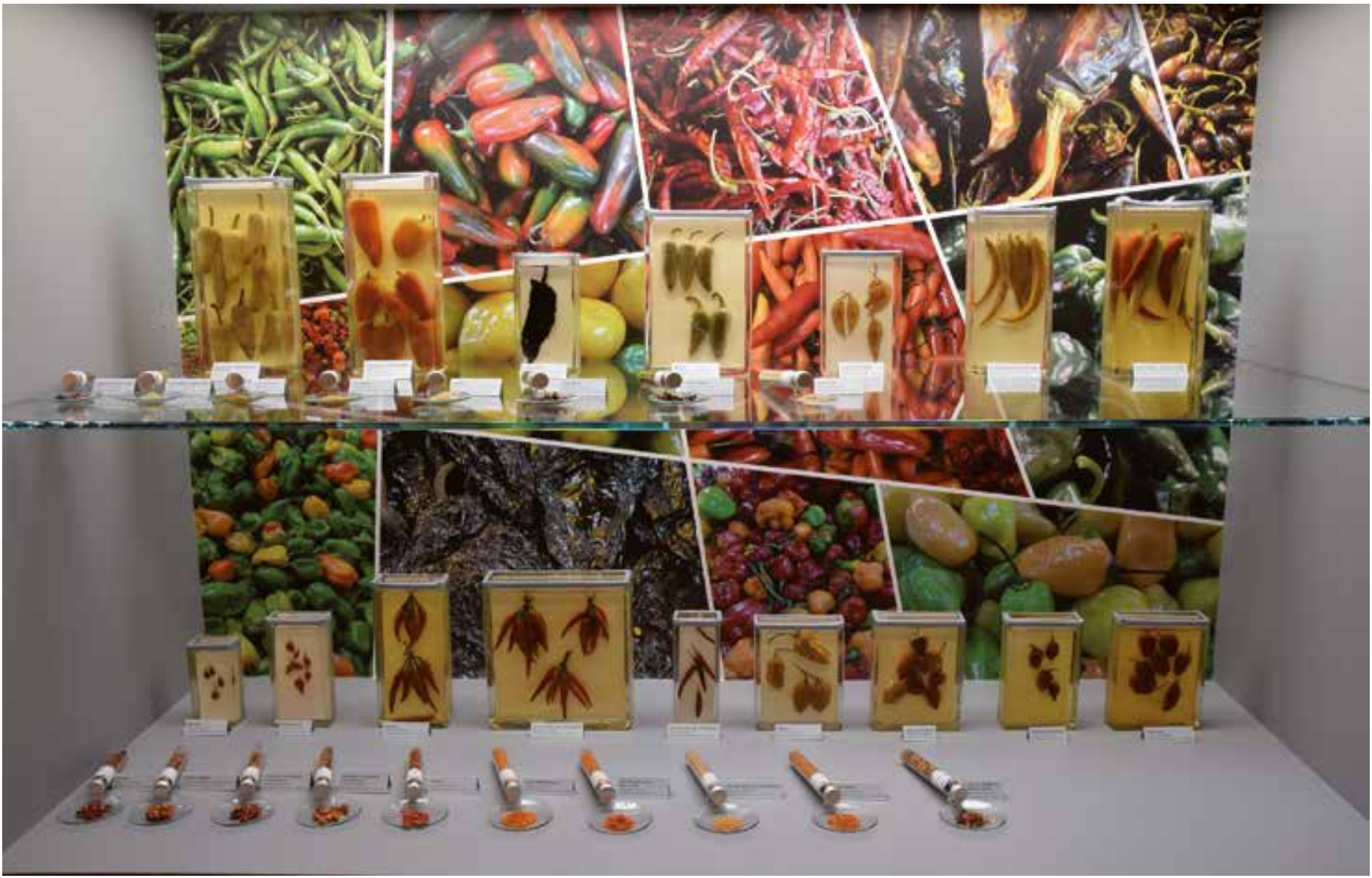

Ausstellungsansicht „Chili \& Schokolade. Der Geschmack Mexikos“, 5.5.2017-25.2.2018 im Botanischen Museum Berlin.

nologisch interessante Gegenstände sammelte und aus der damaligen deutschen Kolonie Kamerun an drei Berliner Institutionen schickte. Neben dem Botanischen Garten gehörten auch das Ethnologische und das Museum für Naturkunde zu den Empfängern.

In seinem ehemaligen Haus, das im abgelegenen Ort Bipindi mitten im Urwald Kameruns steht, leben noch heute Nachfahren von Zenker und seinen fünf Frauen. „Einige von ihnen sind sehr stolz auf ihren Vorfahren, andere sehen ihn eher kritisch. Beides zeigt deutlich, wie sehr die Kolonialzeit bis heute wirksam ist und dass das in den Sammlungen enthaltene Kulturgut sowie die koloniale Geschichte des Botanischen Gartens dringend umfangreich untersucht werden müssen. Dies kann nicht nur von einer Institution ausgehen, sondern muss auch gemeinsam passieren. KOSMOS Berlin und die neue Reihe sind hierfür Ort und Anfang zugleich.", sagt Patricia Rahemipour. Die Berliner Fotografen Yana Wernicke und Jonas Feige haben die in
Kamerun lebende Familie Zenkers mehrfach besucht und fotografiert. Ihre Bilder waren von Oktober 2018 bis Januar 2019 in der Ausstellung „Zenkeri“ im Botanischen Museum zu sehen, einige wurden auch in das Buch Bipindi - Berlin aufgenommen.

So haben Wissenschaftlerinnen und Wissenschaftler verschiedener Disziplinen an einem Strang gezogen, um das Bild des kolonialen Sammlers aus den verschiedensten Perspektiven zu beleuchten. „Dabei wird auch klar, dass die Kolonialzeit für die Familien vor Ort immer noch aktuell ist", sagt Patricia Rahemipour. Zenkers Erbe besteht eben nicht nur aus den von ihm gesammelten Objekten, die heute im Botanischen Museum, im Museum für Naturkunde und im Ethnologischen Museum in Berlin aufbewahrt werden. Sondern sind Teil der Kolonialgeschichte, die bis heute wirkt und deren Aufarbeitung noch am Anfang steht. 


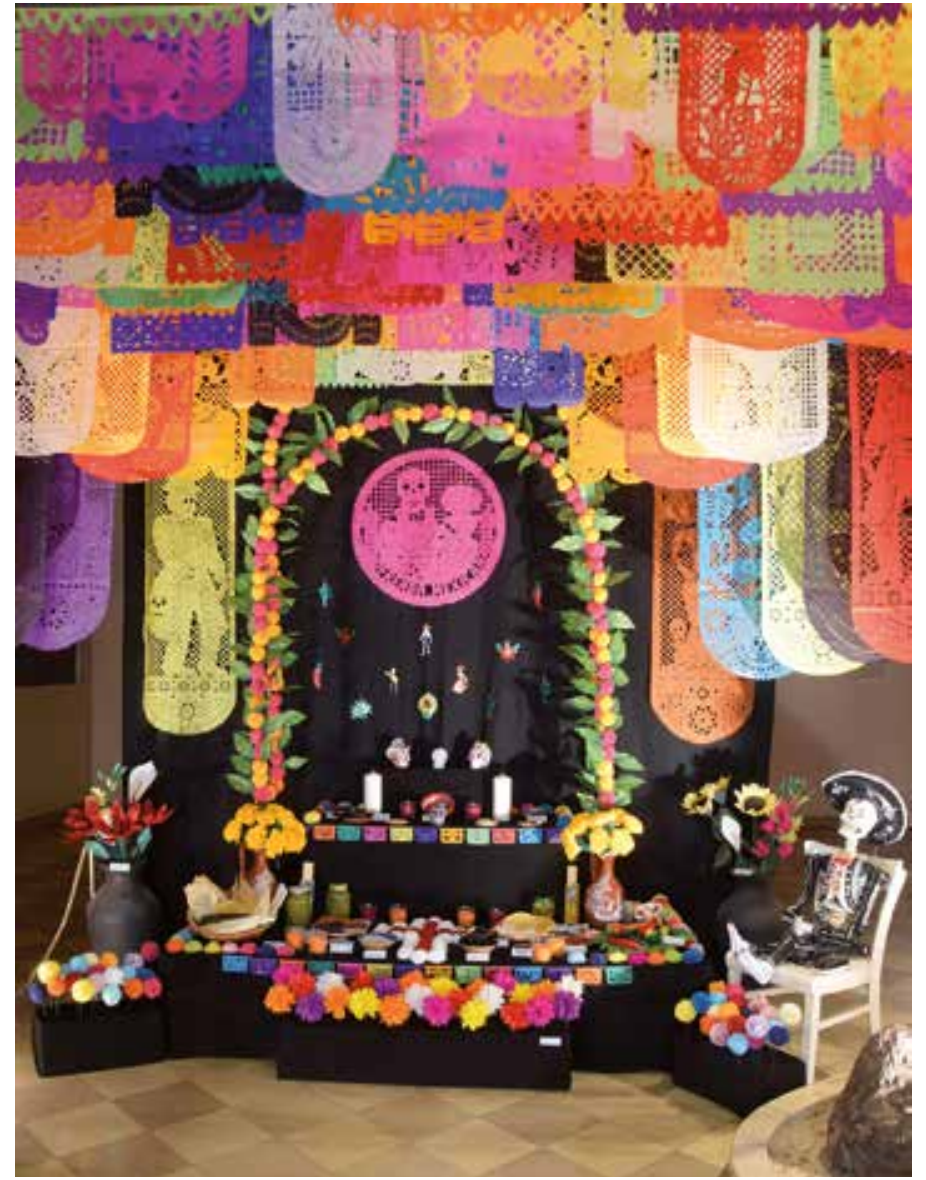

Ofrenda (Totenaltar) aus der Ausstellung „Chili \& Schokolade. Der Geschmack Mexikos“.

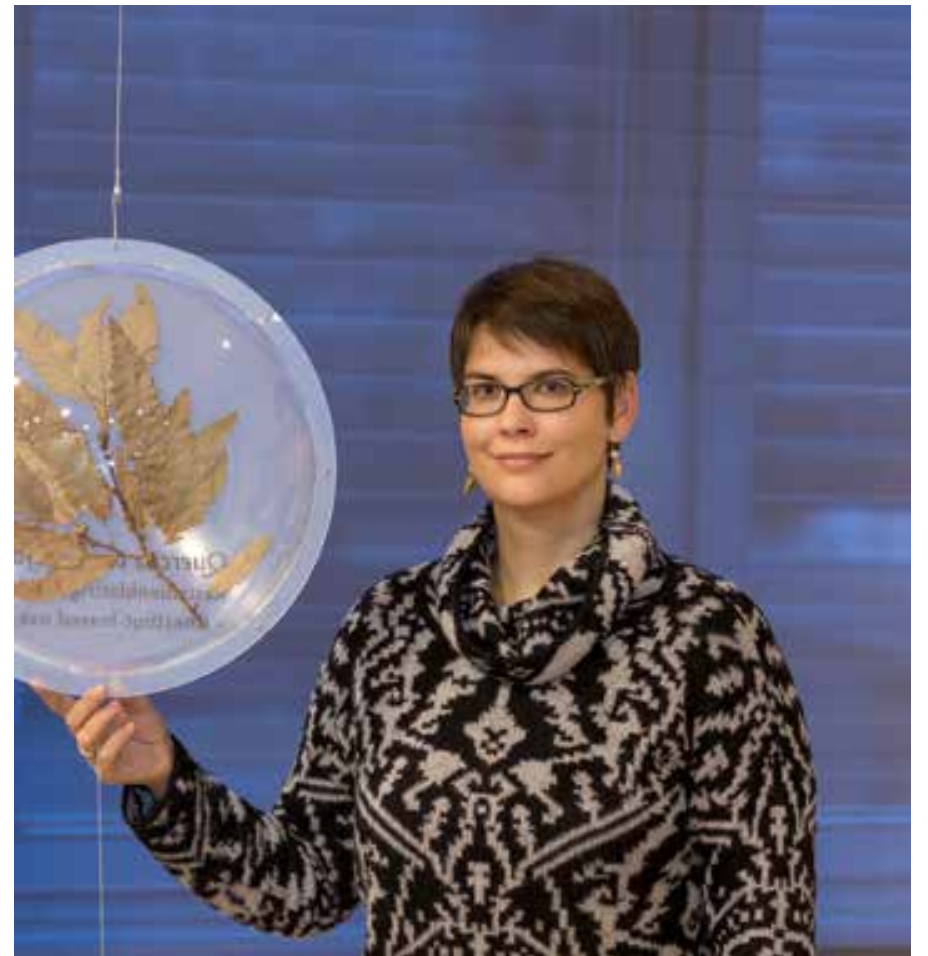

Kathrin Grotz leitet seit 2010 den Bereich Ausstellungen/Museum am BGBM. Zu ihren Aufgaben gehört neben der Konzeption und Organisation von Ausstellungen auch die Betreuung der einzigartigen Sammlung von Pflanzenmodellen. Als studierte Historikerin legt sie den Fokus in den von ihr betreuten Ausstellungsprojekten immer wieder auch auf Themen aus der Wissenschafts- und Institutionengeschichte. Ihr Forschungsinteresse gilt darüber hinaus der kulturhistorischen Bedeutung von Pflanzen, der Entstehung botanischer Sammlungen sowie der Rolle von Modellen in der Biologiedidaktik. 


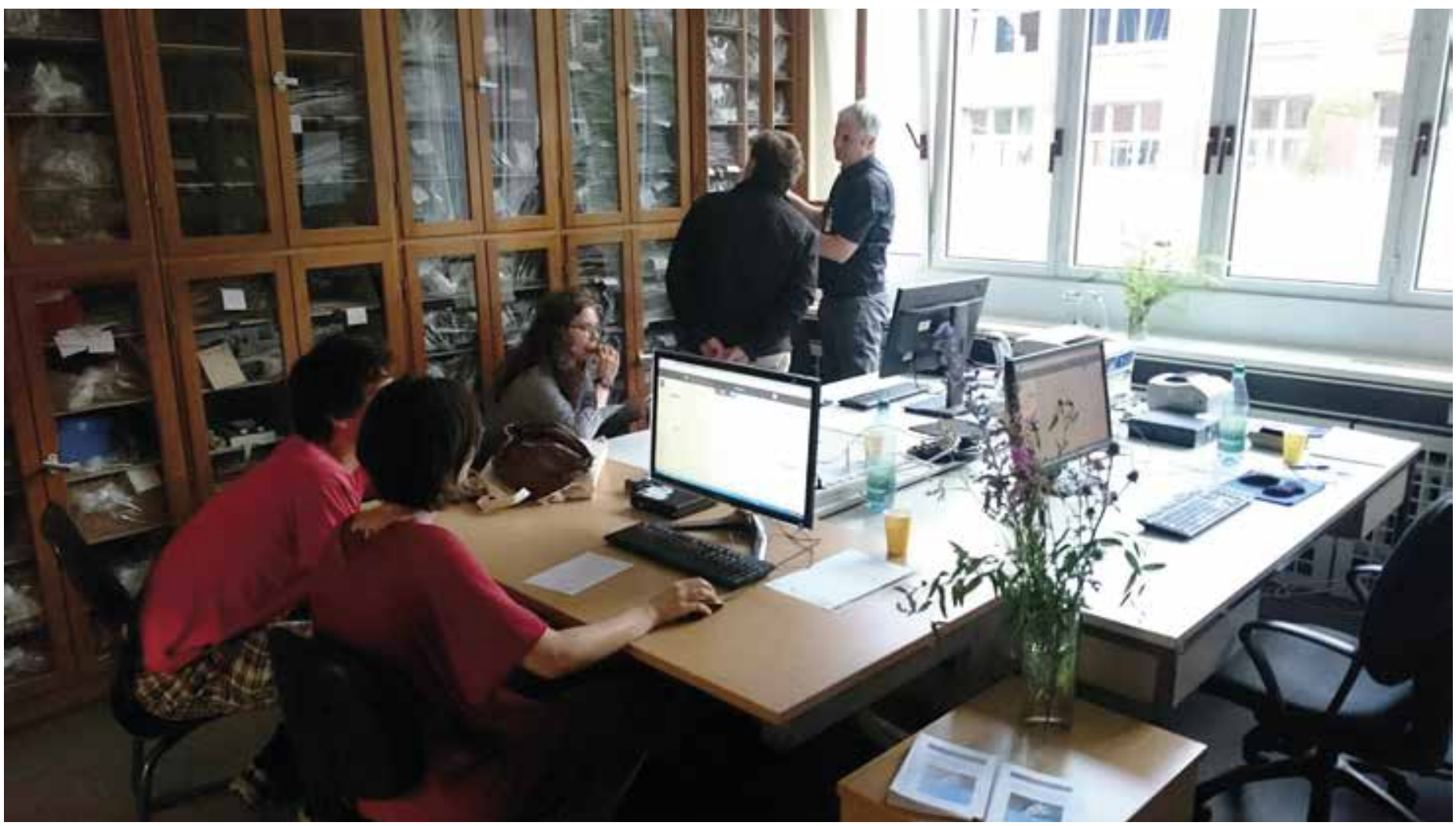

Herbonauten-Workshop bei der Langen Nacht der Wissenschaften 2017.

\section{Wissenschaft zum Mitmachen Bei Citizen-Science-Projekten können alle Interessierten die Forschungsarbeit des BGBM}

unterstützen
Der Mann war Arzt. Hätte man sich denken können. Denn seine Handschrift erfüllt in Sachen Unleserlichkeit alle gängigen Klischees. Da hatte August Leopold von Reuss vor 150 Jahren sorgsam Pflanzen gesammelt und gepresst, auf Papierbögen geklebt und beschriftet. Den heutigen Wissenschaftlerinnen und Wissenschaftlern am BGBM hat er damit ein wertvolles Erbe hinterlassen, das sie für ihre eigene Arbeit nutzen können. Doch dazu muss es ihnen erst einmal gelingen, die schwungvoll verschnörkelten Wörter zu entziffern. Das aber ist oft gar nicht so einfach. Und es kostet viel Zeit.

Das gleiche Problem gibt es auch bei vielen anderen gepressten Pflanzen, die am BGBM aufbewahrt werden. Die riesige Sammlung umfasst insgesamt rund 3,8 Millionen Bögen, auf deren Etiketten der Name der Art und des Sammlers, der Fundort und etliche andere Angaben stehen. Um diese wichtigen Informationen für die Beantwortung vielfältiger Forschungsfragen richtig nutzen zu können, müssen sie in eine Datenbank eingegeben werden - eine Mammutaufgabe, die das BGBM-Team niemals allein bewältigen könnte. Doch im Bürgerforschungsprojekt Herbonauten haben sich bis dato rund 500 engagierte Mitstreiterinnen und Mitstreiter gefunden, die eingescannte Herbar-Belege zu verschiedenen Themen bearbeiten. Virtuell sind sie zum Beispiel schon auf den Spuren Alexander von Humboldts durch Südamerika gereist, haben sich mit Moosen beschäftigt oder sind in die Welt der fleischfressenden Pflanzen eingetaucht. 


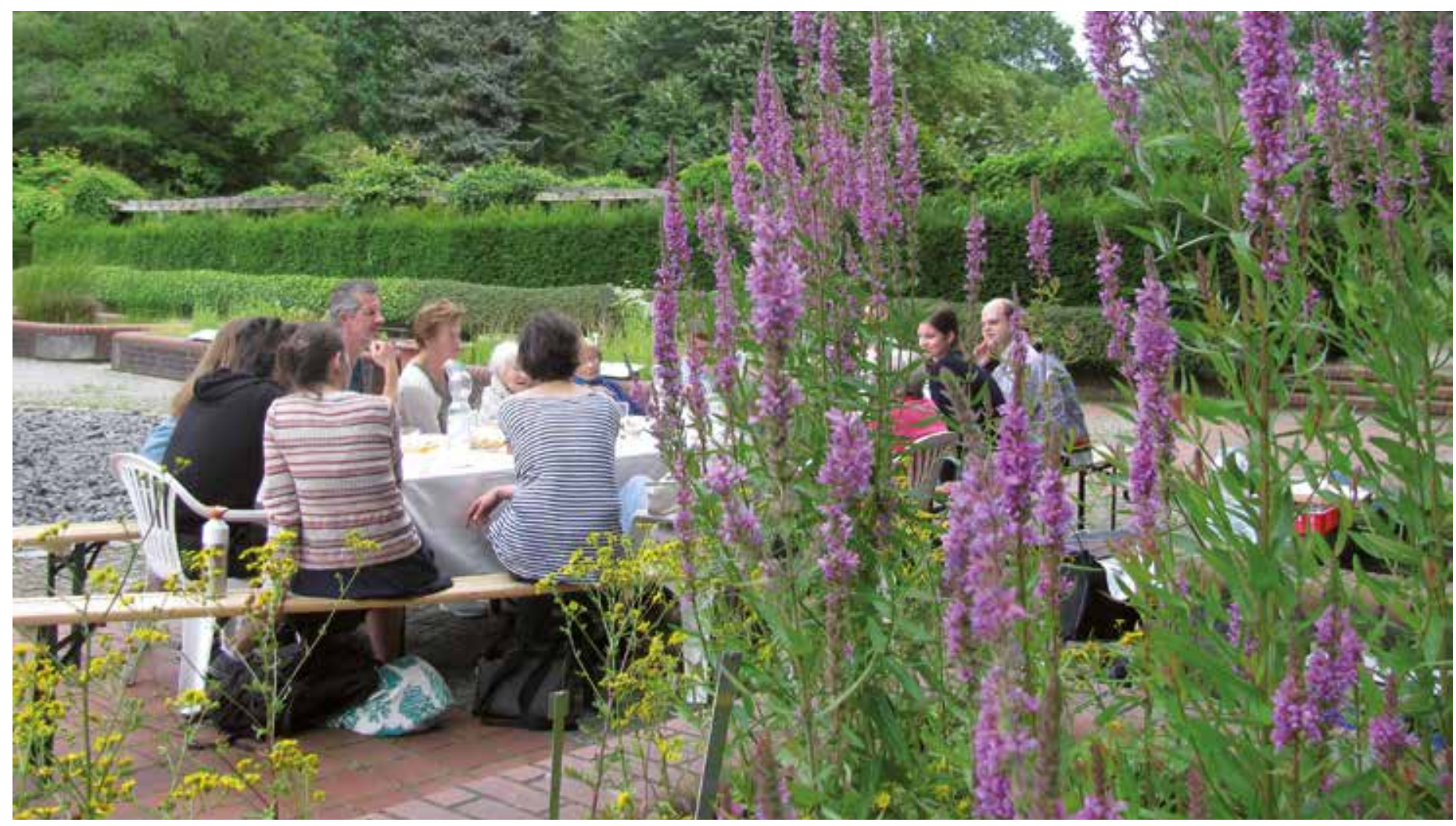

Im Juni 2018 versammelten sich zum Erzählpicknick im Wasserpflanzengarten drei Generationen um einen Tisch.

„Die Idee für dieses Projekt stammt ursprünglich vom Naturkundemuseum in Paris“, sagt Biodiversitätsinformatiker Anton Güntsch, der die Herbonauten am BGBM initiiert hat. „Ich hatte mir erst nicht allzu viel davon versprochen, aber jetzt sind wir begeistert über den Erfolg." Denn sehr rasch fanden sich Interessierte, die sich nun mit geradezu detektivischem Ehrgeiz in die Recherche stürzen, alte Schriften entziffern und zum Beispiel kryptische oder veraltete Ortsangaben in aktuelle GPS-Koordinaten übersetzen.

BGBM-Projektleiterin Agnes Kirchhoff ist beeindruckt vom Engagement, das die Herbonauten dabei an den Tag legen: „Die Leute lesen Tagebücher von Sammlern aus dem 19. Jahrhundert, diskutieren per Internet über mögliche Fundorte und geben sich Tipps zum Entziffern schwer lesbarer Schriften“, sagt die Wissenschaftlerin. In ihren Augen haben die auch unter dem Schlagwort Citizen Science bekannten Bürgerforschungsprojekte ein riesiges Potential. Und diesen Schatz will der BGBM künftig auch bei anderen Forschungsvorhaben nutzen. „Dabei wollen wir den Leuten nicht einseitig vorgeben, was sie machen sollen“, erklärt Agnes Kirchhoff. „Sie können durchaus auch eigene Ideen und Forschungsfragen beisteuern."

Bei einem EU-Projekt namens BigPicnic, das vom internationalen Verband der Botanischen Gärten (BGCl) koordiniert wurde, ist dieser Ansatz schon zum Tragen gekommen. Zusammen mit Fachleuten von Botanischen Gärten und anderen Institutionen haben Bürgerinnen und Bürger in verschiedenen Ländern sich mit dem Thema Ernährungssicherheit beschäftigt. Ziel des dreijährigen Projekts war es, einer breiteren Öffentlichkeit die Bedeutung von Nahrungssicherheit für die Zukunft der Gesellschaft näher zu bringen. Dafür haben so genannte Co-Creation-Teams Formate entwickelt. Am BGBM wurde zum Beispiel ein mobiles Stopp-Motion Filmstudio entwickelt, das Schulklassen ausleihen können. In der Ausleihe enthalten ist auch ein Lastenfahrrad, mit dem man das Studio ganz ökologisch durch die Stadt transportieren kann. Mit den darin enthaltenen Tablets, Stativen und Informationsmaterialien können Trickfilme zum Thema Lebensmittelverschwendung gedreht werden. Einzige Bedingung: Die Filme sollen einer größeren Öffentlichkeit via Youtube-Kanal zu Verfügung gestellt werden.

Zudem hat der BGBM im Rahmen von BigPicnic Science Cafés veranstaltet, bei denen es zum Beispiel um das Haltbarmachen von Lebensmitteln ging. Und beim Erzählpicknick im Wasserpflanzengarten berichteten Zeitzeuginnen über die Hungerjahre der Nachkriegszeit und erfuhren im Gegenzug, welche Ernährungs-Fragen die jüngeren Generationen umtreiben. So trafen auch beim BigPicnic die unterschiedlichsten Perspektiven zusammen. Und genau das ist es, was Bürgerforschungsprojekte so spannend macht. 


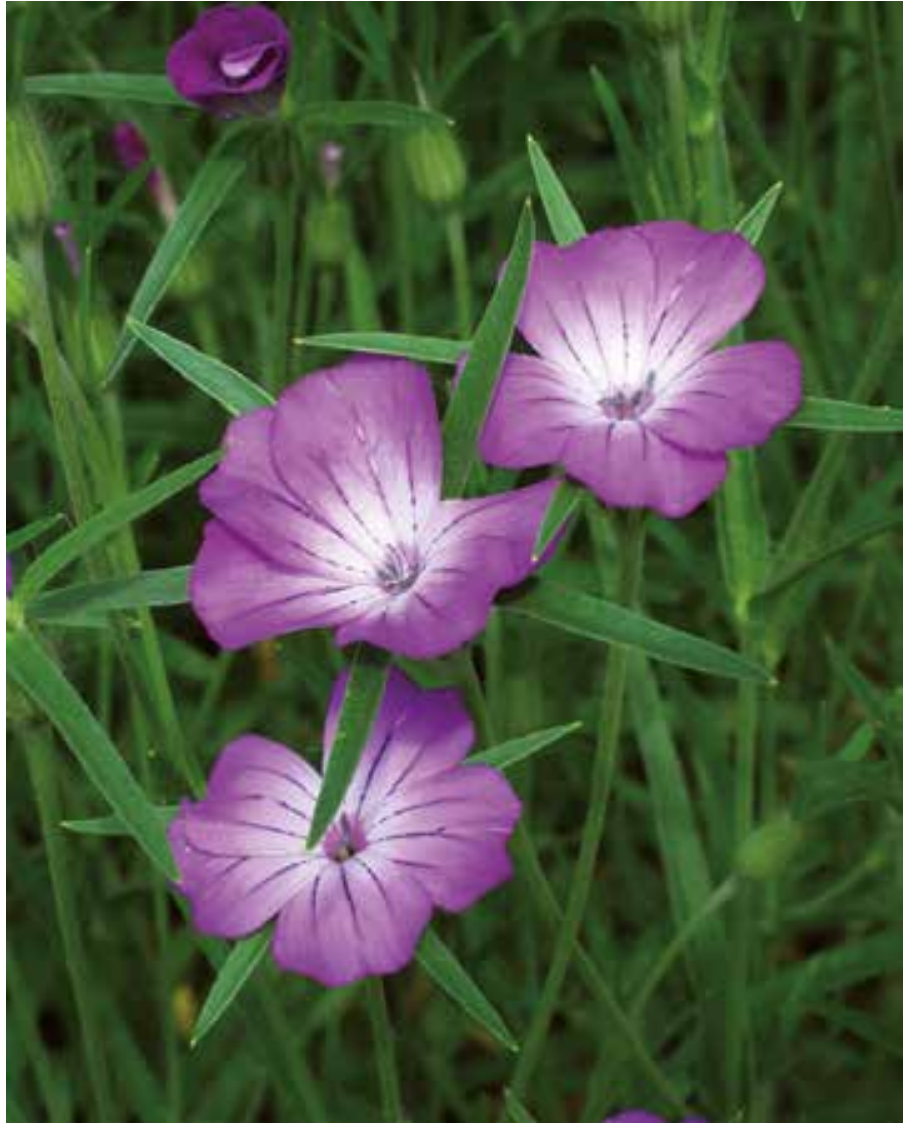

Bis in die 1960er Jahre war die Kornrade (Agrostemma githago) ein weit verbreitetes Wildkraut. Heute ist sie vom Aussterben bedroht und steht auf der Roten Liste der gefährdeten Pflanzen Deutschlands. Um auf den wichtigen Beitrag Botanischer Gärten zum Erhalt von weltweit gefährdeten Wildpflanzen aufmerksam zu machen, wurde die Kornrade als Signet des Vereins gewählt.

\section{Im Zeichen der Kornrade Der Verein der Freunde des BGBM feierte 2017 sein 30-jähriges Bestehen}

Ausgerechnet die Kornrade! Dass dieses anspruchslose Nelkengewächs mit den purpurnen Blüten einmal auf der Roten Liste der bedrohten Arten landen könnte, hätte noch Mitte des 20. Jahrhunderts wohl kaum jemand gedacht. Denn damals wuchsen die bis zu einen Meter hohen Pflanzen noch auf zahllosen Getreidefeldern. Ihre Samen landeten beim Dreschen zwischen dem Korn und wurden so Jahr für Jahr wieder mit ausgesät. Bis die moderne Saatgutreinigung dem ein Ende machte und die Bestände der Kornrade immer weiter schrumpften.

Mittlerweile gilt die Pflanze als vom Aussterben bedroht. Und sie ist zu einem Symbol geworden - nicht nur für die Bedrohung der biologischen Vielfalt durch die moderne Landnutzung, sondern auch für den Wunsch, etwas gegen den galoppierenden Artenschwund zu unternehmen. Genau das ist eines der Ziele des gemeinnützigen Vereins der Freunde des Botanischen Gartens und Botanischen Museums Berlin e.V., der am 6. April 2017 sein 30-jähriges Jubiläum feierte. Die Kornrade in seinem Logo soll deutlich machen, wie wichtig Botanische Gärten für den Erhalt von gefährdeten Pflanzenarten sind.

Für diese Idee hat der Verein seit seiner Gründung immer mehr Menschen gewonnen. Bestand er 1987 aus gerade einmal elf begeisterten Pflanzenfans, war die Zahl der Mitglieder 30 Jahre später schon auf 795 gestiegen. Mit ihren Beiträgen und Spenden unterstützen diese 


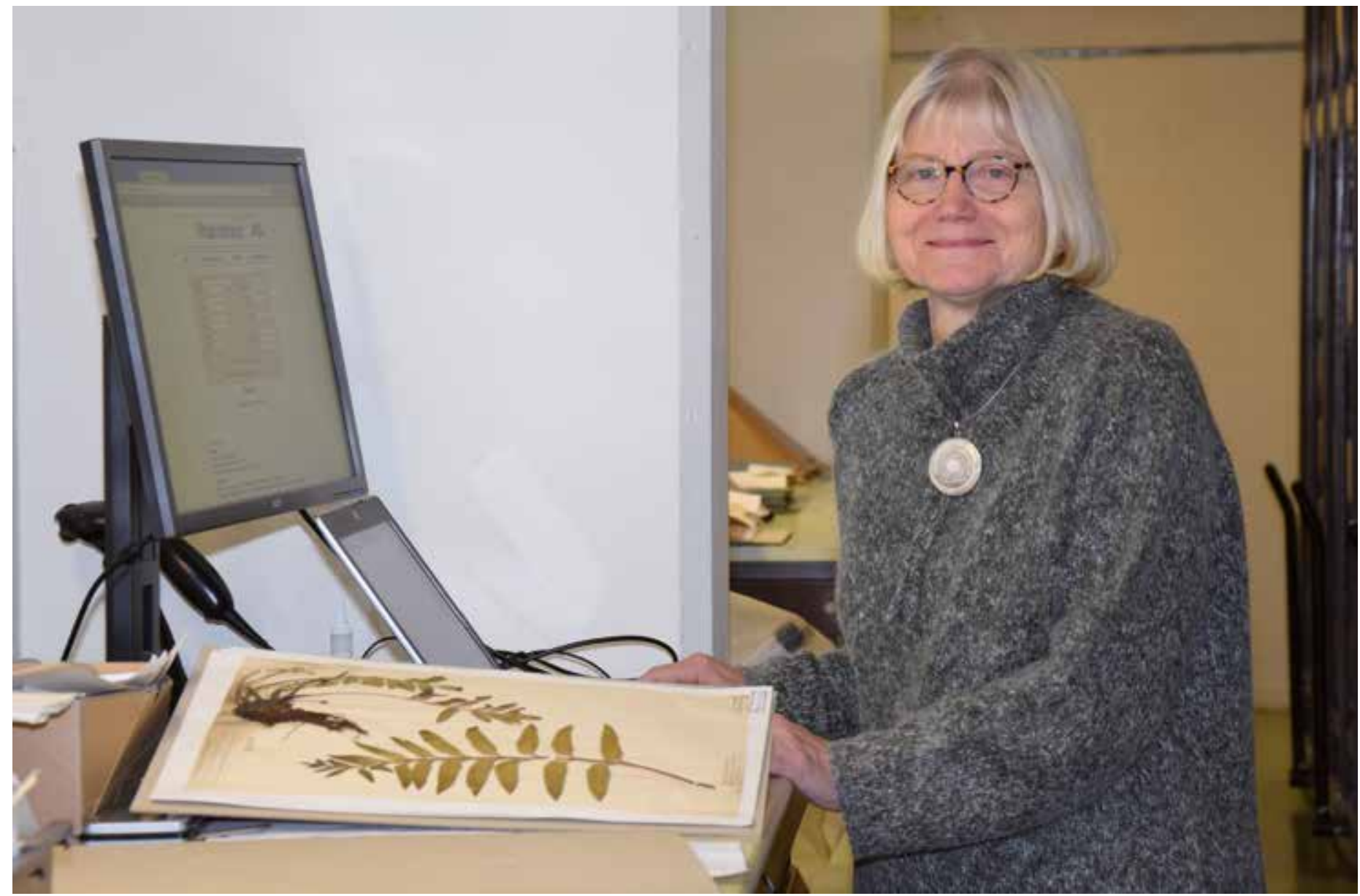

die Arbeit des BGBM. Jedes Jahr fließen zwischen 50.000 und 90.000 Euro in wissenschaftliche Projekte, in Forschungs- und Sammelreisen und in die Kooperationen mit Partnern auf Kuba und in anderen Teilen der Welt. Auch die Digitalisierung von historischen Sammlungen und das Vermitteln von botanischem Wissen liegen dem Verein am Herzen. So hat er beispielsweise das Besucherinformationssystem im Großen Tropenhaus finanziert.

Viele erfolgreiche Projekte des BGBM wären ohne die Unterstützung seiner Freunde und Förderer gar nicht möglich gewesen. Zumal sich einige von ihnen nicht nur finanziell, sondern auch persönlich engagieren und ehrenamtlich mitarbeiten. Da man aber nie genug Freundinnen und Freunde haben kann, sind weitere Mitglieder jederzeit willkommen. Zum Jubiläum gab es daher auch eine kleine Werbemaßnahme in eigener Sache: Um Besucherinnen und Besucher auf sich aufmerksam zu machen, hat der Verein 2017 eine Informationstafel am Italienischen Garten vor den Schaugewächshäusern aufgestellt. Daneben wiegten sich auf einem kleinen Beet auch Kornraden im Wind. Ein lebendiges Beispiel für Pflanzen, die schon in der Jungsteinzeit nach Mitteleuropa gekommen sind - und die ohne Unterstützung wohl keine Zukunft haben werden.
Prof. a.D. Dr. Brigitte Zimmer ist Spezialistin für Farne und arbeitet schon seit 1982 in verschiedenen Funktionen am BGBM. Von 1998 bis 2006 war sie Leiterin einer Abteilung Herbarsammlungen und Öffentlichkeitsarbeit. Seither arbeitet sie als ehrenamtliche Wissenschaftlerin am BGBM und betreut das Farnherbarium. Das Farnherbarium hat den Zweiten Weltkrieg unbeschadet überstanden und ist eine der wichtigsten Sammlungen von Farnpflanzen weltweit mit einer hohen Zahl von Typen (Referenzbelegen für wissenschaftliche Pflanzennamen). Seit 2007 ist sie zudem Vorsitzende des Vereins der Freunde des Botanischen Gartens und Botanischen Museums Berlin e.V., in dem sie seit 1991 Mitglied ist. 


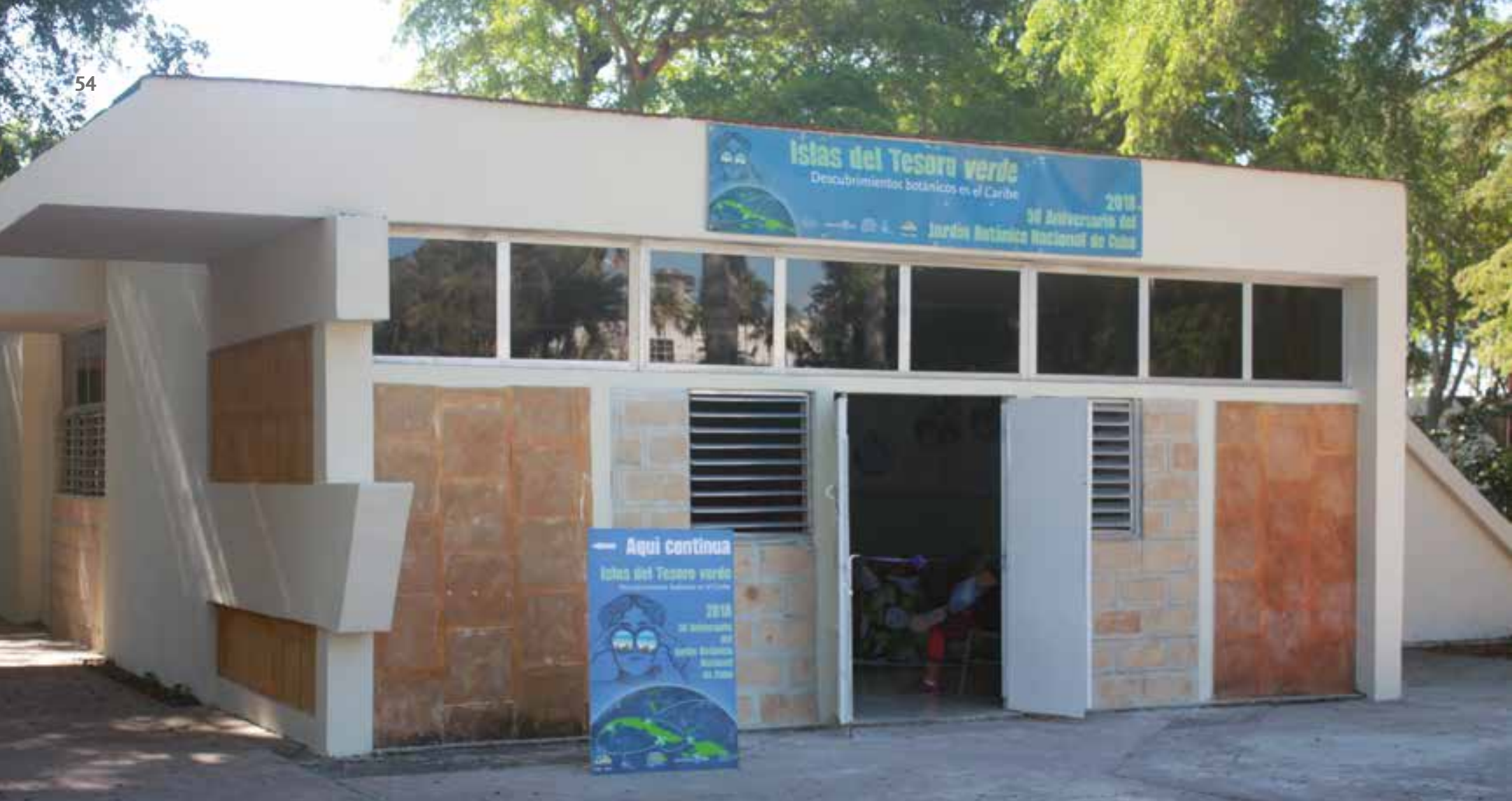

Die Ausstellung „Grüne Schatzinseln“ wird im Botanischen Garten von Havanna gezeigt.

\section{Grüne Schatzinseln in Havanna}

Eine Ausstellung rechtzeitig zum Eröffnungstermin fertig zu bekommen, kann eine nervenaufreibende Sache sein. Zum 50. Jubiläum des Botanischen Gartens von Havanna sollte in Kuba die Ausstellung „Grüne Schatzinseln“ eröffnen, die am BGBM schon mit großem Erfolg gelaufen war. Sie präsentiert die gemeinsamen Aktivitäten beider Institutionen, die Pflanzenwelt der Karibik zu erforschen. Die Flora von Kuba ist dabei ein zentrales Produkt dieser Zusammenarbeit, aber auch Erkenntnisse darüber, woher die Vorfahren der vielen endemischen und nur in Kuba gedeihenden Arten kamen, als sie vor mehreren Millionen Jahren die Insel besiedelten. Die Geschichten aus Jahrzehnten einer fruchtbaren Kooperation zwischen kubanischen und deutschen Botanikern geben dabei auch Einblicke in die Geschichte der Botanischen Gärten in Havanna und Berlin. Was lag also näher, als sie in einer spanisch-englischen Version auch vor Ort zu zeigen?

Gefördert durch den Verein der Freunde wurden die zentralen Elemente der Ausstellung per Container nach Kuba verschifft und weitere Materialien beschafft. In Havanna musste der Aufbau dann in knapper Zeit geschafft werden. Doch da sich alle Beteiligten Tag und Nacht in die Arbeit stürzten, gab es ein Happy End - mit ausgelassener Eröffnungsfeier.

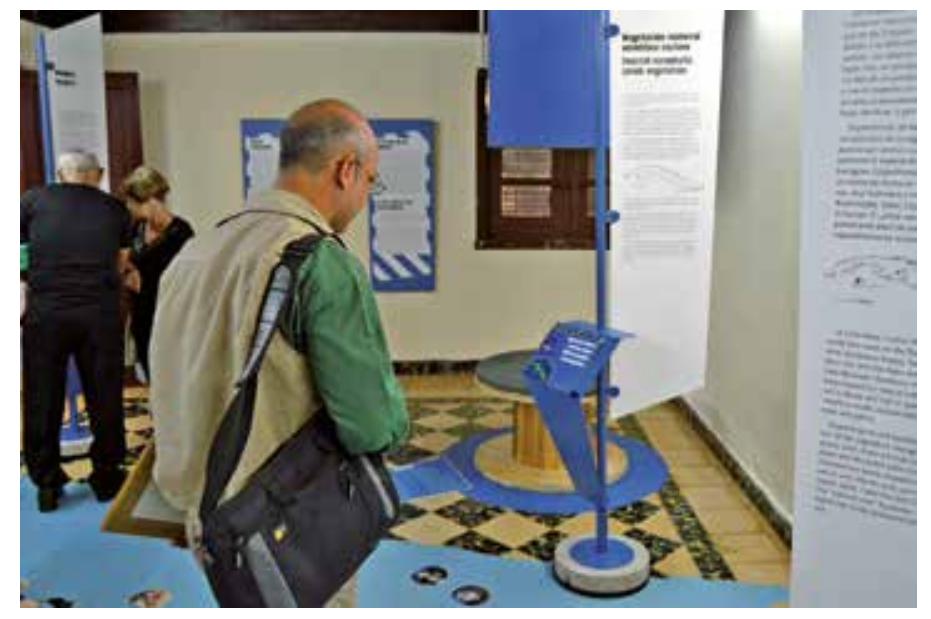

Blick in die Gemeinschaftsausstellung „Grüne Schatzinseln“ im Botanischen Garten von Havanna. 


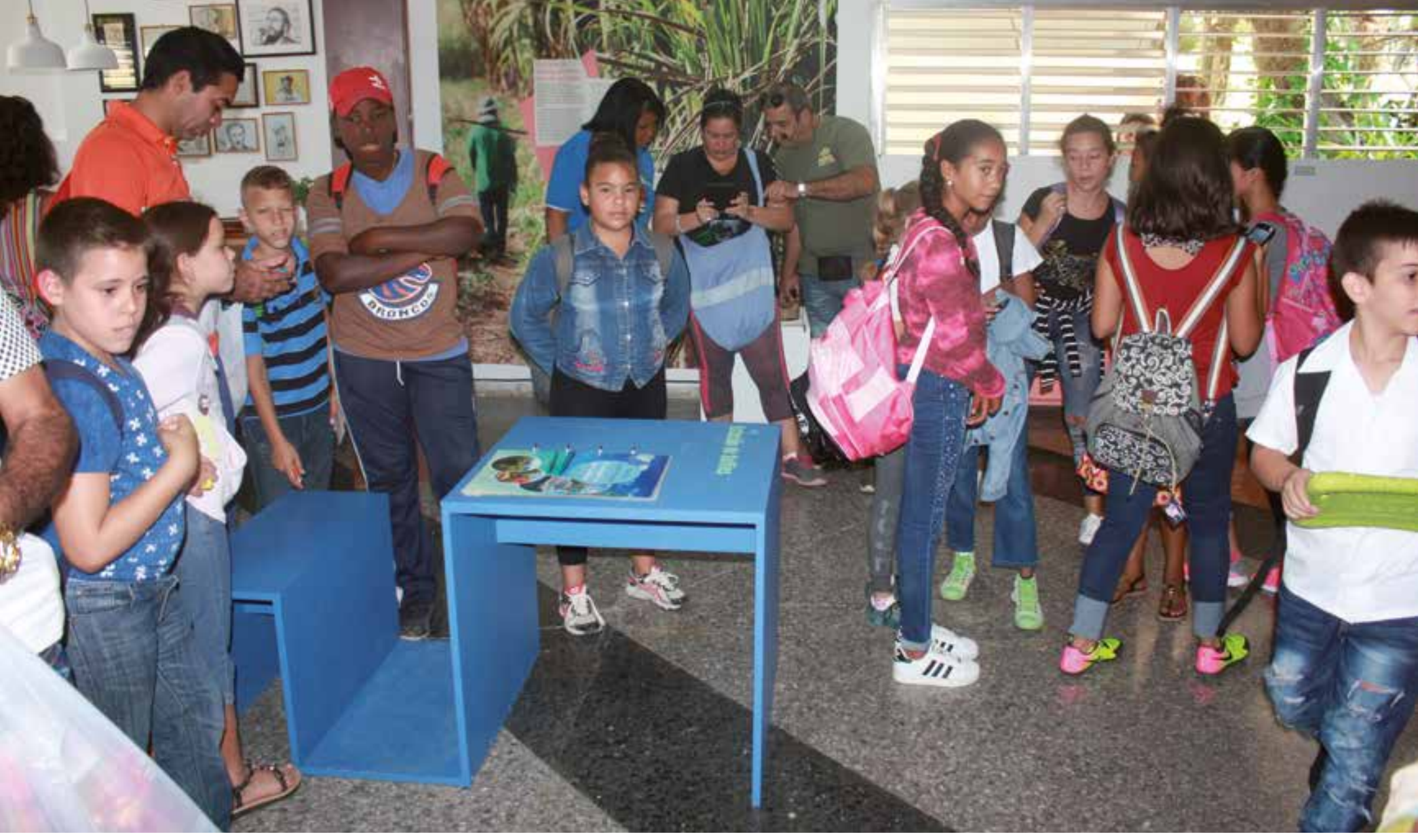

Die Ausstellung findet großen Anklang bei Kindern und Jugendlichen.

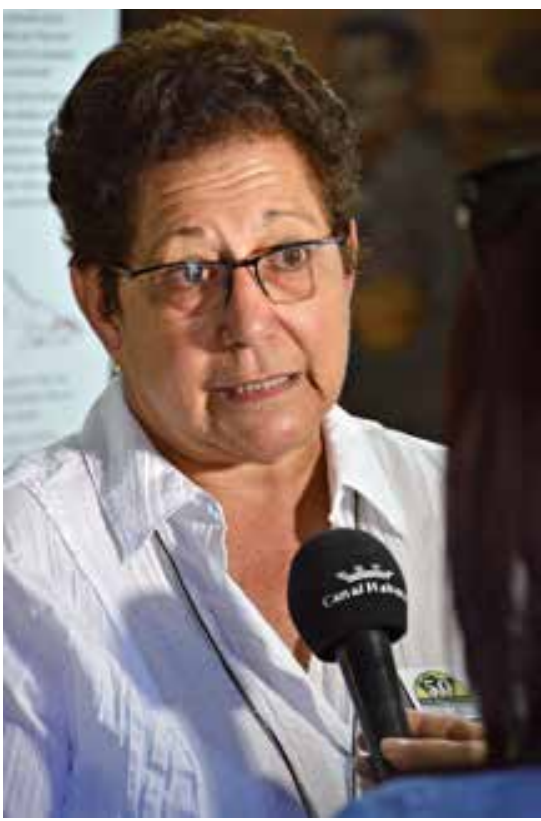

Dra. Rosa Rankin Rodríguez, Botanischer Garten, Havanna berichtet über die Ausstellung.

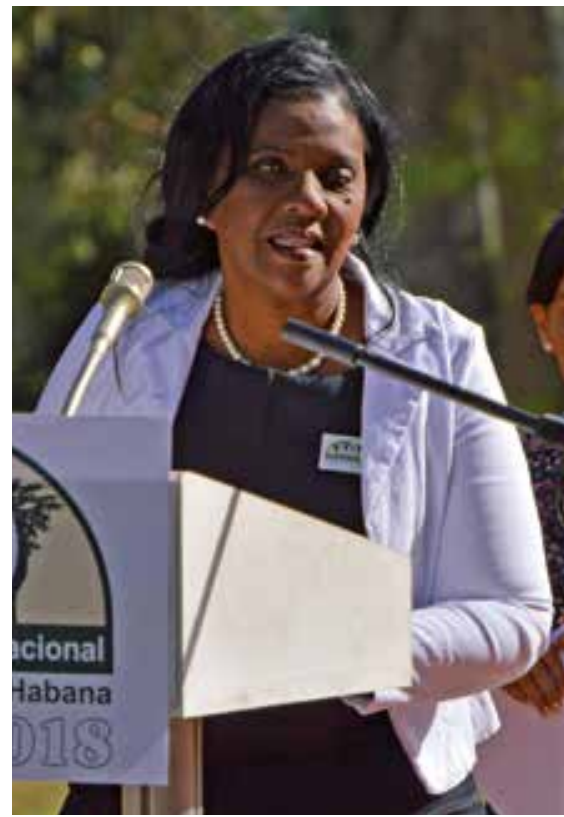

Rede von Nora Hernández Monterrey, Direktorin des Nationalen Botanischen Gartens, Havanna, anlässlich des 50-jährigen Jubiläums.

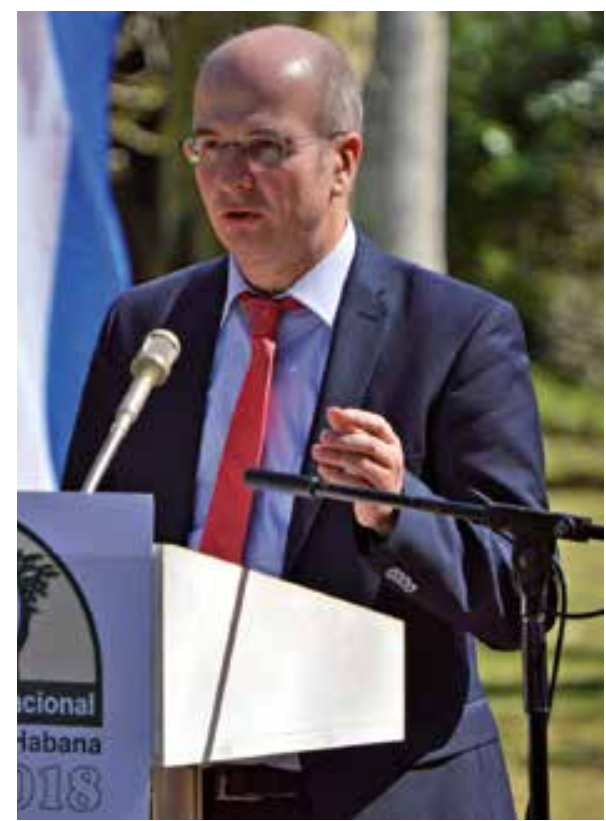

Professor Dr. Thomas Borsch übermittelt die Glückwünsche des Botanischen Gartens und Botanischen Museums Berlin. 


\section{Organisation}

Organigramm Zentraleinrichtung Botanischer Garten und Botanisches Museum Berlin der Freien Universität Berlin

\section{Direktor}

Stabsstelle

Wissenschaftskoordination
Stabsstelle

Öffentlichkeitsarbeit \& Marketing

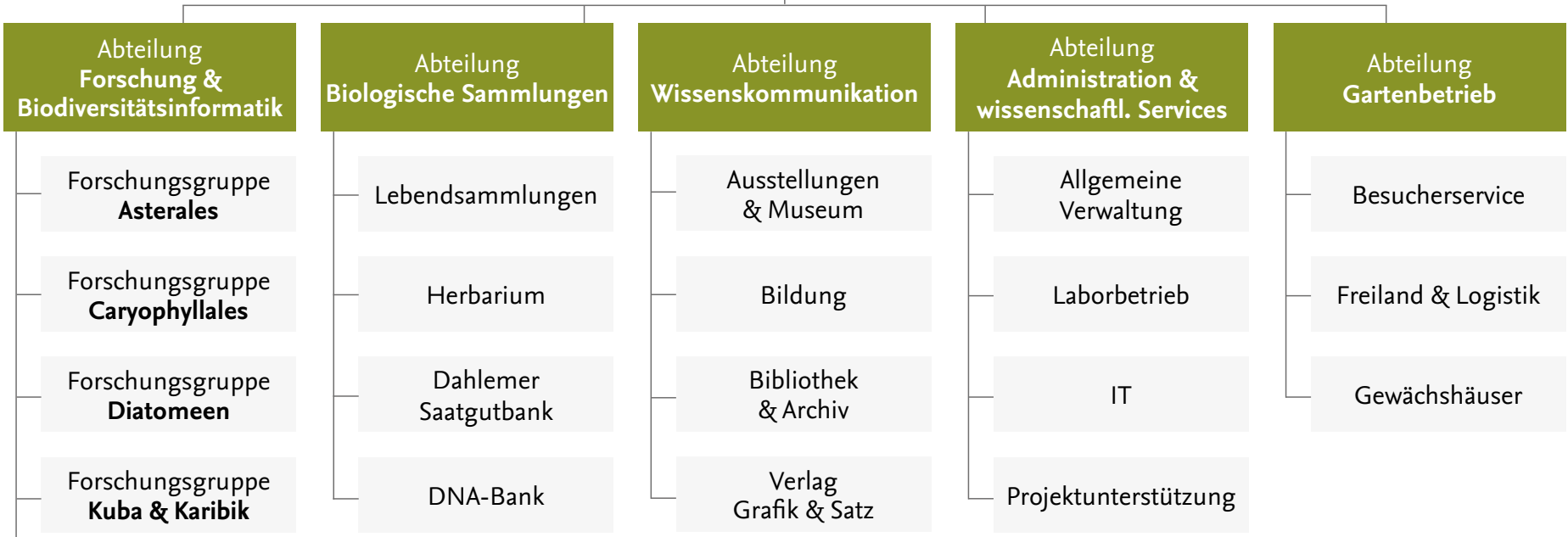

Forschungsgruppe Europa \& Mittelmeergebiet

F\&E-Gruppe Biodiversitätsinformatik \& wissenschaftliche Informationssysteme
Das vorliegende Organigramm wurde zum 1. Januar 2018 mit der Integration des Gemeinschaftsbetriebs Garten in die neu geschaffene Abteilung Gartenbetrieb der Zentraleinrichtung Botanischer Garten und Botanische Museum wirksam.

Der Bereich IT in der Abteilung Administration und wissenschaftliche Services wurde zum 1. Juni 2019 in die Zentraleinrichtung Datenverarbeitung (ZEDAT) überführt. 


\section{Zahlen \& Fakten}

\begin{tabular}{|lccc|}
\hline Personal & 2017 & 2018 & 2019 \\
\hline Beschäftigte gesamt & 165 & 218 & 213 \\
\hline Wissenschaftliches Personal & 46 & 50 & 42 \\
\hline sonstiges Personal & 99 & 151 & 156 \\
\hline studentische Hilfskräfte & 20 & 17 & 10 \\
\hline Auszubildende* & 7 & 10 & 3 \\
\hline Freiwilliges Ökologisches Jahr* & 2 & 3 & \\
* nicht in Anzahl Beschäftigte enthalten & & &
\end{tabular}

$\begin{array}{lccc} & 2017 & 2018 & 2019 \\ \text { national } & 99 & 90 & 33 \\ \text { international } & 63 & 80 & 85 \\ \text { * inkl. wissenschaftliche Gäste im Herbarium } & & \end{array}$

2017-2019

national

international

\section{2}

9
Personal

2017-2019
Gastwissenschaftlerinnen und Gastwissenschaftler*

2017-2019
Doktorandinnen und Doktoranden

2017-2019 


\section{Assoziierte und ehrenamtliche Wissenschaft- lerinnen und Wissenschaftler 2017-2019}

\section{Ehrenamtliche}

2017-2019
Prof. Dr. Werner Greuter

Prof. Dr. Hans-Walter Lack

Dr. Thomas Raus

Dr. Henricus Sipman
Dr. Brigitte Zimmer (Prof. a.D.)

Prof. Dr. Arne Strid

Dr. Neela Enke

Prof. Dr. Eckhard Willing
Peter Hirsch

Michael Ristow

Dr. Regine Jahn

Evelin Bartels; Barbara Bartz; Lotte Burkhardt; Sonja-Maria Czérkus-Yavuz; Anne Döpfner; Regina Ehrich; Christian Feldt; Detlef Gustke; Anette Höner; Margit Jaroschewski; Margit Keipke; Hartmut Krebs; Marianne Kubicki; Erich Liebert; Gerhard Neumann; Regina Ostrower; Tjalda Picksak-Schmidt; Gudrun Scharte; Cora-Beate Schaumann; Birgit Schubert; Michael Schubert; Monika Senge; Regina Stark; Tom Stawowy; Dietmar Weinert.

Aufgrund von Datenschutzbestimmungen dürfen hier nur Ehrenamtliche namentlich genannt werden, die hierzu explizit eingewilligt haben. Der BGBM wird von zahlreichen Ehrenamtlichen unterstützt, die hier nicht genannt sind, ihnen allen gebührt großer Dank für ihr Engagement. 


\section{Artikel in begutachteten Zeitschriften}

Acuña R., Fließwasser S., Markus A., Henning T., Luebert F. \& Weigend M. 2017: Phylogenetic relationships and generic re-arrangements in "South Andean Loasas" (Loasaceae). - Taxon 66: 365-378.

Berendsohn W. G., Müller A., Kohlbecker A., Güntsch A., Luther K. \& Plitzner P. 2017: The CDM applied: handling of names, taxa and concepts in a conservation context. - Biodiversity Information Science and Standards 1: e20364.

Bingham H. C., Doudin M., Weatherdon L. V., Despot-Belmonte K., Wetzel F., Groom Q., Lewis E., Regan E., Appeltans W., Güntsch A., Mergen P., Agosti D., Penev L., Hoffmann A., Saarenmaa H., Geller G., Kim K., Kim H., Archambeau A.-S., Häuser C., Schmeller D. S., Geijzendorffer I., García Camacho A., Guerra C., Robertson T., Runnel V., Valland N. \& Martin C. S. 2017: The biodiversity informatics landscape: elements, connections and opportunities. - Research Ideas and Outcomes 3: e14059.

Borchhardt N., Schiefelbein U., Abarca N., Boy J., Mikhailyuk T., Sipman H. J. M. \& Karsten U. 2017: Diversity of algae and lichens in biological soil crusts of Ardley and King George islands, Antarctica. - Antarctic Science 29: 229-237.

Broeck D., Lücking R., Gaya E., Chaves J. L., Lejju J. B. \& Ertz D. 2017: Heterocyphelium leucampyx (Arthoniales, Ascomycota): another orphaned mazaediate lichen finds its way home. - The Lichenologist 49: 333-345.

Buaruang K., Boonpragob K., Mongkolsuk P., Sangvichien E., Vongshewarat K., Polyiam W., Rangsiruji A., Saipunkaew W., Naksuwankul K., Kalb J., Parnmen S., Kraichak E., Phraphuchamnong P., Meesim S., Luangsuphabool T., Nirongbut P., Poengsungnoen V., Duangphui N., Sodamuk M., Phokaeo S., Molsil M., Aptroot A., Kalb K., Lücking R. \& Lumbsch T. 2017: A new checklist of lichenized fungi occurring in Thailand. - MycoKeys 23: 1-91.

Cáceres M. E. S., Aptroot A. \& Lücking R. 2017: Lichen fungi in the Atlantic rain forest of Northeast Brazil: the relationship of species richness with habitat diversity and conservation status. - Brazilian Journal of Botany 40: 145-156.

Cáceres M. E. S., Aptroot A., Mendonça C. d. O., Santos L. A. d. \& Lücking R. 2017: Sprucidea, a further new genus of rain forest lichens in the family Malmideaceae (Ascomycota). - The Bryologist 120: 202-211.

Callmander M. W., Durbin O. D., Lack H. W., Bungener P., Martin P. \& Gautier L. 2017: Etienne-Pierre Ventenat (1757-1808) and the gardens of Cels and Empress Joséphine. - Candollea 72: 87-132.

Cocquyt C., Taylor J. C. \& Kusber W.-H. 2017: Reinvestigation of African Surirella taxa (Bacillariophyta) described by B. J. Cholnoky with some remarks on digitization of diatom types. - Fottea 17: 34-56.

Dal Forno M., Bungartz F., Yánez-Ayabaca A., Lücking R. \& Lawrey J. D. 2017: High levels of endemism among Galapagos basidiolichens. - Fungal Diversity 85: 45-73.

Dal-Forno M., Lücking R., Bungartz F., Yánez-Ayabaca A., Marcelli M. P., Spielmann A. A., Coca L. F., Chaves J. L., Aptroot A., Sipman H. J. M., Sikaroodi M., Gillevet P. \& Lawrey J. D. 2017: From one to six: unrecognized species diversity in the genus Acantholichen (lichenized Basidiomycota: Hygrophoraceae). - Mycologia 108: 38-55.

Dantas J. O., Alves E. S., Lücking R. \& Cáceres M. E. S. 2017: Three new species of Graphidaceae (lichenized Ascomycota) from the semi-arid region of northeast Brazil. - Phytotaxa 331: 289-294.

Diederich P., Lücking R., Aptroot A., Sipman H. J. M., Braun U., Ahti T. \& Ertz D. 2017: New species and new records of lichens and lichenicolous fungi from the Seychelles. - Herzogia 30: 182-236.

Domina G., Greuter W. \& Raimondo F. M. 2017: A taxonomic reassessment of the Centaurea busambarensis complex (Compositae, Cardueae), with description of a new species from the Egadi Islands (W Sicily). - Israel Journal of Plant Sciences 64: 48-56.

Doostmohammadi M. \& Kilian N. 2017: Lactuca pumila (Asteraceae, Cichorieae) revisited: additional evidence for a phytogeographical link between SE Zagros and Hindu Kush. - Phytotaxa 307: 133-140.

Duwe V., Muller L. A. H., Borsch T. \& Ismail S. A. 2017: Pervasive genetic differentiation among Centra European populations of the threatened Arnica montana L. and genetic erosion at lower elevations. - Perspectives in Plant Ecology, Evolution and Systematics 27: $45-56$.

Fichtmueller D., Gleisberg M., Karam N., MüllerBirn C., \& Güntsch A. 2017: Terminologies as a neglected part of research data: Making supplementary research data available through the GFBio Terminology Service. - In: Algergawy, A., Karam, N., Klan, F., Jonquet, C. (ed.), Proceedings of the 2nd International Workshop on Semantics for Biodiversity co-located with 16th International Semantic Web Conference (ISWC 2017), October 2017, Vienna, Austria. - CEUR Workshop Proceedings 1933.

Gasparyan A., Sipman H. J. M. \& Lücking R. 2017: Ramalina europaea and $R$. labiosorediata, two new species of the R. pollinaria group (Ascomycota: Ramalinaceae), and new typifications for Lichen pollinarius and L. squarrosus. - The Lichenologist 49: 301-319.

Gregor T., Hand R. \& Paule J. 2017: Chromosomenzahlen von Farn- und Samenpflanzen aus Deutschland 10. - Kochia 10: 45-53.
BGBMPublikationen 2017 
Groom Q., Hyam R. \& Güntsch A. 2017: Stable identifiers for collection specimens. - Nature 546: 33 .

Gruenstaeudl M., Nauheimer L. \& Borsch T. 2017: Plastid genome structure and phylogenomics of Nymphaeales: conserved gene order and new insights into relationships. - Plant Systematics and Evolution 303: 1251-1270.

Güntsch A., Berendsohn W. G., Müller A. \& Kohlbecker A. 2017: EDIT platform projects: what's next. - Biodiversity Information Science and Standards 1: e20365.

Güntsch A., Hyam R., Hagedorn G., Chagnoux S., Röpert D., Casino A., Droege G., Glöckler F., Gödderz K., Groom Q., Hoffmann J., Holleman A., Kempa M., Koivula H., Marhold K., Nicolson N., Smith V. S. \& Triebel D. 2017: Actionable, long-term stable and semantic web compatible identifiers for access to biological collection objects. - Database 2017: baxoo3.

Güntsch A., Kohlbecker A., Müller A., Berendsohn W. G., Luther K. \& Plitzner P. 2017: EDIT Platform web services in the biodiversity infrastructure landscape. - Biodiversity Information Science and Standards 1: e20363.

Haji Moniri M. \& Sipman H. J. M. 2017: New and noteworthy lichens from the semi-desert areas of North East Iran. - Iranian Journal of Botany 23: 140-144.

Hand R. 2017: Physospermum cornubiense in Cyprus reported in error. - Cypricola 2: 1-2.

Hand R. 2017: Some noteworthy records of flowering plants in Cyprus (1997-2016). - Cypricola 1: 1-8.

Hand R. \& Buttler K. P. 2017: Beiträge zur Fortschreibung der Florenliste Deutschlands (Pteridophyta, Spermatophyta) - neunte Folge. - Kochia 10: 55-72.

Hand R., Grossmann A. \& Lauterbach D. 2017: Endemics and their common congener plant species on an East Mediterranean island: a comparative functional trait approach. - Plant Ecology 218: 139-150.

Hand R. \& Niederbichler C. 2017: Oxyria digyna (L.) Hill - neu für das Karwendelgebirge. - Berichte der Bayerischen Botanischen Gesellschaft 87: 227.

Hyde K. D., Maharachchikumbura S. S. N., Hongsanan S., Samarakoon M. C., Lücking R., Pem D., Harishchandra D., Jeewon R., Zhao R.-L., Xu J.-C., Liu J.-K., Al-Sadi A. M., Bahkali A. H. \& Elgorban A. M. 2017: The ranking of fungi: a tribute to David L. Hawksworth on his 7oth birthday. - Fungal Diversity 84: 1-23.

Jahn R., Abarca N., Gemeinholzer B., Mora D., Skibbe O., Kulikovskiy M., Gusev E., Kusber W.-H. \& Zimmermann J. 2017: Planothidium lanceolatum and Planothidium frequentissimum reinvestigated with molecular methods and morphology: four new spe- cies and the taxonomic importance of the sinus and cavum. - Diatom Research 32: 75-107.

Jahn R., Kusber W.-H. \& Cocquyt C. 2017: Differentiating Iconella from Surirella (Bacillariophyceae): Typifying four Ehrenberg names and a preliminary checklist of the African taxa. - PhytoKeys 82: 73-112.

Jia Z.-F. \& Lücking R. 2017: Resolving the genus Phaeographina Müll. Arg. in China. - MycoKeys 21: 13-32.

Jia Z.-F. \& Lücking R. 2017: Resolving the species of the lichen genus Graphina Müll. Arg. in China, with some new combinations. - MycoKeys 25: 13-29.

Jones K. E., Korotkova N., Petersen J., Henning T., Borsch T. \& Kilian N. 2017: Dynamic diversification history with rate upshifts in Holarctic bell-flowers (Campanula and allies). - Cladistics 33: 637-666.

Kilian N., Galbany-Casals M., Sommerer R., Oberprieler C., Smissen R., Miller A. \& Rabe K. 2017: Systematics of Libinhania, a new endemic genus of Gnaphalieae (Asteraceae) from the Socotra archipelago (Yemen), inferred from plastid, low-copy nuclear and nuclear ribosomal DNA loci. - Botanical Journal of the Linnean Society 183: 373-412.

Kilian N., Hand R., Hadjikyriakou G. N., Christodoulou C. S. \& Bou Dagher-Kharrat M. 2017: Astartoseris (Cichorieae, Asteraceae), a new, systematically isolated monospecific genus accommodating Lactuca triquetra endemic to Lebanon and Cyprus. - Willdenowia 47: 115-125.

Kilian N., Sennikov A., Wang Z.-H., Gemeinholzer B. \& Zhang J.-W. 2017: Sub-Paratethyan origin and Middle to Late Miocene principal diversification of the Lactucinae (Compositae: Cichorieae) inferred from molecular phylogenetics, divergence-dating and biogeographic analysis. - Taxon 66: 675-703.

Knapp S., Turland N. J. \& Zhang L. 2017: Shenzhen nomenclature section. - Taxon 66: 1260-1261.

Kohlbecker A., Müller A., Berendsohn W., Güntsch A., Luther K. \& Plitzner P. 2017: The EDIT Platform for Cybertaxonomy, a brief overview. - Biodiversity Information Science and Standards 1: e20368.

Korotkova N., Borsch T. \& Arias S. 2017: A phylogenetic framework for the Hylocereeae (Cactaceae) and implications for the circumscription of the genera. Phytotaxa 327: 1-46.

Kretschmann J., Žerdoner Čalasan A., Kusber W.-H. \& Gottschling M. 2017: Still curling after all these years: Glenodinium apiculatum Ehrenb. (Peridiniales, Dinophyceae) repeatedly found at its type locality in Berlin (Germany). - Systematics and Biodiversity 16: 200-209.

Kusber W.-H., Cantonati M. \& Lange-Bertalot H. 2017: Validation of five diatom novelties published in "Freshwater benthic diatoms of Central Europe" and 
taxonomic treatment of the neglected species Tryblionella hantzschiana. - Phytotaxa 328: 90-94.

Kusber W.-H., Kohlbecker A., Güntsch A., Berendsohn W. G. \& Jahn R. 2017: Registration of names and types of algae by PhycoBank. - Phycologia 56 (Supplement): 110 .

Löffler F., Opasjumruskit K., Karam N., Fichtmüller D., Schindler U., Klan F., Müller-Birn C., \& Diepenbroek M. 2017: Honey bee versus Apis mellifera: a semantic search for biological data. - In: Blomqvist E., Hose K., Paulheim H., Ławrynowicz A., Ciravegna F., Hartig O. (ed.) The Semantic Web: ESWC 2017 Satellite Events. ESWC 2017. - Lecture Notes in Computer Science 10577.

Löffler F., Pfaff C.-T., Karam N., Fichtmüller D., Klan F. 2017: What do biodiversity scholars search for? Identifying high-level entities for biological metadata. - In: Algergawy, A., Karam, N., Klan, F., Jonquet, C. (ed.), Proceedings of the 2nd International Workshop on Semantics for Biodiversity co-located with 16th International Semantic Web Conference (ISWC 2017), October 2017, Vienna, Austria. - CEUR Workshop Proceedings 1933.

Lücking R., Dal Forno M., Moncada B., Coca L. F., Vargas-Mendoza L. Y., Aptroot A., Arias L. J., Besal B., Bungartz F., Cabrera-Amaya D. M., Cáceres M. E. S., Chaves J. L., Eliasaro S., Gutiérrez M. C., Hernández Marin J. E., Ángeles Herrera-Campos M. d. I., Holgado-Rojas M. E., Jonitz H., Kukwa M., Lucheta F., Madriñán S., Marcelli M. P., Azevedo Martins S. M. d., Mercado-Díaz J. A., Molina J. A., Morales E. A., Nelson P. R., Nugra F., Ortega F., Paredes T., Patiño A. L., Peláez-Pulido R. N., Pérez R. E. P., Perlmutter G. B., Rivas-Plata E., Robayo J., Rodríguez C., Simijaca D. F., Soto-Medina E., Spielmann A. A., Suárez-Corredor A., Torres J.-M., Vargas C. A., Yánez-Ayabaca A., Weerakoon G., Wilk K., Pacheco M. C., Diazgranados M., Brokamp G., Borsch T., Gillevet P. M., Sikaroodi M. \& Lawrey J. D. 2017: Turbo-taxonomy to assemble a megadiverse lichen genus: seventy new species of Cora (Basidiomycota: Agaricales: Hygrophoraceae), honouring David Leslie Hawksworth's seventieth birthday. - Fungal Diversity 84: 139-207.

Lücking R., Hodkinson B. P. \& Leavitt S. D. 2017: The 2016 classification of lichenized fungi in the Ascomycota and Basidiomycota - approaching one thousand genera. - The Bryologist 119: 361-416.

Lücking R., Hodkinson B. P. \& Leavitt S. D. 2017: Corrections and amendments to the 2016 classification of lichenized fungi in the Ascomycota and Basidiomycota. - The Bryologist 120: 58-69.

Lücking R. \& Moncada B. 2017: Dismantling Marchandiomphalina into Agonimia (Verrucariaceae) and Lawreymyces gen. nov. (Corticiaceae): setting a precedent to the formal recognition of thousands of voucherless fungi based on type sequences. - Fungal Diversity 84: 119-138.

Lücking R., Moncada B., McCune B., Farkas E., Goffinet B., Parker D., Chaves J. L., Lőkös L., Nelson P. R., Spribille T., Stenroos S., Wheeler T., YanezAyabaca A., Dillman K., Gockman O. T., Goward T., Hollinger J., Tripp E. A., Villella J., Álvaro-Alba W. R., Arango C. J., Cáceres M. E. S., Coca L. F., Printzen C. Rodríguez C., Scharnagl K., Rozzi R., Soto-Medina E. \&Yakovchenko L. S. 2017: Pseudocyphellaria crocata (Ascomycota: Lobariaceae) in the Americas is revealed to be thirteen species, and none of them is $P$. crocata. - The Bryologist 120: 441-500.

Lücking R., Moncada B. \& Smith C. W. 2017: The genus Lobariella (Ascomycota: Lobariaceae) in Hawaii: late colonization, high inferred endemism and three new species. - The Lichenologist 49: 673-691.

Lücking R., Thorn R. G., Saar I., Piercey-Normore M. D., Moncada B., Doering J., Mann H., Lebeuf R., Voitk M. \& Voitk A. 2017: A hidden basidiolichen rediscovered: Omphalina oreades is a separate species in the genus Lichenomphalia (Basidiomycota: Agaricales: Hygrophoraceae). - The Lichenologist 49: 467-481.

Malekmohammadi M., Akhani H. \& Borsch T. 2017: Phylogenetic relationships of Limonium (Plumbaginaceae) inferred from multiple chloroplast and nuclear loci. - Taxon 66: 1128-1146.

Malekmohammadi M., Lack H. W., Lomonosova M. \& Akhani H. 2017: The discovery, naming and typification of Limonium gmelini (Plumbaginaceae). - Willdenowia 47: 99-106.

Mandel J. R., Barker M. S., Bayer R. J., Dikow R. B., Gao T.-G., Jones K. E., Keeley S., Kilian N., Ma H., Siniscalchi C. M., Susanna A., Thapa R., Watson L. \& Funk V. A. 2017: The Compositae Tree of Life in the age of phylogenomics. - Journal of Systematics and Evolution 55: 405-410.

Medeiros I. D., Kraichak E., Lücking R., Mangold A. \& Lumbsch H. T. 2017: Assembling a taxonomic monograph of tribe Wirthiotremateae (lichenized Ascomycota: Ostropales: Graphidaceae). - Fieldiana Life and Earth Sciences 9: 1-31.

Mora D., Carmora J., Jahn R., Zimmermann J. \& Abarca N. 2017: Epilithic diatom communities of selected streams from the Lerma-Chapala Basin, Central Mexico, with the description of two new species. - PhytoKeys 88: 39-69.

Müller A., Berendsohn W. G., Kohlbecker A., Güntsch A., Plitzner P. \& Luther K. 2017: A comprehensive and standards-aware common data model (CDM) for taxonomic research. - Biodiversity Information Science and Standards 1: e20367.

Oberprieler C., Ott T., Hipper A., Kilian N., Bog M., Tomasello S. \& Meister J. 2017: Pleistocene shaping of genetic diversity in a monsoon-affected environ- 
ment: the case of Gymnosporia (Celastraceae) in the southern Arabian Peninsula. - Plant Systematics and Evolution 303: 1399-1412.

Paukov A., Sipman H. J. M., Kukwa M., Repin, R. \& Teptina A. 2017: New lichen records from the mountains Kinabalu and Tambuyukon (Kinabalu Park, Malaysian Borneo). - Herzogia 30: 237-252.

Plitzner P., Henning T., Müller A., Güntsch A., Karam N., Kilian N. 2017: Bottom-up taxon characterisations with shared knowledge: describing specimens in a semantic context. - In: Algergawy, A., Karam, N., Klan, F., Jonquet, C. (ed.), Proceedings of the 2nd International Workshop on Semantics for Biodiversity (S4BioDiv 2017) co-located with 16th International Semantic Web Conference (ISWC 2017), Oct 2017, Vienna, Australia. - CEUR Workshop Proceedings 1933.

Plitzner P., Müller A., Güntsch A., Berendsohn W. G., Kohlbecker A., Kilian N., Henning T. \& Stöver B. 2017: The CDM applied: unit-derivation, from field observations to DNA sequences. - Biodiversity Information Science and Standards 1: e20366.

Raab-Straube E. von \& Raus T. 2017: Euro+Med-Checklist Notulae, 7 [Notulae ad floram euromediterraneam pertinentes No. 36]. - Willdenowia 47: 89-96.

Raab-Straube E. von \& Raus T. 2017: Euro+Med-Checklist Notulae, 8 [Notulae ad floram euromediterraneam pertinentes No. 37]. - Willdenowia 47: 293-309.

Raus T. 2017: The many contributions of Avinoam Danin to the Euro and Med plant checklists. - Israel J. PI. Sci. 64: 3-17.

Slovák M., Kučera J., Lack H. W., Ziffer-Berger J., Melicharková M., Záveská E. \& Vd’ačaný P. 2017: Diversity dynamics and transoceanic Eurasian-Australian disjunction in the genus Picris (Compositae) induced by the interplay of shifts in intrinsic / extrinsic traits and paleoclimatic oscillations. - Molecular Phylogenetics and Evolution 119: 182-195.

Soto-Medina E., Aptroot A. \& Lücking R. 2017: Aspidothelium silverstonei and Astrothelium fuscosporum, two new corticolous lichen species from Colombia. Cryptogamie / Mycologie 38: 253-258.

Soto-Medina E. A. \& Lücking R. 2017: A new species of Rhytidhysteron (Ascomycota: Patellariaceae) from Colombia, with a provisional working key to known species in the world. - Revista de la Academia Colombiana de Ciencias Exactas, Físicas y Naturales 41: 59-63.

Soto-Medina E. A., Lücking R. \& Torres A. M. 2017: Nuevos registros de líquenes (familia Graphidaceae) para Colombia. - Biota Colombiana 18: 30-41.

Sparrius L. B., Aptroot A., Sipman H. J. M., Pérez-Vargas I., Matos P., Gerlach A. \& Vervoort M. 2017: Esti- mating the population size of the endemic lichens Anzia centrifuga (Parmeliaceae) and Ramalina species (Ramalinaceae) on Porto Santo (Madeira archipelago). - The Bryologist 120: 293-301

Suhrbier L., Kusber W. H., Tschöpe O., Güntsch A. \& Berendsohn W. G. 2017: AnnoSys-implementation of a generic annotation system for schema-based data using the example of biodiversity collection data. Database 2017: baxo18.

Sylvester S. P., Heitkamp F., Sylvester M. D. P. V., Jungkunst H. F., Sipman H. J. M., Toivonen J. M., Gonzales Inca C. A., Ospina J. C. \& Kessler M. 2017: Relict high-Andean ecosystems challenge our concepts of naturalness and human impact. - Scientific Reports 7: 3334 .

Tillmann U., Hoppenrath M., Gottschling M., Kusber W.-H. \& Elbrächter M. 2017: Plate pattern clarification of the marine dinophyte Heterocapsa triquetra sensu Stein (Dinophyceae) collected at the Kiel Fjord (Germany). - Journal of Phycology 53: 1305-1324.

Torres-Montúfar A., Borsch T., Fuentes S., Clase T., Peguero B. \& Ochoterena H. 2017: The new Hispaniolan genus Tainus (Rubiaceae) constitutes an isolated lineage in the Caribbean biodiversity hotspot. -Willdenowia 47: 259-270.

Tschöpe O., Suhrbier, L., Güntsch, A., Berendsohn, W. G. 2017: AnnoSys2: reaching out to the semantic web. - In: Algergawy, A., Karam, N., Klan, F., Jonquet, C. (ed.), Proceedings of the 2nd International Workshop on Semantics for Biodiversity (S4BioDiv 2017) co-located with 16th International Semantic Web Conference (ISWC 2017). Oct 2017, Vienna, Australia. - CEUR Workshop Proceedings 1933.

Turland N. J., Kempa M., Knapp S., Senková E. \& Wiersema J. H. 2017: XIX International Botanical Congress: preliminary guiding mail vote on nomenclature proposals. - Taxon 66: 995-1000.

Turland N. J. \& Wiersema J. H. 2017: Synopsis of proposals on nomenclature - Shenzhen 2017: a review of the proposals concerning the "International code of nomenclature for algae, fungi, and plants" submitted to the XIX International Botanical Congress. - Taxon 66: $217-274$.

Turland N. J., Wiersema J. H., Monro A. M., Deng Y.-F. \& Zhang L. 2017: XIX International Botanical Congress: report of congress action on nomenclature proposals. - Taxon 66: 1234-1245.

Van den Boom P. P. G., Sipman H. J. M., Divakar P. K. \& Ertz D. 2017: New or interesting records of lichens and lichenicolous fungi from Panama with descriptions of ten new species. - Sydowia 69: 47-72.

Van Den Broeck D., Lücking R., Gaya E., Chaves J. L., Lejju J. B. \& Ertz D. 2017. Heterocyphelium leucampyx (Arthoniales, Ascomycota): another orphaned mazae- 
diate lichen finds its way home. - The Lichenologist 49: 333-345.

Wagner F., Härtl S., Vogt R. \& Oberprieler C. 2017: "Fix me another marguerite!": species delimitation in a group of intensively hybridizing lineages of ox-eye daisies (Leucanthemum Mill., Compositae-Anthemideae). - Molecular Ecology 26: 4260-4283.

Wei X.-L., Leavitt S. D., Huang J.-P., Esslinger T. L., Wang L.-S., Moncada B., Lücking R., Divakar P. K. \& Lumbsch H. T. 2017: Parallel Miocene-dominated diversification of the lichen-forming fungal genus Oropogon (Ascomycota: Parmeliaceae) in different continents. - Taxon 66: 1269-1281.

Wiersema J. H., May T. W. \& Turland N. J. 2017: Report on corrections and future considerations for appendices II-VIII of the "International code of nomenclature for algae, fungi, and plants". - Taxon 66: 772-775.

Wijayawardene N. N., Hyde K. D., Rajeshkumar K. C., Hawksworth D. L., Madrid H., Kirk P. M., Braun U., Singh R. V., Crous P. W., Kukwa M., Lücking R., Kurtzman C. P., Yurkov A., Haelewaters D., Aptroot A., Lumbsch H. T., Timdal E., Ertz D., Etayo J., Phillips A. J. L., Groenewald J. Z., Papizadeh M., Selbmann L., Dayarathne M. C., Weerakoon G., Jones E. B. G., Suetrong S., Tian Q., Castañeda-Ruiz R. F., Bahkali A. H., Pang K.-L., Tanaka K., Dai D. Q., Sakayaroj J., Hujslová M., Lombard L., Shenoy B. D., Suija A., Maharachchikumbura S. S. N., Thambugala K. M. Wanasinghe D. N., Sharma B. O., Gaikwad S., Pandit G., Zucconi L., Onofri S., Egidi E., Raja H. A., Kodsueb R., Cáceres M. E. S., Pérez-Ortega S., Fiuza P. O., Monteiro J. S., Vasilyeva L. N., Shivas R. G., Prieto M., Wedin M., Olariaga I., Lateef A. A., Agrawal Y., Fazeli S. A. S., Amoozegar M. A., Zhao G. Z., Pfliegler W. P., Sharma G., Oset M., Abdel-Wahab M. A., Takamatsu S., Bensch K., Silva N. I. d., De Kesel A., Karunarathna A., Boonmee S., Pfister D. H., Lu Y.-Z., Luo Z.-L., Boonyuen N., Daranagama D. A., Senanayake I. C., Jayasiri S. C., Samarakoon M. C., Zeng X.-Y., Doilom M., Quijada L., Rampadarath S., Heredia G., Dissanayake A. J., Jayawardana R. S., Perera R. H., Tang L. Z., Phukhamsakda C., Hernández-Restrepo M., Ma X., Tibpromma S., Gusmao L. F. P., Weerahewa D. \& Karunarathna S. C. 2017: Notes for genera: Ascomycota. - Fungal Diversity 86: 1-594.

Wissemann V. \& Lack H. W. 2017: "In communal joy towards all that is alive" - Gerhard Wagenitz (19272017). - Taxon 66: 1003-1007.

\section{Monographien}

Greuter W. 2017: Plantas vasculares de Cuba : inventario preliminar $=$ Vascular plants of Cuba: a preliminary checklist, ed. 2. - Berlin, Havanna: Botanischer Garten \& Botanisches Museum Berlin \& Jardín Botánico Nacional, Universidad de La Habana.
Grotz K. 2017: Chili \& Schokolade: der Geschmack Mexikos : Ausstellungstexte „für die Tasche“. - Berlin: BGBM Press.

Kusber W.-H., Jahn R. \& Korsch H. 2017: Rote Liste und Gesamtartenliste der Armleuchteralgen (Characeae). - Berlin: Universitätsverlag der TU Berlin.

Raab-Straube E. von 2017: Taxonomic revision of Saussurea subgenus Amphilaena (Compositae, Cardueae). - Englera 34, Berlin: BGBM Press.

Rahemipour P. 2017: Chili \& Schokolade - der Geschmack Mexikos: ein botanisches Kochbuch. - Berlin: BGBM Press.

Rudolph K., Jahn R. \& Kusber W.-H. 2017: Rote Liste und Gesamtartenliste der limnischen Rotalgen (Rhodophyta) und Braunalgen (Phaeophyceae). - Berlin: Universitätsverlag der TU Berlin.

\section{Herausgeberschaft}

Christodoulou C. S., Hadjikyriakou G. N. \& Hand R. 2017: Cypricola 1-3. - Lefkosia \& Berlin: Selbstverlag der Editoren.

Greuter W. \& Rankin Rodríguez R. 2017: Flora de la República de Cuba. Fascículo 22 Dioscoreaceae. Ericaceae. Zygophyllaceae - Berlin: Botanischer Garten \& Botanisches Museum Berlin.

Hofmann K., Ickerodt U., Maluck M. \& Rahemipour P. (ed.) 2017: Kulturerbe = Kulturpflicht?: Theoretische Reflexionen zum Umgang mit archäologischen Orten. - Sonderheft der Archäologischen Nachrichten aus Schleswig-Holstein 3.

Turland N. 2017: Willdenowia: Annals of the Botanic Garden and Botanical Museum Berlin-Dahlem 47. Berlin: BGBM Press.

Turland N. 2017: Englera: Serial publication of the Botanic Garden and Botanical Museum Berlin 34. Berlin: BGBM Press.

\section{Beiträge zu Schriftenreihen, Positionspa- piere und Festschriften}

Barina Z., Somogyi G. \& Lack H. W. 2017: The beginnings of floristic research in Albania. - In: Barina Z. (ed.), Distribution atlas of vascular plants in Albania. - Budapest: Hungarian Natural History Museum.

Barina Z., Somogyi G. \& Lack H. W. 2017: Increasing interest after World War I. - In: Barina Z. (ed.), Distribution atlas of vascular plants in Albania. - Budapest: Hungarian Natural History Museum.

Barina Z., Somogyi G. \& Lack H. W. 2017: World War I as a power for botanical studies. - In: Barina Z. (ed.), Distribution atlas of vascular plants in Albania. - Budapest: Hungarian Natural History Museum. 
Lack H. W. 2017: Padua und die botanische Erforschung des Stato da Mar und Ägyptens von den Anfängen bis Carl von Linné (1753). - In: Engelhardt D. \& Frigo G. F. (ed.), Padua als Europäisches Wissenschaftszentrum von der Renaissance bis zur Aufklärung. - Europäische Wissenschaftsbeziehungen 12, Aachen: Shaker Verlag.

Lack H. W. 2017: Deutsche und österreichische Botaniker in Albanien - von den Anfängen bis 1945. - In: Seidl J. Kästner I., Kiefer J. \& Kiehn M. (ed.), Deutsche und österreichische Forschungsreisen auf den Balkan und nach Nahost. - Europäische Wissenschaftsbeziehungen 13, Aachen: Shaker Verlag.

Lack H. W. \& Geltman D. V. 2017: Adolf Engler und seine Beziehungen zu Botanikern in Russland. - In: Kästner I. \& Schippan M. (ed.), Deutsch-russische Zusammenarbeit wissenschaftlicher und kultureller Institutionen vom 18. zum 20. Jahrhundert. - Europäische Wissenschaftsbeziehungen 14, Aachen: Shaker Verlag.

Laute T. 2017: Lokale Anzucht von Gehölzen für historische Gärten in Zeiten des Klimawandels. Anzucht von Gehölzen im Botanischen Garten Berlin-Dahlem. - S. 238-241 in: Kühn N., Gillner S. \& Schmidt-Wiegand A. (ed.), Gehölze in historischen Gärten im Klimawandel. - Berlin: Universitätsverlag der TU Berlin.

\section{Beiträge zu taxonomischen Informations- systemen}

Dimopoulos P., Raus T. \& Strid A. (ed.) 2017: Flora of Greece web. Vascular Plants of Greece. An Annotated Checklist. Version I (June 2017). - Published at: http:// portal.cybertaxonomy.org/flora-greece/

Henning T., Holstein N. \& Raab-Straube E. von 2017: Cucurbitaceae. - In: Euro+Med Plantbase the information resource for Euro-Mediterranean plant diversity. - Published at http://ww2.bgbm.org/ EuroPlusMed/PTaxonDetail.asp? Nameld $=18447 \&$ PTR efFk=7500000

Henning T., Weigend M., Mello-Silva R. \& Acuña-Castillo R. 2017: Loasaceae Juss. - Flora do Brasil 2020 em construção. - Rio de Janeiro: Jardím Botânico, http://floradobrasil.jbrj.gov.br/reflora/ floradobrasil/FB150

Korotkova N. \& Raab-Straube E. von 2017: Cactaceae. - In: Euro+Med Plantbase - the information resource for Euro-Mediterranean plant diversity. - Published at http://ww2.bgbm.org/EuroPlusMed/PTaxonDetail. asp?Nameld=94373\&PTRefFk=7500000

Raab-Straube E. von 2017: Caprifoliaceae. - In: Euro+Med Plantbase - the information resource for Euro-Mediterranean plant diversity. - Published at http://ww2.bgbm.org/EuroPlusMed/PTaxonDetail. asp? Nameld $=15390$ \&PTRefFk $=7500000$
Raab-Straube E. von 2017: Diervillaceae. - In: Euro+Med Plantbase - the information resource for Euro-Mediterranean plant diversity. - Published at http://ww2.bgbm.org/EuroPlusMed/PTaxonDetail. asp? Nameld=7503107\&PTRefFk=7500000

Raab-Straube E. von 2017: Linnaeaceae. - In: Euro+Med Plantbase - the information resource for Euro-Mediterranean plant diversity. - Published at http://ww2.bgbm.org/EuroPlusMed/PTaxonDetail. asp? Nameld=7503108\&PTRefFk=7500000

Raab-Straube E. von 2017: Tropaeolaceae. - In: Euro+Med Plantbase - the information resource for Euro-Mediterranean plant diversity. - Published at http://ww2.bgbm.org/EuroPlusMed/PTaxonDetail. asp? Nameld $=94609 \&$ PTRefFk $=7500000$

Raab-Straube E. von 2017: Viburnaceae. - In: Euro+Med Plantbase - the information resource for Euro-Mediterranean plant diversity. - Published at http://ww2.bgbm.org/EuroPlusMed/PTaxonDetail. asp?Nameld=2405\&PTRefFk=7500000

Raab-Straube E. von \& Henning T. 2017: Valerianaceae. - In: Euro+Med Plantbase - the information resource for Euro-Mediterranean plant diversity. - Published at http://ww2.bgbm.org/EuroPlusMed/ PTaxonDetail.asp? Nameld $=34903 \&$ PTRefFk $=7500000$

\section{Nicht-begutachtete Zeitschriftenartikel}

Grotz K. \& Rahemipour P. 2017: Chili und Schokolade: der Geschmack Mexikos. - Museumsjournal 2017(2): 54-55.

Hajós G. \& Lack H. W. 2017: Ein seltenes, dem Fürsten Ligne gewidmetes Gartenbuch aus Wien um 1808-1812. - Historische Gärten 23: 20-35.

Kusber W.-H. 2017: Rezension von: Diatoms and the continuing relevance of morphology to studies on taxonomy, systematics and biogeography: celebrating the work and impact of Patricia A. Sims on the occasion of her 8oth birthday / editors Jakub Witkowski, David Williams \&J. Patrick Kociolek; Stuttgart: J. Cramer in der Gebr. Borntraeger Verlagsbuchhandlung, 2015. Nova Hedwigia. Beiheft; 144; 978-3-443-51066-4. - Willdenowia 47: 225-226.

Kusber W.-H. 2017: Phytoflagellaten-Studien im Naturschutzgebiet „Aland-Elbe-Niederung“ mit Erstfunden für Sachsen-Anhalt. - Mitteilungen zur Floristischen Kartierung in Sachsen-Anhalt 22: 3-10.

Lack H. W. 2017: Die Araukarien von Laxenburg. Historische Gärten 23: 27-32.

Lücking R. 2017: Rezension von: Lichens of Finland / edited by Soili Stenroos, Saara Velmala, Juha Pykälä, Teuvo Ahti . Helsinki, Finland: Finnish Museum of Natural History LUOMUS, University of Helsinki, 2016. Norrlinia ; 30; 978-951-51-2266-7. - The Bryologist 119: 459-462. 
Zimmermann J. \& Hürlimann J. 2017: Umwelt-DNA (eDNA): die revolutionierte Artensuche. - FaunaFocus 35: 1-12.
Zimmermann J. \& Hürlimann J. 2017: Umwelt-DNA (eDNA): Molekularbiologie erobert Arten-, Gewässerund Naturschutz. - Wasser Energie Luft = Eau Énergie Air 109: 163-172.

the Chocó biogeographic region in Colombia. - The Bryologist 121: 295-305.

Cocquyt C., Kusber W.-H. \& Jahn R. 2018: Epithemia hirudiniformis and related taxa within the subgenus Rhopalodiella subg. nov. in comparison to Epithemia subg. Rhopalodia stat. nov. (Bacillariophyceae) from East Africa. - Cryptogamie Algologie 39: 35-62.

Dal-Forno M., Moncada B. \& Lücking R. 2018: Sticta aongstroemii, a newly recognized species in the $S$. damicornis morphodeme (Lobariaceae) potentially endemic to the Atlantic Forest in Brazil. - The Lichenologist 50: 691-696.

ment of land cover change in peri-urban High Andean environments south of Bogotá, Colombia. - Land 7: 75.

Aptroot A., Sipman H. J. M., Mercado Diaz J. A., Mendonça C. d. O., Feuerstein S. C., Cunha-Dias I. P. R., Pereira T. A. \& Cáceres M. E. S. 2018: Eight new species of Pyrenulaceae from the Neotropics, with a key to 3-septate Pyrgillus species. - The Lichenologist 50: 77-87.

Berendsohn W. G., Borsch T., Güntsch A., Kohlbecker A., Korotkova N., Luther K., Müller A., Plitzner P. \& Mering S. von 2018: Using the EDIT Platform for Cybertaxonomy to prepare and publish a treatment for the Caryophyllales Network: an online synthesis of the Nepenthaceae. - Willdenowia 48: 335-344.

Boom P. P., Sipman H. J. M., Divakar P. K. \& Ertz D. 2018: New or interesting records of lichens and lichenicolous fungi from Suriname, with descriptions of eight new species. - Ascomycete.org 10: 244-258.

Borsch T., Flores-Olvera H., Zumaya S. \& Müller K. 2018: Pollen characters and DNA sequence data converge on a monophyletic genus Iresine (Amaranthaceae, Caryophyllales) and help to elucidate its species diversity. - Taxon 67: 944-976.

Buttler K. P. \& Hand R. 2018: Beiträge zur Fortschreibung der Florenliste Deutschlands (Pteridophyta, Spermatophyta) - zehnte Folge. - Kochia 11: 91-101.

Canal D., Köster N., Jones K. E., Korotkova N., Croat T. B. \& Borsch T. 2018: Phylogeny and diversification history of the large neotropical genus Philodendron (Araceae): accelerated speciation in a lineage dominated by epiphytes. - American Journal of Botany 105: 1035-1052.

Coca L. F., Lücking R. \& Moncada B. 2018: Two new, sympatric and semi-cryptic species of Sulzbacheromyces (lichenized Basidiomycota, Lepidostromatales) from
Di Vincenzo V., Gruenstaeudl M., Nauheimer L., Wondafrash M., Kamau P., Demissew S. \& Borsch T. 2018: Evolutionary diversification of the African achyranthoid clade (Amaranthaceae) in the context of sterile flower evolution and epizoochory. - Annals of Botany 122: 69-85.

Dias E. F., Kilian N., Silva L., Schaefer H., Carine M., Rudall P. J., Santos-Guerra A. \& Moura M. 2018: Phylogeography of the Macaronesian lettuce species Lactuca watsoniana and L. palmensis (Asteraceae). Biochemical Genetics 56: 315-340.

Dostert N., Caceres F., Brokamp G. \& Weigend M. 2018: Propagación in situ de ratania - Krameria lappacea (Krameriaceae): factores limitantes de la propagación natural y efectos de resiembra. - Revista Peruana de Biología 25: 29-34.

Duwe V., Muller L. A. H., Reichel K., Zippel E., Borsch T. \& Ismail S. A. 2018: Genetic structure and genetic diversity of the endangered grassland plant Crepis mollis (Jacq.) Asch. as a basis for conservation management in Germany. - Conservation Genetics 19: 527-543.

Elbrächter M., Hoppenrath M., Jahn R. \& Kusber W.H. 2018: Stability of the generic names Alexandrium Halim and Gessnerium Halim at risk because of Peridinium splendor-maris Ehrenberg, the first documented bloom of Alexandrium (Dinophyceae). - Notulae Algarum 60: 1-6.

Fazio A. T., Adler M. A., Parnmen S., Lücking R. \& Maier M. S. 2018: Production of the bioactive pigment elsinochrome A by a cultured mycobiont strain of the lichen Graphis elongata. - Mycological Progress 17: 479-487.

Gallinat A. S., Primack R. B., Willis C. G., Nordt B., Stevens A.-D., Fahey R., Whittemore A. T., Du Y. \& Panchen Z. A. 2018: Patterns and predictors of fleshy
BGBMPublikationen 2018 
fruit phenology at five international botanical gardens. - American Journal of Botany 105: 1824-1834.

Gasparyan A., Sipman H. J. M., Marini L. \& Nascimbene J. 2018: The inclusion of overlooked lichen microhabitats in standardized forest biodiversity monitoring. - The Lichenologist 50: 231-237.

Gottschling M., Tillmann U., Kusber W.-H., Hoppenrath M. \& Elbrächter M. 2018: (2607) Proposal to conserve the name Heterocapsa (Dinophyceae) with a conserved type. - Taxon 67: 632-633.

Gottschling M., Tillmann U., Kusber W.-H., Hoppenrath M. \& Elbrächter M. 2018: A Gordian knot: nomenclature and taxonomy of Heterocapsa triquetra (Peridiniales: Heterocapsaceae). - Taxon 67: 179-185.

Gregor T., Bauer J., Engelhardt M., Hand R., Hein H., Lippert W., Mayer A., Meierott L., Parker H. \& Juraj P. 2018: Amelancher ovalis s. I.: zwei Zytotypen in Deutschland. - Kochia 11: 65-75.

Gruenstaeudl M., Gerschler N. \& Borsch T. 2018: Bioinformatic workflows for generating complete plastid genome sequences: an example from Cabom$\mathrm{ba}$ (Cabombaceae) in the context of the phylogenomic analysis of the water-lily clade. - Life 8: 25 .

Güntsch A., Groom Q., Hyam R., Chagnoux S., Röpert D., Berendsohn W. G., Casino A., Droege G., Gerritsen W., Holetschek J., Marhold K., Mergen P., Rainer H., Smith V. S. \& Triebel D. 2018: Standardised globally unique specimen identifiers. - Biodiversity Information Science and Standards 2: e26658.

Güzel M. E., Kilian N., Gültepe M., Kandemır A. \& Coşcunçuncelebi K. 2018: Contributions to the taxonomy of Lactuca (Asteraceae) in Turkey. - Turkish Journal of Botany 42: 197-207.

Hand R. 2018: Additional data on Beta in Cyprus. Cypricola 5: 1-3.

Hand R. 2018: Thalictrum subsectio Thalictrum: Nachträge zum Namenskatalog der in Europa vorkommenden Arten. - Haussknechtia 14: 35-42.

Henning T., Mittelbach M., Ismail S. A., Acuña-Castillo R. H. \& Weigend M. 2018: A case of behavioural diversification in male floral function the evolution of thigmonastic pollen presentation. - Scientific Reports 8: 14018.

Henning T., Plitzner P., Güntsch A., Berendsohn W. G., Müller A. \& Kilian N. 2018: Building compatible and dynamic character matrices: current and future use of specimen-based character data. - Botany Letters 165: 352-360.

Hidalgo B. F., Ruiz J. L. F., Hechavarría J. L. G., Morales B. M., de Vales Fernández D., Díaz L. M. L., Pérez A. M., Bazan S. F. \& Borsch T. 2018: Redescubrimiento del endémico cubano Phyllanthus formosus (Phyllanthaceae). Revista del Jardín Botánico Nacional 39: 97-102.
Ismail S. A., Duwe V. K., Zippel E. \& Borsch T. 2018: Assessment of current genetic structure from local to geographic scales indicates brake down of historically extensive gene flow in the dry grassland species Scabiosa canescens Waldst. \& Kit. (Dipsacaceae). - Diversity and Distributions 24: 233-243.

Jia Z.-F., Lücking R., Li H. \& Meng Q.-F. 2018: A preliminary study of the lichen genus Fissurina (Graphidaceae) in China. - Mycosystema 37: 881-895.

Jones K. E., Schilling E. E., Dias E. E. \& Kilian N. 2018: Northern Hemisphere disjunctions in Lactuca (Cichorieae, Asteraceae): independent Eurasia to North America migrations and allopolyploidization. - Willdenowia 48: 259-284.

Jørgensen P. M. \& Lücking R. 2018: The 'Rustici Pauperrimi': A Linnaean myth about lichens rectified. The Linnean 34: 9-12.

Joshi S., Upreti D. K., Divakar P. K., Lumbsch H. T. \& Lücking R. 2018: A re-evaluation of thelotremoid Graphidaceae (lichenized Ascomycota: Ostropales) in India. - The Lichenologist 50: 627-678.

Kalb J., Lücking R. \& Kalb K. 2018: The lichen genera Allographa and Graphis (Ascomycota: Ostropales, Graphidaceae) in Thailand - eleven new species, forty-nine new records and a key to all one hundred and sixteen species so far recorded for the country. Phytotaxa 377: 1-83.

Kantvilas G., Rivas Plata E. \& Lücking R. 2018: The lichen genus Coenogonium in Tasmania. - The Lichenologist 50: $571-582$.

Karadimou E., Kallimanis A. S., Tsiripidis I., Raus T., Bergmeier E. \& Dimopoulos P. 2018. Functional diversity changes over $100 \mathrm{yr}$ of primary succession on a volcanic island: insights into assembly processes. - Ecosphere 9: eo2374.

Kirchhoff A., Bügel U., Santamaria E., Reimeier F., Röpert D., Tebbje A., Güntsch A., Chaves F., Steinke K.-H. \& Berendsohn W. 2018: Toward a service-based workflow for automated information extraction from herbarium specimens. - Database 2018: bay103.

Kirschbaum U. \& Sipman H. J. M. 2018: Lichen records from Northern Cyprus. - Herzogia 31: 245-251.

Korotkova N., Parolly G., Khachatryan A., Ghulikyan L., Sargsyan H., Akopian J., Borsch T. \& Gruenstaeud M. 2018: Towards resolving the evolutionary history of Caucasian pears (Pyrus, Rosaceae): phylogenetic relationships, divergence times and leaf trait evolution. - Journal of Systematics and Evolution 56: 35-47.

Kusber W.-H., Skibbe O. \& Jahn R. 2018: Is Trieres Ashworth \& E. C. Theriot 2013 (Bacillariophyta) a superfluous redescription of Microtheca Ehrenberg 1838? - Notulae Algarum 81: 1-6.

Lack H. W. 2018: (2621) Proposal to conserve the name Scabiosa caucasica (Lomelosia caucasica) with 
a conserved type against S. caucasea (Dipsacaceae). Taxon 67: 645-646.

Lack H. W. 2018: The discovery and naming of Lomelosia caucasica (Dipsacaceae) with notes on its nomenclature and its early cultivation. - Willdenowia 48: 185-194.

Lack H. W. 2018: Schönheit ohne Farbe. Die Pflanzenabbildungen von Alexander von Humboldts: „Voyage aux régions équinoxiales du Nouveau Continent". - Annals of the History and Philosophy of Biology 22: 17-28.

Luch R. \& Lücking R. 2018: The genus Halegrapha new to Hawaii, with the new and potentially endemic species Halegrapha paulseniana (Ascomycota: Graphidaceae). - Willdenowia 48: 415-423.

Lücking R. \& Hawksworth D. L. 2018: Formal description of sequence-based, voucherless fungi: promises and pitfalls, and how to resolve them. IMA Fungus 9: 143-166.

Lücking R. \& Kalb K. 2018: Formal instatement of Allographa (Graphidaceae): how to deal with a hyperdiverse genus complex with cryptic differentiation and paucity of molecular data. - Herzogia 31: 525-561.

Lücking R., Kirk P. M. \& Hawksworth D. L. 2018: Sequence-based nomenclature: a reply to Thines et al. and Zamora et al. and provisions for an amended proposal "from the floor" to allow DNA sequences as types of names. - IMA Fungus 9: 185-198.

Lücking R., Moncada B., Llerena N. \& Huhtinen S. 2018: Saving the name Lobaria peltigera with a new type from the TUR-Vainio herbarium, and its transfer to the genus Yoshimuriella. - Graphis Scripta 30: 12-19.

Maharramova E., Huseynova I., Kolbaia S., Gruenstaeudl M., Borsch T. \& Muller L. A. H. 2018: Phylogeography and population genetics of the riparian relict tree Pterocarya fraxinifolia (Juglandaceae) in the South Caucasus. - Systematics and Biodiversity 16: $14-27$.

Makris C. \& Hand R. 2018: Some remarks on Silene oliveriana Otth (Caryophyllaceae). - Cypricola 6: 1-8.

Maphangwa K. W., Sipman H. J. M., Tekere M. \& Zedda L. 2018: Epiphytic Lichen diversity on Jacaran$d a$ and Acacia trees in Pretoria (Tshwane, Republic of South Africa). - Herzogia 31: 949-964.

Marić Pfannkuchen D., Godrijan J., Smodlaka Tanković M., Baričević A., Kužat N., Djakovac T., Pustijanac E., Jahn R. \& Pfannkuchen M. 2018: The ecology of one cosmopolitan, one newly introduced and one occasionally advected species from the genus Skeletonema in a highly structured ecosystem, the Northern Adriatic. - Microbial Ecology 75: 674-687.

Menezes A. A., Cáceres M. E. S., Passos Bastos C. J. \& Lücking R. 2018: The latitudinal diversity gradient of epiphytic lichens in the Brazilian Atlantic Forest: does Rapoport's rule apply? - The Bryologist 121: 480-497.

Moncada B., Mercado-Díaz J. A. \& Lücking R. 2018: The identity of Sticta damicornis (Ascomycota: Lobariaceae): a presumably widespread taxon is a Caribbean endemic. - The Lichenologist 50: 591-597.

Oberprieler C., Konowalik K., Fackelmann A. \& Vogt R. 2018: Polyploid speciation across a suture zone: phylogeography and species delimitation in S French Leucanthemum Mill. representatives (CompositaeAnthemideae). - Plant Systematics and Evolution 304: 1141-1155.

Obst M., Vicario S., Lundin K., Berggren M., Karlsson A., Haines R., Williams A., Goble C., Mathew C. \& Güntsch A. 2018: Marine long-term biodiversity assessment suggests loss of rare species in the Skagerrak and Kattegat region. - Marine Biodiversity 48: 2165-2176.

Pawlowski J., Kelly-Quinn M., Altermatt F., Apothéloz-Perret-Gentil L., Beja P., Boggero A., Borja A., Bouchez A., Cordier T., Domaizon I., Feio M. J., Filipe A. F., Fornaroli R., GrafW., Herder J., Hoorn B., Iwan Jones J., Sagova-Mareckova M., Moritz C., Barquín J., Piggott J. J., Pinna M., Rimet F., Rinkevich B., Sousa-Santos C., Specchia V., Trobajo R., Vasselon V., Vitecek S., Zimmermann J., Weigand A., Leese F. \& Kahlert M. 2018: The future of biotic indices in the ecogenomic era: integrating (e)DNA metabarcoding in biological assessment of aquatic ecosystems. - The Science of the Total Environment 637/638: 1295-1310.

Pereira T. A., Passos P. O., Santos L. A., Lücking R. \& Cáceres M. E. S. 2018: Going extinct before being discovered? New lichen fungi from a small fragment of the vanishing Atlantic Rainforest in Brazil. - Biota Neotropica 18: e20170445.

Perlmutter G. B., Rivas Plata E. \& Lücking R. 2018. Is Stirtonia alba in North America? Resolving a nomenclatural impasse and assessing the taxonomic status of the Arthonia alba complex. - The Bryologist 121: 80-86.

Petersen M., Glöckler F., Kiessling W., Döring M., Fichtmüller D., Laphakorn L., Baltruschat B. \& Hoffmann J. 2018: History and development of ABCDEFG: a data standard for geosciences. - Fossil Record 21: 47-53.

Pischon H., Petrick A., Müller M., Köster N., Pietsch J. \& Mundhenk L. 2018: Grayanotoxin I intoxication in pet pigs. - Veterinary Pathology 55: 896-899.

Raab-Straube E. von \& Raus T. 2018: Euro+Med-Checklist Notulae, 9 [Notulae ad floram euromediterraneam pertinentes No. 38]. - Willdenowia 48: 195-220.

Ranft H., Moncada B., de Lange P. J., Lumbsch H. T. \& Lücking R. 2018. The Sticta filix morphodeme (Ascomycota: Lobariaceae) in New Zealand, with the 
newly recognized species $S$. dendroides and $S$. menziesii: indicators of forest health in a threatened island biota? - The Lichenologist 50: 185-210.

Reimeier F., Röpert D., Güntsch A., Kirchhoff A. \& Berendsohn W. G. 2018: Service-based information extraction from herbarium specimens. - Biodiversity Information Science and Standards 2: e25415.

Rimet F., Abarca N., Bouchez A., Kusber W.-H., Jahn R., Kahlert M., Keck F., Kelly M. G., Mann D. G., Piuz A., Trobajo R., Tapolczai K., Vasselon V. \& Zimmermann J. 2018: The potential of High-Throughput Sequencing (HTS) of natural samples as a source of primary taxonomic information for reference libraries of diatom barcodes. - Fottea 18: 37-54.

Schubert H., Caballero Calvo A., Rauchecker M., Rojas-Zamora O., Brokamp G. \& Schütt B. 2018: Assessment of land cover changes in the hinterland of Barranquilla (Colombia) using Landsat imagery and logistic regression. - Land 7: 152.

Simijaca D., Moncada B. \& Lücking R. 2018: Bosque de roble o plantación de coníferas, ¿qué prefieren los líquenes epífitos? - Colombia Forestal 21: 123-141.

Sipman H. J. M. 2018: Diorygma upretii spec. nov., a poleotolerant lichen in the tropics. - Cryptogam Biodiversity and Assessment, Special issue 2018: 5 .

Sipman H. J. M. 2018: New species and new records of Australian lichens. - Australasian Lichenology 82: 92-105.

Sipman H. J. M. 2018: Three new lichen species and 48 new records from Vanuatu. - Australasian Lichenology 82: 106-129.

Sobreira P. N. B., Cáceres M. E. S., Maia L. C. \& Lücking R. 2018: Flabelloporina, a new genus in the Porinaceae (Ascomycota, Ostropales), with the first record of F. squamulifera from Brazil. - Phytotaxa 358: $67-75$.

Skibbe O., Zimmermann J., Kusber W.-H., Abarca N., Buczkó K. \& Jahn R. 2018: Gomphoneis tegelensis sp. nov. (Bacillariophyceae): a morphological and molecular investigation based on selected single cells. - Diatom Research 33: 251-262.

Stordeur R., Beck A., Christl S., Czarnota P., Eckstein J., Kison H.-U., Otte V., Seelemann A., Sipman H. J. M., Schiefelbein U. \& Ungethüm K. 2018: Beiträge zur Flechtenflora Sachsen-Anhalts und angrenzender Regionen (Teil 1). - Herzogia 31: 700-715.

Torres-Montúfar A., Borsch T. \& Ochoterena H. 2018: When homoplasy is not homoplasy: dissecting trait evolution by contrasting composite and reductive coding. - Systematic Biology 67: 543-551.

Turland N. J. 2018: Preparing the New Shenzhen code. - Taxon 67: 463-464.
Vijver B. van de \& Kusber W.-H. 2018: Validation of Navicula adminensis D. Roberts \& McMinn ("Navicula adminii" D. Roberts \& McMinn) (Naviculaceae, Bacillariophyceae). - Notulae Algarum 65: 1.

Vogt R., Konowalik K. \& Oberprieler C. 2018: Karyological analysis reveals two new polyploid marguerite taxa (Leucanthemum, Compositae-Anthemideae) in S France and NW Italy. - Willdenowia 48: 221-226.

Vogt R., Lack H. W. \& Raus T. 2018: The herbarium of Ignaz Dörfler in Berlin [De herbario berolinensi notulae No. 55]. - Willdenowia 48: 57-92.

Widhelm T. J., Bertoletti F. R., Asztalos M. J., Mercado-Díaz J. A., Huang J.-P., Moncada B., Lücking R., Magain N., Sérusiaux E., Goffinet B., Crouch N., Mason-Gamer R. \& Lumbsch H. T. 2018. Oligocene origin and drivers of diversification in the genus Sticta (Lobariaceae, Ascomycota). - Molecular Phylogenetics and Evolution 126: 58-73.

Wirth V. \& Sipman H. J. M. 2018: Xanthoparmelia krcmarii, a new species from South Africa with haemathamnolic acid. - Herzogia 31: 505-509.

Wirth V., Sipman H. J. M. \& Curtis-Scott O. 2018: A sketch of the lichen biota in a Renosterveld vegetation habitat. - Carolinea 76: 35-55.

Xavier-Leite A. B., Cáceres M. E. S., Goto B. T. \& Lücking R. 2018: The genus Gyalideopsis (lichenized Ascomycota: Gomphillaceae) in Brazil: updated checklist, key to species, and two novel taxa with unique hyphophores. - The Bryologist 121: 32-40.

Yin Z.-J., Kilian N., Li B.-Z., Sun H.-Y., Zhao M.-X. \&Wang Z.-H. 2018: A new species of Melanoseris (Lactucinae, Cichorieae, Asteraceae) from SW Xizang, China, based on morphological and molecular data. - Phytotaxa 357: 189-197.

\section{Monographien}

Garve E., Matzke-Hajek G., Adler J., Bleeker W., Breunig T., Caspari S., Dunkel F. G., Fritsch R., Gottschlich G., Gregor T., Hand R., Hauck M., Korsch H., Meierott L., Meyer N., Renker C., Katrin R., Schulz D., Täuber T., Uhlemann I., Welk E., Weyer K., Wörz A., Zahlheimer W., Zehm A. \& Zimmermann F. 2018: Rote Liste und Gesamtartenliste der Farn- und Blütenpflanzen (Trachaeophyta) Deutschlands. - In: Metzing D., Hofbauer N., Ludwig G. \& Matzke Hajek G. (ed.), Rote Liste gefährdeter Tiere, Pflanzen und Pilze Deutschlands 7. Pflanzen. - Bonn-Bad Godesberg: Bundesamt für Naturschutz.

Greuter W. \& Rankin Rodríguez R. (transl.) 2018: Código internacional de nomenclatura para algas, hongos y plantas (Código de Shenzhen): adoptado por el decimonoveno Congreso Internacional de Botánica, Shenzhen, China, julio de 2017 / edición en español a cargo de Werner Greuter y Rosa Rankin Rodríguez. 
- Berlín: Stiftung Herbarium Greuter (Fundación Herbario Greuter).

Kasten J., Kusber W.-H., Riedmüller U., Tworeck A., Oschwald L. \& Mischke U. 2018: Steckbriefe der Phytoplankton-Indikatortaxa in den WRRL-Bewertungsverfahren PhytoSee und PhytoFluss mit Begleittext. - Berlin: BGBM Press.

Kusber W.-H. \& Gutowski A. 2018: Rote Liste und Gesamtartenliste der Zieralgen (Desmidiales) Deutschlands. - In: Metzing D., Hofbauer N., Ludwig G. \& Matzke Hajek G. (ed.), Rote Liste gefährdeter Tiere, Pflanzen und Pilze Deutschlands 7. Pflanzen. - BonnBad Godesberg: Bundesamt für Naturschutz.

Lack H. W. 2018: Alexander von Humboldt and the botanical exploration of the Americas, ed. 2. - London: Prestel.

Lack H. W. 2018: Alexander von Humboldt und die botanische Erforschung Amerikas, ed. 2. - München: Prestel.

Lack H. W. 2018: Redouté. The book of flowers. Das Buch der Blumen. Le livre des fleurs. - Köln: Taschen.

Lack H. W. 2018: Redouté. The book of flowers. II libro de fiori. El libro de los flores. - Köln: Taschen.

Lange P. de, Blanchon D., Knight A., Elix J. A., Lücking R., Frogley K., Harris A., Cooper J. \& Rolfe J. 2018: Conservation status of New Zealand indigenous lichens and lichenicolous fungi, 2018. - New Zealand Threat Classification Series 27.

Turland N. J., Wiersema J. H., Barrie F. R., Greuter W., Hawksworth D. L., Herendeen P. S., Knapp S., Kusber W.-H., Li D.-Z., Marhold K., May T. W., McNeill J., Monro A. M., Prado J., Price M. J. \& Smith G. F. (ed.) 2018: International Code of Nomenclature for algae, fungi, and plants (Shenzhen Code) adopted by the Nineteenth International Botanical Congress Shenzhen, China, July 2017. - Glashütten: Koeltz Botanical Books.

Rahemipour P. 2018: Bipindi - Berlin: ein wissenschaftshistorischer und künstlerischer Beitrag zur Kolonialgeschichte des Sammelns. - Berlin: BGBM Press.

\section{Herausgeberschaft}

Kusber W.-H., Abarca N., Van A. L. \& Jahn R. (ed.) 2018: Abstracts of the 25th International Diatom Symposium, Berlin 25-30 June 2018 Berlin: BGBM Press.

Christodoulou C. S., Hadjikyriakou G. N. \& Hand R. 2018: Cypricola 4-10. - Lefkosia \& Berlin: Selbstverlag der Editoren.

Greuter W., Rankin Rodríguez R. \& González Gutiérrez P. A. 2018: Flora de la República de Cuba. Fascículo 23. Combretaceae. Oxalidaceae. - Berlin: Botanischer Garten \& Botanisches Museum Berlin.
Turland N. 2018: Willdenowia: Annals of the Botanic Garden and Botanical Museum Berlin 48. - Berlin: BGBM Press.

\section{Beiträge zu Schriftenreihen, Positionspa- piere und Festschriften}

Cannon P., Aguirre-Hudson B., Aime C., Ainsworth A. M., Bidartondo M., Hawksworth D. L., Kirk P., Leitch I. \& Lücking R. 2018: 1. Definition and diversity. Pp. 4-11 in: Willis K. J. (ed.), State of the World's Fungi. Report. - Kew: Royal Botanic Gardens.

Grotz K. 2018: Between Teaching and Interior Design: The (Lost) Art of Botanical Models. In: Spendel M. (Hrsg.) 2016: Property of a Private Collection. - Berlin: Press LMP: 52-64. - Ebook: http://propertyofa privatecol-lection.press/mp.net

Hawksworth D. L. \& Lücking R. 2018: Fungal diversity revisited: 2.2 to 3.8 million species. - Pp. 79-95 in: Heitman J., Howlett B. J., Crous P. W., Stukenbrock E. H., James T. Y. \& Gow N. A. R. (ed.): The Fungal Kingdom. -Washington, DC: American Society for Microbiology.

Lack H. W. 2018: Botanik. - In: Ette, O. (ed.), Alexander von Humboldt-Handbuch : Leben - Werk - Wirkung. - Stuttgart: J. B. Metzler Verlag.

Leese F., Bouchez A., Abarenkov K., Altermatt F., Borja Á., Bruce K., Ekrem T., Čiampor Jr F., Čiamporová-Zatovičová Z., Costa F. O., Duarte S., Elbrecht V., Fontaneto D., Franc A., Geiger M. F., Hering D., Kahlert M., Kalamujić Stroil B., Kelly M., Keskin E., Liska I., Mergen P., Meissner K., Pawlowski J., Penev L., Reyjol Y., Rotter A., Steinke D., Wal B. van der, Vitecek S., Zimmermann J. \& Weigand A. M. 2018: Why we need sustainable networks bridging countries, disciplines, cultures and generations for aquatic biomonitoring 2.0: A perspective derived from the DNAqua-Net COST Action. - In: Bohan D., Dumbell A., Woodward G. \& Jackson M. (ed.), Next generation biomonitoring: Part 1. - Advances in Ecological Research 58.

Lo Presti R. M., Oberprieler C. \& Vogt R. 2018: Tribus $\mathrm{VI}$ - Anthemideae (gen. 56, 58-73, 75-79). - Pp. 815-881 in: Pignatti, S. (ed.), Flora d'Italia,ed. 2, 3. - Milano: Edagricole.

Lücking R. \& Nelsen M. P. 2018: On Ediacarans, protolichens, and lichen-derived Penicillium: a critical reassessment of the evolution of lichenization in fungi. - Pp. 551-590 in: Krings M., Harper C. J., Cuneo N. R. \& Rothwell G. W. (ed.), Transformative paleobotany: papers to commemorate the life and legacy of Thomas N. Taylor. - San Diego: Academic Press.

Niskanen T., Douglas B., Kirk P., Crous P. W., Lücking R., Matheny P. B., Cai L., Hyde K. D. \& Cheek M. 2018: New discoveries: species of fungi described 
in 2017. - Pp. 18-23 in: Willis K. J. (ed.), State of the World's fungi. Report. - Kew: Royal Botanic Gardens.

Raus T. 2018: Santorin: Vegetation und Vulkanismus. - In: Lienau C., Blume H.-D. \& Katsanakis A. (ed.), Hellenika. Jahrbuch für griechische Kultur und deutsch-griechische Beziehungen, Neue Folge 13. Münster: Lit-Verlag.

\section{Beiträge zu taxonomischen Informations- systemen}

Dimopoulos P., Raus T. \& Strid A. (ed.) 2018: Flora of Greece web. Vascular Plants of Greece. An Annotated Checklist. Version June 2018. - Published at: http:// portal.cybertaxonomy.org/flora-greece/

Raab-Straube E. von 2018: Aizoaceae. - In: Euro+Med Plantbase - the information resource for Euro-Mediterranean plant diversity. - Published at http://ww2.bgbm.org/EuroPlusMed/PTaxonDetail. asp?Nameld=907\&PTRefFk=7500000

Raab-Straube E. von 2018: Bignoniaceae. - In: Euro+Med Plantbase - the information resource for Euro-Mediterranean plant diversity. - Published at http://ww2.bgbm.org/EuroPlusMed/PTaxonDetail. asp?Nameld $=100238 \&$ PTRefFk $=7500000$

Raab-Straube E. von 2018: Celastraceae. - In: Euro+Med Plantbase - the information resource for Euro-Mediterranean plant diversity. - Published at http://ww2.bgbm.org/EuroPlusMed/PTaxonDetail. asp?Nameld $=18397 \&$ PTRefFk $=7100000$

Raab-Straube E. von 2018: Cistaceae. - In: Euro+Med Plantbase - the information resource for Euro-Mediterranean plant diversity. - Published at http://ww2.bgbm.org/EuroPlusMed/PTaxonDetail. asp?Nameld $=18774 \&$ PTRefFk $=7500000$

Raab-Straube E. von 2018: Convolvulaceae. - In: Euro+Med Plantbase - the information resource for Euro-Mediterranean plant diversity. - Published at http://ww2.bgbm.org/EuroPlusMed/PTaxonDetail. asp?Nameld $=18971 \&$ PTRefFk $=7400000$

Raab-Straube E. von 2018: Cytinaceae. - In: Euro+Med Plantbase - the information resource for Euro-Mediterranean plant diversity. - Published at http://ww2.bgbm.org/EuroPlusMed/PTaxonDetail. asp?Nameld $=27438 \&$ PTRefFk $=7500000$

Raab-Straube E. von 2018: Elaeagnaceae. - In: Euro+Med Plantbase - the information resource for Euro-Mediterranean plant diversity. - Published at http://ww2.bgbm.org/EuroPlusMed/PTaxonDetail. asp? Nameld $=94591 \&$ PTRefFk $=7400000$

Raab-Straube E. von 2018: Frankeniaceae. - In: Euro+Med Plantbase - the information resource for Euro-Mediterranean plant diversity. - Published at http://ww2.bgbm.org/EuroPlusMed/PTaxonDetail. asp? Nameld $=100168 \&$ PTRefFk $=7500000$
Raab-Straube E. von 2018: Lauraceae. - In: Euro+Med Plantbase - the information resource for Euro-Mediterranean plant diversity. - Published at http://ww2.bgbm.org/EuroPlusMed/PTaxonDetail. asp?Nameld $=25240 \&$ PTRefFk $=7500000$

Raab-Straube E. von 2018: Linaceae. - In: Euro+Med Plantbase - the information resource for Euro-Mediterranean plant diversity. - Published at http:// ww2.bgbm.org/EuroPlusMed/PTaxonDetail.asp? Nameld $=95624 \&$ PTRefFk $=7400000$

Raab-Straube E. von 2018: Martyniaceae. - In: Euro+Med Plantbase - the information resource for Euro-Mediterranean plant diversity. - Published at http://ww2.bgbm.org/EuroPlusMed/PTaxonDetail. asp?Nameld $=26346 \&$ PTRefFk $=7500000$

Raab-Straube E. von 2018: Montiaceae. - In: Euro+Med Plantbase - the information resource for Euro-Mediterranean plant diversity. - Published at http://ww2.bgbm.org/EuroPlusMed/PTaxonDetail. asp?Nameld=7300084\&PTRefFk=7300000

Raab-Straube E. von 2018: Onagraceae. - In: Euro+Med Plantbase - the information resource for Euro-Mediterranean plant diversity. - Published at http://ww2.bgbm.org/EuroPlusMed/PTaxonDetail. asp?Nameld=26049\&PTRefFk=7100000

Raab-Straube E. von 2018: Polemoniaceae. - In: Euro+Med Plantbase - the information resource for Euro-Mediterranean plant diversity. - Published at http://ww2.bgbm.org/EuroPlusMed/PTaxonDetail. asp? Nameld $=28172 \&$ PTRefFk $=7500000$

Raab-Straube E. von 2018: Polygalaceae. - In: Euro+Med Plantbase - the information resource for Euro-Mediterranean plant diversity. - Published at http://ww2.bgbm.org/EuroPlusMed/PTaxonDetail. asp?Nameld=28159\&PTRefFk=7500000

Raab-Straube E. von 2018: Rutaceae. - In: Euro+Med Plantbase - the information resource for Euro-Mediterranean plant diversity. - Published at http://ww2.bgbm.org/EuroPlusMed/PTaxonDetail. asp?Nameld $=31668 \&$ PTRefFk $=7500000$

Raab-Straube E. von 2018: Sapindaceae. - In: Euro+Med Plantbase - the information resource for Euro-Mediterranean plant diversity. - Published at http://ww2.bgbm.org/EuroPlusMed/PTaxonDetail. asp?Nameld=31689\&PTRefFk=7100000

Raab-Straube E. von 2018: Talinaceae. - In: Euro+Med Plantbase - the information resource for Euro-Mediterranean plant diversity. - Published at http://ww2.bgbm.org/EuroPlusMed/PTaxonDetail. asp? Nameld $=7300085 \&$ PTRefFk $=7300000$

Raab-Straube E. von \& Henning T. 2018: Violaceae. In: Euro+Med Plantbase - the information resource for Euro-Mediterranean plant diversity. - Published at http://ww2.bgbm.org/EuroPlusMed/PTaxonDetail. asp?Nameld $=35443 \&$ PTRefFk $=7500000$ 


\section{Nicht-begutachtete Zeitschriftenartikel}

Brokamp G., Steinecke H. \& Cole T. C. H. 2018: Palmen - eine systematische Übersicht. - Der Palmengarten, Sonderheft 50: 9-14.

Couvreur T. L. P., Kamga Mogue S. \& Brokamp G. 2018: Raphia - Afrikanische Bäume des Lebens. - Der Palmengarten, Sonderheft 50: 54-61.

Flores-Olvera H., Ochoterena H., Arias S., Berendsohn W. G., Borsch T., Mering S. von \& Zuloaga F. O. 2018. The Caryophyllales 2018 Conference in Mexico \& Advances of the Global Caryophyllales Initiative. Taxon 67: 1253-1254.

Gomes de Freitas C. \& Brokamp G. 2018: Attalea speciosa, die Babassupalme. - Der Palmengarten 82: 29-37.

Grotz K. 2018: Statt Nelken, Pfeffer und Zimt: wie Pflanzen aus der Neuen Welt unseren Speisezettel veränderten. - Museumsjournal 2018(2): 26-27.

Jahn R. 2018: Rezension zu: Krienitz, Lothar: Die Nachfahren des Feuervogels Phönix. 1. Auflage. Berlin: Springer, 2018. 978-3662-56586-5. - News / GfBS 35: 36-37.

Jahn R., Abarca N., Kusber W.-H., Mora D. \& Zimmermann J. 2018: Preface. - In: Kusber W.-H., Abarca N., Van A. L. \& Jahn R. (ed.), Abstracts of the 25th International Diatom Symposium, Berlin 25-30 June 2018. Berlin: BGBM Press.

\section{Artikel in begutachteten Zeitschriften}

Akhani H., Samadi N., Noormohammadi A. \& Borsch T. 2019: A new species of Tamarix (Tamaricaceae) from Hormozgan Province, S Iran, supported by morphology and molecular phylogenetics. - Willdenowia 49: 127-139.

Al-Handal A. Y., Wulff A., Riaux-Gobin C., Jahn R. 2019: Two new ma rine species of Cocconeis (Bacillariophyceae) from the west coast of Sweden. - European Journal of Taxonomy 497: 1-16.

Al-Handal A. Y., Zimmermann J., Jahn R., Torstensson A. \& Wulff A. 2019: Nitzschia biundulata sp. nov. a new sea ice diatom (Bacillariophyceae) from the Ross Sea, Antarctica. - Nova Hedwigia 108: 281-290.

Aptroot A., Maphangwa K. W., Zedda L., Tekere M., Alvarado P. \& Sipman H. J. M. 2019: The phylogenetic position of Culbersonia is in the Caliciaceae (lichenized ascomycetes). - The Lichenologist 51: 187-191.

Aptroot A., Sipman H. J. M., Barreto F. M. O., Nunes A. D. \& Cáceres M. E. S. 2019: Ten new species and 34
Lack H. W. 2018: Gartenreisen nach England um 1790: der ,jardinier de Vienne“, Henriette Freifrau von Itzenplitz und die Pagode von Schönenberg. Historische Gärten 24: 25-28.

Lack H. W. \& Wissemann V. 2018: Gerhard Wagenitz (1927-2017). - Willdenowia 48: 147-160.

Marquardt J., Güntsch A., Zizka G., Koch M. A. \& Borsch T. 2018: Was wächst wo?: Ein Online-Portal für die Lebendsammlungen Botanischer Gärten. News / GfBS 35: 53-55.

Mischke U., Kusber W.-H., Kasten J., Hoehn E., Tworeck A., Oschwald L., Dürselen C.-D., Täuscher L. \& Riedmüller 2018: Aktualisierung der Taxaliste Phytoplankton für die WRRL-Bewertungsverfahren. - In: Deutschen Gesellschaft für Limnologie (DGL) (ed.), Ergebnisse der Jahrestagung 2017 der Deutschen Gesellschaft für Limnologie (DGL) und der deutschen und österreichischen Sektion der Societas Internationalis Limnologiae (SIL), Brandenburgische Technische Universität Cottbus-Senftenberg: Cottbus, 25.29. Sept. 2017. - Hardegsen: Eigenverlag der DGL.

Mora D. 2018: Diatom research over time and space" -The Bryologist 120: 549-550

Seitz H. \& Hand R. 2018: Anmerkungen zu einem Thalictrum minus-Vorkommen im Mittelfränkischen Becken. - Regnitzflora 9: 68-70.

new country records of Trypetheliaceae. - The Lichenologist 51: 27-43.

Belous O. P., Genkal S. I., Jahn R. \& Zimmermann J. 2019: Rare species of centric diatom algae (Bacillariophyta, Centrophyceae) from Ukraine. - International Journal on Algae 21: 67-74.

Belous O. P., Genkal S. I., Jahn R. \& Zimmermann J. 2019: Редкие виды центрических диатомовых водорослей (Bacillariophyta, Centrophyceae) для флоры Украины [Rare species of centric diatom algae (Bacillariophyta, Centrophyceae) from Ukraine]. Al'gologia 29: 77-87.

Canal D., Köster N., Celis M., Croat T. B., Borsch T. \& Jones K. E. 2019: Out of Amazonia and back again: historical biogeography of the species-rich neotropical genus Philodendron (Araceae). - Annals of the Missouri Botanical Garden 104: 49-68.

Cavalcante J. G., Santos L. A., Aptroot A., Lücking R. \& Cáceres M. E. S. 2019: A new species of Lecanora (Ascomycota: Lecanoraceae) from mangrove in northeast Brazil identified using DNA barcoding and phenotypical characters. - The Bryologist 122: 553-558.
BGBM- 
Dal Forno M., Kaminsky L., Rosentreter R., McMullin R. T., Aptroot A. \& Lücking R. 2019: A first phylogenetic assessment of Dictyonema s.lat. in southeastern North America reveals three new basidiolichens, described in honor of James D. Lawrey. - Plant and Fungal Systematics 64: 383-392.

Dillen M., Groom Q., Chagnoux S., Güntsch A., Hardisty A., Haston E., Livermore L., Runnel V., Schulman L., Willemse L., Wu Z. \& Phillips S. 2019: A benchmark dataset of herbarium specimen images with label data. - Biodiversity Data Journal 7: e31817.

Elbrächter M., Gottschling M., Hoppenrath M., Jahn R., Montresor M., Tillmann U. \& Kusber W.-H. 2019: (2686) Proposal to conserve the name Alexandrium against Blepharocysta (Dinophyceae). - Taxon 68: 589-590.

Gavalas I. \& Sipman H. J. M. 2019: A lichen inventory on the island of Iraklia (Cyclades Islands, Greece). Parnassiana Archives 7: 31-49.

Gottschling M., Tillmann U., Elbrächter M., Kusber W.-H. \& Hoppenrath M. 2019: Glenodinium triquetrum Ehrenb. is a species not of Heterocapsa F.Stein but of Kryptoperidinium Er.Lindem. (Kryptoperidiniaceae, Peridiniales). - Phytotaxa 391: 155-158.

Gottschling M., Tillmann U., Kusber W.-H., Elbrächter M. \& Hoppenrath M. 2019: To be or not to be: On the usefulness of infraspecific names in Heterocapsa steinii (Heterocapsaceae, Peridiniales). - Phytotaxa 395: 134-136.

Greuter W. \& Karl R. 2019: Ein neues Johanniskraut von den Kykladen (Ägäis, Griechenland): Hypericum (sect. Drosocarpium) perfoliatum subsp. phitosianum (Hypericaceae). - Botanika Chronika 22: 39-47.

Hamilton P. B., Savoie A. M., Sayre C. M., Skibbe O., Zimmermann J. \& Bull R. D. 2019: Novel Neidium Pfitzer species from western Canada based upon morphology and plastid DNA sequences. - Phytotaxa 419: 39-62.

Hamilton P. B., Stachura-Suchoples K., Kusber W.H., Bouchard A. \& Jahn R. 2019: Typification of the puzzling diatom species Neidium iridis (Neidiaceae). Plant Ecology and Evolution 152: 392-401.

Henning T., Acuña Castillo R., Rodríguez Rodríguez E. F., García Llatas L. F. \& Weigend M. 2019: A new striking and critically endangered species of Nasa (Loasaceae, Cornales) from North Peru. - PhytoKeys 121: 13-28.

Herrera-Campos M. Á., Barcenas-Peña A., Miranda-González R., Mejía M. A., González J. A. B., Colín P. M., Téllez N. S. \& Lücking R. 2019: New lichenized Arthoniales and Ostropales from Mexican seasonally dry tropical forest. - The Bryologist 122: 62-83.

Hyde K. D., Tennakoon D. S., Jeewon R., Bhat D. J., Maharachchikumbura S. S. N., Rossi W., Leonardi M.,
Lee H. B., Mun H. Y., Houbraken J., Nguyen T. T. T., Jeon S. J., Frisvad J. C., Wanasinghe D. N., Lücking R., Aptroot A., Cáceres M. E. S., Karunarathna S. C., Hongsanan S., Phookamsak R., Silva N. I., Thambugala K. M., Jayawardena R. S., Senanayake I. C., Boonmee S., Chen J., Luo Z.-L., Phukhamsakda C., Pereira O. L., Abreu V. P., Rosado A. W. C., Bart B., Randrianjohany E., Hofstetter V., Gibertoni T. B., Silva Soares A. M., Plautz H. L., Sotão H. M. P., Xavier W. K. S., Bezerra J. D. P., Oliveira T. G. L., Souza-Motta C. M., Magalhães O. M. C., Bundhun D., Harishchandra D., Manawasinghe I. S., Dong W., Zhang S.-N., Bao D.-F., Samarakoon M. C., Pem D., Karunarathna A., Lin C.-G., Yang J., Perera R. H., Kumar V., Huang S.K., Dayarathne M. C., Ekanayaka A. H., Jayasiri S. C., Xiao Y., Konta S., Niskanen T., Liimatainen K., Dai Y.C., Ji X.-H., Tian X.-M., Mešić A., Singh S. K., Phutthacharoen K., Cai L., Sorvongxay T., Thiyagaraja V., Norphanphoun C., Chaiwan N., Lu Y.-Z., Jiang H.-B., Zhang J.-F., Abeywickrama P. D., Aluthmuhandiram J. V. S., Brahmanage R. S., Zeng M., Chethana T., Wei D., Réblová M., Fournier J., Nekvindová J., Nascimento Barbosa R., Santos J. E. F., Oliveira N. T., Li G.-J., Ertz D., Shang Q.-J., Phillips A. J. L., Kuo C.-H., Camporesi E., Bulgakov T. S., Lumyong S., Jones E. B. G., Chomnunti P., Gentekaki E., Bungartz F., Zeng X.-Y., Fryar S., Tkalčec Z., Liang J., Li G., Wen T.-C., Singh P. N., Gafforov Y., Promputtha I., Yasanthika E., Goonasekara I. D., Zhao R.-L., Zhao Q., Kirk P. M., Liu J.-K., Yan J., Mortimer P. E., Xu J. \& Doilom M. 2019: Fungal diversity notes 1036-1150: taxonomic and phylogenetic contributions on genera and species of fungal taxa. - Fungal Diversity 96: 1-242.

Jagielski T., Bakuła Z., Gawor J., Maciszewski K., Kusber W.-H., Dyląg M., Nowakowska J., Gromadka R. \& Karnkowska A. 2019: The genus Prototheca (Trebouxiophyceae, Chlorophyta) revisited: implications from molecular taxonomic studies. - Algal Research 43: 101639.

Jahn R., Kusber W.-H., Skibbe O., Zimmermann J., Van A. T., Buczkó K. \& Abarca N. 2019: Gomphonella olivacea (Bacillariophyceae) - a new phylogenetic position for a well-known taxon, its typification, new species and combinations. - Plant Ecology and Evolution 152: 219-247.

Jatnika M. F., Weerakoon G., Arachchige O., Noer I. S., Voytsekhovich A. \& Lücking R. 2019: Discoveries through social media and in your own backyard: two new species of Allographa (Graphidaceae) with pigmented lirellae from the Palaeotropics, with a world key to species of this group. - The Lichenologist 51: 227-233.

Jones K., Fér T., Schmickl R. E., Dikow R. B., Funk V. A., Herrando-Moraira S., Johnston P. R., Kilian N., Siniscalchi C. M., Susanna A., Slovák M., Thapa R., Watson L. E. \& Mandel J. R. 2019: An empirical assessment of a single family-wide hybrid capture locus 
set at multiple evolutionary timescales in Asteraceae. - Applications in Plant Sciences 7: e11295.

Kraichak E., Allende L., Obermayer W., Lücking R. \& Lumbsch H. T. 2019: Scale-dependent co-occurrence patterns of closely related genotypes in a lichen species complex. - Plant and Fungal Systematics 64: 163-172.

Kusber W.-H., Kohlbecker A., Mohamad H., Güntsch A., Berendsohn W. G. \& Jahn R. 2019: Registration of algal novelties in PhycoBank: serving the scientific community and filling gaps in the global names backbone. - Biodiversity Information Science and Standards 3: 37285 .

Kusber W.-H. \& Lange-Bertalot H. 2019: Navicula metareichardtiana Lange-Bertalot \& Kusber, a new name for Navicula reichardtiana Lange-Bertalot, nom. illeg. (Naviculaceae, Bacillariophyta). - Notulae Algarum 102: $1-2$

Lack H. W. 2019: The discovery and naming of Papaver orientale s. I. (Papaveraceae) with notes on its nomenclature and early cultivation. - Candollea 74: 47-64.

Lack H.W. 2019: Proposal to conserve the name Papaver pseudo-orientale (Fedde) Medw. against P. $\times$ pseudo-orientale E. G. Camus. - Taxon 68: 406-407.

Lack H. W. 2019: Michiel's Codice erbario (c. 1550) and the flora of Greece. - Botanika Chronika 22: 63-72.

Lack H. W. 2019: Flora Graeca on the European continent. - Gardens' Bulletin Singapore 71 Suppl. 2: 107-120.

Lack H. W., Rabe K. \& Kilian N. 2019: The Reuss herbarium. - Willdenowia 49: 197-208.

Lima E. L., Maia L. C., Barroso Martins M. C., Silva N. L., Lücking R. \& Cáceres M. E. S. 2019: Five new species of Graphidaceae from the Brazilian Northeast, with notes on Diorygma alagoense. - The Bryologist 122: $414-422$.

Lücking R. 2019: Stop the abuse of time! Strict temporal banding is not the future of rank-based classifications in fungi (including lichens) and other organisms. - Critical Reviews in Plant Sciences 38: 199-253.

Lücking, R. 2019: Corrigendum: Correction. Stop the abuse of time! A critical review of temporal banding for rank-based classifications in Fungi (including lichens) and other organisms. - Critical Review in Plant Sciences 38: 431.

Lücking R., Moncada B. \& Hawksworth D. L. 2019: Gone with the wind: sequencing its type species supports inclusion of Cryptolechia in Gyalecta (Ostropales: Gyalectaceae). - The Lichenologist 51: 287-299.
Lücking R., Moncada B., Martínez-Habibe M. C., Salgado-Negret B. E., Celis M., Rojas-Zamora O., Rodríguez-M G. M., Brokamp G. \& Borsch T. 2019: Biological diversity on Colombian Caribbean dry forest remnants in Atlántico: lichen communities in Distrito Regional de Manejo Integrado Luriza and the Reserva Forestal Protectora El Palomar. - Caldasia 41: 194-214.

May T. W., Redhead S. A., Bensch K., Hawksworth D. L., Lendemer J., Lombard L. \& Turland N. J. 2019: Chapter F of the International Code of Nomenclature for algae, fungi, and plants as approved by the 11th International Mycological Congress, San Juan, Puerto Rico, July 2018. - IMA Fungus 10: 21.

Menteli V., Krigas N., Avramakis M., Turland N. \& Vokou D. 2019: Endemic plants of Crete in electronic trade and wildlife tourism: current patterns and implications for conservation. - Journal of Biological Research-Thessaloniki 26: 10.

Mittelbach M., Kolbaia S., Weigend M. \& Henning T. 2019: Flowers anticipate revisits of pollinators by learning from previously experienced visitation intervals. - Plant Signaling \& Behavior 14: 1595320.

Moncada B., Pérez-Pérez R. E. \& Lücking R. 2019: The lichenized genus Cora (Basidiomycota: Hygrophoraceae) in Mexico: high species richness, multiple colonization events, and high endemism. - Plant and Fungal Systematics 64: 393-411.

Mora D., Abarca N., Proft S., Grau J. H., Enke N., Carmora J., Skibbe O., Jahn R. \& Zimmermann J. 2019: Morphology and metabarcoding: a test with stream diatoms from Mexico highlights the complementarity of identification methods. - Freshwater Science 38: 448-464.

Mora D., Abarca N., Zimmermann J., Bansemer J., Proft S., Skibbe O., Carmora J. \& Jahn R. 2019: A barcode reference library of stream diatoms from Central Mexico: setting the baseline for eDNA-based diversity assessments and biomonitoring. - Genome 62: 411 .

Motta K., Amórtegui K., Moncada B. \& Lücking R. 2019: New species in the genus Graphis with transversally septate ascospores (Ascomycota: Ostropales: Graphidaceae) from Colombia. - Phytotaxa 401: 257-266.

Naksuwankul K. \& Lücking R. 2019: Three new species and new records of foliicolous lichen genus Porina (Porinaceae, Ostropales) and artificial key to species from Thailand. - Phytotaxa 400: 51-63.

Nelsen M. P., Lücking R., Boyce C. K., Lumbsch H. T. \& Ree R. H. 2019: No support for the emergence of lichens prior to the evolution of vascular plants. Geobiology 18: 3-13.

Oberprieler C., Schinhärl L., Wagner F., Hugot L. \& Vogt R. 2019: Karyological and molecular analysis of 
Leucanthemum (Compositae, Anthemideae) in Corsica. -Willdenowia 49: 411-420.

Olivier-Jimenez D., Chollet-Krugler M., Rondeau D., Beniddir M. A., Ferron S., Delhaye T., Allard P.-M., Wolfender J.-L., Sipman H. J. M., Lücking R., Boustie J. \& Le Pogam P. 2019: A database of high-resolution MS/MS spectra for lichen metabolites. - Scientific Data 6: 294

Panitsa M., Iliadou. E., Kokkoris I., Kallimanis A., Patelodimou C., Strid A., Raus T., Bergmeier E. \& Dimopoulos P. 2019: Distribution patterns of ruderal plant diversity in Greece. - Biodiversity and Conservation 28: 1-23.

Raab-Straube E. von 2019: From Flora Europaea and Med-Checklist to Euro+Med PlantBase: the never-ending task for a happy Sisyphos. - Bocconea 28: 271-272.

Raab-Straube E. von \& Raus T. 2019: Euro+Med-Checklist Notulae, 10 [Notulae ad floram euromediterraneam pertinentes No. 39]. - Willdenowia 49: 95-115.

Raab-Straube E. von \& Raus T. 2019: Euro+Med-Checklist Notulae, 11 [Notulae ad floram euromediterraneam pertinentes No. 40]. - Willdenowia 49: 421-445.

Rabone M., Harden-Davies H., Collins J. E., Zajderman S., Appeltans W., Droege G., Brandt A., Pardo-Lopez L., Dahlgren T. G., Glover A. G., Horton T. 2019: Access to Marine Genetic Resources (MGR): raising awareness of best-practice through a new agreement for Biodiversity Beyond National Jurisdiction (BBNJ). - Frontiers in Marine Science 6: 520.

Raimondo F. M., Gabrielian E. \& Greuter W. 2019: The genus Aria (Sorbus s. I. Rosaceae) in the Sicilian flora: taxonomic updating re-evaluation, description of a new species and two new combinations for one Sicilian and one SW Asian species. - Botanika Chronika 22: 15-37.

Raus T. 2019: Zitierhygiene 5: „Unter Wölf(f)en“: Wolf, F. O. Wolf, Joh. Wolf, Th. Wolf, H. Wolff, J. P. Wolff, M. Wolff und P. Wolff als Nomenklatoren mitteleuropäischer Phanerogamen. - Kochia 12: 115-134.

Raus T., Karadimou E. \& Dimopoulos P. 2019: Taxonomic and functional plant diversity of the Santorini-Christiana island group (Aegean Sea, Greece). -Willdenowia 49: 363-381.

Rimet F., Gusev E., Kahlert M., Kelly M., Kulikovskiy M., Maltsev Y., Mann D. G., Pfannkuchen M., Trobajo R., Vasselon V., Zimmermann J., Bouchez A. 2019: Diat.barcode, an open-access curated barcode library for diatoms. Scientific Reports 9: 15116.

Santos L. A., Aptroot A., Lücking R. \& Cáceres M. E. S. 2019: High diversification in the Neoprotoparmelia multifera complex (Ascomycota, Parmeliaceae) in northeast Brazil revealed by DNA barcoding and phenotypical characters. - The Bryologist 122: 539-552.

Santos V. M. O., Cáceres M. E. S. \& Lücking R. 2019. Diversity of foliicolous lichens in isolated montane rainforests (Brejos) of northeastern Brazil and their biogeography in a neotropical context. - Ecological Research 219: 1-16.

Schneider F. D., Fichtmüller D., Gossner M. M., Güntsch A., Jochum M., König-Ries B., Le Provost G., Manning P., Ostrowski A., Penone C. \& Simons N. K. 2019: Towards an ecological trait data standard. Methods in Ecology and Evolution 10: 2006-2019.

Schroer S., Häffner E. \& Hölker F. 2019: Impact of artificial illumination on the development of a leafmining moth in urban trees. - International Journal of Sustainable Lighting 21: 1-10.

Silakadze N., Kilian N., Korotkova N., Mosulishvili M. \& Borsch T. 2019: Multiple evolutionary origins of high mountain bellflowers with solitary flowers and calyx scales render a core Caucasian clade of the Scapiflorae group (Campanulaceae). - Systematics and Biodiversity 17: 690-711.

Soto-Medina E., Lücking R., Silverstone-Sopkin P. A. \& Torres A. M. 2019: Changes in functional and taxonomic diversity and composition of corticolous lichens in an altitudinal gradient in Colombia. Cryptogamie Mycologie 40: 97-115.

Szukala A., Korotkova N., Gruenstaeudl M., Sennikov A. N., Lazkov G. A., Litvinskaya S. A., Gabrielian E., Borsch T. \& Raab-Straube E. von 2019: Phylogeny of the Eurasian genus Jurinea (Asteraceae: Cardueae): support for a monophyletic genus concept and a first hypothesis on overall species relationships. - Taxon 68: 112-131.

Tzanoudakis D., Tsakiri M. \& Raus T. 2019: What is Allium achaium Boiss. \& Orph.?: disentangling the taxonomy of a Greek mountain species. - Willdenowia 49: 231-239.

Wagner F., Ott T., Zimmer C., Reichhart V., Vogt R. \& Oberprieler C. 2019: "At the crossroads towards polyploidy": genomic divergence and extent of homoploid hybridization are drivers for the formation of the ox-eye daisy polyploid complex (Leucanthemum, Compositae-Anthemideae). - New Phytologist 223: 2039-2053.

Weerakoon G., Aptroot A., Lücking R., Arachchige O. \&Wijesundara S. 2019: Graphis and Allographa (lichenized Ascomycota: Graphidaceae) in Sri Lanka, with six new species and a biogeographical comparison investigating a potential signature of the "biotic ferry" species interchange. - The Lichenologist 51: 515-559.

Widhelm T. J., Grewe F., Huang J.-P., Mercado-Díaz J. A., Goffinet B., Lücking R., Moncada B., Mason-Gamer R. \& Lumbsch H. T. 2019: Multiple historical 
processes obscure phylogenetic relationships in a taxonomically difficult group (Lobariaceae, Ascomycota). - Scientific Reports 9: 8968.

Zakeri Z., Sipman H., Paukov A. \& Otte V. 2019: Neotypification of Aspiciliella cupreoglauca and lectotypification and synonymization of Aspicilia reticulata (Megasporaceae, Ascomycota). - The Lichenologist 51: 97-99.

Zakeri Z., Sipman H., Paukov A. \& Otte V. 2019: Validation of the typifications of Aspiciliella cupreoglauca and Aspicilia reticulata. - The Lichenologist 51: 493.

Zimmermann J., Abarca N., Bansemer J., Bettig J., Dröge G., Kusber W.-H., Luther K., Mora D., Proft S., Skibbe O., Van A. L. \& Jahn R. 2019: German Barcode of Life 2 (GBOL2): diatom DNA barcoding and eDNA metabarcoding in the context of the EU Water Framework Directive (2000/60/EC). - Genome 62: 453.

\section{Monographien}

Brandstetter J. \& Zippel E. 2019: Wie Schmetterlinge leben: wundersame Verwandlungen, raffinierte Täuschungen und prächtige Farbspiele. - Bern: Haupt Verlag.

Greuter W. 2019: Inventario de las plantas cubanas silvestres parientes de las cultivadas de importancia alimenticia, agronómica y forestal = A checklist of Cuban wild relatives of cultivated plants important for food, agriculture and forestry. - Berlin, Havanna: Botanischer Garten und Botanisches Museum Berlin \& Jardín Botánico Nacional, Universidad de La Habana.

Lack H. W. 2019: Kauneimmat Kukat. Pierre-Joseph Redoutén maalauksina. De vackraste blommorna målade av Pierre-Joseph Redouté. The book of flowers - Helsinki.

Lack, H. W. 2019: Alexander von Humboldt und die botanische Erforschung Amerikas, ed. 3. - München: Prestel.

Turland N. J. 2019: The code decoded: a user's guide to the International Code of Nomenclature for algae, fungi, and plants. - Sofia: Pensoft Publishers.

\section{Herausgeberschaft}

Christodoulou C. S., Hadjikyriakou G. N. \& Hand R. 2019: Cypricola 12-14. - Lefkosia \& Berlin: Selbstverlag der Editoren.

Dau A., Köster N. \& Schlumpberger B. 2019: Forscher, Sammler, Pflanzenjäger - unterwegs mit Humboldt \& Co: eine Ausstellung des Verbands Botanischer Gärten zum 250. Geburtstag Alexander von Humboldts. - Osnabrück: Verband Botanischer Gärten e.V.
Greuter W., Rankin Rodríguez R. \& González Gutiérrez P. A. 2019: Flora de la República de Cuba. Serie A, Plantas vasculares, Fascículo 24: Malpighiaceae - Berlin: Botanischer Garten und Botanisches Museum Berlin.

Greuter W., Rankin Rodríguez R. \& González Gutiérrez P. A. 2019: Flora de la República de Cuba. Serie A, Plantas vasculares, Fascículo 25: Gesneriaceae, Surianaceae - Berlin: Botanischer Garten und Botanisches Museum Berlin.

Grotz K. 2019: Geliebt, gegossen, vergessen: Phänomen Zimmerpflanze. - Berlin: BGBM Press.

Parolly G. \& Rohwer J. G. (ed.) 2019: Schmeil-Fitschen. Die Flora Deutschlands und angrenzender Länder: ein Buch zum Bestimmen aller wildwachsenden und häufig kultivierten Gefäßpflanzen, 97. überarbeitete und erweiterte Auflage. - Wiebelsheim: Quelle \& Meyer.

Rahemipour P. \& Grotz K. 2019: Wie Wissen wächst. Alexander von Humboldt, ein Album amicorum und die Pflanzen. - Pp. 65-74 in: Blankenstein D., Savoy B., Gross R. \& Scriba A. (ed.), Wilhelm und Alexander von Humboldt. - Darmstadt: wbg (Wissenschaftliche Buchgesellschaft).

Turland N. 2019: Willdenowia: Annals of the Botanic Garden and Botanical Museum Berlin, 49. - Berlin: BGBM Press.

Turland N. 2019: Englera: Serial publication of the Botanic Garden and Botanical Museum Berlin, 35-36. - Berlin: BGBM Press.

\section{Beiträge zu Schriftenreihen, Positionspa- piere und Festschriften}

Greuter W. 2019: Dimitrios Phitos - a dedication. Botanika Chronika 22: V-VIII.

Grotz K. 2019: Botanical dioramas - just beautiful? Pp. 89-98 in: Scheersoi A. \& Dale Tunnicliffe S. (ed.), Natural history dioramas - traditional exhibits for current educational themes: socio-cultural aspects. Cham: Springer International Publishing.

Grotz K. 2019: Nachruhm - Die Humboldt-Orte. Pp. 181-185 in: Spies P., Tintemann U. \& Mende J. (ed.) 2019: Berliner Kosmos. - Alexander und Wilhelm von Humboldt in Berlin. - Berlin: Wienand.

Grotz K. \& Rahemipour P. 2019: Wie Wissen wächst. Alexander von Humboldt, ein Album amicorum und die Pflanzen. Pp. 65-74 in: Blankenstein D., Savoy B., Gross R. \& Scriba A. (ed.) 2019: Wilhelm und Alexander von Humboldt. Katalog zur gleichnamigen Ausstellung im Deutschen Historischen Museum. Darmstadt: Theiss.

Grotz K. \& Rahemipour P. 2019: Pflanze, Ikone, Phänomen: der Gummibaum. - Pp. 112-117 in: Grotz K. 
\& Rahemipour P. (ed.), Geliebt, gegossen, vergessen: Phänomen Zimmerpflanze. - Berlin: BGBM Press.

Häffner E. 2019: Wem gehören die Zimmerpflanzen? - Pp. 126-129 in: Grotz K. \& Rahemipour P. (ed.), Geliebt, gegossen, vergessen: Phänomen Zimmerpflanze. - Berlin: BGBM Press.

Köster N. 2019: Das schönste Blatt am Fenster: Familiengeschichte einer echten Berliner Pflanze. - Pp. 106-111 in: Grotz K. \& Rahemipour P. (ed.), Geliebt, gegossen, vergessen: Phänomen Zimmerpflanze. Berlin: BGBM Press.

Lack H. W. 2019: Die Einführung der binären Nomenklatur für Pflanzen im Ostseeraum. - Pp. 137-160 in: Kiefer J., Kästner I. \& Manger K. (ed.), Der Ostseeraum aus wissenschafts- und kulturhistorischer Sicht. - Europäische Wissenschaftsbeziehungen 15, Aachen: Shaker Verlag.

Lack H. W. 2019: Bekanntes im Unbekannten. - Pp. 36-39 in: Dau A., Köster N. \& Schlumpberger B. (ed.), Forscher, Sammler, Pflanzenjäger - unterwegs mit Humboldt \& Co. - Osnabrück: Verband Botanischer Gärten e.V.

Lack H. W. 2019: Nikolaus Joseph Jacquin. Collector of sugar apple trees and menageries for the Emperor. - Pp. 26-35 in: Anon. (ed.), Nature's explorers. Adventurers who recorded the wonders of the natural world. - London: Natural History Museum; \& 2019: Nikolaus Joseph Jacquin, Zimtapfelbäume und exotische Tiere für den Kaiser. - Pp. 26-35 in: Anon. (ed.), Naturerkundungen mit Skizzenheft und Staffelei. 23 Forschungsreisende aus vier Jahrhunderten. - Bern: Haupt Verlag.

Lack H. W. 2019: Alexander von Humboldt. My estate for my expedition. - Pp. 78-87 in: Anon. (ed.), Nature's explorers. Adventurers who recorded the wonders of the natural world. - London: Natural History Museum; \& 2019: Alexander von Humboldt. Mein Erbe für meine Expedition. - Pp. 78-87 in: Anon. (ed.), Naturerkundungen mit Skizzenheft und Staffelei. 23 Forschungsreisende aus vier Jahrhunderten. - Bern: Haupt Verlag.

Lack H. W. 2019: Künstliche und natürliche Systeme und ihre Anwendung auf die Botanik. - Pp. 194-205 in: Knebel K., Maul G. \& Schmuck T. (ed.), Abenteuer der Vernunft. Goethe und die Naturwissenschaften um 1800. - Dresden : Sandstein Verlag.

Lack H. W. 2019: Der große Unterschied. Die Herbarien von Goethe und Humboldt. - Pp. 252-261 in: Knebel K., Maul G. \& Schmuck T. (ed.), Abenteuer der Vernunft. Goethe und die Naturwissenschaften um 1800. - Dresden : Sandstein Verlag.

Nordt B. 2019: Apiales. - In: Parolly G. \& Rohwer J. G. (ed.), Schmeil-Fitschen. Die Flora Deutschlands und angrenzender Länder, 97. überarbeitete und erweiterte Auflage. - Wiebelsheim: Quelle \& Meyer.
Nordt B. 2019: Fabales. - In: Parolly G. \& Rohwer J. G. (ed.), Schmeil-Fitschen. Die Flora Deutschlands und angrenzender Länder, 97. überarbeitete und erweiterte Auflage. - Wiebelsheim: Quelle \& Meyer.

Nordt B. 2019: Malvales. - In: Parolly G. \& Rohwer J. G. (ed.), Schmeil-Fitschen. Die Flora Deutschlands und angrenzender Länder, 97. überarbeitete und erweiterte Auflage. - Wiebelsheim: Quelle \& Meyer.

Nordt B. 2019: Zygophyllales. - In: Parolly G. \& Rohwer J. G. (ed.), Schmeil-Fitschen. Die Flora Deutschlands und angrenzender Länder, 97. überarbeitete und erweiterte Auflage. - Wiebelsheim: Quelle \& Meyer.

Parolly G. 2019: Acorales. - In: Parolly G. \& Rohwer J. G. (ed.), Schmeil-Fitschen. Die Flora Deutschlands und angrenzender Länder, 97. überarbeitete und erweiterte Auflage. - Wiebelsheim: Quelle \& Meyer.

Parolly G. 2019: Alismatales. - In: Parolly G. \& Rohwer J. G. (ed.), Schmeil-Fitschen. Die Flora Deutschlands und angrenzender Länder, 97. überarbeitete und erweiterte Auflage. - Wiebelsheim: Quelle \& Meyer.

Parolly G. 2019: Allgemeines zum Aufbau und Inhalt der Flora: Grundbegriffe, Leitlinien und Konzepte: allgemeines zum Bestimmen und Sammeln von Pflanzen, Bemerkungen zur Flora und Vegetation des Gebiets. - In: Parolly G. \& Rohwer J. G. (ed.), Schmeil-Fitschen. Die Flora Deutschlands und angrenzender Länder, 97. überarbeitete und erweiterte Auflage. -Wiebelsheim: Quelle \& Meyer.

Parolly G. 2019: Arecales. - In: Parolly G. \& Rohwer J. G. (ed.), Schmeil-Fitschen. Die Flora Deutschlands und angrenzender Länder, 97. überarbeitete und erweiterte Auflage. - Wiebelsheim: Quelle \& Meyer.

Parolly G. 2019: Asparagales. - In: Parolly G. \& Rohwer J. G. (ed.), Schmeil-Fitschen. Die Flora Deutschlands und angrenzender Länder, 97. überarbeitete und erweiterte Auflage. - Wiebelsheim: Quelle \& Meyer.

Parolly G., Raab-Straube E. von \& Vogt R. 2019: Asterales: Asteraceae. - In: Parolly G. \& Rohwer J. G. (ed.), Schmeil-Fitschen. Die Flora Deutschlands und angrenzender Länder, 97. überarbeitete und erweiterte Auflage. - Wiebelsheim: Quelle \& Meyer.

Parolly G. 2019: Asterales: Campanulaceae; Menyanthaceae. - In: Parolly G. \& Rohwer J. G. (ed.), Schmeil-Fitschen. Die Flora Deutschlands und angrenzender Länder, 97. überarbeitete und erweiterte Auflage. Wiebelsheim: Quelle \& Meyer.

Parolly G. 2019: Brassicales. - In: Parolly G. \& Rohwer J. G. (ed.), Schmeil-Fitschen. Die Flora Deutschlands und angrenzender Länder, 97. überarbeitete und erweiterte Auflage. - Wiebelsheim: Quelle \& Meyer.

Parolly G. 2019: Caryophyllales (excl. Droseraceae). In: Parolly G. \& Rohwer J. G. (ed.), Schmeil-Fitschen. 
Die Flora Deutschlands und angrenzender Länder, 97. überarbeitete und erweiterte Auflage. - Wiebelsheim: Quelle \& Meyer.

Parolly G. 2019: Dioscoreales. - In: Parolly G. \& Rohwer J. G. (ed.), Schmeil-Fitschen. Die Flora Deutschlands und angrenzender Länder, 97. überarbeitete und erweiterte Auflage. - Wiebelsheim: Quelle \& Meyer.

Parolly G. 2019: Dipsacales. - In: Parolly G. \& Rohwer J. G. (ed.), Schmeil-Fitschen. Die Flora Deutschlands und angrenzender Länder, 97. überarbeitete und erweiterte Auflage. - Wiebelsheim: Quelle \& Meyer.

Parolly G. 2019: Liliales. - In: Parolly G. \& Rohwer J. G. (ed.), Schmeil-Fitschen. Die Flora Deutschlands und angrenzender Länder 97. überarbeitete und erweiterte Auflage. - Wiebelsheim: Quelle \& Meyer.

Parolly G. 2019: Violaceae. - In: Parolly G. \& Rohwer J. G. (ed.), Schmeil-Fitschen. Die Flora Deutschlands und angrenzender Länder, 97. überarbeitete und erweiterte Auflage. - Wiebelsheim: Quelle \& Meyer.

Sipman H. \& Raus T. 2019: Lichens and lichenicolous fungi. - In: Biel B. \& Tan K., Flora of Amorgos. - Kifissia: The Goulandris Natural History Museum.

Vogt R. 2019: CLIX. Compositae - Asteroideae (gen. 110-115, 118-119, 121) (Leucanthemum, Rhodanthemum, Coleostephus, Glossopappus, Mauranthemum, Lepidophorum ( pp. 1848-1896), Castrilanthemum, Hymenostemma (pp. 1902-1907), Prolongoa (pp. 1930-1932). - In: Benedi C., Buira A., Rico E., Crespo M. B., Quintanar A. \& Aedo C. (ed.), Flora ibérica: plantas vasculares de la Península Ibérica e Islas Baleares 16,3. Compositae (partim). - Madrid: Real Jardín Botánico, C.S.I.C.

\section{Beiträge zu taxonomischen Informations- systemen}

Dimopoulos P., Raus T. \& Strid A. (ed.) 2019: Flora of Greece web. Vascular Plants of Greece. An Annotated Checklist. Version March 2019. - Published at: http:// portal.cybertaxonomy.org/flora-greece/

\section{Nicht-begutachtete Zeitschriftenartikel}

Grotz K. \& Rahemipour P. 2019: Geliebt. Gegossen. Vergessen: Phänomen Zimmerpflanze. - Museumsjournal 2019(1): 84-85.

Grotz K. \& Rahemipour P. 2019: Wie Wissen wächst: Alexander von Humboldt und die Wurzeln der Wissensproduktion. - Museumsjournal 2019(4): 50-51.

Humm A. 2019: BigPicnic Studios. Ein partizipatives Ausstellungsprojekt. - Museumsjournal 2019(2): $84-85$.

Lack H. W. 2019: Die letzten Tulpen der Kartause Mauerbach. - Historische Gärten 25: 31-35.
Lack H. W. 2019: Eine andere Form der Erinnerung. Alexander von Humboldt als Zeichner / A different form of remembrance. Alexander von Humboldt the draughtsman. - Humboldt Forum 5: 28-29.

Lauterbach D., Burkart M., Dreilich A., Löwenstein P. Zippel E. \& Stevens A.-D. 2019: Beiträge der Botanischen Gärten Potsdam und Berlin zum botanischen Artenschutz in Brandenburg. - Naturschutz und Landschaftspflege in Brandenburg 28: 4-23.

Lücking R., Dal Forno M. \& Will-Wolf S. 2019: James Donald (“Jim") Lawrey: a tribute to a unique career in lichenology. - Plant and Fungal Systematics 64: 117-135.

Rahemipour P. \& Grotz K. 2019: Provenienzforschung im Kontext botanischer Sammlungen. - Museumsjournal 2019(1): 40-41.

Sipman H. J. M. 2019: Caloplaca glomerata (Variospora glomerata) war in Deutschland! - Herzogiella 6: 52-54

Sipman H., Hertel H. \& Schrüfer K. 2019: Dr. Johannes Knoph (1951-2019). - Herzogia 32: 263-268.

Stevens A.-D., Droege G., Zippel E., Häffner E. \& Borsch T. 2019: Documentation of specimens at the Botanic Garden and Botanical Museum Berlin with regard to ABS. - BG Journal 16: 22-25.

Truong B. V., Raab-Straube E. von, Hein P., Duwe V. K., Bui V. H., Tu B. N., Tran H. D. \& Luong D. T. 2019: Orchideen botanisieren in den Wolken : auf der Jagd nach seltenen Orchideen im Bach Ma National Park, Vietnam $=$ Orchidizing through the cloud : a trip to hunt for rare orchids in Bach Ma National Park, Vietnam. - Orchideenjournal 26: 30-37. 
Neu beschriebene

Arten von

BGBM-Autoren

$2017-2019$
Name

Acanthothecis alba Herrera-Camp., Barcenas-Peña \& Lücking47)

Allium oreohellenicum Tzanoud., Tsakiri \& Raus ${ }^{57)}$

Allographa anguilliradians Lücking ex Lücking ${ }^{29)}$

Allographa atrocelatoides J. Kalb, Lücking \& Kalb ${ }^{26}$

Allographa bambusicola Weerakoon, Lücking \& Aptroot ${ }^{58}$

Allographa jayatilakana Weerakoon, Arachchige \& Lücking49)

Allographa kamojangensis Jatnika, Noer \& Lücking49)

Allographa kansriana J. Kalb, Lücking \& Kalb ${ }^{26)}$

Allographa schummii J. Kalb, Lücking \& Kalb ${ }^{26)}$

Allographa sitianoides J. Kalb, Lücking \& Kalb ${ }^{26)}$

Allographa uruguayensis Lücking ex Lücking ${ }^{29}$ )

Allographa weerasooriyana Weerakoon, Arachchige \& Lücking ${ }^{58}$

Aria phitosiana Raimondo \& Greuter ${ }^{55}$ )

Aspidothelium silverstonei Soto-Medina, Aptroot \& Lücking ${ }^{16}$

Asteristion australianum I. Medeiros, Lücking, Mangold \&

Lumbsch ${ }^{12)}$

Astrothelium bullatothallinum Aptroot \& Sipman ${ }^{44)}$

Astrothelium cayennense Aptroot \& Sipman ${ }^{44)}$

Astrothelium diaphanocorticatum Aptroot \& Sipman ${ }^{44)}$

Astrothelium fuscosporum Soto-Medina, Aptroot \& Lücking ${ }^{16)}$

Astrothelium macroeustomum Aptroot \& Sipman ${ }^{44)}$

Astrothelium minicecidiogenum Aptroot \& Sipman ${ }^{44)}$

Astrothelium palaeoexostemmatis Sipman \& Aptroot44)

Astrothelium tanianum Aptroot \& Sipman44)

Bactrospora lecanorina Herrera-Camp., Altamirano \& Lücking47)

Brachysira altepetlensis D. Mora, R Jahn \& N. Abarca ${ }^{13)}$

Chapsa inspersa E.L. Lima \& Lücking54)

Cocconeis magnoareolata Al-Handal, Riaux-Gob., R. Jahn \&

A.K.Wulff42)

Coenogonium atherospermatis Kantvilas, Rivas Plata \& Lücking ${ }^{27}$

Coenogonium australiense Kantvilas \& Lücking ${ }^{27)}$

Coenogonium beaverae Lücking \& Diederich5)

Coenogonium urceolatum Kantvilas, Rivas Plata \& Lücking ${ }^{27)}$

Cora benitoana Moncada, R.-E. Pérez \& Lücking ${ }^{51}$

Cora buapana Moncada, R.-E. Pérez \& Lücking51)

Cora dewisanti subsp. mexicana Moncada, R.-E. Pérez \& Lücking ${ }^{51)}$

Cora galapagoensis Dal Forno, Bungartz \& Lücking3)

Cora guzmaniana Moncada, R.-E. Pérez \& Lücking ${ }^{51)}$

Cora ixtlanensis Moncada, R.-E. Pérez \& Lücking ${ }^{51)}$

Cora lawreyana Moncada, R.-E. Pérez \& Lücking ${ }^{51)}$

Cora marusae Moncada, R.-E. Pérez \& Lücking ${ }^{51)}$

Cora totonacorum Moncada, R.-E. Pérez \& Lücking ${ }^{51)}$

Cora zapotecorum Moncada, R.-E. Pérez \& Lücking ${ }^{51)}$

Crocynia didymica Sipman ${ }^{35}$ )

Crypthonia streimannii Sipman ${ }^{35}$ )

Cryptoschizotrema minus E.L. Lima \& Lücking54)

Cryptothecia chamelensis Herrera-Camp., Bautista \& Lücking ${ }^{47)}$

Cyphellostereum georgianum Dal Forno, McMullin \& Lücking45)
Organismus

Flechte

Flechte Trinidad und Tobago

Flechte Thailand

Flechte Sri Lanka

Flechte Sri Lanka

Flechte Indonesien

Flechte Thailand

Flechte Thailand

Flechte Thailand

Flechte Uruguay

Flechte Sri Lanka

Gefäßpflanze Italien

Flechte Kolumbien

Flechte Australien

Flechte Venezuela

Flechte Französisch-Guyana

Flechte Papua-Neuguinea

Flechte Kolumbien

Flechte Französisch-Guyana

Flechte Costa Rica

Flechte Thailand

Flechte Malaysia

Flechte Mexiko

Kieselalge Mexiko

Flechte Brasilien

Kieselalge Schweden

Flechte Australien

(Tasmanien)

Flechte $\quad$ Australien

Flechte Seychellen

Flechte Australien

Flechte Mexiko

Flechte Mexiko

Flechte Mexiko

Flechte Ecuador (Galapagos)

Flechte Mexiko

Flechte Mexiko

Flechte Mexiko

Flechte Mexiko

Flechte Mexiko

Flechte Mexiko

Flechte Vanuatu

Flechte Vanuatu

Flechte Brasilien

Flechte Mexiko

Flechte USA 


\begin{tabular}{|c|c|c|}
\hline Name & Organismus & Herkunftsland \\
\hline Cyphellostereum unoquinoum Dal Forno, Bungartz \& Lücking3) & Flechte & Ecuador (Galapagos) \\
\hline Dictyonema barbatum Dal Forno, Bungartz \& Lücking3) & Flechte & Ecuador (Galapagos) \\
\hline Dictyonema darwinianum Dal Forno, Bungartz \& Lücking3) & Flechte & Ecuador (Galapagos) \\
\hline Dictyonema lawreyi Dal Forno, Kaminsky \& Lücking45) & Flechte & USA \\
\hline Dictyonema ramificans Dal Forno, Yánez-Ayabaca \& Lücking3) & Flechte & Ecuador (Galapagos) \\
\hline Dictyonema subobscuratum Dal Forno, Bungartz \& Lücking3) & Flechte & Ecuador (Galapagos) \\
\hline Diorygma sophianum E.L. Lima \& Lücking54) & Flechte & Brasilien \\
\hline Diorygma upretii Sipman 36$)$ & Flechte & Singapur \\
\hline Epithemia vandevijveri Cocquyt \& R. Jahn²2) & Kieselalge & Reunion \\
\hline Fissurina aperta Herrera-Camp., Barcenas-Peña \& Lücking47) & Flechte & Mexiko \\
\hline Fissurina atlantica T.A. Pereira, M. Cáceres \& Lücking $\left.{ }^{30}\right)$ & Flechte & Brasilien \\
\hline Fissurina jaliscoensis Herrera-Camp., Barcenas-Peña \& Lücking47) & Flechte & Mexiko \\
\hline Fissurina linoana Lücking, Moncada \& G. Rodr.50) & Flechte & Kolumbien \\
\hline Fissurina reticulata R. Miranda, Herrera Camp. \& Lücking47) & Flechte & Mexiko \\
\hline Fissurina seychellensis Lücking \& Diederich5) & Flechte & Seychellen \\
\hline $\begin{array}{l}\text { Fissurina tenuimarginata Herrera-Camp., Barcenas-Peña \& } \\
\text { Lücking47) }\end{array}$ & Flechte & Mexiko \\
\hline Gomphoneis tegelensis R. Jahn \& N. Abarca37) & Kieselalge & Deutschland \\
\hline Gomphonella acsiae R. Jahn \& N. Abarca ${ }^{24)}$ & Kieselalge & Ungarn \\
\hline Gomphonella coxiae R. Jahn \& N. Abarca ${ }^{24)}$ & Kieselalge & Deutschland \\
\hline $\begin{array}{l}\text { Gomphonema clavatuloides Rimet, D.G. Mann, Trobajo \& N. } \\
\text { Abarca33) }\end{array}$ & Kieselalge & Frankreich (Mayotte) \\
\hline Graphis alba Dantas, Lücking \& M. Cáceres4) & Flechte & Brasilien \\
\hline Graphis albocarpa J. Kalb, Lücking \& Kalb²6) & Flechte & Thailand \\
\hline Graphis amaliana Amórtegui, Moncada \& Lücking ${ }^{52)}$ & Flechte & Kolumbien \\
\hline Graphis carmenelisana Moncada, Motta \& Lücking52) & Flechte & Kolumbien \\
\hline Graphis emersella J. Kalb, Lücking \& Kalb ${ }^{26)}$ & Flechte & Thailand \\
\hline Graphis flosculifera Weerakoon, Lücking \& Aptroot ${ }^{58)}$ & Flechte & Sri Lanka \\
\hline Graphis kavintuca Motta, Moncada \& Lücking52) & Flechte & Kolumbien \\
\hline Graphis khaojoneana J. Kalb, Lücking \& Kalb²6) & Flechte & Thailand \\
\hline Graphis lindsayana Lücking \& Diederich5) & Flechte & Seychellen \\
\hline Graphis lurizana Lücking, Moncada \& Celis ${ }^{50)}$ & Flechte & Kolumbien \\
\hline Graphis mokanarum Lücking, Moncada \& M.C. Martínez $z^{50)}$ & Flechte & Kolumbien \\
\hline Graphis omiana J. Kalb, Lücking \& Kalb ${ }^{26)}$ & Flechte & Thailand \\
\hline Graphis rajapakshana Weerakoon, Lücking \& Aptroot ${ }^{58)}$ & Flechte & Sri Lanka \\
\hline Graphis rimosothallina Weerakoon, Lücking \& Aptroot58) & Flechte & Sri Lanka \\
\hline Graphis rosalbinana Moncada, Amortegui \& Lücking52) & Flechte & Kolumbien \\
\hline Graphis santanderiana Motta, Moncada \& Lücking ${ }^{52)}$ & Flechte & Kolumbien \\
\hline Graphis schummiana J. Kalb, Lücking \& Kalb²6) & Flechte & Thailand \\
\hline Graphis solmariana Motta, Moncada \& Lücking52) & Flechte & Kolumbien \\
\hline Graphis subaltamirensis Passos, M. Cáceres \& Lücking 30 ) & Flechte & Brasilien \\
\hline Graphis subfiliformis E.L. Lima \& Lücking ${ }^{54)}$ & Flechte & Brasilien \\
\hline Graphis sublitoralis J. Kalb, Lücking \& Kalb26) & Flechte & Thailand \\
\hline Graphis subschroederi J. Kalb, Lücking \& Kalb²6) & Flechte & Thailand \\
\hline Graphis thunsinhalayensis Weerakoon, Arachchige \& Lücking58) & Flechte & Sri Lanka \\
\hline Gyalideopsis aptrootii Xavier-Leite, M. Cáceres \& Lücking39) & Flechte & Brasilien \\
\hline Gyalideopsis caespitosa Barcenas-Peña, Herrera-Camp. \& Lücking47) & Flechte & Mexiko \\
\hline Gyalideopsis marcellii Xavier-Leite, M. Cáceres \& Lücking39) & Flechte & Brasilien \\
\hline Halegrapha paulseniana Luch \& Lücking ${ }^{28)}$ & Flechte & USA (Hawaii) \\
\hline Halegrapha redonographoides Dantas, Lücking \& M. Cáceres4) & Flechte & Brasilien \\
\hline
\end{tabular}


Name

Herpothallon alae Sipman35)

Heterocapsa steinii Tillmann, Gottschling, Hoppenrath, Kusber \& Elbr. ${ }^{17)}$

Lawreymyces bogotensis Lücking \& Moncada9)

Lawreymyces columbiensis Lücking \& Moncada9)

Lawreymyces confusus Lücking \& Moncada9)

Lawreymyces foliaceae Lücking \& Moncada9)

Lawreymyces palicei Lücking \& Moncada9)

Lawreymyces pulchellae Lücking \& Moncada9)

Lawreymyces spribillei Lücking \& Moncada9)

Leucanthemum xaramisii Florian Wagner, Vogt \& Oberpr. ${ }^{19)}$

Leucanthemum xathosii Florian Wagner, Vogt \& Oberpr. ${ }^{19}$ )

Leucanthemum xmarchii Konowalik, Vogt \& Oberpr. ${ }^{88)}$

Leucanthemum xporthosii Florian Wagner, Vogt \& Oberpr. ${ }^{19)}$

Leucodecton granulosum Sipman ${ }^{34}$

Libinhania discolor A.G. Mill., R. Sommerer \& N. Kilian ${ }^{8)}$

Libinhania fontinalis A.G. Mill., R. Sommerer \& N. Kilian ${ }^{8)}$

Libinhania hegerensis A.G. Mill. \& N. Kilian ${ }^{8)}$

Libinhania nivea A.G. Mill., R. Sommerer \& N. Kilian ${ }^{8}$

Libinhania pendula A.G. Mill., R. Sommerer \& N. Kilian ${ }^{8)}$

Lobariella flynniana Lücking, Moncada \& C.W. Sm. ${ }^{10)}$

Lobariella robusta Lücking, Moncada \& C. W. Sm. ${ }^{10) v}$

Lobariella sandwicensis Lücking, Moncada \& C. W. Sm. ${ }^{10)}$

Micarea squamulosa Aptroot, Lücking \& M. Cáceres ${ }^{48)}$

Myriotrema hypoconsticticum van den Boom \& Sipman ${ }^{18)}$

Myriotrema protofrustillatum Sipman34)

Neidium beatyi P.B. Ham., Savoie, C.M. Sayre, Skibbe, J. Zimm. \& R.D. Bull46)

\begin{tabular}{|c|c|c|}
\hline $\begin{array}{l}\text { Neidium collare P.B. Ham., Savoie, C.M. Sayre, Skibbe, J. Zimm. \& } \\
\text { R.D. Bull46) }\end{array}$ & Kieselalge & Kanada \\
\hline $\begin{array}{l}\text { Neidium lavoieanum P.B. Ham., Savoie, C.M. Sayre, Skibbe, J. } \\
\text { Zimm. \& R.D. Bull46) }\end{array}$ & Kieselalge & Kanada \\
\hline $\begin{array}{l}\text { Neidium vandusenense P.B. Ham., Savoie, C.M. Sayre, Skibbe, J. } \\
\text { Zimm. \& R.D. Bull46) }\end{array}$ & Kieselalge & Kanada \\
\hline Neoprotoparmelia nigra L.A.Santos, Lücking \& Aptroot56) & Flechte & Brasilien \\
\hline Neoprotoparmelia pseudomultifera L.A.Santos, Lücking \& Aptroot ${ }^{56)}$ & Flechte & Brasilien \\
\hline Neoprotoparmelia purpurea L.A.Santos, Lücking \& Aptroot56) & Flechte & Brasilien \\
\hline Neoprotoparmelia rubrofusca Lücking \& L.A.Santos $\left.{ }^{56}\right)$ & Flechte & Brasilien \\
\hline $\begin{array}{l}\text { Nitzschia biundulata Al-Handal, J. Zimmerman, R. Jahn, } \\
\text { Torstensson \& A. Wulff43) }\end{array}$ & Kieselalge & Antarktis \\
\hline Ocellularia cipoensis L.A. Santos, M. Cáceres \& Lücking ${ }^{30)}$ & Flechte & Brasilien \\
\hline Ocellularia etayoi van den Boom \& Sipman ${ }^{18)}$ & Flechte & Panama \\
\hline Ocellularia sosma T.A. Pereira, M. Cáceres \& Lücking 30) & Flechte & Brasilien \\
\hline Ocellularia submordenii Lückingº) & Flechte & Brasilien \\
\hline Ocellularia tomatlanensis Herrera-Camp., Colín \& Lücking47) & Flechte & Mexiko \\
\hline Ocellularia upretii S. Joshi, Divakar, Lumbsch \& Lücking 25) & Flechte & Indien \\
\hline Phaeographis galeanoae Lücking, Moncada \& B. Salgado-N.50) & Flechte & Kolumbien \\
\hline $\begin{array}{l}\text { Phaeographis sarcographoides Herrera-Camp., N. Sánchez \& } \\
\text { Lücking47) }\end{array}$ & Flechte & Mexiko \\
\hline
\end{tabular}

Organismus Herkunftsland

Flechte

Vanuatu

Dinoflagellat Deutschland

Pilz Kolumbien

Pilz Kolumbien

Pilz Kolumbien

Pilz Kolumbien

Pilz Kolumbien

Pilz Kolumbien

Pilz Kolumbien

Gefäßpflanze Frankreich

Gefäßpflanze Frankreich

Gefäßpflanze Italien

Gefäßpflanze Italien

Flechte Australien

Gefäßpflanze Jemen

Gefäßpflanze Jemen

Gefäßpflanze Jemen

Gefäßpflanze Jemen

Gefäßpflanze Jemen

Flechte USA (Hawaii)

Flechte USA (Hawaii)

Flechte USA (Hawaii)

Flechte Brasilien

Flechte Panama

Flechte Australien

Kieselalge Kanada 


\begin{tabular}{|c|c|c|}
\hline Name & Organismus & Herkunftsland \\
\hline Planothidium cryptolanceolatum R. Jahn \& N. Abarca7) & Kieselalge & Südkorea \\
\hline Planothidium naradoense R. Jahn \&J. Zimmermann7) & Kieselalge & Südkorea \\
\hline Planothidium suncheonmanense R. Jahn \& J. Zimmermann) & Kieselalge & Südkorea \\
\hline Planothidium taeansa R. Jahn \& N. Abarca7) & Kieselalge & Südkorea \\
\hline Porina lumbschii Naksuwankul \& Lücking53) & Flechte & Thailand \\
\hline Porina sorediata Aptroot, Lücking \& M. Cáceres ${ }^{48)}$ & Flechte & Brasilien \\
\hline Porina subatriceps Naksuwankul \& Lücking ${ }^{53)}$ & Flechte & Thailand \\
\hline Porina thailandica Naksuwankul \& Lücking53) & Flechte & Thailand \\
\hline Pseudochapsa aptrootiana M. Cáceres, T.A. Pereira \& Lücking ${ }^{30)}$ & Flechte & Brasilien \\
\hline Pseudocyphellaria deyi Lücking ${ }^{11)}$ & Flechte & USA \\
\hline Pseudocyphellaria holarctica McCune, Lücking \& Moncada ${ }^{11)}$ & Flechte & USA \\
\hline Pseudocyphellaria punctata Lücking \& Moncada ${ }^{11)}$ & Flechte & USA \\
\hline Pyrenula subvariabilis Aptroot \& Sipman 20$)$ & Flechte & Guyana \\
\hline Ramalina europaea Gasparyan, Sipman \& Lücking6) & Flechte & Schweden \\
\hline Ramalina labiosorediata Gasparyan, Sipman \& Lücking6) & Flechte & USA \\
\hline Rhytidhysteron columbiense Soto-Medina \& Lücking ${ }^{15)}$ & Pilz & Kolumbien \\
\hline Sarcographa atlantica E.L. Lima \& Lücking54) & Flechte & Brasilien \\
\hline Sarcographa praslinensis Lücking \& Diederich5) & Flechte & Seychellen \\
\hline Sarcographa subglobosa Lücking \& Diederich5) & Flechte & Seychellen \\
\hline Saussurea glandulosissima Raab-Straube $\mathrm{e}^{14)}$ & Gefäßpflanze & China \\
\hline Saussurea hengduanshanensis Raab-Straube ${ }^{14)}$ & Gefäßpflanze & China \\
\hline Saussurea kawakarpo Raab-Straube ${ }^{14)}$ & Gefäßpflanze & China \\
\hline Saussurea septentrionalis Raab-Straube ${ }^{14)}$ & Gefäßpflanze & China \\
\hline Saussurea sichuanica Raab-Straube $\mathrm{e}^{14)}$ & Gefäßpflanze & China \\
\hline Saussurea sikkimensis Raab-Straube ${ }^{14)}$ & Gefäßpflanze & Indien \\
\hline Saussurea sunhangii Raab-Straube ${ }^{14)}$ & Gefäßpflanze & China \\
\hline Sellaphora queretana D. Mora, N. Abarca \& J.Carmona ${ }^{13}$ ) & Kieselalge & Mexiko \\
\hline Sprucidea granulosa M. Cáceres, Aptroot \& Lücking ${ }^{1)}$ & Flechte & Brasilien \\
\hline Sprucidea rubropenicillata M. Cáceres, Aptroot \& Lücking ${ }^{1)}$ & Flechte & Brasilien \\
\hline Sticta aongstroemii Dal Forno, Moncada \& Lücking ${ }^{23)}$ & Flechte & Brasilien \\
\hline Stirtonia borinquensis Perlmutter, Rivas Plata \& Lücking ${ }^{31)}$ & Flechte & Puerto Rico \\
\hline Stirtonia caribaea Perlmutter, Rivas Plata \& Lücking ${ }^{31)}$ & Flechte & Kuba \\
\hline Sulcopyrenula biseriata Aptroot \& Sipman ${ }^{20)}$ & Flechte & Guyana \\
\hline Sulzbacheromyces chocoensis Coca, Lücking \& Moncada ${ }^{21)}$ & Flechte & Kolumbien \\
\hline Sulzbacheromyces tutunendo Coca, Lücking \& Moncada ${ }^{21)}$ & Flechte & Kolumbien \\
\hline Surirella coei Cocquyt, J.C. Taylor \& Kusber²) & Kieselalge & Kenia \\
\hline Tamarix humboldtiana Akhani, Borsch \& N. Samadi41) & Gefäßpflanze & Iran \\
\hline Thelotrema pachysporoides Dantas, Lücking \& M. Cáceres4) & Flechte & Brasilien \\
\hline Vigneronia mexicana Herrera-Camp., Bautista \& Lücking47) & Flechte & Mexiko \\
\hline Xanthoparmelia krcmarii Sipman \& V. Wirth ${ }^{40)}$ & Flechte & Südafrika \\
\hline
\end{tabular}




\section{Neu beschriebene} Familien und Gattungen von BGBM-Autoren
Name

Astartoseris N. Kilian, Hand, Hadjik., Christodoulou \& M. Bon Dagher-Kharrat ${ }^{59)}$

Austrotrema I. Medeiros, Lücking \& Lumbsch ${ }^{12)}$

Cryptoschizotrema Aptroot, Lücking \& M. Cáceres ${ }^{48}$

Cystocoleaceae Locq. ex Lücking, B.P.Hodk. \& S.D.Leav. ${ }^{62)}$

Flabelloporina Sobreira, M. Cáceres \& Lücking ${ }^{61)}$

Lawreymyces Lücking \& Moncada9)

Libinhania N. Kilian, Galbany, Oberpr. \&A.G. Mill. ${ }^{8}$

Sprucidea M. Cáceres, Aptroot \& Lücking ${ }^{1)}$

Tainus Torr.-Montúfar, H. Ochot. \& Borsch $\left.{ }^{60}\right)$
Organismus

Herkunftsland

Gefäßpflanzen Zypern und Libanon

Flechten weltweit

Flechten pantropisch

Flechte weltweit

Flechten Neotropis

Pilze weltweit

Gefäßpflanzen Sokotra

Flechten Neotropis

Gefäßpflanzen Karibik

Quellen (die vollständigen Literaturangaben sind der Publikationsliste auf S. 59-77 zu entnehmen):

1) Cáceres et al. 2017 - Bryologist 120: 202-211. ${ }^{2)}$ Cocquyt et al. 2017 - Fottea 17: 34-56. ${ }^{3)}$ Dal Forno et al. 2017

- Fungal Divers. 85: 45-73. ${ }^{4)}$ Dantas et al. 2017 - Phytotaxa 331: 289-294. ${ }^{5)}$ Diederich et al. 2017 - Herzogia 30: 182-236. ${ }^{6}$ Gasparyan et al. 2017 - Lichenologist 49: 301-319. $\left.{ }^{7}\right)$ Jahn et al. 2017 - Diatom Research 32: 75-107. 8) Kilian et al. 2017 - Bot. J. Linn. Soc. 183(3): 373-412. ${ }^{9}$ Lücking et al. 2017 - Fungal Divers. 84: 119-138. ${ }^{10)}$ Lücking et al. 2017 - Lichenologist 49: 673-691. ${ }^{11}$ Lücking et al. 2017 - Bryologist 120: 441-500. ${ }^{12}$ Medeiros et al. 2017 - Fieldiana Life Earth Sci. 9: 1-31. ${ }^{13)}$ Mora et al. 2017 - PhytoKeys 88: $\left.39-69 .{ }^{14}\right)$ Raab-Straube 2017 Englera 34: 1-274. ${ }^{15)}$ Soto-Medina et al. 2017 - Revista Acad. Colomb. Ci. Exact. Nat. 41: 59-63. ${ }^{16)}$ Soto-Medina et al. 2017 - Cryptogamie, Mycologie 38: 253-258. ${ }^{17)}$ Tillmann et al. 2017 -J. Phycol. 53: 1305-1324. ${ }^{18)}$ Van den Boom et al. 2017 - Sydowia 69: 47-72. ${ }^{19)}$ Wagner et al. 2017 - Mol. Ecol. 26: 4260-4283. ${ }^{20)}$ Aptroot et al. 2018 - Lichenologist 50: 77-87. ${ }^{21)}$ Coca et al. 2018 - Bryologist 121: 295-305. ${ }^{22)}$ Cocquyti et al. 2018 - Cryptogam., Algol. 9: 35-62. 23) Dal Forno et al. 2018 - Lichenologist 50: 691-696. ${ }^{24)}$ Jahn et al. 2018 - Plant Ecol. Evol. 152: 219-247. ${ }^{25)}$ Joshi et al. 2018 - Lichenologist 50: 627-678. ${ }^{26)}$ Kalb et al. 2018 - Phytotaxa 377: 1-83. ${ }^{27)}$ Kantvilas et al. 2018 - Lichenologist 50: 571-582. ${ }^{28)}$ Luch et al. 2018 - Willdenowia 48: 415-423. ${ }^{29)}$ Lücking et al. 2018 Herzogia 31: 525-561. ${ }^{30)}$ Pereira et al. 2018 - Biota Neotrop. 18(1): e20170445. ${ }^{31)}$ Perlmutter et al. 2018 - Bryologist 121: 80-86. ${ }^{32)}$ Raab-Straube et al. 2018 - Willdenowia 48: 195-220. ${ }^{33)}$ Rimet et al. 2018 - Fottea 18: 37-54. ${ }^{34)}$ Sipman 2018 - Australas. Lichenol. 82: 92-105. ${ }^{35)}$ Sipman 2018 - Australas. Lichenol. 82: 106-129. ${ }^{36)}$ Sipman 2018 - Crypt. Biodivers. Assess., Special Issue (2018): 01-05. ${ }^{37)}$ Skibbe et al. 2018 - Diatom Res. 33: 251-262. ${ }^{38)}$ Vogt et al. 2018 - Willdenowia 48: 221-226. ${ }^{39}$ ) Xavier-Leite et al. 2018 - Bryologist 121: $32-40 .{ }^{40)}$ Wirth et al. 2018 - Herzogia 31: 505-509. ${ }^{41)}$ Akhani et al. 2019 - Willdenowia 49: 127-139. ${ }^{42)}$ Al-Handal et al. 2019 - Eur. J. Taxon. 497: 1-16. ${ }^{43}$ Al-Handal et al. 2019 - Nova Hedwigia 108: 281-290. ${ }^{44)}$ Aptroot et al. 2019 - Lichenologist 51: 27-43. ${ }^{45)}$ Dal Forno et al. 2019 - Plant Fungal Syst. 64: 383-392. ${ }^{46)}$ Hamilton et al. 2019 - Phytotaxa 419: 39-62. ${ }^{47)}$ Herrera-Campos et al. 2019 - Bryologist 122: 62-83. ${ }^{48)}$ Hyde et al. 2019 - Fungal Divers. 96: 1-242. 49) Jatnika et al. 2019 - Lichenologist 51: 227-233. ${ }^{50)}$ Lücking et al. 2019 - Caldasia 41: 194-214. ${ }^{51)}$ Moncada et al. 2019 - Plant Fungal Syst. 64: 393-411. ${ }^{52)}$ Motta et al. 2019 - Phytotaxa 401: $257-266 .{ }^{53)}$ Naksuwankul et al. 2019 - Phytotaxa 400: 51-63. ${ }^{54)}$ Lima-Nascimento et al. 2019 - Bryologist 122: 414-422. ${ }^{55)}$ Raimondo et al. 2019 - Bot. Chron. 22: 15-37. ${ }^{56)}$ Santos et al. 2019 - Bryologist 122: 539-552. ${ }^{577}$ Tzanoudakis et al. 2019 - Willdenowia 49: 231-239. ${ }^{58}$ Weerakoon et al. 2019 - Lichenologist 51: 515-559. 59) Kilian et al. 2017 - Willdenowia 47: 115-125. ${ }^{60)}$ Torres-Montúfar et al. 2017 - Willdenowia 47: 259-270. ${ }^{61}$ Sobreira et al. 2018 - Phytotaxa 358: 67-75. ${ }^{62}$ Lücking et al. 2017 - The Bryologist 119: 361-416. 
Der BGBM stellt Datenbanken und Online-Ressourcen zur Verfügung, die zum einen der Erschließung der eigenen Sammlungen dienen und zum anderen grundlegende Biodiversitätsdaten zu Organismengruppen oder geographischen Regionen präsentieren. Dazu kommen allgemeinere Serviceportale, die am BGBM gehostet werden:

\section{Digitalisierte Sammlungen am BGBM}

Virtual Herbarium - Digital Specimen Images at the Herbarium Berolinense (Virtuelles Herbarium - Digitale Herbarbelege des Berliner Herbariums) - Zugang zum den Berliner Daten im JACQ System (s.u.)

http://ww2.bgbm.org/herbarium/default.cfm

BoGART - Die Bestandsdatenbank der Lebendsammlung des BGBM

http://ww2.bgbm.org/bogartdb/BogartPublic.asp

BioCASE-BGBM - Biological Collection Access Service for Europe. Portal for BGBM Collections (gemeinsamer Zugang zu den Sammlungsdaten des BGBM) http://search.biocase.org/bgbm

LICHCOL - Lichen (\& Fungus) Herbarium Database (Bestandsdatenbank des Flechten- und Pilzherbariums Berlin) http://archive.bgbm.org/scripts/ASP/lichcol [will be integrated into the BGBM Herbarium database in the JACQ system - see below].

DNA-Bank - Informationssystem für die DNA-Sammlung des BGBM (Zugang über das Portal des Global Genome Biodiversity Network) http://data.ggbn.org/ggbn_portal/search/result?institution=BGBM\%2C+Berlin

MuseumPlus-Datenbank des BGBM im Europeana Collections Portal

https://www.europeana.eu/portal/en/search?q=europeana_collectionName\%3A\%2811635_Ag_EU_OpenUp\%5C\%21_ MuseumPlus\%29

\section{Taxonomische Informationssysteme zu Organismengruppen}

AlgaTerra - Information System on Terrestrial and Limnic Micro Algae (Informationssystem zu den terrestrischen und limnischen Mikroalgen - fortlaufend aktualisiert)

http://www.algaterra.net

Campanula Portal (globale Online-Monographie der Gattung Campanula (Glockenblumen) - fortlaufend aktualisiert)

https://campanula.e-taxonomy.net/portal

Cichorieae Portal (globale Online-Monographie der Cichorieae (Korbblütengewächse) - fortlaufend aktualisiert) http://cichorieae.e-taxonomy.net/portal

Caryophyllales Portal - A global synthesis of species diversity in the angiosperm order Caryophyllales - fortlaufend aktualisiert

http://caryophyllales.org
Online-

Ressourcen und Datenbanken 


\section{Floren und Checklisten}

Euro+Med Plantbase - The Information Resource for Euro-Mediterranean Plant Diversity (Verzeichnis der Gefäßpflanzen und ihrer Verbreitung in Europa und im Mittelmeerraum - fortlaufend aktualisiert)

http://ww2.bgbm.org/EuroPlusMed/query。asp

Med-Checklist - A Critical Inventory of Vascular Plants of the Circum-Mediterranean Countries (kritisches Inventar der Gefäßpflanzen des Mittelmeerraums - wie in Buchform publiziert)

http://ww2.bgbm.org/mcl

Flora Hellenica Database (Arne Strid) http://www.florahellenica.com

Flora of Greece - an annotated checklist http://portal.cybertaxonomy.org/flora-greece/

Flora of Cyprus - A Dynamic Checklist (Online-Flora der Gefäßpflanzen Zyperns mit Abbildungen, Verbreitungskarten und Bestimmungsschlüsseln - fortlaufend aktualisiert)

http://www.flora-of-cyprus.eu

Flora of Cuba Database - Base de Datos de Especímenes de la Flora de Cuba - con Mapas de Distribución Versión 10.0 (2014) a Versión 11 (2016) (Datenbank der Herbarbelege der Flora von Cuba mit Verbreitungskarten) http://wwz.bgbm.org/FloraOfCuba

The Spermatophyta of Cuba - A Preliminary Checklist

http://wfospecimens.cybertaxonomy.org

http://portal.cybertaxonomy.org/flora-cuba

\section{Service-Portale für Sammlungsdaten}

BioCASE - Biological Collection Access Service for Europe. Portal for European Biodiversity (gemeinsamer Zugang zu den biologischen Sammlungsdaten europäischer Herkunft) http://search.biocase.org/europe (direkter Zugang zum Suchkatalog)

BioCASE - Biological Collection Access Service for Europe. Portal for German Phytodiversity (gemeinsamer Zugang zu den botanischen Sammlungsdaten deutscher Herkunft) http://search.biocase.de/botany (direkter Zugang zum Suchkatalog)

EDIT - Specimen and Observation Explorer for Taxonomists (für Taxonomen optimiertes Zugangsportal für Sammlungsdaten weltweit)

http://search.biocase.org/edit

GBIF-D Algae \& Protozoa Datenportal (Datenbank für Algen und Einzeller) http://protists.gbif.de/protists

VH/de - Virtuelles Herbarium Deutschland (Digitalisierte Sammlungsinformationen aus deutschen Herbarien) http://vh.gbif.de/vh

GGBN - Global Genome Biodiversity Network (Internationales DNA-Bank Netzwerk) http://www.ggbn.org 
WFO Specimens - World Flora Online Initiative, Specimen Explorer Prototype for Phytotaxonomists (Belegsuche für die Phytotaxonomie)

http://wfospecimens.cybertaxonomy.org

Botanic Garden Berlin Observations (BoBO)

http://bobo.biocase.org

Caucasus Plant Biodiversity Initiative, Specimen explorer with focus on Caucasian Plants (Belegsuche mit Schwerpunkt auf Kaukasischen Pflanzen) http://caucasus.e-taxonomy.net/

\section{Webservices}

UTIS - Unified Taxonomic Backbone for the European Biodiversity Observation Network (EU BON) (taxonomisches Rückgrat für das Europäische Netzwerk zur Biodiversitäts-Beobachtung)

http://cybertaxonomy.eu/eu-bon/utis

Name rest services - Zugriff auf die in den verschiedenen Datenbanken der EDIT Platform gehaltenen Daten (z.B. auch des "Catalogue of Life")

https://cybertaxonomy.eu/cdmlib/rest-api-name-catalogue.html

BioCASe - Biological Collections Access Service. Maschinenlesbarer Zugang zu den Sammlungsdaten des BGBM.

http://ww3.bgbm.org/biocase

\section{Software}

EDIT Platform for Cybertaxonomy - Open Source Software Tools and Services Covering All Aspects of the Taxonomic Workflow (Arbeitsplattform mit Open-Source-Softwarewerkzeugen, die den gesammten taxonomischen Arbeitsprozess abdecken)

www.cybertaxonomy.eu

BioCASE Network Software Components (Softwarekomponenten zur Vernetzung und Bereitstellung von Sammlungsdaten im BioCASE, GBIF und GGBN Netzwerk)

http://biocase.org/products/index.shtml

AnnoSys - Web-based system for correcting and enriching biological collection data (Korrektur und Ergänzung biologischer Sammlungsdaten über das World Wide Web)

https://annosys.bgbm.fu-berlin.de

JACQ Virtual Herbaria - Unified and jointly administered specimen management system for herbaria (Kollaboratives Sammlungsmanagement für Herbarien - in Zusammenarbeit mit dem Naturhistorischen Museum und der Universität Wien)

http://herbarium.univie.ac.at/database/collections.htm

Die Herbonauten - Das Herbar der Bürgerwissenschaften

https://herbonauten.de 


\section{Archivierte Systeme}

Folgende Informationssysteme werden weiter technisch bereitgestellt, aber nicht mehr aktualisiert:

Bohlmann Files - A Database of Natural Substances in the Compositae (Datenbank natürlicher Inhaltsstoffe der Korbblütengewächse). Zugang: n.kilian@bgbm.org

DERMBASE - Names of Dermateaceae (Ascomycetes) (Datenbank der wissenschaftlichen Namen der Schlauchpilzfamilie Dermataceae)

http://ww2.bgbm.org/projects/dermbase/query.cfm

IOPI-GPC - International Organization for Plant Information, Provisional Global Plant Checklist (provisorische globale Pflanzencheckliste der Internationalen Organisation für Pflanzeninformation)

http://archive.bgbm.org/IOPI/GPC/default.asp

Names in Current Use for Extant Plant Genera (NCU-3e) (Standardliste der Gattungsnamen und Publikationszitate für Pflanzen, Algen und Pilze) http://archive.bgbm.org/iapt/ncu/genera/Default.htm

IAPT Registration of Plant Names Trial (Versuchsdatenbank für die Registrierung von neu veröffentlichten Pflanzennamen) http://archive.bgbm.org/registration/QueryForm.htm 


\begin{tabular}{|c|c|c|c|}
\hline Förderorganisation & Projekttitel & Projektleiter/in & Laufzeit \\
\hline $\mathrm{BfN}$ & $\begin{array}{l}\text { F+E-Vorhaben „Forschung zur Erstellung der Roten } \\
\text { Listen } 2020 \text { - Vorbereitungsphase“ - Teilvorhaben } \\
\text { Kooperation Checklisten (FKZ } 3515 \text { 860301). }\end{array}$ & Berendsohn & $2015-2018$ \\
\hline $\mathrm{BfN}$ & $\begin{array}{l}\text { Umsetzung der EU - Verordnung 511/2014: } \\
\text { Identifizierung von potentiellen Nutzern } \\
\text { genetischer Ressourcen in Deutschland (Az Z } 1.2532 \\
\text { O2/2016/F/18Z). }\end{array}$ & Borsch & $2016-2017$ \\
\hline $\mathrm{BfN}$ & $\begin{array}{l}\text { GSPC-Symposium: Schutz bedrohter Pflanzenarten } \\
\text { in Mitteleuropa - Genetische Grundlagen und } \\
\text { Naturschutzpraxis }\end{array}$ & Borsch & $2016-2017$ \\
\hline $\mathrm{BfN}$ & $\begin{array}{l}\text { WIPs-de II: Ansiedlungen und } \\
\text { Populationsstützungen gefährdeter } \\
\text { Verantwortungsarten (WIPS-De II) (FKZ 3518685Bol) }\end{array}$ & Stevens & $2018-2023$ \\
\hline $\mathrm{BfN}$ & $\begin{array}{l}\text { Verbundvorhaben WIPS de: Aufbau eines } \\
\text { nationalen Netzwerkes zum Schutz gefährdeter } \\
\text { Wildpflanzenarten in besonderer Verantwortung } \\
\text { Deutschlands. Teilvorhaben: Beprobungsraum } \\
\text { Nordost, Saatgutsammlung und -lagerung (FKZ } \\
\text { 3513685Bo4). }\end{array}$ & Stevens & $2013-2018$ \\
\hline BMBF & $\begin{array}{l}\text { CAUCDESTR - Pilotstudie zur Integration einer } \\
\text { taxonomischen Checkliste und georeferenzierten } \\
\text { Verbreitungsdaten, mit anschließender Erzeugung } \\
\text { von Verbreitungskarten (o1DK17038). }\end{array}$ & $\begin{array}{l}\text { Berendsohn/ } \\
\text { Korotkova }\end{array}$ & $2017-2019$ \\
\hline BMBF & $\begin{array}{l}\text { VietBio: Innovative Methoden der } \\
\text { Biodiversitätserfassung: Kapazitätsentwicklung mit } \\
\text { Partnerländern in Südost-Asien am Beispiel Vietnam. }\end{array}$ & Borsch & $2018-2020$ \\
\hline BMBF & $\begin{array}{l}\text { ColCari - Kooperation it der Universidad del Norte } \\
\text { Barranquilla zu Integrativer Biodiversitätsforschung } \\
\text { in der kolumbianischen Karibik (o1DN19004) }\end{array}$ & Borsch & $2019-2021$ \\
\hline BMBF & $\begin{array}{l}\text { ColBioDiv - Kooperation mit dem Botanischen } \\
\text { Garten Bogotá und der Universidad del Norte } \\
\text { Barranquilla (o1DN17006). }\end{array}$ & Borsch & $2017-2020$ \\
\hline BMBF & $\begin{array}{l}\text { German Barcode of Life II (GBOL-2) - Von der } \\
\text { Wissenschaft zur Anwendung TP 4: Verifikation von } \\
\text { Saatgut und Baumschulware (FKZ olLlisoE). }\end{array}$ & Borsch & $2016-2019$ \\
\hline
\end{tabular}




\begin{tabular}{|c|c|c|c|}
\hline Förderorganisation & Projekttitel & Projektleiter/in & Laufzeit \\
\hline BMBF & $\begin{array}{l}\text { EvoBoGa - Verbundprojekt: Pflanzensammlungen } \\
\text { Botanischer Gärten: Lebendige Ressourcen für die } \\
\text { integrative Evolutionsforschung. TP: Kakteen: Analyse } \\
\text { von Evolution, Artkonzeption und Entwicklung der } \\
\text { Lebensammlung als Ressource für Forschung und } \\
\text { Artenschutz (oI UQ1708A). }\end{array}$ & $\begin{array}{l}\text { Borsch/ } \\
\text { Güntsch }\end{array}$ & $2017-2020$ \\
\hline BMBF & $\begin{array}{l}\text { EDAPHOBASE - Informationssystem, Daten- } \\
\text { Repositorium, Daten-Infrastruktur und Service- } \\
\text { Plattform für die Bodenzoologie - Teilprojekt } 6 \\
\text { BGBM: Einbindung in und Verknüpfung mit GBIF } \\
\text { (FKZ o1Ll13O1F). }\end{array}$ & Güntsch & $2013-2017$ \\
\hline BMBF & $\begin{array}{l}\text { German Barcode of Life II (GBOL-2) - DNA } \\
\text { Barcoding von Diatomeen im Rahmen der EU } \\
\text { Wasserrahmenrichtlinie (WRRL): Diatomeen (FKZ } \\
\text { O1LI15oE). }\end{array}$ & Jahn & $2016-2019$ \\
\hline $\begin{array}{l}\text { Botschaft von } \\
\text { Mexiko }\end{array}$ & $\begin{array}{l}\text { Ausstellung - Chili und Schokolade - Der } \\
\text { Geschmack Mexikos }\end{array}$ & Grotz & $2017-2018$ \\
\hline DFG & $\begin{array}{l}\text { AnnoSys II - Ein generisches Annotationssystem } \\
\text { für Biodiversitätsdaten (Programm: LIS - } \\
\text { Wissenschaftliche Literaturversorgung und } \\
\text { Informationssysteme) (BE 2283/4-2). }\end{array}$ & $\begin{array}{l}\text { Berendsohn/ } \\
\text { Güntsch }\end{array}$ & $2014-2018$ \\
\hline DFG & $\begin{array}{l}\text { GFBio III - Deutsche Vereinigung zur Kuration } \\
\text { biologischer Daten (GU 1109/3-3). }\end{array}$ & Güntsch & $2018-2021$ \\
\hline DFG & $\begin{array}{l}\text { GFBio II - Deutsche Vereinigung für biologische } \\
\text { Daten (GU 1109/3-2). }\end{array}$ & Güntsch & $2015-2018$ \\
\hline DFG & $\begin{array}{l}A B C D \text { 3.0 - Eine Community-Plattform für die } \\
\text { Entwicklung und Dokumentation des ABC-Standards } \\
\text { für naturkundliche Sammlungsdaten (GU 1109/6-1). }\end{array}$ & Güntsch & $2014-2019$ \\
\hline DFG & $\begin{array}{l}\text { StanDAP-Herb - Ein prozessoptimiertes } \\
\text { Standardverfahren zur Erschließung von digitalen } \\
\text { Herbarbelegen (BE 2283/12-1). }\end{array}$ & $\begin{array}{l}\text { Güntsch/ } \\
\text { Berendsohn }\end{array}$ & $2014-2017$ \\
\hline DFG & $\begin{array}{l}\text { IDS } 2018-25 . \text { Internationales Diatomeen } \\
\text { Symposium, Berlin 25.-30.06.2018. }\end{array}$ & Jahn & $2018-2018$ \\
\hline
\end{tabular}




\begin{tabular}{|c|c|c|c|}
\hline Förderorganisation & Projekttitel & Projektleiter/in & Laufzeit \\
\hline DFG & $\begin{array}{l}\text { Algen-Registrierung: Aufbau einer globalen } \\
\text { Registration und eines Indexes für Wissenschaftliche } \\
\text { Namen und Typen von Algen (Programm LIS: } \\
\text { Wissenschaftliche Literaturversorgung und } \\
\text { Informationssysteme) (JA 874/8-1). }\end{array}$ & $\begin{array}{l}\text { Jahn/Güntsch/ } \\
\text { Berendsohn }\end{array}$ & $2016-2019$ \\
\hline DFG & $\begin{array}{l}\text { Entwicklung und Optimierung von neuartigen } \\
\text { phylogenomischen Methoden zur Aufklärung der } \\
\text { Artenvielfalt und Evolution im Tribus Cichorieae } \\
\text { (Compositae/Korbblüter), die wichtige Erkenntnisse } \\
\text { zum Stammbaum der Korbblüterfamilie liefern (JO } \\
\text { 1534/1-1). }\end{array}$ & Jones & $2018-2019$ \\
\hline
\end{tabular}

\begin{tabular}{|c|c|c|c|}
\hline DFG & $\begin{array}{l}\text { Auf Additivität gerichtete dauerhafte Verknüpfung } \\
\text { strukturierter taxonomischer Merkmalsdaten mit } \\
\text { individuellen Sammlungsobjekten (LIS) (KI 1175/2-1). }\end{array}$ & Kilian & $2017-2019$ \\
\hline DFG & $\begin{array}{l}\text { Aufbau eines Sammlungs-Erschließungssystems } \\
\text { für die nordhemisphärische Blütenpflanzengattung } \\
\text { Campanula (Programm: LIS - Wissenschaftliche } \\
\text { Literaturversorgung und Informationssysteme) (KI } \\
\text { 1175/1-1). }\end{array}$ & Kilian & $2012-2017$ \\
\hline
\end{tabular}

\begin{tabular}{|c|c|c|c|}
\hline DFG & $\begin{array}{l}\text { SPP } 1991 \text { Erstellung und Validierung einer } \\
\text { bioinformatischen Methoden-Pipeline zur } \\
\text { Artabgrenzung und zur phylogenetischen Netzwerk- } \\
\text { Rekonstruktion in Polyploidkomplexen (Taxon- } \\
\text { OMICS VO 1595/3-1). }\end{array}$ & Vogt & $2017-2020$ \\
\hline DFG & $\begin{array}{l}\text { SPP 1158: Biodiversität und Biogeographie mariner } \\
\text { benthischer Diatomeen in Antarktischen und } \\
\text { Arktischen Küstengewässern zur Überprüfung } \\
\text { des Vorkommens von Endemismus mittels } \\
\text { hochauflösender Taxonomie und eDNA } \\
\text { Metabarcoding (ZI 1628/2-1). }\end{array}$ & Zimmermann & $2019-2022$ \\
\hline
\end{tabular}

\begin{tabular}{|c|c|c|c|}
\hline EU & $\begin{array}{l}\text { Access to digital resources of European Heritage } \\
\text { (Europeana DSI 2) (GA Nr. CEF-TC-2015-1-O1). }\end{array}$ & Berendsohn & $2016-2017$ \\
\hline EU & $\begin{array}{l}\text { SYNTHESYS III - Synthesis of systematic resources } \\
\text { (Network Activities) (GA Nr. 312253). }\end{array}$ & Berendsohn & $2013-2017$ \\
\hline EU & $\begin{array}{l}\text { SYNTHESYS PLUS - Synthesis of systematic } \\
\text { resources, Network Activities (Horizon } \\
\text { 2020-INFRAIA) (GA Nr. 823827). }\end{array}$ & Güntsch & $2019-2023$ \\
\hline EU & $\begin{array}{l}\text { EU BON - Building the European Biodiversity } \\
\text { Observation Network (GA Nr. 308454). }\end{array}$ & $\begin{array}{l}\text { Güntsch/ } \\
\text { Berendsohn }\end{array}$ & $2012-2017$ \\
\hline
\end{tabular}




\begin{tabular}{|c|c|c|c|}
\hline Förderorganisation & Projekttitel & Projektleiter/in & Laufzeit \\
\hline EU & $\begin{array}{l}\text { DNAqua-Net - Developing new genetic tools for } \\
\text { bioassessment of aquatic ecosystems in Europe } \\
\text { (COST Action CA15219). }\end{array}$ & Jahn & $2016-2021$ \\
\hline EU & $\begin{array}{l}\text { SYNTHESYS III - Synthesis of systematic resources } \\
\text { (DE-TAF Access) (GA Nr. 312253). }\end{array}$ & Jahn & $2013-2017$ \\
\hline EU & $\begin{array}{l}\text { Big Picnic. Big Questions - engaging the public } \\
\text { with Responsible Research and Innovation on Food } \\
\text { Security (GA Nr. 710780). }\end{array}$ & Rahemipour & $2016-2019$ \\
\hline EU & $\begin{array}{l}\text { SYNTHESYS PLUS - Synthesis of systematic } \\
\text { resources, DE-TAF Access (Horizon 2020-INFRAIA) } \\
\text { (GA Nr. 823827). }\end{array}$ & Vogt & $2019-2023$ \\
\hline EU & $\begin{array}{l}\text { MOBILISE - Mobilising Data, Policies and Experts in } \\
\text { Scientific Collections } \\
\text { (COST Action CAl7106). }\end{array}$ & Berendsohn & $2018-2022$ \\
\hline $\begin{array}{l}\text { Friederike- } \\
\text { Schaumann Stiftung }\end{array}$ & $\begin{array}{l}\text { Moosgarten im Botanischen Garten und } \\
\text { Botanischen Museum. }\end{array}$ & Stevens & $2012-2017$ \\
\hline KSB & $\begin{array}{l}\text { Licht, Luft und Scheiße. Archäologien der } \\
\text { Nachhaltigkeit. Bauhaus-Ausstellung } 2019 \\
\text { (BHF.o127). }\end{array}$ & Rahemipour & $2018-2020$ \\
\hline KSL/Lotto Stiftung & $\begin{array}{l}\text { Erwerb einer kulturgeschichtlich bedeutsamen } \\
\text { Sammlung von Pilzbüchern von Christian Volbracht. }\end{array}$ & Kilian & $2018-2019$ \\
\hline Land Berlin & $\begin{array}{l}\text { Vorbereitung und Durchführung von } \\
\text { Programmangeboten für das IGA-Klassenzimmer im } \\
\text { Rahmen des IGA-Campus - IGA } 2017 .\end{array}$ & Rahemipour & 2017 \\
\hline $\begin{array}{l}\text { Landestalsperren- } \\
\text { verwaltung Sachsen }\end{array}$ & $\begin{array}{l}\text { Verifizierung taxonomischer Bestimmungen von } \\
\text { Phytoplanktonarten. }\end{array}$ & $\begin{array}{l}\text { Jahn/ } \\
\text { Zimmermann }\end{array}$ & $2015-2017$ \\
\hline $\begin{array}{l}\text { Smithsonian } \\
\text { Institution }\end{array}$ & GGBN - Datenstandards und Datenqualität. & Güntsch & $2019-2021$ \\
\hline $\begin{array}{l}\text { Smithsonian } \\
\text { Institution }\end{array}$ & $\begin{array}{l}\text { Global Genome Biodiversity Network } 2016 \\
\text { Conference (GGBN), 19.-25.6.2016. }\end{array}$ & Güntsch & $2016-2017$ \\
\hline Verein der Freunde & $\begin{array}{l}\text { Vergleich der morhologischen und genetischen } \\
\text { Diversität von Süßwasser-Kieselalgen aus } \\
\text { Zentralmexiko mit Südmexiko, Nordamerika und } \\
\text { Europa. }\end{array}$ & Abarca Mejia & 2019 \\
\hline Verein der Freunde & $\begin{array}{l}\text { Sammelreise zur Unterstützung des Projektes } \\
\text { „Systematik und Phylogenie der andinen } \\
\text { Sandkräuter (Arenaria, Caryophyllaceae)“. }\end{array}$ & $\begin{array}{l}\text { Berendsohn/ } \\
\text { v. Mering }\end{array}$ & 2017 \\
\hline
\end{tabular}




\begin{tabular}{|c|c|c|c|}
\hline Förderorganisation & Projekttitel & Projektleiter/in & Laufzeit \\
\hline Verein der Freunde & $\begin{array}{l}\text { Umsetzung der Globalen Synthese der Artenvielfalt } \\
\text { der Caryophyllales: Limonium. }\end{array}$ & $\begin{array}{l}\text { Berendsohn/ } \\
\text { v. Mering }\end{array}$ & 2017 \\
\hline Verein der Freunde & $\begin{array}{l}\text { Die Gattung Dianthus (Caryophyllaceae) in } \\
\text { Griechenland und Erarbeitung eines Treatments für } \\
\text { die Flora of Greece. }\end{array}$ & Borsch & 2019 \\
\hline Verein der Freunde & $\begin{array}{l}\text { Fortführung des Flora de Cuba Projektes und des } \\
\text { Projektes zum Erforschen des Endemismus der Flora } \\
\text { Cubas und der Karibik. }\end{array}$ & Borsch & $2017-2019$ \\
\hline Verein der Freunde & Erwerbungen der Bibliothek des BGBM. & Kilian & $2018-2019$ \\
\hline Verein der Freunde & $\begin{array}{l}\text { Sammel- und Forschungsreise der } \\
\text { Forschungsgruppe Asterales in Nordperu mit } \\
\text { Sammelschwerpunkt Gynoxys-Gruppe. }\end{array}$ & Kilian & 2018 \\
\hline Verein der Freunde & Sammelreisen in den Nordkaukasus 2019. & $\begin{array}{l}\text { Korotkova/ } \\
\text { Raab-Straube }\end{array}$ & 2019 \\
\hline Verein der Freunde & $\begin{array}{l}\text { Flora von Kuba: Inventarisierung und DNA- } \\
\text { Barcoding der Flechtenpilze von historischen } \\
\text { Typuslokalitäten. }\end{array}$ & Lücking & 2018 \\
\hline Verein der Freunde & $\begin{array}{l}\text { Flora von Kuba: Monografien der Flechtenfamilien } \\
\text { Graphidaceae und Lobariaceae. }\end{array}$ & Lücking & 2019 \\
\hline Verein der Freunde & $\begin{array}{l}\text { Erarbeitung der Grundlagen und Erstellung eines } \\
\text { DFG-Antrages zur Erforschung der Geschichte des } \\
\text { Projektes: Botanischer Garten und Botanisches } \\
\text { Museum Berlin-Dahlem in der Zeit des } \\
\text { Nationalsozialismus. }\end{array}$ & Rahemipour & 2017-2018 \\
\hline Verein der Freunde & $\begin{array}{l}\text { Lichenologisch-botanische Forschungs- und } \\
\text { Sammelreise auf die Inseln Amorgos und Skiros } \\
\text { (Ägäis, Griechenland). }\end{array}$ & Sipman & 2018 \\
\hline Vokswagen Stiftung & $\begin{array}{l}\text { Kaukasus II - Developing Tools for Conserving the } \\
\text { plant diversity of the South Caucasus (Az } 89950 \text { ). }\end{array}$ & Borsch & $2017-2020$ \\
\hline
\end{tabular}




\section{Ausgerichtete} wissenschaftliche Veranstaltungen

$2017-2019$
Wissenschaftliche Veranstaltungen am Botanischen Garten und Botanischen Museum Berlin

Schutz bedrohter Pflanzenarten in Mitteleuropa: Genetische Grundlagen und Naturschutzpraxis. Fachsymposium am Botanischen Garten und Botanischen Museum Berlin, 23.-25. Februar 2017, 75 TN.

Collection Management \& Botanical Garden curation workshop. Workshop des BGBM für Teilnehmerinnen und Teilnehmer aus dem Südkaukasus, 18.-30. September 2017, 7 TN.

German Federation for Biological Data (GFBio) 5. Vollversammlung. Veranstalter: German Federation for Biological Data (GFBio), 28.-30. November 2017, 45 TN.

CEN concept development meeting "WG29 on DNA and eDNA“ in CEN/TC 230. Veranstaltung gefördert durch EU COST Action „DNAqua-NET“, 8. Februar 2018, 12 TN.

25th International Diatom Symposium. Internationale Konferenz. Veranstalter: International Society for Diatom Research (ISDR). Gefördert durch Deutsche Forschungsgemeinschaft (DFG), International Union of Biological Sciences (IUBS), International Society for Diatom Research (ISDR) und EU COST Action „DNAqua-NET“, 25.-30. Juni 2018, 212 TN.

DNAqua-NET Information/Group Meeting COST Action 15219. Veranstaltung gefördert durch EU COST Action „DNAqua-NET“, 27.-28. Juni 2018, 30 TN.

Freshwater Symposium. Veranstalter: Alliance for Freshwater Life, 5.-7. November 2018, >100 TN.

Wildpflanzenschutz in Deutschland II (WIPs-De II). Auftaktveranstaltung in Kooperation mit dem Projektleiter Botanischer Garten Regensburg, 27.-28. März 2019, 75 TN.

Koordinationstreffen DFG-Schwerpunktprogramm „Antarktisforschung“. 20. November 2019, 5 TN.

In Kooperation ausgerichtete Veranstaltungen außerhalb des BGBM:

Developing Tools for Conserving the Plant Diversity of the Transcaucasus. Mid-term project status seminar, Botanisches Institut der Staatlichen Ilia-Universität, Tiflis, 11.-13. Oktober 2017, 30 TN.

Colombian-German Biodiversity Network for Integrated Biodiversity Management in Exemplar Regions of Columbia (ColBioDiv). Kickoff Workshop, Botanischer Garten „José Celestino Mutis“ Bogotá, Bogotá, 7.-9. November 2017.

Manejo Integrado de la Biodiversidad en el Caribe Colombiano. Workshop an der Universidad del Norte, Barranquilla, 27.-29. Juni 2018.

Sammeln von Wildpflanzen-Saatgut nach ENSCONET-Richtlinien. Workshop an der Hochschule Sachsen-Anhalt, Bernburg, 18. März 2019.

Saatgutbanken für den botanischen Artenschutz - Möglichkeiten und Grenzen von Saatgutbanken, Techniken des Sammelns und Lagerns. Workshop für das Landesumweltamt Sachsen sowie Vertreterinnen und Vertreter der unteren Naturschutzbehörden, Nossen, 25. Oktober 2019.

$\mathrm{TN}=$ Teilnehmerinnen und Teilnehmer 


\begin{tabular}{|c|c|c|c|}
\hline Lebendsammlungen Bestand & 2017 & 2018 & 2019 \\
\hline Familien & 310 & 313 & 315 \\
\hline Gattungen & 3184 & 3230 & 3282 \\
\hline Taxa (Arten, Unterarten, Varietäten etc.) & 17776 & 18238 & 18689 \\
\hline Akzessionen & 30741 & 31717 & 32654 \\
\hline davon Wildherkünfte (in \%) & 58,4 & 59,1 & 59,6 \\
\hline Lebendsammlungen Zugänge/Abgaben & 2017 & 2018 & 2019 \\
\hline hinzugekommene Akzessionen & 1647 & 1567 & 1428 \\
\hline ausgeschiedene Akzessionen & 2870 & 591 & 491 \\
\hline an andere Gärten abgegebene Akzessionen & 237 & 159 & 277 \\
\hline an andere Gärten abgegebene Pflanzen(teile) & 289 & 252 & 493 \\
\hline Bereitgestellte Pflanzen(teile) & 2017 & 2018 & 2019 \\
\hline Akzessionen für die Lehre & 374 & 275 & 314 \\
\hline Pflanzen(teile) für die Lehre & 8394 & 6520 & 7748 \\
\hline Akzessionen für die Forschung & 196 & 411 & 302 \\
\hline Pflanzen(teile) für die Forschung & 841 & 1316 & 880 \\
\hline
\end{tabular}




\begin{tabular}{|cccc}
\hline Dahlemer Saatgutbank & 2017 & 2018 & 2019 \\
\hline Bestand (Zahl der Akzessionen) & 11265 & 12015 & 12948 \\
\hline Neuzugänge (Zahl der Akzessionen) & 674 & 750 & 149 \\
\hline Projekte & 1060 & 1106 & 448 \\
\hline Base Collection (Langzeitlagerung) & 706 & 691 & ca. 400 \\
\hline Access Collection (für Saatguttausch) & 674 & 750 & 3053 \\
\hline Positionen im Index Seminum, davon & 3053 & 3053 & 792 \\
\hline abgegebene Saatgutproben & 455 & 1557 & 257 \\
\hline Inland & 72 & 363 & 535 \\
\hline Ausland & 383 & 1190 & 42
\end{tabular}

Herbarium Berolinense B

$\begin{array}{lccc}\text { Herbarium Bestand } & 2017 & 2018 & 2019 \\ \text { Gesamtzahl aller Belege } & \text { ca. } 3,84 \text { Mio. } & \text { ca. } 3,87 \text { Mio. } & 3,88 \text { Mio. } \\ \text { Typusbelege } & >40000 & >40000 & >40000 \\ \text { Gartenherbar } & 50969 & 51306 & 51672 \\ \begin{array}{l}\text { Herbarium Neuzugänge } \\ \text { Gesamtzahl Neuzugänge, davon }\end{array} & 2017 & 2018 & 2019 \\ \quad \text { durch Schenkung } & 28104 & 32118 & 15318 \\ \text { durch Tausch } & 20098 & 19779 & 2044 \\ \quad \text { durch Kauf } & 6710 & 6064 & 1713 \\ \text { durch eigene Sammeltätigkeiten } & 108 & 50 & 9221 \\ \text { Neuzugänge Gartenherbar } & 893 & 5887 & 2193\end{array}$




\begin{tabular}{|c|c|c|c|}
\hline Herbarium - Leihverkehr, Tausch, Gäste & 2017 & 2018 & 2019 \\
\hline Ausleihanfragen & 230 & 251 & 225 \\
\hline $\begin{array}{l}\text { Leihgaben von B an andere Institutionen, } \\
\text { Anzahl Belege }\end{array}$ & 1607 & 2176 & 1551 \\
\hline Anzahl Sendungen & 104 & 101 & 102 \\
\hline $\begin{array}{l}\text { Leihgaben an B von anderen Institutionen, } \\
\text { Anzahl Belege }\end{array}$ & 5799 & 268 & 632 \\
\hline Anzahl Sendungen & 58 & 16 & 12 \\
\hline $\begin{array}{l}\text { Anzahl der Institutionen, mit denen wir } \\
\text { Leihverkehr hatten }\end{array}$ & 164 & 154 & 134 \\
\hline an Tauschpartner dauerhaft abgegebene Belege & 14995 & 6882 & 5299 \\
\hline Digitales Herbarium & 2017 & 2018 & 2019 \\
\hline Neu digitalisierte Belege, davon & 1470 & 26549 & 48713 \\
\hline Aufgrund von Leihanfragen & 581 & 301 & 760 \\
\hline Im Rahmen von Projekten & 889 & 26248 & 47953 \\
\hline Gesamtzahl der online verfügbaren Belege & 171814 & 182568 & 611381 \\
\hline Zugriffe / Downloads & 74765 & 82456 & 104753 \\
\hline
\end{tabular}

DNA-Bank

$\begin{array}{lll}2017 & 2018 & 2019\end{array}$

\begin{tabular}{|lccc|}
\hline Bestand (Zahl der DNA-Proben) & 23853 & 30820 & 36666 \\
\hline Neuzugänge, davon & 4576 & 6967 & 5846 \\
\hline durch Schenkung, Tausch mit Partnern & 0 & 0 & 5766 \\
\hline durch eigene Forschungsaktivitäten & 4576 & 6967 & 104 \\
\hline abgegebene DNA-Proben (Zahl) & 69 & 80 & 13 \\
\hline Abgegebene DNA-Proben (Empfänger*innen) & 11 & 10 & 10 \\
\hline
\end{tabular}




\section{Bibliothek Bestand \& Kataloge}

\begin{tabular}{|lrrr|}
\hline Monographien und Zeitschriftenbände & 212762 & 214535 & 216201 \\
\hline laufende Zeitschriften mit Druckausgaben & 660 & 640 & 576 \\
\hline Sonderdrucke & 144312 & 144490 & 144724 \\
\hline CD-ROMs, DVDs und Videokassetten & 456 & 458 & 460 \\
\hline Mikrofilm- und Mikrofiche-Titel & 4178 & 4178 & 4178 \\
\hline
\end{tabular}

Neuzugänge

\begin{tabular}{|lccc}
\hline & 2017 & 2018 & 2019 \\
\hline Monographien, davon & 929 & 899 & 1019 \\
\hline durch Kauf & 153 & 152 & 185 \\
\hline durch Tausch / Schenkung & 776 & 747 & 834 \\
\hline Zeitschriftenbände, davon & 1053 & 973 & 770 \\
\hline durch Kauf & 266 & 176 & 169 \\
\hline durch Tausch / Schenkung & 787 & 797 & 601 \\
\hline Sonderdrucke & 237 & 178 & 228 \\
\hline $\begin{array}{l}\text { CD-ROMs und DVDs } \\
\text { Ausgaben für Beteiligungen an Datenbanken }\end{array}$ und Onlinezeitschriftenpaketen & $8652 €$ & $14290 €$ & 3 \\
\hline
\end{tabular}




\section{Willdenowia:}

Willdenowia 47(1) https://bioone.org/journals/willdenowia/volume-47/issue-1

Willdenowia 47(2) https://bioone.org/journals/willdenowia/volume-47/issue-2

Willdenowia 47(3) https://bioone.org/journals/willdenowia/volume-47/issue-3

\section{Englera:}

Raab-Straube E. von 2017: Taxonomic revision of Saussurea subgenus Amphilaena (Compositae, Cardueae). Englera 34. - Berlin: Botanic Garden and Botanical Museum Berlin, Freie Universität Berlin.

\section{Jahresbericht:}

Mission grüne Vielfalt. BGBM-Jahresbericht 2015-2016. - Berlin: Botanischer Garten und Botanisches Museum Berlin, Freie Universität Berlin.

\section{Weitere Publikationen:}

Greuter W. \& Rankin Rodríguez R. 2017: Plantas vasculares de Cuba: inventario preliminar. Segunda edición, actualizada, de Espermatófitos de Cuba con inclusión de los Pteridófitos. Vascular plants of Cuba: a preliminary checklist. Second updated edition of The Spermatophyta of Cuba with Pteridophyta added. - Berlin: Botanischer Garten \& Botanisches Museum Berlin; La Habana: Jardín Botánico Nacional, Universidad de La Habana. https:// doi.org/10.3372/cubalist.2017.1

Greuter W. \& Rankin Rodríguez R. (ed.) 2017: Flora de la República de Cuba. Fascículo 22. Dioscoreaceae. Ericaceae. Zygophyllaceae. - Berlin: Botanischer Garten und Botanisches Museum Berlin.

Grotz K., Ochoterena H. \& Rahemipour P. (ed.) 2017: Chili \& Schokolade. Der Geschmack Mexicos. Ausstellungstexte »für die Tasche«. - Berlin: Botanischer Garten und Botanisches Museum Berlin, Freie Universität Berlin.

Rahemipour P. \& Grotz K. 2017: Chili \& Schokolade. Der Geschmack Mexicos. Ein botanisches Kochbuch. - Berlin: Botanischer Garten und Botanisches Museum Berlin, Freie Universität Berlin.

2018

\section{Willdenowia}

Willdenowia 48(1) https://bioone.org/journals/willdenowia/volume-48/issue-1

Willdenowia 48(2) https://bioone.org/journals/willdenowia/volume-48/issue-2

Willdenowia 48(3) https://bioone.org/journals/willdenowia/volume-48/issue-3

Jahresbericht:

Diversity is our mission. BGBM Annual report 2015-2016. - Berlin: Botanic Garden and Botanical Museum Berlin, Freie Universität Berlin. 


\section{Weitere Publikationen:}

Burkhardt L. 2018: Verzeichnis eponymischer Pflanzennamen - Erweiterte Edition. Index of Eponymic Plant Names - Extended Edition. Index de Noms éponymiques des Plantes - Édition augmentée. - Berlin: Botanic Garden and Botanical Museum Berlin, Freie Universität Berlin. https://doi.org/10.3372/epolist2018

Greuter W., Rankin Rodríguez R. \& González Gutiérrez P. A. (ed.) 2018: Flora de la República de Cuba. Fascículo 23. Combretaceae. Oxalidaceae. - Berlin: Botanischer Garten und Botanisches Museum Berlin.

Kasten J., Kusber W.-H., Riedmüller U., Tworeck A., Oschwald L. \& Mischke U. 2018: Steckbriefe der Phytoplankton-Indikatortaxa in den WRRL-Bewertungsverfahren PhytoSee und PhytoFluss mit Begleittext - 1. Lieferung: 50 Steckbriefe ausgewählter Indikatortaxa. - Berlin: Botanic Garden and Botanical Museum Berlin, Freie Universität Berlin. https://doi.org/10.3372/spi.o1

Kusber W.-H., Abarca N., Van A. L. \& Jahn R. (ed.) 2018: Abstracts of the 25th International Diatom Symposium, Berlin 25-30 June 2018. - Berlin: Botanic Garden and Botanical Museum Berlin, Freie Universität Berlin. https:// doi.org/10.3372/ids2018

Rahemipour P. (ed.) 2018: Bipindi - Berlin. Ein wissenschaftshistorischer und künstlerischer Beitrag zur Kolonialgeschichte des Sammelns. - KOSMOS Berlin - Forschungsperspektive Sammlungen, Bd. 1. - Botanischer Garten und Botanisches Museum Berlin, Freie Universität Berlin.

Willing R. \& Willing E. 2018: A Willing Contribution to Flora Hellenica. Field records 2014. - Berlin: Botanic Garden and Botanical Museum Berlin. https://doi.org/10.3372/wfr2014

Willing R. \& Willing E. 2018: A Willing Contribution to Flora Hellenica. Field records 2015. - Berlin: Botanic Garden and Botanical Museum Berlin. https://doi.org/10.3372/wfr2015

Willing R. \& Willing E. 2018: A Willing Contribution to Flora Hellenica. Field records 2016. - Berlin: Botanic Garden and Botanical Museum Berlin. https://doi.org/10.3372/wfr2016

Willing R. \& Willing E. 2018: 38th Willing Contribution to Flora Hellenica. Crete, April 2017. - Berlin: Botanic Garden and Botanical Museum Berlin. https://doi.org/10.3372/wfr2017.1

Willing R. \& Willing E. 2018: 39th Willing Contribution to Flora of Greece. June-July 2017. - Berlin: Botanic Garden and Botanical Museum Berlin. https://doi.org/10.3372/wfr2017.2

\section{Willdenowia:}

Willdenowia 49(1) https://bioone.org/journals/willdenowia/volume-49/issue-1 Willdenowia 49(2) https://bioone.org/journals/willdenowia/volume-49/issue-2 Willdenowia 49(ᄀ3) https://bioone.org/journals/willdenowia/volume-49/issue-3 


\section{Englera:}

Casper S. J. 2019: The insectivorous genus Pinguicula (Lentibulariaceae) in the Greater Antilles. - Englera 35. Berlin: Botanic Garden and Botanical Museum Berlin, Freie Universität Berlin.

Dowe J. L. 2019: Wendland's Palms. Hermann Wendland (1825-1903) of Herrenhausen Gardens, Hannover: his contribution to the taxonomy and horticulture of the palms (Arecaceae). - Englera 36. - Berlin: Botanic Garden and Botanical Museum Berlin, Freie Universität Berlin.

\section{Weitere Publikationen:}

Greuter W. \& Rankin Rodríguez R. 2019: Inventario de las plantas cubanas silvestres parientes de las cultivadas de importancia alimenticia, agronómica y forestal. A Checklist of Cuban wild relatives of cultivated plants important for food, agriculture and forestry. - Berlin: Botanischer Garten und Botanisches Museum Berlin; La Habana: Jardín Botánico Nacional, Universidad de La Habana. https://doi.org/10.3372/cubalist.2019.1

Greuter W., Rankin Rodríguez R. \& González Gutiérrez P. A. (ed.) 2019: Flora de la República de Cuba. Fascículo 24. Malpighiaceae. - Berlin: Botanischer Garten und Botanisches Museum Berlin.

Greuter W., Rankin Rodríguez R. \& González Gutiérrez P. A. (ed.) 2019: Flora de la República de Cuba. Fascículo 25. Gesneriaceae. Surianaceae. - Berlin: Botanischer Garten und Botanisches Museum Berlin.

\section{Sonderausstellungen}

\subsubsection{6-26.02.2017}

Grüne Schatzinseln: Botanische Entdeckungen in der Karibik

Kuration: K. Grotz, S. Fuentes.

Gestaltung: Yvonne Rieschl

Partner: Jardín Botánico Nacional, Universidad de la Habana, Cuba; Jardín Botánico Nacional Santo Domingo, Dominikanische Republik. Gefördert durch den Verein der Freunde des Botanischen Gartens und Botanischen Museums Berlin-Dahlem e.V.

05.05.2017-25.02.2018

Chili und Schokolade. Der Geschmack Mexikos

Kuration: K. Grotz, P. Rahemipour \& H. Ochoterena.

Gestaltung: Yvonne Rieschl

Partner: Instituto de Biología der Universidad Autónoma de México, Ciudad de México (UNAM); Universum, Museo de las Ciencias de la UNAM; Goethe-Institut Mexiko. Gefördert durch die Botschaft von Mexiko in Deutschland im Dua-len Jahr Mexiko-Deutschland.

16.06. - 31.08.2018

Victoria Kabinett. 166 Jahre. 100 Bilder

Kuration: K. Grotz, P. Rahemipour

Gestaltung: Yvonne Rieschl 
07.12.2018-29.06.2019

Geliebt, gegossen, vergessen: Phänomen Zimmerpflanze

Kuration: K. Grotz,P. Rahemipour

Gestaltung: Yvonne Rieschl

16.08.2019-27.10.2019

Licht Luft Scheiße: Perspektiven auf Ökologie und Moderne

Kuration: Sandra Bartoli, Marco Clausen, Silvan Linden, Åsa Sonjasdotter \& Florian Wüst (nGbK-Projektgrup-

pe)

Kathrin Grotz \& Patricia Rahemipour (BGBM)

Gestaltung: Büros für Konstruktivismus, Berlin

\section{Galerieausstellungen}

29.09.2016 - 08.01.2017

Dove vai? / Wohin gehst du?: Collagen, Malerei und Zeichnungen von Gudula Fisauli

09.03.2017-14.05.2017

„Herbarium“ Objekte von Anne Carnein

Botanisches Museum \& Anne Carnein

02.06.2017-24.09.2017

IK \& die vielen anderen: schafft diese Welt das? Arbeiten von Mark Swysen

Botanischer Garten und Botanisches Museum Berlin in Zusammenarbeit mit dem Kulturamt Steglitz-Zehlendorf

29.06.2018-02.09.2018

Sometimes I hear the plants whisper: Objekte und Installationen von Karine Bonneval

Botanischer Garten und Botanisches Museum Berlin in Zusammenarbeit mit dem Kulturamt Steglitz-Zehlendorf

11.10.2018 - 06.01.2019

Zenkeri: Fotografien von Yana Wernicke \& Jonas Feige

In Kooperation mit Frantic Gallery, Tokyo

26.01. -8.04 .2018$

México lindo. Botanische Illustrationen von Elvia Esparza

Botanisches Museum Berlin \& Mexikanische Botschaft in Deutschland

\section{Externe Ausstellungen}

18.03.2016 - 01.01. 2017

„Der Apfel. Kultur mit Stiel“

Museum im Herrenhaus, Domäne Dahlem, Berlin

30.09. 2016 - 08.01.2017

"Gestaltung“

Martin-Gropius-Bau, Berlin 
08.10.2016 - 09.01.2017

"Der Britische Blick: Deutschland - Erinnerungen einer Nation“

Martin-Gropius-Bau, Berlin

14.10.2016 - 14.05.2017

"Deutscher Kolonialismus - Geschichte und Gegenwart"

Deutsches Historisches Museum, Berlin

02.11.2016 - 26.02.2017

„Extreme! Natur und Kultur am Humboldtstrom“

Humboldt-Box, Berlin

13.04.2017 - 15.10.2017

Ausstellung „Palmen“ als Beitrag zur Internationalen Gartenausstellung

Kathrin Grotz, Patricia Rahemipour, Stephanie Henkel

Gärten der Welt, Berlin

07.07.2017 - 14.01.2018

„Vorsicht Kinder! Geschützt geliebt, gefährdet“

Kathrin Grotz \& Patricia Rahemipour

20.10.2017-14.01.2018

„Form follows flower. Moritz Meurer, Karl Blossfeldt und Co.“

Kunstgewerbemuseum, Berlin

21.09. 2018 - 13.01. 2019

„Aus Westfalen in die Südsee. Katholische Mission in den deutschen Kolonien“

Stadtmuseum Münster

\begin{tabular}{|c|c|c|c|c|}
\hline & 2017 & 2018 & 2019 & Presse- und \\
\hline Pressemitteilungen & 28 & 28 & 19 & \\
\hline Newsletter & 12 & 10 & 12 & arbeit \\
\hline Printbeiträge & 606 & 601 & 479 & \\
\hline TV-Beiträge & 56 & 48 & 40 & \\
\hline Funkbeiträge & 120 & 90 & 57 & \\
\hline Online-Beiträge & 272 & 319 & 335 & \\
\hline
\end{tabular}

* Zahlen ohne Clipping-Service ermittelt. 


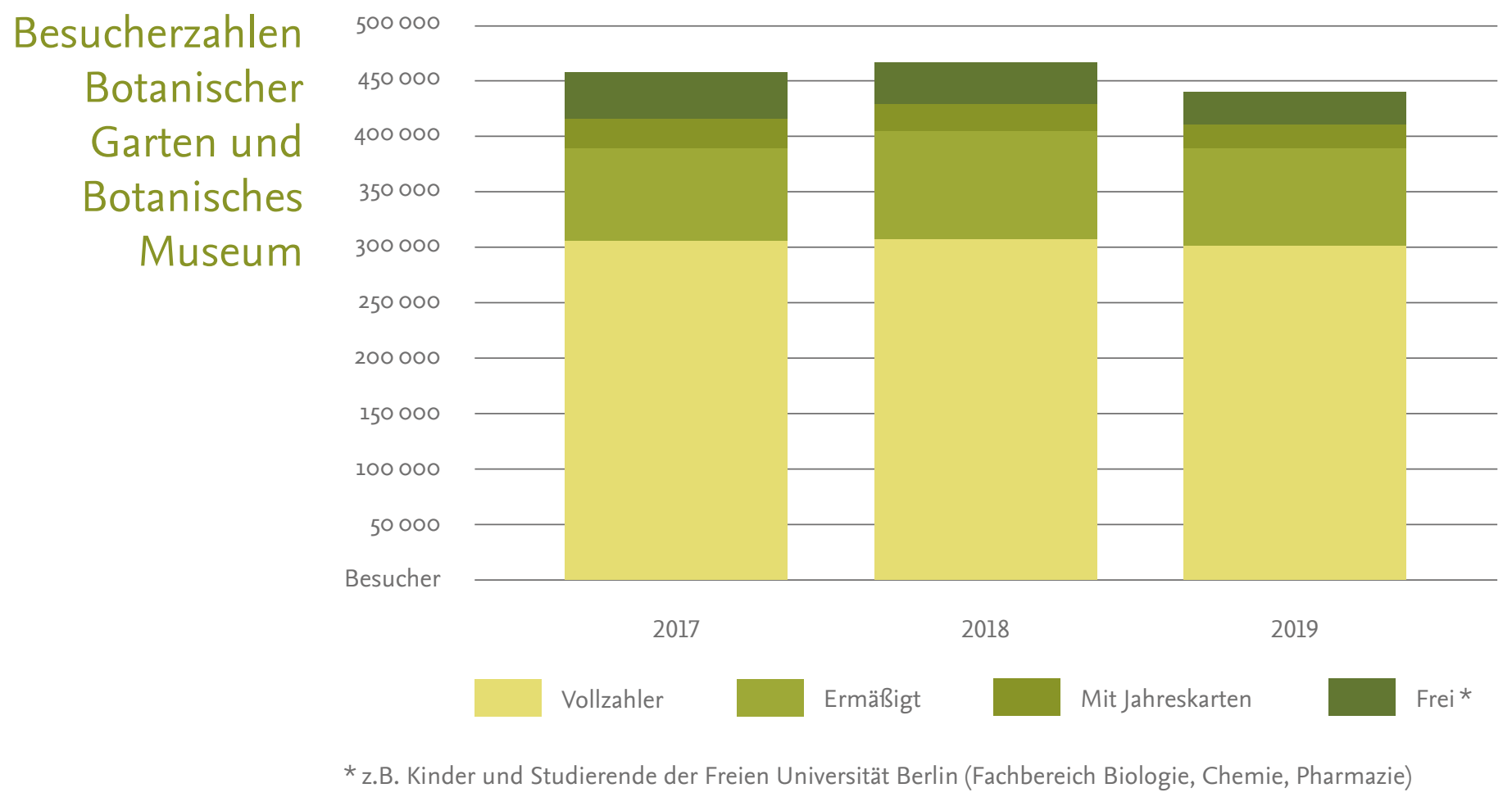




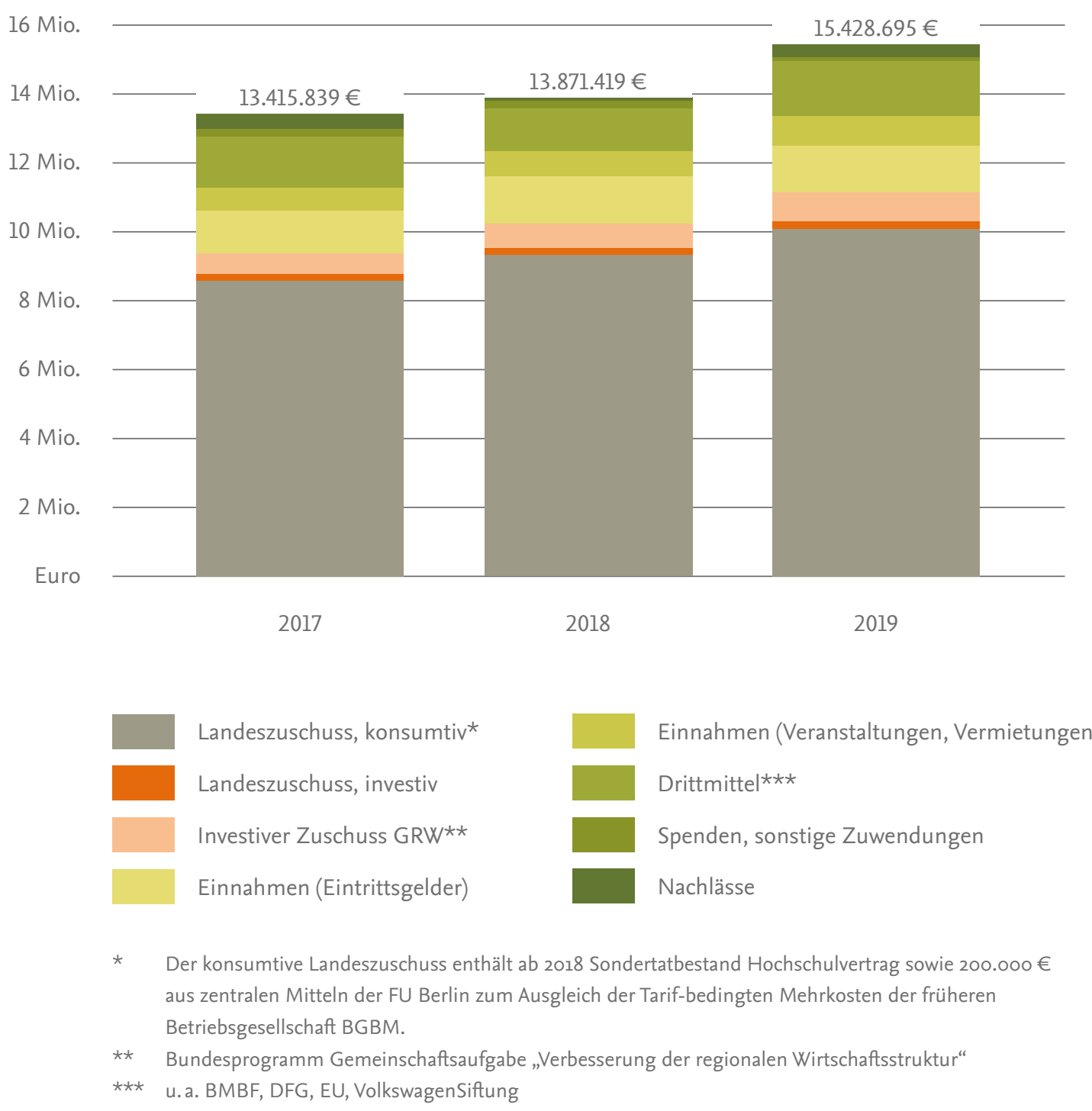




\section{Impressum}

Wir danken Kerstin Viering für das Verfassen der Thementexte (S. 6 - 55) sowie den Kolleginnen und Kollegen des BGBM für ihre Unterstützung. Besonderer Dank für die Zusammenstellung der neu beschriebenen Gattungen, Familien und Arten, die Überprüfung der Publikationen und zahlreiche Bildbeiträge gilt Dr. Robert Lücking sowie Dr. Norbert Kilian für die Redaktion der Publikationsbeiträge.

Alle Rechte vorbehalten

Das Werk ist urheberrechtlich geschützt. Jede Verwertung außerhalb der Freigrenzen des Urheberrechts ist ohne Zustimmung des Verlags unzulässig und strafbar. Das gilt insbesondere für Vervielfältigungen, Übersetzungen, Mikroverfilmungen und die Einspeicherung und Verarbeitung in elektronischen Systemen.

1. Auflage, Dezember 2020

Herausgeber: BGBM Press 2020

(C) Botanischer Garten und Botanisches Museum Berlin, Freie Universität Berlin 2020

Projektkoordination: Eva Häffner, Nadine Csonka

Titelbild: Fotografie von Dr. Robert Lücking

Satz: Michael Rodewald

Druck und Bindung: LASERLINE Druckzentrum Berlin KG

Schrift: Nexus Sans

Bildnachweis: BGBM S. 48; Thomas Borsch S. 36, S. 37, S. 54 oben, S. 55 oben; Grischa Brokamp S. 30; Peter Engelke S. 44, S. 45; Tamara Freyer-Dohlus S. 53; FG Diatomeen S. 27 unten, S. 29 oben, S. 41, S. 42; Kim Govers S. 40; Anton Güntsch S. 16; Julia Gravendyck S. 7; Herbarium BGBM S. 18; Christine Hillmann-Huber S. 11, S. 17, S. 46, S. 47 , S. 48 , S. 49 links, Christian Kielmann S. 29 unten; Agnes Kirchhoff S. 20, S. 50 ; (c) Luxigon S. 15; Robert Lücking S. 4 , S. 6 , S. $8 / 9$, S. 24 , S. 25 , S. 26 , S. 28 , S. 31 , S. 32 , S. 33 , S. 34 , S. 35 , S. 54 unten, S. 55 unten; Gabriele Michaelis S. 12; André Obermüller S. 22, S. 49 rechts; Katharina Rosenkranz S. 51; Nicholas Turland S. 13 oben; Vanessa Di Vincenzo S. 43 links; Bernd Wannenmacher S. 5, S. 10, S. 13 unten, S. 19, S. 23 rechts, S. 27 oben, S. 43 rechts; Elke Zippel S. 21, S. 23 links, Hannah Zippel S. 14.

ISBN: 978-3-946292-38-8

DOI: https://doi.org/10.3372/JB.2017-2019.de.1 
